\title{
STn-PS A1 as an Entirely Carbohydrate Immunogen: Synthesis and Immunological Evaluation
}

Mengchao Shi, Kristopher A. Kleski, Kevin R. Trabbic, Jean-Paul Bourgault and Peter R. Andreana*

Department of Chemistry and Biochemistry and School of Green Chemistry and Engineering, University of Toledo, 2801 West Bancroft Street, Toledo, Ohio 43606, United States.

Corresponding Author:

*peter.andreana@utoledo.edu 


\section{Table of Contents}

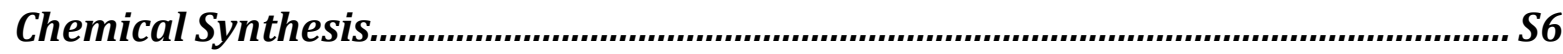

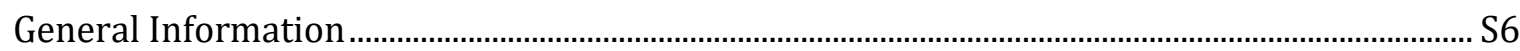

Preparation of sialyl phosphate donor 3 ……………………………………............................ S6

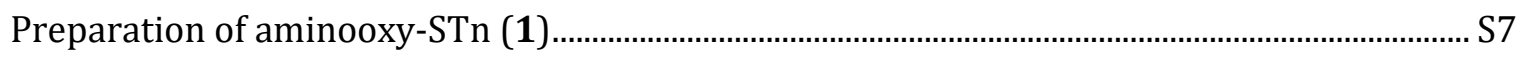

General sialylation procedure and preparation of sialyl glycosides $\mathbf{9 ,} \mathbf{1 0}$ and $\mathbf{1 1} \ldots \ldots . . . . . . . . . . . S 11$

Preparation of STn-PS A1 (16) conjugate ....................................................................................

Identification of spin systems in STn-PSA1 (16)......................................................................... 14

SI Figure 1. Comparison of three new spin systems in the STn-PS A1 (16) construct.......S15

SI Figure 2. Spin system of oxidized galactofuranose residue of PS A1 ..................................S16

SI Figure 3. Spin system of $N$-acetylgalactosamine of STn ....................................................... 16

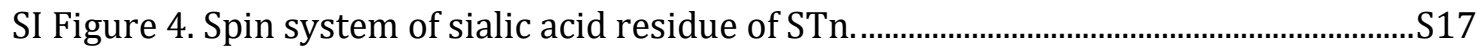

SI Figure 5. Spin system of galactofuranose reside of PS A1 ...................................................... 17

SI Figure 6. Spin system of N-acetylgalactosamine residue of PS A1 . .....................................S18

SI Figure 7. Spin system of 2-acetamido-4-amino-6-deoxy-galactose residue of PS A1....S18

SI Figure 8. Spin system of pyruvate galactose residue of PS A1 ……....................................S19

Determination of STn loading by ${ }^{1}$ H NMR......................................................................................... 19

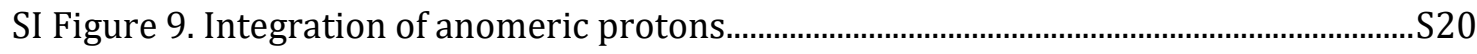

SI Figure 10. Integration of the 3-position of sialic acid and methyl groups.........................S21

Determination of STn loading by a modified Svennerholm method ..........................................S21

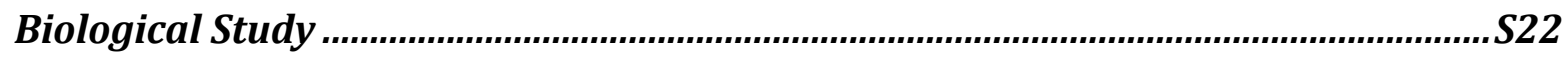

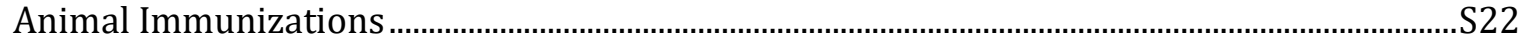

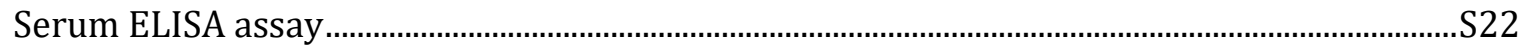

SI Table 1. The antibody titers of STn-specific antibodies of each group...............................S23

Fluorescence-Activated Cell Sorting (FACS) ……............................................................................... 24

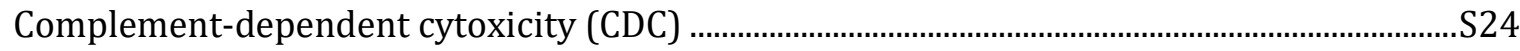

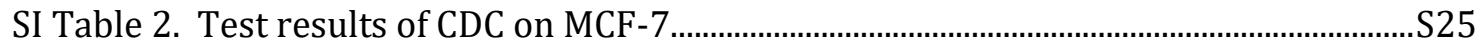

SI Table 3. Test results of CDC on OVCAR-5

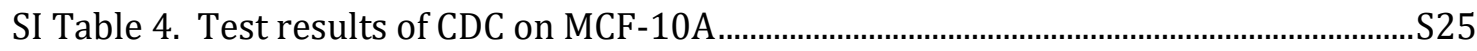

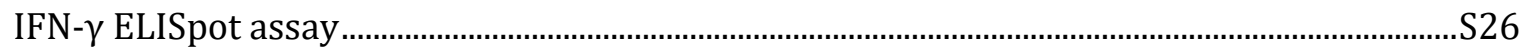

SI Table 5. Test results of IFN- $\gamma$ ELISpot assay ............................................................................. 27

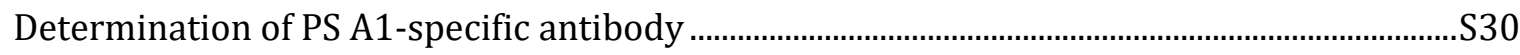

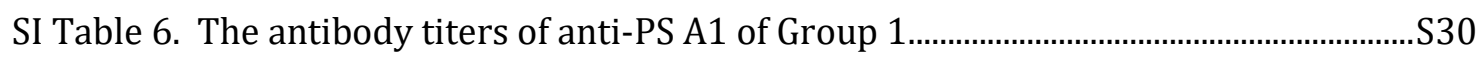

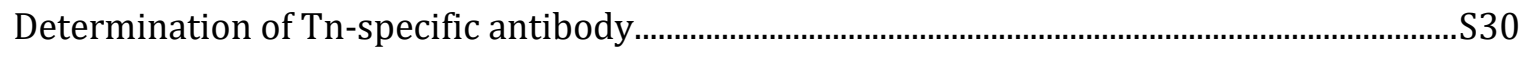


SI Table 7. The average antibody titers of Tn-specific antibodies of each group

SI Figure 11. MALDI-TOF of Tn-BSA

NMR Spectrum of related compounds.

${ }^{1} \mathrm{H}$ NMR spectrum of $\mathbf{S} \mathbf{1}$ S33

${ }^{13} \mathrm{C}$ NMR spectrum of $\mathbf{S} \mathbf{1}$ S34

${ }^{1} \mathrm{H}$ NMR spectrum of 3 . S35

${ }^{13} \mathrm{C}$ NMR spectrum of 3 . S36

DEPT135 spectrum of 3 . .S37

COSY spectrum of $\mathbf{3}$ S38

${ }^{1} \mathrm{H}$ NMR spectrum of 4 . S39

${ }^{13} \mathrm{C}$ NMR spectrum of 4 . ..S40

DEPT135 spectrum of 4 .

COSY spectrum of 4 ..S42

${ }^{1} \mathrm{H}$ NMR spectrum of 8 . .543

${ }^{13} \mathrm{C}$ NMR spectrum of $\mathbf{8}$. ..S44

DEPT135 spectrum of 8 . .$S 45$

COSY spectrum of 8 .$S 46$

HSQC spectrum of $\mathbf{8}$ S47

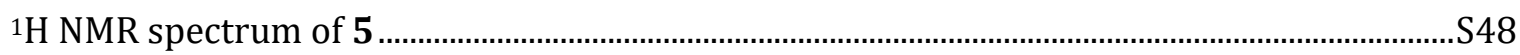

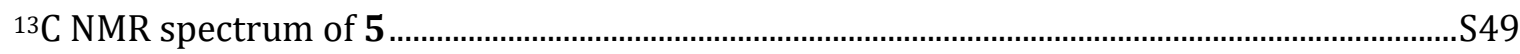

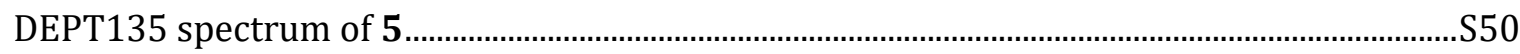

COSY spectrum of 5

HMBC spectrum of 5

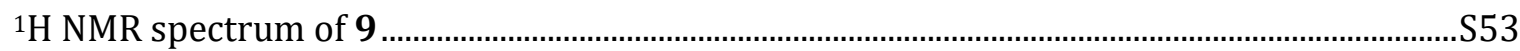

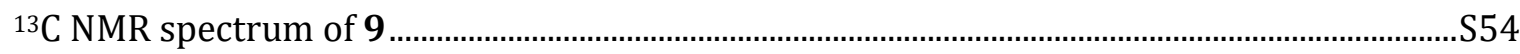

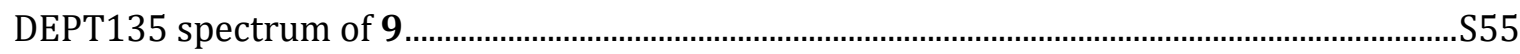

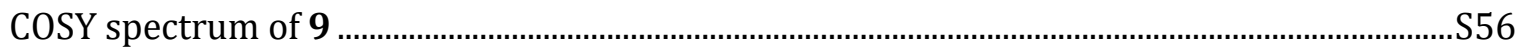

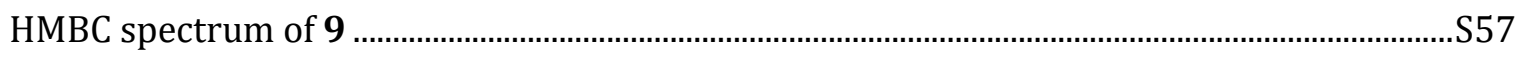

HSQC spectrum of 9

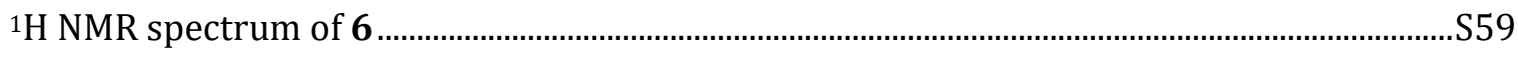

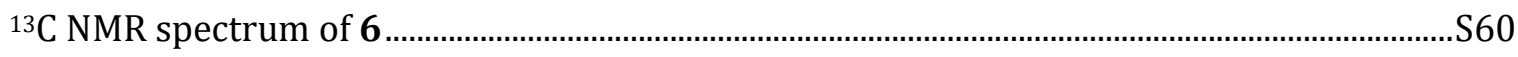

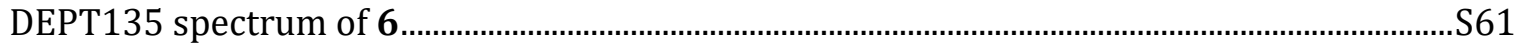

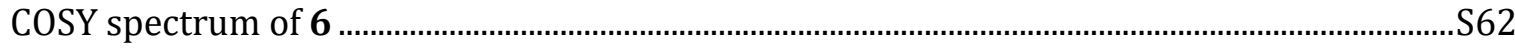

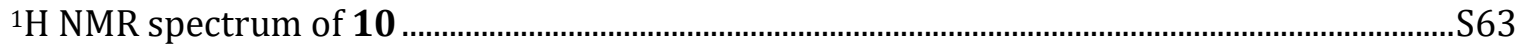




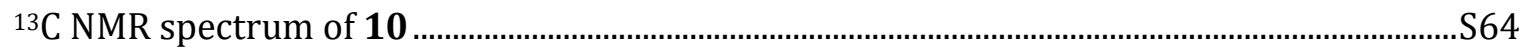

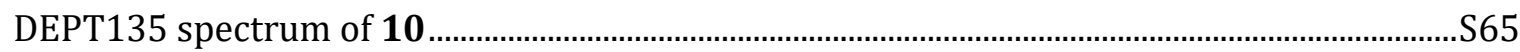

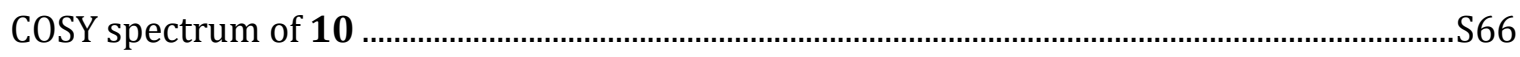

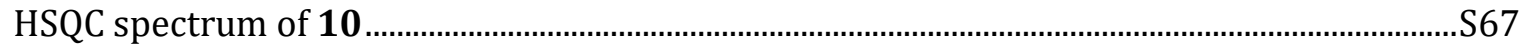

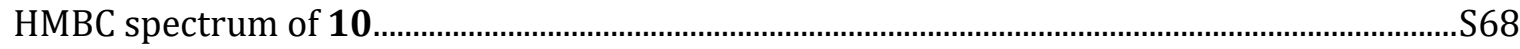

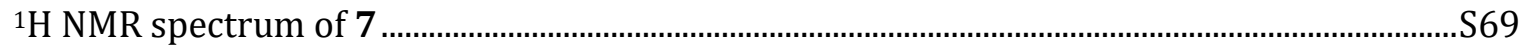

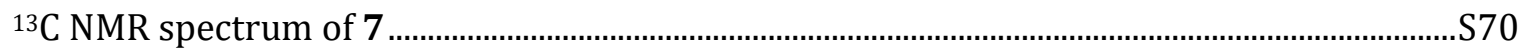

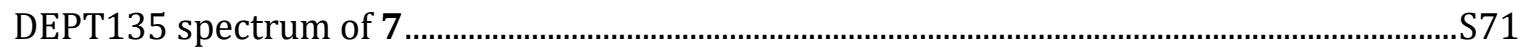

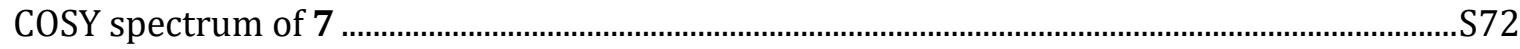

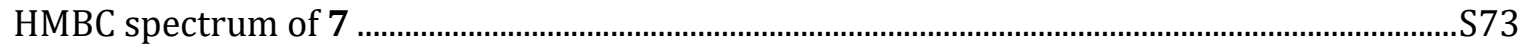

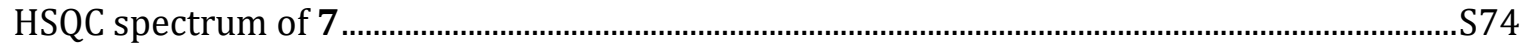

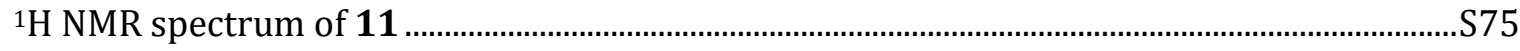

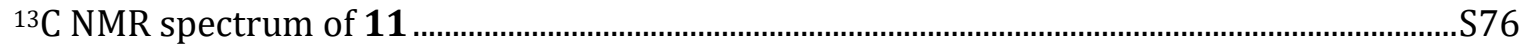

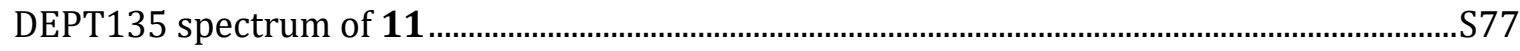

COSY spectrum of $\mathbf{1 1}$

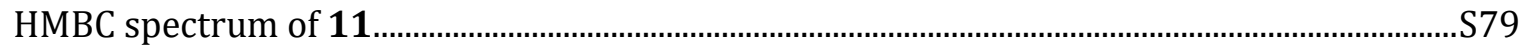

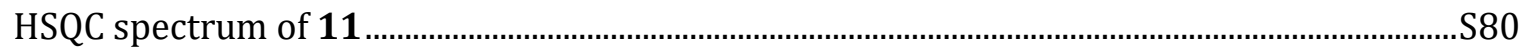

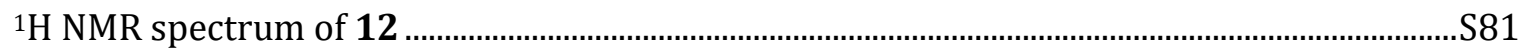

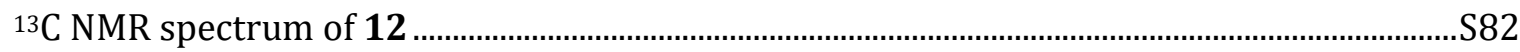

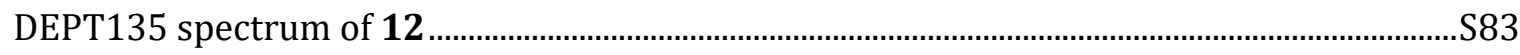

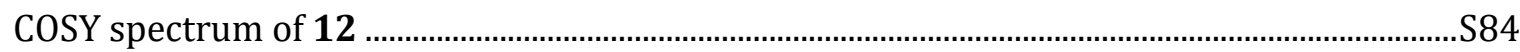

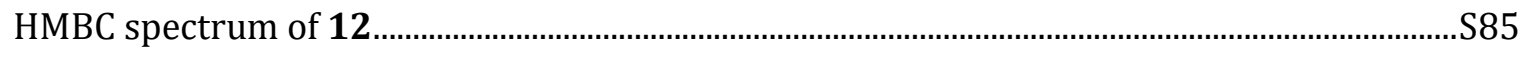

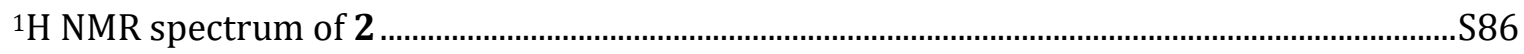

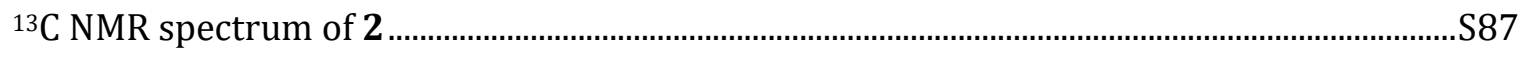

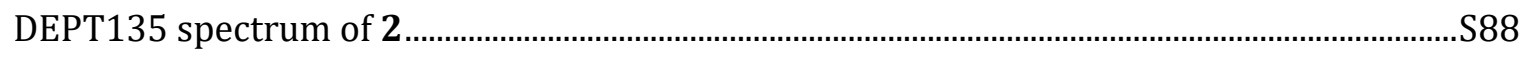

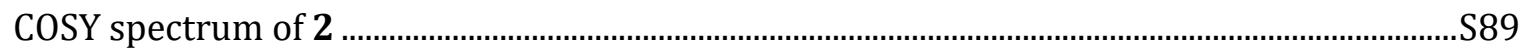

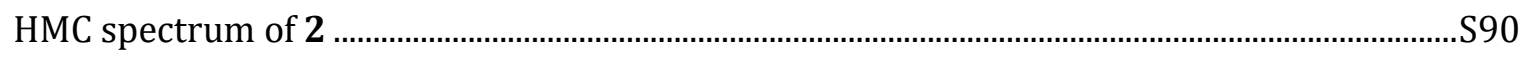

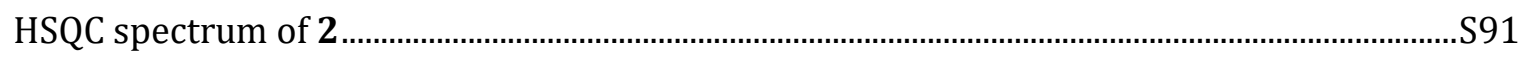

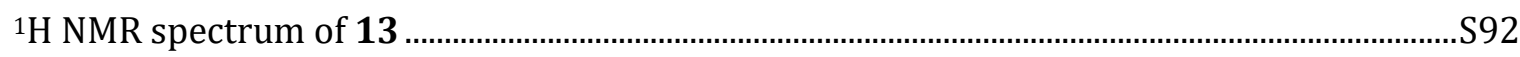

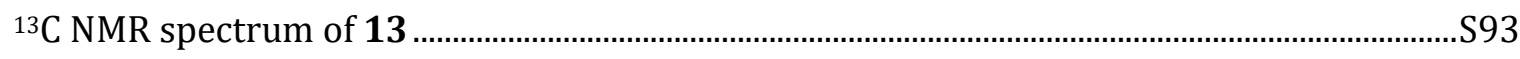

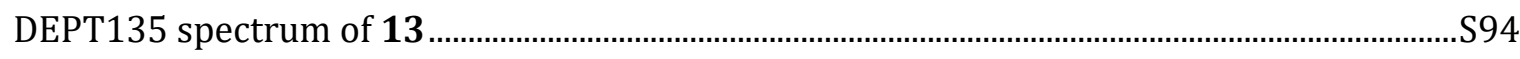

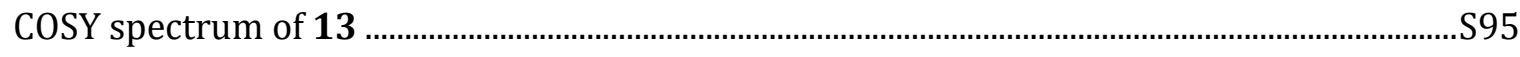

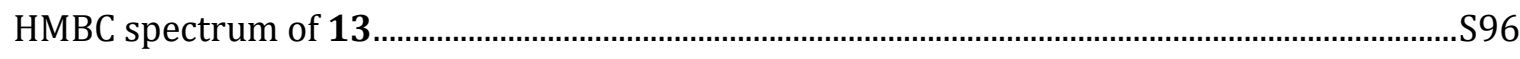

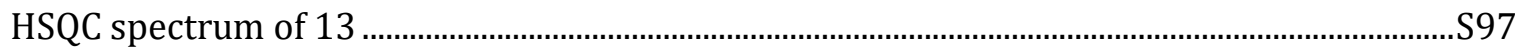




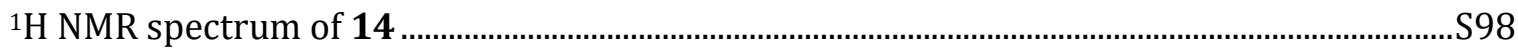

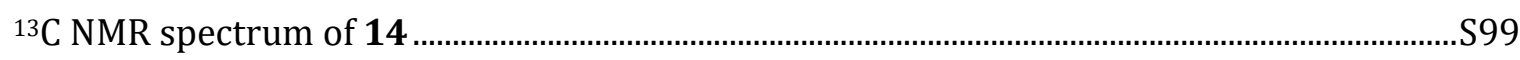

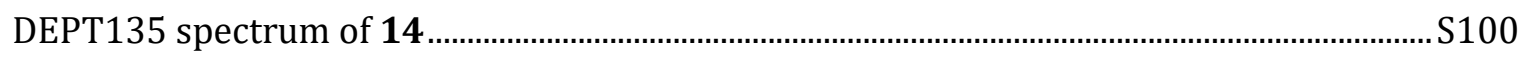

COSY spectrum of 14

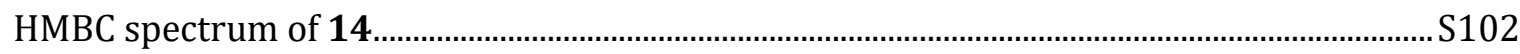

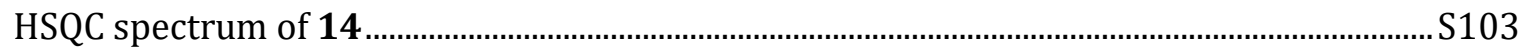

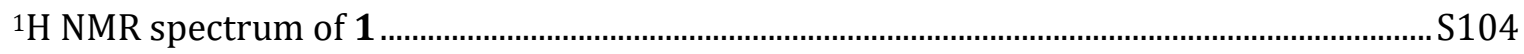

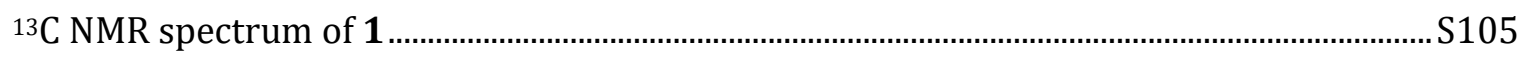

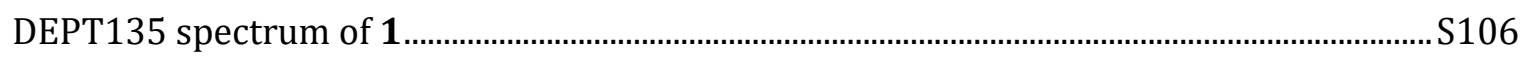

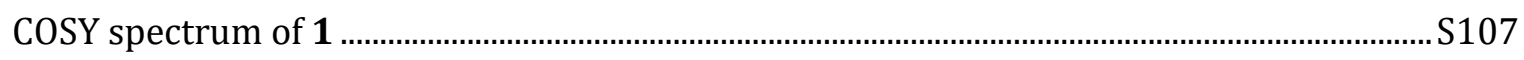

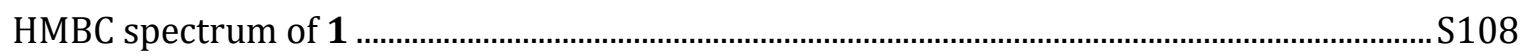

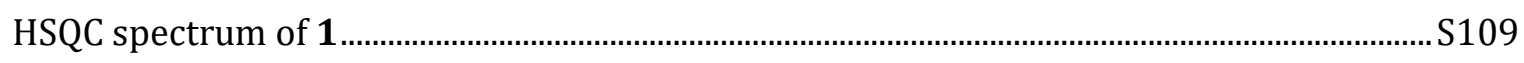

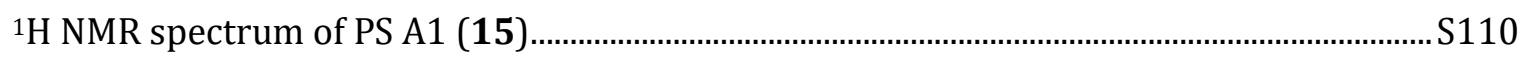

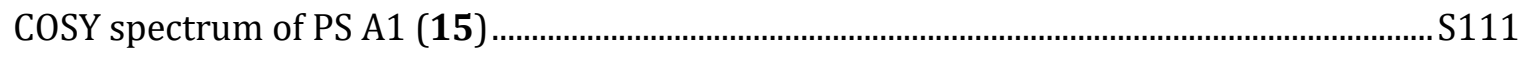

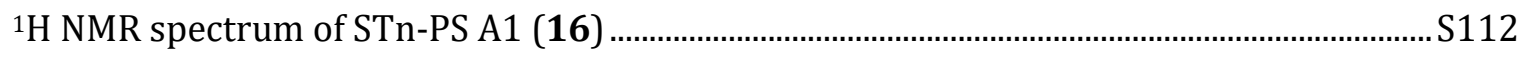

Comparison of STn-PS A1 (16) and PS A1 (15)...................................................................... 1113

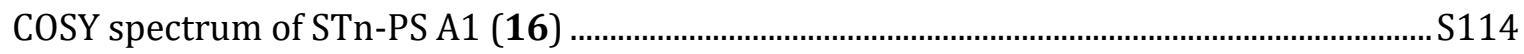

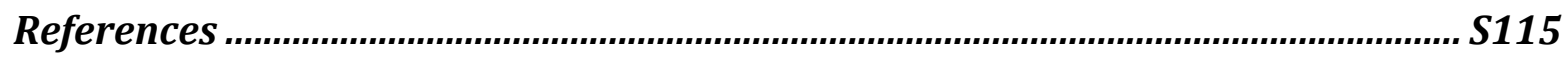




\section{Chemical Synthesis}

General Information: Sialic acid and D-galactosamine hydrochloride were purchased form Ningbo Hongxiang Biotechonology Co. ltd. Relevant reagents and solvents were purchased from commercial sources and used without further purification. Synthesized compounds were purified using flash chromatography with SiliCycle Inc. $60 \AA$ 230-400 mesh silica gel or size exclusion chromatography with Bio-Gel P-2 (Bio-Rad Laboratories, Inc). Thin layer chromatography (TLC) was performed with SiliCycle Inc. silica gel TLC $250 \mu \mathrm{m} \mathrm{w} / \mathrm{h}$ F-254. Proton and carbon NMR spectra were recorded using a Bruker Avance III 600 Ultrafield Cryoprobe spectrometer. The residual chloroform peak was referenced to 7.26 and $77 \mathrm{ppm}$ in proton and carbon spectra respectively. The residual HDO was referenced to $4.79 \mathrm{ppm}$ when spectra were taken using $\mathrm{D}_{2} \mathrm{O}$. Mass spectral data were taken on a Waters ESI-MS LCT premier XE machine. Zwitterionic polysaccharide PS A1 (15) was isolated and purified as previously described.1,2

\section{Preparation of sialyl phosphate donor 3}
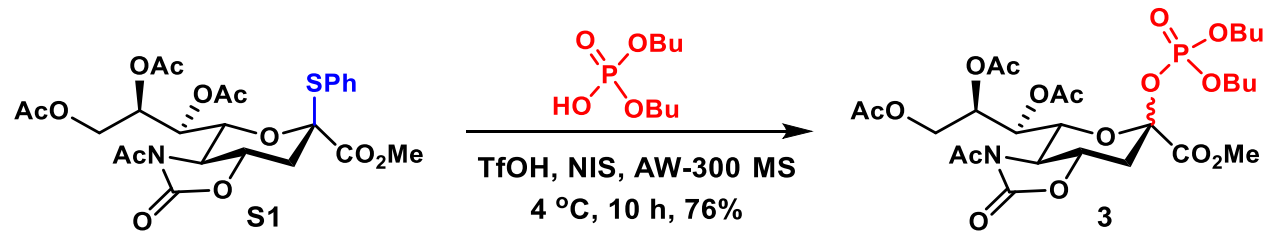

Compound $\mathbf{S} 1$ was prepared as previously described ${ }^{3}$ and all the spectroscopic data coincided with what was reported in the literature. A solution of thio-sialyl donor S1 (568 mg, $1.0 \mathrm{mmol}$ ), dibutyl phosphate $(630 \mathrm{mg}, 595 \mu \mathrm{L}, 3.0 \mathrm{mmol}$ ) and $2.0 \mathrm{~g}$ of activated AW-300 MS in dry DCM (20 mL) was stirred under argon at room temperature for $1 \mathrm{~h}$. The reaction mixture was then cooled to $4{ }^{\circ} \mathrm{C}$ and NIS (450 mg, $2.0 \mathrm{mmol}$ ) and TfOH (15 $\mathrm{mg}, 8.9 \mu \mathrm{L}, 0.1 \mathrm{mmol}$ ) were added simultaneously. After stirring for 10 hours, the reaction mixture was diluted with $20 \mathrm{~mL}$ of DCM and quenched with $30 \mathrm{~mL}$ sat. $\mathrm{Na}_{2} \mathrm{~S}_{2} \mathrm{O}_{3}$ and $\mathrm{NaHCO}_{3}$ aqueous solution. The aqueous layer was extracted twice with DCM. The combined organic layers were washed with $30 \mathrm{~mL}$ sat. $\mathrm{NaHCO}_{3}$ and $30 \mathrm{~mL}$ brine then dried with anhydrous $\mathrm{MgSO}_{4}$, filtered through a thick pad of Celite $囚$ and concentrated under vacuum. Anomeric $\alpha / \beta$ ratios were determined using ${ }^{1} \mathrm{H}$ NMR analysis of the unpurified reaction material; found $\alpha / \beta$ ratio of $1: 8$. The "crude" compound was purified using silica gel column chromatography to afford sialyl phosphate donor $\mathbf{3}$ as a light yellow syrup (508 mg, $0.76 \mathrm{mmol}, 76 \%, \alpha / \beta=1: 8)$. $\beta$-Isomer: ${ }^{1} \mathrm{H}$ NMR $(600 \mathrm{MHz}$ ,CHLOROFORM-d) $\delta=5.62(\mathrm{dd}, J=1.9,3.9 \mathrm{~Hz}, 1 \mathrm{H}), 5.26(\mathrm{ddd}, J=2.7,4.1,7.0 \mathrm{~Hz}, 1 \mathrm{H}$ ), 4.73 (dd, $J=1.9,9.4 \mathrm{~Hz}, 1 \mathrm{H}), 4.63-4.52(\mathrm{~m}, 2 \mathrm{H}), 4.16-4.04(\mathrm{~m}, 5 \mathrm{H}), 3.86(\mathrm{~s}, 3 \mathrm{H}), 3.78$ (dd, $J=9.5,11.4 \mathrm{~Hz}, 1 \mathrm{H}), 2.89(\mathrm{dd}, J=3.8,12.7 \mathrm{~Hz}, 1 \mathrm{H}), 2.50(\mathrm{~s}, 3 \mathrm{H}), 2.30$ (dt, $J=2.8$, $12.7 \mathrm{~Hz}, 1 \mathrm{H}), 2.13(\mathrm{~s}, 3 \mathrm{H}), 2.10(\mathrm{~s}, 3 \mathrm{H}), 2.03(\mathrm{~s}, 3 \mathrm{H}), 1.71-1.62(\mathrm{~m}, 4 \mathrm{H}), 1.44$ - $1.34(\mathrm{~m}$, $4 \mathrm{H}), 0.94(\mathrm{t}, J=7.4 \mathrm{~Hz}, 3 \mathrm{H}), 0.95(\mathrm{t}, J=7.3 \mathrm{~Hz}, 3 \mathrm{H}) ;{ }^{13} \mathrm{C}$ NMR $(151 \mathrm{MHz}$, CHLOROFORMd) $\delta=172.2,170.6,170.6,169.8,165.6,153.5,98.8,98.8,76.7,74.0,72.6,71.8,68.5,68.5$, 68.4, 68.3, 62.9, 58.8, 53.5, 36.1, 36.0, 32.1, 32.1, 32.1, 32.0, 24.7, 21.0, 20.8, 18.6, 18.6, 13.5; ESI HRMS: Exact Mass calcd [M+Na] $]^{+}$for $\mathrm{C}_{27} \mathrm{H}_{42} \mathrm{NNaO}_{16} \mathrm{P} 690.2133$, found: $[\mathrm{M}+\mathrm{Na}]^{+}$ $\mathrm{C}_{27} \mathrm{H}_{42} \mathrm{NNaO}{ }_{16} \mathrm{P} 690.2128$. 


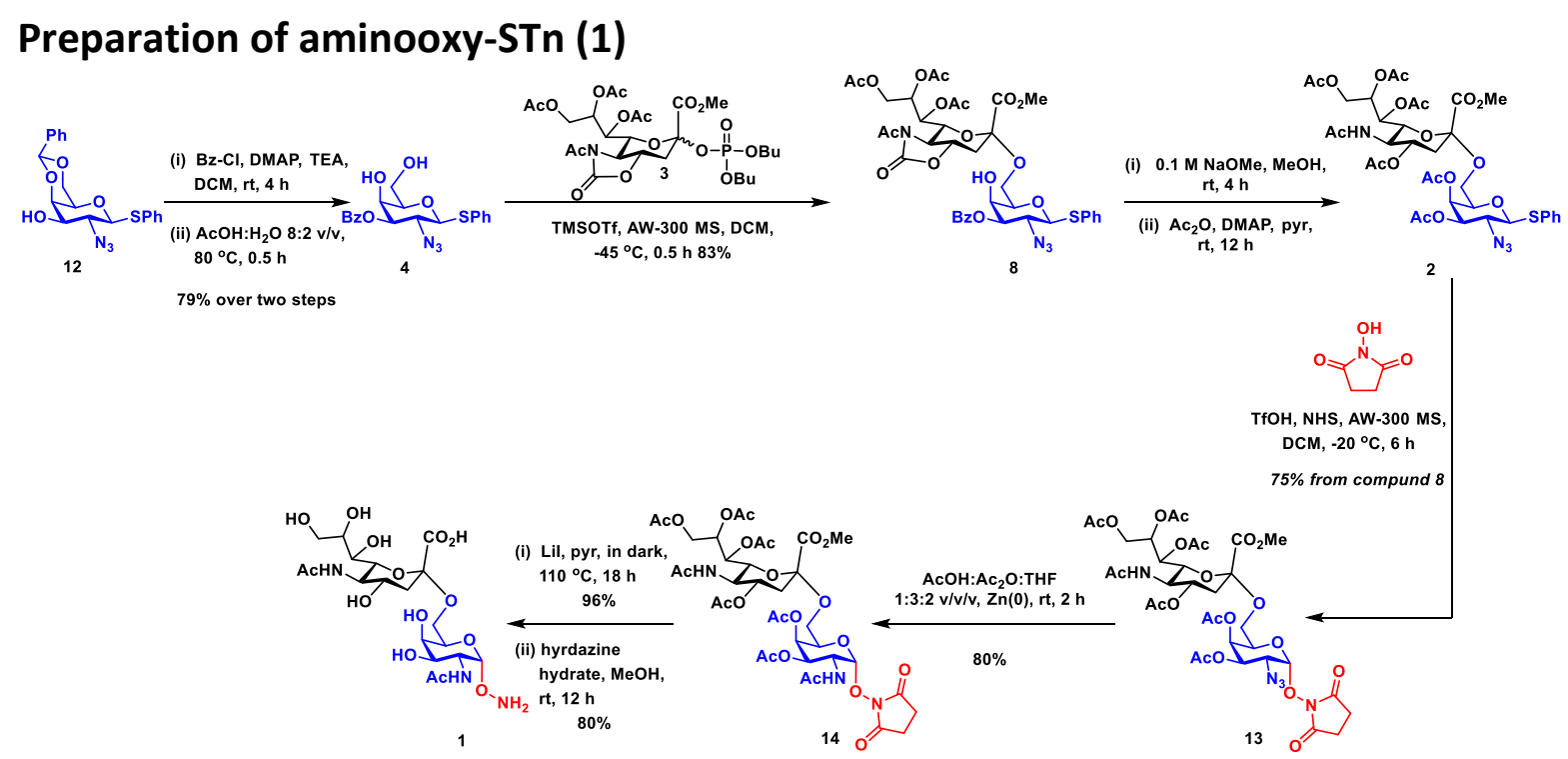

Phenyl-2-azido-4-benzoyl-2-deoxy-1-thio- $\beta$-D-galactopyranoside (4)

Compound $12^{4}$ (386 mg, $1.0 \mathrm{mmol}$ ) was dissolved in $40 \mathrm{~mL}$ dry DCM. To this was added a catalytic amount of DMAP (25 mg, $0.2 \mathrm{mmol})$ and TEA (405 mg, $558 \mu \mathrm{L}, 4.0 \mathrm{mmol}$ ). After a short period of time ( $<5 \mathrm{mins}$ ), benzoyl chloride ( $211 \mathrm{mg}, 175 \mu \mathrm{L}, 1.5 \mathrm{mmol}$ ) was added dropwise over $20 \mathrm{~min}$. The mixture was allowed to stir at room temperature until TLC analysis indicated complete consumption of $\mathbf{1 2}$. The reaction was quenched by adding an excessive amount of saturated sodium bicarbonate solution. The organic layer was washed with sat $\mathrm{NaHCO}_{3}(3 \times 50 \mathrm{~mL})$, brine $(50 \mathrm{~mL})$ and the resulting organic layer was dried over $\mathrm{NaSO}_{4}$. The solvent was then removed under vacuum to afford an offwhite solid. The unpurified intermediate was dissolved in $50 \mathrm{~mL}$ of $80 \%$ acetic acid and heated to $80^{\circ} \mathrm{C}$ for 1.5 hours. After the reaction mixture was cooled, it was azeotroped with toluene $(3 \times 50 \mathrm{~mL})$ to remove any unwanted solvent/water. The "crude" material was then purified on silica gel chromatography using a 15:1 DCM/MeOH mixture to afford diol 4 (317 mg, $0.79 \mathrm{mmol}, 79 \%$ over two steps) as a white foam. ${ }^{1} \mathrm{H}$ NMR $(600 \mathrm{MHz}$, CHLOROFORM-d) $\delta=8.05(\mathrm{~d}, J=7.3 \mathrm{~Hz}, 2 \mathrm{H}), 7.65-7.54(\mathrm{~m}, 3 \mathrm{H}), 7.43(\mathrm{t}, J=$ $7.8 \mathrm{~Hz}, 2 \mathrm{H}), 7.38-7.31(\mathrm{~m}, 3 \mathrm{H}), 4.98(\mathrm{dd}, J=2.8,10.2 \mathrm{~Hz}, 1 \mathrm{H}), 4.59(\mathrm{~d}, J=10.1 \mathrm{~Hz}, 1 \mathrm{H})$, 4.31 (br. s., $1 \mathrm{H}$ ), 3.97 (t, $J=10.1 \mathrm{~Hz}, 1 \mathrm{H}$ ), 3.90 (dd, $J=5.4,11.8 \mathrm{~Hz}, 1 \mathrm{H}), 3.84$ (dd, $J=4.0$, $11.6 \mathrm{~Hz}, 1 \mathrm{H}$ ), 3.60 (t, J = 5.1 Hz, $1 \mathrm{H}$ ), 3.36 (br. s., $1 \mathrm{H}), 3.09$ (br. s., $1 \mathrm{H}) ;{ }^{13} \mathrm{C}$ NMR $(151 \mathrm{MHz}$, CHLOROFORM-d) $\delta=165.8,133.7,132.8,131.7,129.9,129.2,129.1,128.6,128.4,86.9$, 77.9, 76.4, 67.3, 62.5, 60.0; ESI HRMS: Exact Mass calcd $[\mathrm{M}+\mathrm{Na}]^{+}$for $\mathrm{C}_{19} \mathrm{H}_{19} \mathrm{~N}_{3} \mathrm{NaO}_{5} \mathrm{~S}$ 424.4260, found: $[\mathrm{M}+\mathrm{Na}]^{+} \mathrm{C}_{19} \mathrm{H}_{19} \mathrm{~N}_{3} \mathrm{NaO}_{5} \mathrm{~S} 424.4258$.

Methyl-5-acetamido-7,8,9-tri- $O$-acetyl-3,5-dideoxy-D-glycero- $\alpha$-D-galacto-non-2ulopyranosylonate-( $2 \rightarrow 6)$-2-azido-2-deoxy-3-benzoyl-1-thio- $\beta$-D-glactopyranoside (8)

A solution of sialyl phosphate donor 3 ( $87 \mathrm{mg}, 0.13 \mathrm{mmol}$ ), acceptor 4 ( $40 \mathrm{mg}, 0.10$ mmol) and $500 \mathrm{mg}$ pulverized activated AW-300 molecular sieves in $10 \mathrm{~mL}$ anhydrous DCM was stirred under argon at room temperature for 2 hours. The reaction mixture 
was then cooled to $-45{ }^{\circ} \mathrm{C}$ followed by the addition of TMSOTf ( $29 \mathrm{mg}, 27.3 \mu \mathrm{L}, 0.13$ mmol). Reaction progress was monitored by TLC analysis and after visualizing complete conversion of the starting material (usually $20 \mathrm{~min}$ ), the reaction mixture was neutralized using excess DIPEA at the same temperature. It was then diluted with 20 mL DCM and filtered through a thick pad of Celite ${ }^{\circledR}$. The filtrate was washed with brine ( $3 \times 50 \mathrm{~mL}$ ), dried over $\mathrm{MgSO}_{4}$, filtered, and concentrated under vacuum. The residue was purified using silica gel column chromatography to provide 8 (72 $\mathrm{mg}, 0.083 \mathrm{mmol}, 83 \%)$. Only the $\alpha$-anomer was detected and it was confirmed by long range ${ }^{3} J_{\mathrm{C} 1-\mathrm{H} 3 \mathrm{ax}}$ coupling experiment $\left({ }^{3} \mathrm{C}_{\mathrm{C}-\mathrm{H} 3 \mathrm{ax}}=6.60 \mathrm{~Hz}\right.$, pulse program: hmbcetgpjcl2nd). ${ }^{1} \mathrm{H} \quad \mathrm{NMR}$ (600MHz ,CHLOROFORM-d) $\delta=8.12-8.07(\mathrm{~m}, 2 \mathrm{H}), 7.71-7.63(\mathrm{~m}, 2 \mathrm{H}), 7.59(\mathrm{t}, J=7.4$ $\mathrm{Hz}, 1 \mathrm{H}), 7.46(\mathrm{t}, J=7.8 \mathrm{~Hz}, 2 \mathrm{H}), 7.38-7.30(\mathrm{~m}, 3 \mathrm{H}), 5.57(\mathrm{dd}, J=1.6,7.1 \mathrm{~Hz}, 1 \mathrm{H}), 5.48$ $(\mathrm{dt}, J=2.8,7.3 \mathrm{~Hz}, 1 \mathrm{H}), 5.03(\mathrm{dd}, J=2.9,10.1 \mathrm{~Hz}, 1 \mathrm{H}), 4.65(\mathrm{~d}, J=10.3 \mathrm{~Hz}, 1 \mathrm{H}), 4.60(\mathrm{dd}$, $J=1.5,9.4 \mathrm{~Hz}, 1 \mathrm{H}), 4.46(\mathrm{dd}, J=2.8,12.1 \mathrm{~Hz}, 1 \mathrm{H}), 4.29(\mathrm{dd}, J=2.9,5.3 \mathrm{~Hz}, 1 \mathrm{H}), 4.08$ $3.90(\mathrm{~m}, 4 \mathrm{H}), 3.88-3.76(\mathrm{~m}, 5 \mathrm{H}), 3.72$ (dd, $J=9.4,11.1 \mathrm{~Hz}, 1 \mathrm{H}), 3.01(\mathrm{~d}, J=5.5 \mathrm{~Hz}, 1 \mathrm{H})$, $2.88(\mathrm{dd}, J=3.5,12.7 \mathrm{~Hz}, 1 \mathrm{H}), 2.49(\mathrm{~s}, 3 \mathrm{H}), 2.16(\mathrm{t}, J=12.7 \mathrm{~Hz}, 1 \mathrm{H}), 2.12(\mathrm{~s}, 3 \mathrm{H}), 2.04$ (s, $3 \mathrm{H}), 1.89$ (s, $3 \mathrm{H}) ;{ }^{13} \mathrm{C}$ NMR (151MHz ,CHLOROFORM-d) $\delta=172.0,171.2,170.4,170.0$, 168.3, 165.6, 153.5, 133.5, 132.7, 132.4, 129.9, 129.4, 129.0, 128.5, 128.1, 99.2, 87.0, 76.5, 76.3, 76.1, 74.7, 72.1, 69.6, 66.1, 63.7, 63.5, 60.0, 59.0, 53.3, 35.7, 24.6, 21.0, 21.0, 20.6, 20.6; ESI HRMS: Exact Mass calcd [M+Na] ${ }^{+}$for $\mathrm{C}_{38} \mathrm{H}_{42} \mathrm{~N}_{4} \mathrm{NaO}_{17} \mathrm{~S} 881.2163$, found: [M+Na] ${ }^{+}$ $\mathrm{C}_{38} \mathrm{H}_{42} \mathrm{~N}_{4} \mathrm{NaO}_{17} \mathrm{~S} 881.2159$.

Methyl-5-acetamido-4,7,8,9-tetra- $O$-acetyl-3,5-dideoxy-D-glycero- $\alpha$ - D-galacto-non-2-

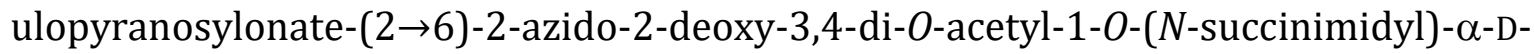
glactopyranoside (13)

Disaccharide 8 ( $86 \mathrm{mg}, 0.10 \mathrm{mmol}$ ) was dissolved in $5 \mathrm{~mL}$ of a $0.1 \mathrm{M}$ sodium methoxide solution and stirred at room temperature for 4 hours to obtain quantitative acetyl group deprotection. The reaction was then neutralized by Amberlite ${ }^{\circledR}$ IR120 acidic resin, filtered through a thick pad of Celite ${ }^{\circledR}$ and the solvent removed under vacuum to afford a white solid. The resulting solid was dissolved in $10 \mathrm{~mL}$ pyridine and a catalytic amount of DMAP ( $2.5 \mathrm{mg}, 0.02 \mathrm{mmol}$ ) was added. This was followed-up by adding $2 \mathrm{~mL}$ of acetic anhydride to the reaction flask. After 12 hours of stirring at room temperature, the reaction reached completion and then it was azeotroped with toluene $(3 \times 20 \mathrm{~mL})$ to remove pyridine. The unpurified mixture was then diluted with $20 \mathrm{~mL}$ ethyl acetate and washed with a $20 \mathrm{~mL} 0.1 \mathrm{M} \mathrm{HCl}$ solution and sat. $\mathrm{NaHCO}_{3}(3 \times 20 \mathrm{~mL})$. The organic layer was dried over $\mathrm{MgSO}_{4}$, filtered through a thick pad of silica gel with $3 \% \mathrm{MeOH}$ in ethyl acetate. The solvents were then removed under vacuum to afford intermediate 2 . The resulting residue of 2 was re-dissolved in $10 \mathrm{~mL}$ of anhydrous DCM, followed by the addition of $N$-hydroxysuccinimide ( $35 \mathrm{mg}, 0.30 \mathrm{mmol}$ ) and $500 \mathrm{mg} \mathrm{AW}-300$ molecular sieves. The mixture was kept stirring for $30 \mathrm{~min}$ at room temperature, then cooled to $20{ }^{\circ} \mathrm{C}$. NIS ( $68 \mathrm{mg}, 0.30 \mathrm{mmol}$ ) was then added to the reaction mixture immediately followed by adding a catalytic amount of TfOH $(3 \mathrm{mg}, 1.8 \mu \mathrm{L}, 0.02 \mathrm{mmol})$. The reaction process was monitored by TLC and noted to be complete after 6 hours. Adding $10 \mathrm{~mL}$ sat. sodium thiosulfate solution quenched the reaction and then the organic layer was diluted with another $20 \mathrm{~mL}$ DCM, washed with sat. $\mathrm{NaHCO}_{3}(3 \times 30 \mathrm{~mL})$, dried over 
$\mathrm{MgSO}_{4}$, filtered through a thick pad of Celite ${ }^{\circledR}$ and concentrated under vacuum. The residue was purified using silica gel column chromatography to afford 13 (65 mg, 0.075 mmol, $75 \%$ over three steps). ${ }^{1} \mathrm{H}$ NMR $(600 \mathrm{MHz}, \mathrm{CHLOROFORM-d)} \delta=5.61$ (d, $J=3.7$ $\mathrm{Hz}, 1 \mathrm{H}), 5.54(\mathrm{~d}, J=1.8 \mathrm{~Hz}, 1 \mathrm{H}), 5.48-5.41(\mathrm{~m}, 2 \mathrm{H}), 5.35-5.31(\mathrm{~m}, 1 \mathrm{H}), 5.18(\mathrm{~d}, J=9.2$ $\mathrm{Hz}, 1 \mathrm{H}), 4.96(\mathrm{t}, J=6.9 \mathrm{~Hz}, 1 \mathrm{H}), 4.93-4.86(\mathrm{~m}, 1 \mathrm{H}), 4.28(\mathrm{dd}, J=2.8,12.5 \mathrm{~Hz}, 1 \mathrm{H}), 4.11$ $(\mathrm{dd}, J=5.0,12.7 \mathrm{~Hz}, 1 \mathrm{H}), 4.04-3.99(\mathrm{~m}, 2 \mathrm{H}), 3.91(\mathrm{dd}, J=3.8,11.5 \mathrm{~Hz}, 1 \mathrm{H}), 3.84-3.77$ $(\mathrm{m}, 4 \mathrm{H}), 3.28(\mathrm{dd}, J=7.3,9.7 \mathrm{~Hz}, 1 \mathrm{H}), 2.82-2.74(\mathrm{~m}, 4 \mathrm{H}), 2.57(\mathrm{dd}, J=4.6,12.8 \mathrm{~Hz}, 1 \mathrm{H})$, 2.19 - 2.15 (m, 7 H), 2.12 - 2.10 (m, 3 H), 2.07 (s, 3 H), 2.04 - 2.02 (m, 6 H), 1.93 - 1.87 (m, $5 \mathrm{H}) ;{ }^{13} \mathrm{C}$ NMR $(151 \mathrm{MHz}, \mathrm{CHLOROFORM}-\mathrm{d}) \delta=170.9,170.6,170.4,170.2,170.1,169.9$, 169.7, 169.5, 167.8, 101.5, 98.4, 72.4, 69.6, 68.9, 68.3, 68.0, 67.3, 67.2, 62.3, 61.9, 56.7, 52.8, 49.5, 37.7, 25.5, 23.2, 21.0, 21.0, 20.9, 20.8, 20.7, 20.6, 20.6, 20.5; ESI HRMS: Exact Mass calcd $[\mathrm{M}+\mathrm{Na}]^{+}$for $\mathrm{C}_{34} \mathrm{H}_{45} \mathrm{~N}_{5} \mathrm{NaO}_{21}$ 882.2505, found: $[\mathrm{M}+\mathrm{Na}]^{+} \mathrm{C}_{34} \mathrm{H}_{45} \mathrm{~N}_{5} \mathrm{NaO}_{21}$ 882.2509.

Methyl-5-acetamido-4,7,8,9-tetra- $O$-acetyl-3,5-dideoxy- D-glycero- $\alpha$-D-galacto-non-2ulopyranosylonate-(2 $\rightarrow 6)$-2-acetamido-2-deoxy-3,4-di-O-acetyl-1-O-( $N$-succinimidyl)$\alpha$-D-glactopyranoside (14)

Compound 13 (86 mg, $0.10 \mathrm{mmol}$ ) was dissolved in $5.0 \mathrm{~mL}$ of a 3:2:1 THF/AcOH/Ac2O at $0{ }^{\circ} \mathrm{C}$ and then activated zinc $(130 \mathrm{mg}, 2.0 \mathrm{mmol})$ dust was added. The reaction was then allowed to stir for 2.0 hours and after such time it was diluted with $20 \mathrm{~mL}$ DCM. This mixture was filtered through a thick pad of Celite ${ }$. The organic solution was then separated and washed with brine $(3 \times 30 \mathrm{~mL})$, sat. $\mathrm{NaHCO}_{3}(3 \times 30 \mathrm{~mL})$, dried over $\mathrm{MgSO}_{4}$, filtered and concentrated under vacuum. The mixture was subjected to silica gel purification using 15:1 DCM/MeOH to ultimately provide the $N$-acetylated compound 14 as a white solid (70 mg, $0.08 \mathrm{mmol}, 80 \%) .{ }^{1} \mathrm{H}$ NMR (600MHz ,CHLOROFORM-d) $\delta=6.03$ $(\mathrm{d}, J=9.5 \mathrm{~Hz}, 1 \mathrm{H}), 5.50(\mathrm{~d}, J=1.8 \mathrm{~Hz}, 1 \mathrm{H}), 5.42(\mathrm{dt}, J=2.6,5.5 \mathrm{~Hz}, 1 \mathrm{H}), 5.37-5.27(\mathrm{~m}, 3$ H), 5.27 - $5.17(\mathrm{~m}, 1 \mathrm{H}), 4.95-4.83(\mathrm{~m}, 2 \mathrm{H}), 4.74$ (ddd, J = 3.7, 9.6, $11.6 \mathrm{~Hz}, 1 \mathrm{H}), 4.29$ (dd, $J=2.7,12.6 \mathrm{~Hz}, 1 \mathrm{H}), 4.13(\mathrm{dd}, J=5.0,12.6 \mathrm{~Hz}, 1 \mathrm{H}), 4.06-3.99(\mathrm{~m}, 2 \mathrm{H}), 3.88-3.76(\mathrm{~m}, 4$ H), $3.33(\mathrm{dd}, J=7.4,9.6 \mathrm{~Hz}, 1 \mathrm{H}), 2.84-2.68(\mathrm{~m}, 4 \mathrm{H}), 2.58(\mathrm{dd}, J=4.6,12.8 \mathrm{~Hz}, 1 \mathrm{H}), 2.18$ - $2.15(\mathrm{~m}, 6 \mathrm{H}), 2.13-2.10(\mathrm{~m}, 3 \mathrm{H}), 2.06-2.01(\mathrm{~m}, 12 \mathrm{H}), 1.95-1.86(\mathrm{~m}, 4 \mathrm{H}) ;{ }^{13} \mathrm{C}$ NMR (151MHz ,CHLOROFORM-d) $\delta=170.9,170.7,170.6,170.5,170.2,170.0,169.8,167.8$, 103.7, 98.4, 72.5, 69.8, 69.0, 68.6, 67.6, 67.3, 67.2, 62.3, 62.0, 52.7, 49.5, 47.2, 37.7, 25.4, 23.2, 23.2, 21.0, 20.8, 20.8, 20.7, 20.7; ESI HRMS: Exact Mass calcd $[\mathrm{M}+\mathrm{Na}]^{+}$for $\mathrm{C}_{36} \mathrm{H}_{49} \mathrm{~N}_{3} \mathrm{NaO}_{22}$ 898.2705, found: $[\mathrm{M}+\mathrm{Na}]^{+} \mathrm{C}_{36} \mathrm{H}_{49} \mathrm{~N}_{3} \mathrm{NaO}_{22}$ 898.2707.

5-acetamido-3,5-dideoxy-D-glycero- $\alpha$-D-galacto-non-2-ulopyranosonic acid-(2-6)-2acetamido-2-deoxy-1-aminooxy- $\alpha$-D-glactopyranoside (1)

Intermediate 14 (44 mg, $0.05 \mathrm{mmol}$ ) was dissolved in $15 \mathrm{~mL}$ anhydrous pyridine and treated with lithium iodide $(133 \mathrm{mg}, 1.0 \mathrm{mmol})$ at room temperature. The reaction mixture was then heated to $110^{\circ} \mathrm{C}$ and kept stirring in the dark overnight. Toluene was then used three times $(3 \times 20 \mathrm{~mL})$ to azeotrope solvent and the unpurified material was subjected to a short silica gel chromatography where $10 \% \mathrm{MeOH}$ in DCM was used as the eluent to obtain the demethylated compound as a white solid (41 mg, $0.048 \mathrm{~mol}$, 
96\%). This solid was then dissolved in $3 \mathrm{~mL}$ of methanol then hydrazine hydrate $(112$ $\mathrm{mg}, 110 \mu \mathrm{L}, 2.0 \mathrm{mmol}$ ) was added and the reaction was allowed to stir for 12 hours. The reaction mixture was concentrated under vacuum to dryness. Using a bio-gel P-2 column, with water as the eluent, purified compound 1 was provided $(20 \mathrm{mg}, 0.038 \mathrm{~mol}$, $80 \%) .{ }^{1} \mathrm{H}$ NMR (600MHz ,DEUTERIUM OXIDE) $\delta=5.14(\mathrm{~d}, J=4.0 \mathrm{~Hz}, 1 \mathrm{H}), 4.19$ (dd, $J=$ 4.0, $11.4 \mathrm{~Hz}, 1 \mathrm{H}$ ), 4.03 (dd, $J=4.5,7.4 \mathrm{~Hz}, 1 \mathrm{H}$ ), 3.94 (d, $J=2.9 \mathrm{~Hz}, 1 \mathrm{H}$ ), 3.85 (dd, $J=7.7$, $10.6 \mathrm{~Hz}, 1 \mathrm{H}), 3.79-3.74(\mathrm{~m}, 3 \mathrm{H}), 3.74-3.68(\mathrm{~m}, 1 \mathrm{H}), 3.64-3.50(\mathrm{~m}, 4 \mathrm{H}), 3.47$ (d, $J=$ $9.2 \mathrm{~Hz}, 1 \mathrm{H}), 2.62(\mathrm{dd}, J=4.6,12.5 \mathrm{~Hz}, 1 \mathrm{H}), 1.92(\mathrm{~d}, J=9.5 \mathrm{~Hz}, 6 \mathrm{H}), 1.59(\mathrm{t}, J=12.1 \mathrm{~Hz}, 1$ H); ${ }^{13} \mathrm{C}$ NMR (151MHz, DEUTERIUM OXIDE) $\delta=175.0,174.6,173.3,100.5,72.6,71.7$, 70.5, 68.2, 68.1, 66.7, 63.8, 62.6, 51.7, 48.6, 40.0, 21.9, 21.8; ESI HRMS: Exact mass calcd $[\mathrm{M}-\mathrm{H}+2 \mathrm{Na}]^{+}$for $\mathrm{C}_{19} \mathrm{H}_{33} \mathrm{~N}_{3} \mathrm{Na}_{2} \mathrm{O}_{14}$ 572.1680, found: $[\mathrm{M}-\mathrm{H}+2 \mathrm{Na}]^{+} \mathrm{C}_{19} \mathrm{H}_{32} \mathrm{~N}_{3} \mathrm{Na}_{2} \mathrm{O}_{14}$ 572.1687.

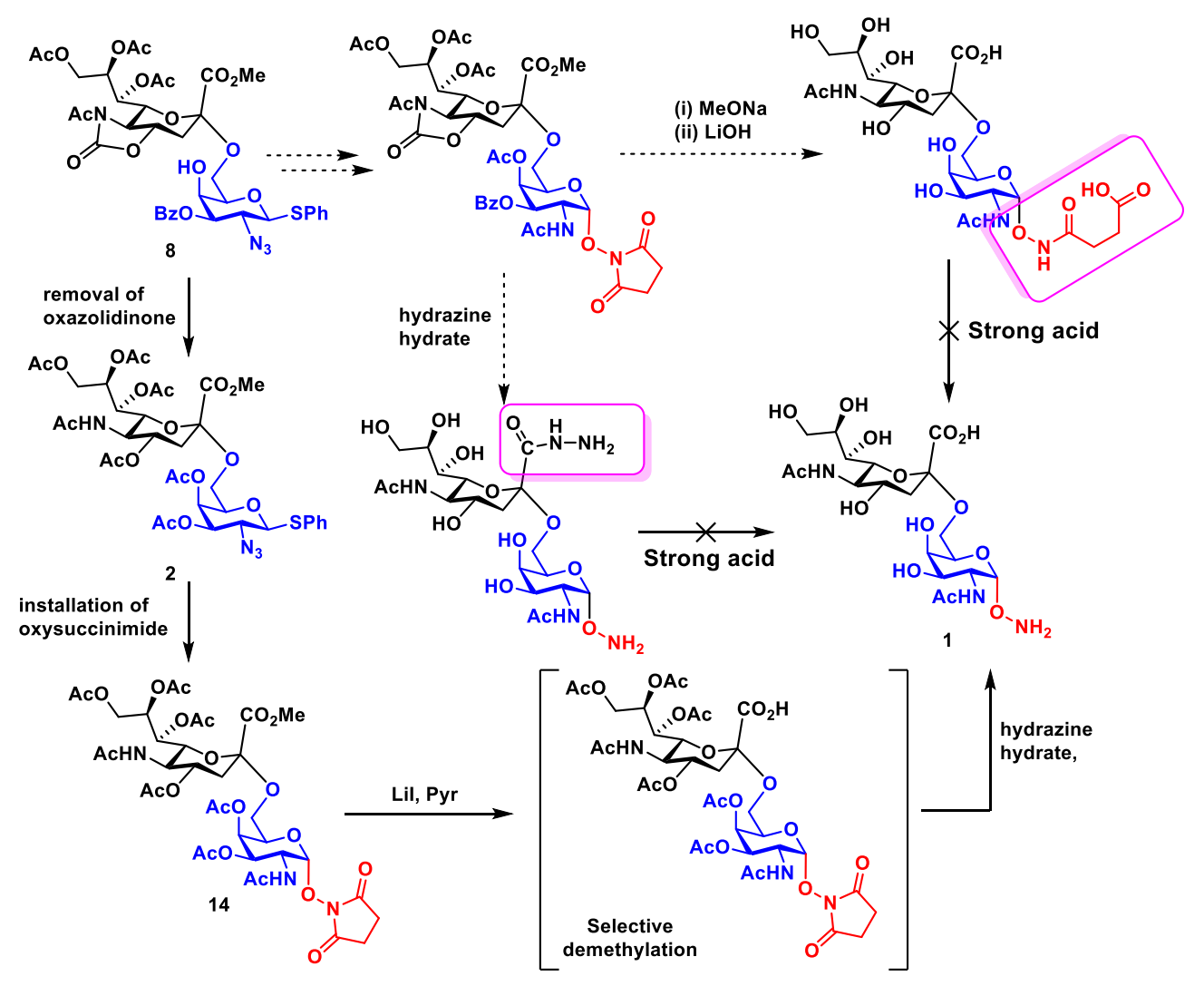

Scheme S1. Rational for the order of transformation of protecting groups. 


\section{General sialylation procedure and preparation of sialyl glycosides 9, 10 and 11}

The highly alpha selective sialylation was performed as previously described. ${ }^{5}$ Sialyl phosphate donor $3(0.13 \mathrm{mmol})$ and acceptor $(4,5,6$ and 7$)(0.10 \mathrm{mmol})$ were dissolved in $10 \mathrm{~mL}$ of dry $\mathrm{CH}_{2} \mathrm{Cl}_{2}$ and $0.5 \mathrm{~g}$ of activated $3 \AA$ molecular sieves was added to the above solution. The mixture was stirred under argon at room temperature for 2 hours and then cooled to $-45{ }^{\circ} \mathrm{C}$ in a dry ice $/ 50 \%$ glycol in $\mathrm{EtOH}$ bath. Once the temperature reached $-45{ }^{\circ} \mathrm{C}$, addition of TMSOTf $(0.13 \mathrm{mmol})$ to the flask was accomplished. The reaction was allowed to stir at the same temperature until TLC indicated complete consumption of the acceptor (usually $20 \mathrm{~min}$ ). Excessive DIPEA was added to the reaction mixture at same temperature to neutralize unreacted TMSOTf. The mixture was then diluted with another $20 \mathrm{~mL}$ DCM and filtered through a thick pad of Celite $\AA$. The filtrate was washed with brine $(3 \times 50 \mathrm{~mL})$, dried over $\mathrm{MgSO}_{4}$, filtered, and the solvent removed under vacuum. The crude material was purified using silica gel column chromatography.

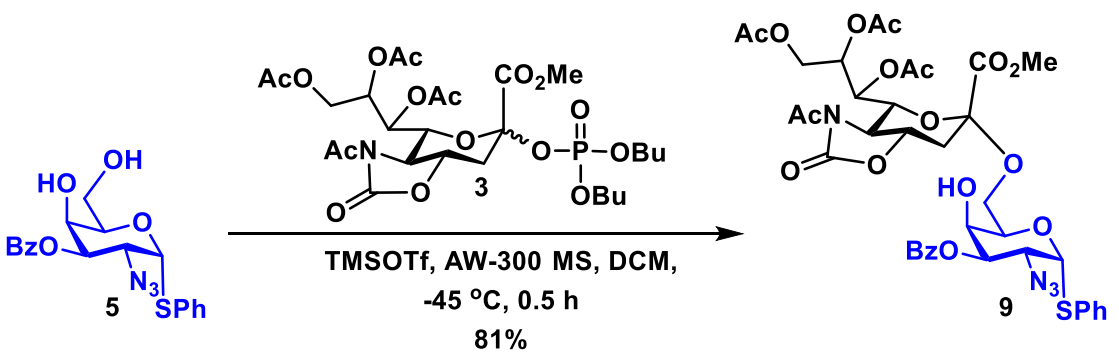

Methyl-5-acetamido-7,8,9-tri- $O$-acetyl-3,5-dideoxy-D-glycero- $\alpha$-D-galacto-non-2ulopyranosylonate-(2 $\rightarrow 6)$-2-azido-2-deoxy-3-benzoyl-1-thio- $\alpha$-D-glactopyranoside (9)

Compound $\mathbf{9}$ was prepared from acceptor $\mathbf{5}$ and donor $\mathbf{3}$ using the general sialylation procedure as described on page S10 above in an $81 \%$ yield ( $69 \mathrm{mg}, 0.081 \mathrm{mmol}$ ). Only the $\alpha$-anomer was found and confirmed by a long range ${ }^{3}{ }_{\mathrm{C} 1-\mathrm{H} 3 \mathrm{ax}}$ coupling experiment ( ${ }^{3} \mathrm{C} 1 \mathrm{-H} 3 \mathrm{ax}=5.90 \mathrm{~Hz}$, pulse program: hmbcetgpjcl2nd). ${ }^{1} \mathrm{H}$ NMR $(600 \mathrm{MHz}, \mathrm{CHLOROFORM-}$ d) $\delta=8.18-8.05(\mathrm{~m}, 2 \mathrm{H}), 7.66-7.54(\mathrm{~m}, 3 \mathrm{H}), 7.47(\mathrm{t}, J=7.8 \mathrm{~Hz}, 2 \mathrm{H}), 7.35-7.29(\mathrm{~m}, 3$ H), $5.75(\mathrm{~d}, J=5.3 \mathrm{~Hz}, 1 \mathrm{H}), 5.54(\mathrm{dd}, J=1.6,7.2 \mathrm{~Hz}, 1 \mathrm{H}), 5.48-5.41(\mathrm{~m}, 1 \mathrm{H}), 5.24(\mathrm{dd}, J$ $=2.9,11.2 \mathrm{~Hz}, 1 \mathrm{H}), 4.68(\mathrm{dd}, J=5.5,11.2 \mathrm{~Hz}, 1 \mathrm{H}), 4.63(\mathrm{t}, J=6.0 \mathrm{~Hz}, 1 \mathrm{H}), 4.58(\mathrm{dd}, J=$ 1.5, $9.4 \mathrm{~Hz}, 1 \mathrm{H}), 4.43-4.33(\mathrm{~m}, 2 \mathrm{H}), 4.08-3.99(\mathrm{~m}, 1 \mathrm{H}), 3.99-3.88(\mathrm{~m}, 2 \mathrm{H}), 3.85-3.76$ (m, $4 \mathrm{H}$ ), 3.72 (dd, $J=9.4,11.1 \mathrm{~Hz}, 1 \mathrm{H}), 3.44-3.37$ (m, $1 \mathrm{H}$ ), 2.85 (dd, $J=3.5,12.1 \mathrm{~Hz}, 1$ H), $2.48(\mathrm{~s}, 3 \mathrm{H}), 2.14-2.08(\mathrm{~m}, 4 \mathrm{H}), 2.03(\mathrm{~s}, 3 \mathrm{H}), 1.90(\mathrm{~s}, 3 \mathrm{H}) ;{ }^{13} \mathrm{C}$ NMR $(151 \mathrm{MHz}$ ,CHLOROFORM-d) $\delta=172.1,171.4,170.6,170.0,168.5,165.6,153.6,133.6,133.5,132.2$, 129.9, 129.3, 129.0, 128.5, 127.7, 99.0, 87.5, 76.0, 74.7, 73.4, 72.0, 69.6, 69.5, 66.8, 64.0, 63.4, 58.9, 58.5, 53.3, 35.7, 24.7, 21.1, 21.0, 20.8, 20.6; ESI HRMS: Excat Mass calcd $[\mathrm{M}+\mathrm{Na}]^{+}$for $\mathrm{C}_{38} \mathrm{H}_{42} \mathrm{~N}_{4} \mathrm{NaO}_{17} \mathrm{~S}$ 881.2163, found: $[\mathrm{M}+\mathrm{Na}]^{+} \mathrm{C}_{38} \mathrm{H}_{42} \mathrm{~N}_{4} \mathrm{NaO}_{17} \mathrm{~S} 881.2161$. 

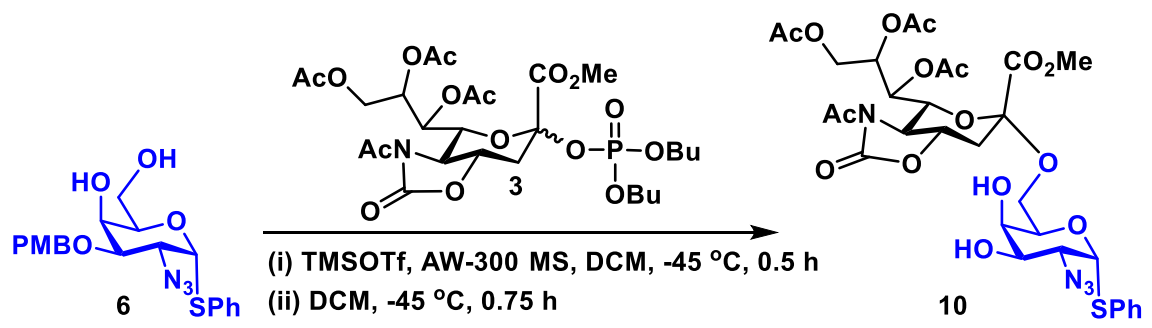

$77 \%$ over two steps

Methyl-5-acetamido-7,8,9-tri- $O$-acetyl-3,5-dideoxy-D-glycero- $\alpha$-D-galacto-non-2ulopyranosylonate-(2 $\rightarrow 6)$-2-azido-2-deoxy-1-thio- $\alpha$-D-glactopyranoside (10)

Compound 10 was prepared from acceptor $\mathbf{6}$ and donor $\mathbf{3}$. Using the general sialylation procedure as previously described on page S10; after TLC indicated the complete consumption of acceptor 6, deprotection of the PMB group commenced by slowly increasing the reaction temperature to $0{ }^{\circ} \mathrm{C}$. At this point the reaction mixture was continually stirred for $45 \mathrm{~min}$ at $0{ }^{\circ} \mathrm{C}$. The reaction was quenched by adding $10 \mathrm{~mL}$ sat. $\mathrm{NaHCO}_{3}$, diluted with $20 \mathrm{~mL}$ DCM and filtered through a thick pad of Celite ${ }^{\circledR}$. The filtrate was washed with brine $(3 \times 50 \mathrm{~mL})$, dried over $\mathrm{MgSO}_{4}$, filtered, and concentrated under vacuum. The residue was purified using silica gel column chromatography to ultimately provide 10 in a 77\% yield (58 $\mathrm{mg}, 0.077 \mathrm{mmol}$ ). Only the $\alpha$-anomer was observed and confirmed by a long range ${ }^{3}{ }_{\mathrm{C} 1}-\mathrm{H} 3 \mathrm{ax}$ coupling experiment $\left({ }^{3} \mathrm{C}_{\mathrm{C} 1-\mathrm{H} 3 \mathrm{ax}}=6.90 \mathrm{~Hz}\right.$, pulse program: hmbcetgpjcl2nd). ${ }^{1} \mathrm{H}$ NMR (600MHz ,CHLOROFORM-d) $\delta=7.67-7.63(\mathrm{~m}, 2 \mathrm{H})$, 7.33 - $7.30(\mathrm{~m}, 3 \mathrm{H}), 5.58$ - $5.51(\mathrm{~m}, 2 \mathrm{H}), 4.62(\mathrm{~d}, J=9.4 \mathrm{~Hz}, 1 \mathrm{H}), 4.54-4.48(\mathrm{~m}, 2 \mathrm{H}), 4.11$ - $4.05(\mathrm{~m}, 1 \mathrm{H}), 4.02-3.97(\mathrm{~m}, 3 \mathrm{H}), 3.85(\mathrm{~s}, 3 \mathrm{H}), 3.82-3.73(\mathrm{~m}, 2 \mathrm{H}), 3.66(\mathrm{t}, J=6.1 \mathrm{~Hz}$, $1 \mathrm{H}$ ), 3.60 (d, $J=6.8 \mathrm{~Hz}, 2 \mathrm{H}$ ), 3.24 (d, $J=3.5 \mathrm{~Hz}, 1 \mathrm{H}$ ), 3.11 (br. s., $1 \mathrm{H}$ ), 2.90 (dd, $J=3.5$, $12.1 \mathrm{~Hz}, 1 \mathrm{H}), 2.51(\mathrm{~s}, 3 \mathrm{H}), 2.18(\mathrm{~d}, J=13.0 \mathrm{~Hz}, 1 \mathrm{H}), 2.16(\mathrm{~s}, 3 \mathrm{H}), 2.03(\mathrm{~s}, 3 \mathrm{H}), 2.01(\mathrm{~s}, 3$ $\mathrm{H}) ;{ }^{13} \mathrm{C}$ NMR (151MHz ,CHLOROFORM-d) $\delta=172.2,171.9,170.6,170.1,168.4,153.5$, 132.3, 128.9, 127.9, 99.1, 87.0, 76.6, 75.9, 74.7, 74.2, 71.9, 69.1, 67.9, 64.1, 64.0, 63.1, 58.9, 53.4, 35.8, 24.7, 21.2, 21.1, 20.9, 20.7; ESI HRMS: Exact Mass calcd [M+Na] ${ }^{+}$for $\mathrm{C}_{31} \mathrm{H}_{38} \mathrm{~N}_{4} \mathrm{NaO}_{16} \mathrm{~S} 777.1901$, found $[\mathrm{M}+\mathrm{Na}]{ }^{+} \mathrm{C}_{31} \mathrm{H}_{38} \mathrm{~N}_{4} \mathrm{NaO}_{16} \mathrm{~S} 777.1909$.

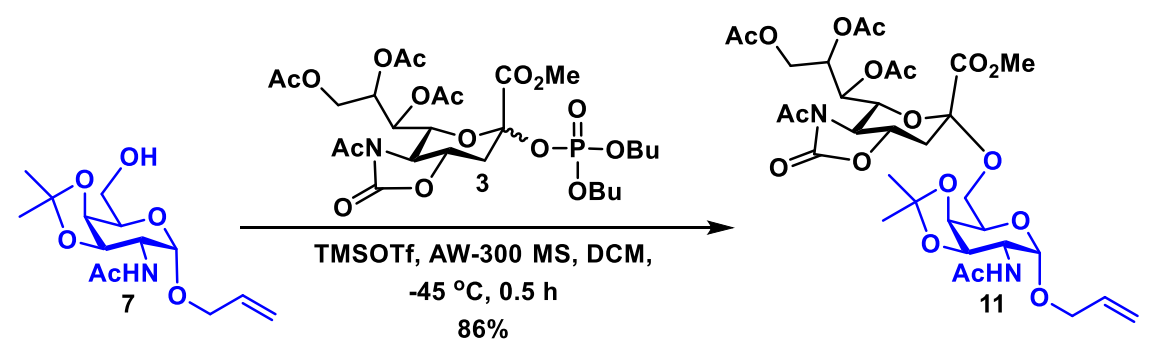

Methyl-5-acetamido-7,8,9-tri- $O$-acetyl-3,5-dideoxy-D-glycero- $\alpha$-D-galacto-non-2ulopyranosylonate-(2 $\rightarrow 6)$-2-acetamido-2-deoxy-3,4-(2,2-dimethypropyl acetal)-1allyloxy- $\alpha$-D-glactopyranoside (11) 
Compound $\mathbf{1 1}$ was prepared from acceptor $\mathbf{7}$ and donor $\mathbf{3}$ using the general sialylation procedure as described above on page S10 in an $86 \%$ yield ( $66 \mathrm{mg}, 0.086 \mathrm{mmol})$. Only the $\alpha$-anomer was found and confirmed by a long range ${ }^{3}{ }^{3} 1-$-н3ах coupling experiment ( $3{ }^{3} \mathrm{c} 1-\mathrm{H} 3 \mathrm{ax}=6.10 \mathrm{~Hz}$, pulse program: hmbcetgpjcl2nd). ${ }^{1} \mathrm{H}$ NMR $(600 \mathrm{MHz}, \mathrm{CHLOROFORM}-$ d) $\delta=5.94-5.83(\mathrm{~m}, 1 \mathrm{H}), 5.64(\mathrm{~d}, J=9.5 \mathrm{~Hz}, 1 \mathrm{H}), 5.58(\mathrm{dd}, J=1.8,6.6 \mathrm{~Hz}, 1 \mathrm{H}), 5.44(\mathrm{dt}$, $J=2.8,6.7 \mathrm{~Hz}, 1 \mathrm{H}), 5.29$ (qd, $J=1.6,17.2 \mathrm{~Hz}, 1 \mathrm{H}), 5.22(\mathrm{dd}, J=1.4,10.4 \mathrm{~Hz}, 1 \mathrm{H}), 4.80(\mathrm{~d}$, $J=3.5 \mathrm{~Hz}, 1 \mathrm{H}), 4.57(\mathrm{dd}, J=1.8,9.4 \mathrm{~Hz}, 1 \mathrm{H}), 4.38(\mathrm{dd}, J=2.9,12.3 \mathrm{~Hz}, 1 \mathrm{H}), 4.27(\mathrm{dt}, J=$ 3.4, $9.2 \mathrm{~Hz}, 1 \mathrm{H}), 4.21-4.03(\mathrm{~m}, 6 \mathrm{H}), 4.00-3.91(\mathrm{~m}, 2 \mathrm{H}), 3.86-3.81(\mathrm{~m}, 3 \mathrm{H}), 3.76$ (dt, J $=1.9,9.3 \mathrm{~Hz}, 2 \mathrm{H}), 2.92(\mathrm{dd}, J=3.6,12.0 \mathrm{~Hz}, 1 \mathrm{H}), 2.49(\mathrm{~s}, 3 \mathrm{H}), 2.18-2.11(\mathrm{~m}, 7 \mathrm{H}), 2.03$ (s, $4 \mathrm{H}), 2.05(\mathrm{~s}, 3 \mathrm{H}), 1.56(\mathrm{~s}, 3 \mathrm{H}), 1.34(\mathrm{~s}, 3 \mathrm{H}) ;{ }^{13} \mathrm{C}$ NMR (151MHz ,CHLOROFORM-d) $\delta$ $=172.1,170.7,170.3,170.0,169.9,168.3,153.7,133.5,117.8,109.6,99.3,96.8,75.9$, 75.0, 74.4, 72.4, 72.2, 69.8, 68.3, 66.2, 64.4, 62.9, 59.1, 53.1, 50.3, 36.1, 28.0, 26.5, 24.7, 23.5, 21.1, 20.9, 20.8; ESI HRMS: Exact Mass calcd [M+Na] ${ }^{+}$for $\mathrm{C}_{33} \mathrm{H}_{46} \mathrm{~N}_{2} \mathrm{NaO}_{18} 781.2643$, found: $[\mathrm{M}+\mathrm{Na}]^{+} \mathrm{C}_{33} \mathrm{H}_{46} \mathrm{~N}_{2} \mathrm{NaO}_{18} 781.2641$.

Preparation of STn-PS A1 (16) conjugate

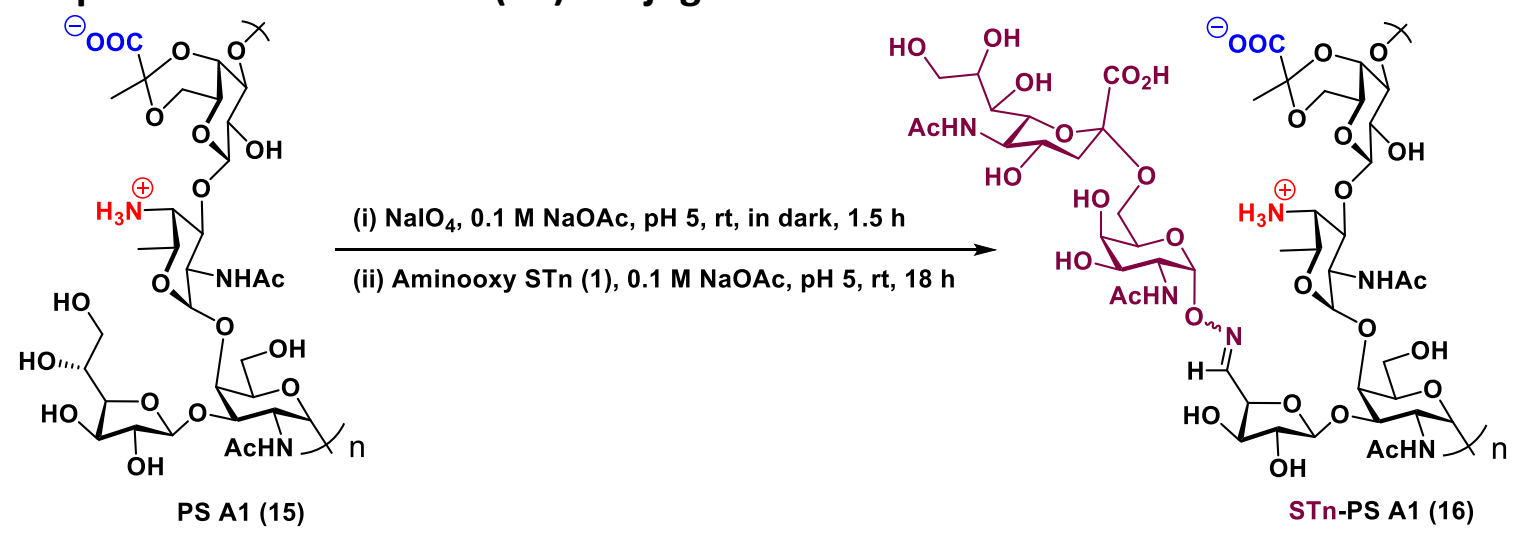

Polysaccharide PS A1 (15) was isolated and purified as previously described.1,2 PS A1 (1 mg, $9.1 \times 10^{-9} \mathrm{~mol}$ ) was dissolved in sodium acetate buffer $(0.5 \mathrm{~mL}, 0.1 \mathrm{M}, \mathrm{pH}=5)$. To this solution was added $55 \mu \mathrm{L}$ of $0.01 \mathrm{M} \mathrm{NaIO}_{4}$ solution $\left(5.5 \times 10^{-7} \mathrm{~mol}\right)$. The reaction was allowed to shake gently for $90 \mathrm{~min}$ in the dark at room temperature. Excess $\mathrm{NaIO}_{4}$ was quenched by adding ethylene glycol and the mixture was continually shaken for another $20 \mathrm{~min}$ in the dark. The oxidized PS A1 was purified with the help of a centrifugal concentrator (Vivaspin, molecular cut-off $30 \mathrm{kDa}$ ). PS A1 was redissolved in sodium acetate buffer $(0.5 \mathrm{~mL}, 0.1 \mathrm{M}, \mathrm{pH}=5)$. Subsequently, $0.8 \mathrm{mg}\left(1.8 \times 10^{-6} \mathrm{~mol}\right)$ of $\alpha$ aminooxy STn (1) was added and the reaction was gently shaken for 18 hours in the dark at room temperature. Unreacted $\alpha$-aminooxy STn (1) was removed using a $30 \mathrm{kDa}$ centrifugal concentrator and purified STn-PS A1 (16) conjugate was obtained as a lyophilized white foam (1.0-1.1 mg). ${ }^{1} \mathrm{H}$ NMR (600MHz, DEUTERIUM OXIDE) $\delta=8.03$ (d, $J=2.8 \mathrm{~Hz}, 1 \mathrm{H}$ ), 5.75 (br. s., $1 \mathrm{H}$ ), 5.62 (br. s., $5 \mathrm{H}$ ), 5.48 (br. s., $1 \mathrm{H}$ ), 5.35 (d, $J=16.5 \mathrm{~Hz}$, $10 \mathrm{H}), 5.06$ - $4.94(\mathrm{~m}, 10 \mathrm{H}), 4.89-4.82(\mathrm{~m}, 7 \mathrm{H}), 4.62-4.45(\mathrm{~m}, 20 \mathrm{H}), 4.41-4.26(\mathrm{~m}, 32$ H), $4.25-4.20(\mathrm{~m}, 6 \mathrm{H}), 4.17-4.12(\mathrm{~m}, 5 \mathrm{H}), 4.12-4.01(\mathrm{~m}, 31 \mathrm{H}), 4.00-3.88(\mathrm{~m}, 41 \mathrm{H})$, $3.87-3.76(\mathrm{~m}, 18 \mathrm{H}), 2.98(\mathrm{~d}, J=8.6 \mathrm{~Hz}, 1 \mathrm{H}), 2.41-2.26(\mathrm{~m}, 36 \mathrm{H}), 1.94(\mathrm{t}, J=11.7 \mathrm{~Hz}, 1$ $\mathrm{H}), 1.75(\mathrm{~d}, J=2.0 \mathrm{~Hz}, 15 \mathrm{H}), 1.67-1.57(\mathrm{~m}, 15 \mathrm{H})$. 
Identification of spin systems in STn-PSA1 (16)

The anomeric proton signals of each carbohydrate residues (except sialic acid) were identified by 2-D COSY experiments (pulse program: COSYGPSW) at $60^{\circ} \mathrm{C}$ by adopting default acquisition parameters of a Bruker Topspin system. 1-D selective gradient TOCSY (pulse program: selmlgp) spectrum were recorded by radiant at the anomeric proton using 120 milliseconds mix-time (SI Figures 1-3, 5-8). It must be noted that the sialic acid residue is an exception due to the absence of anomeric protons for characterization, therefore by using 1-D TOCSY we radiated at the 3-equitorial proton to record spectrum (SI Figure 4). 
SI Figure 1. Comparison of three new spin systems in the STn-PS A1 (16) construct.
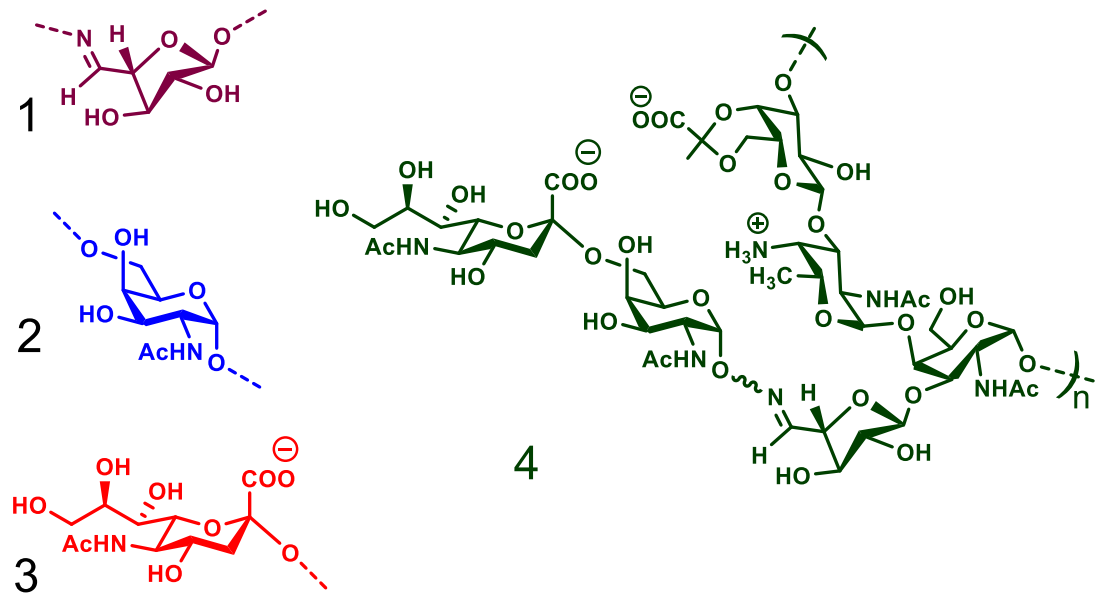

MS-063-overlap1.esp

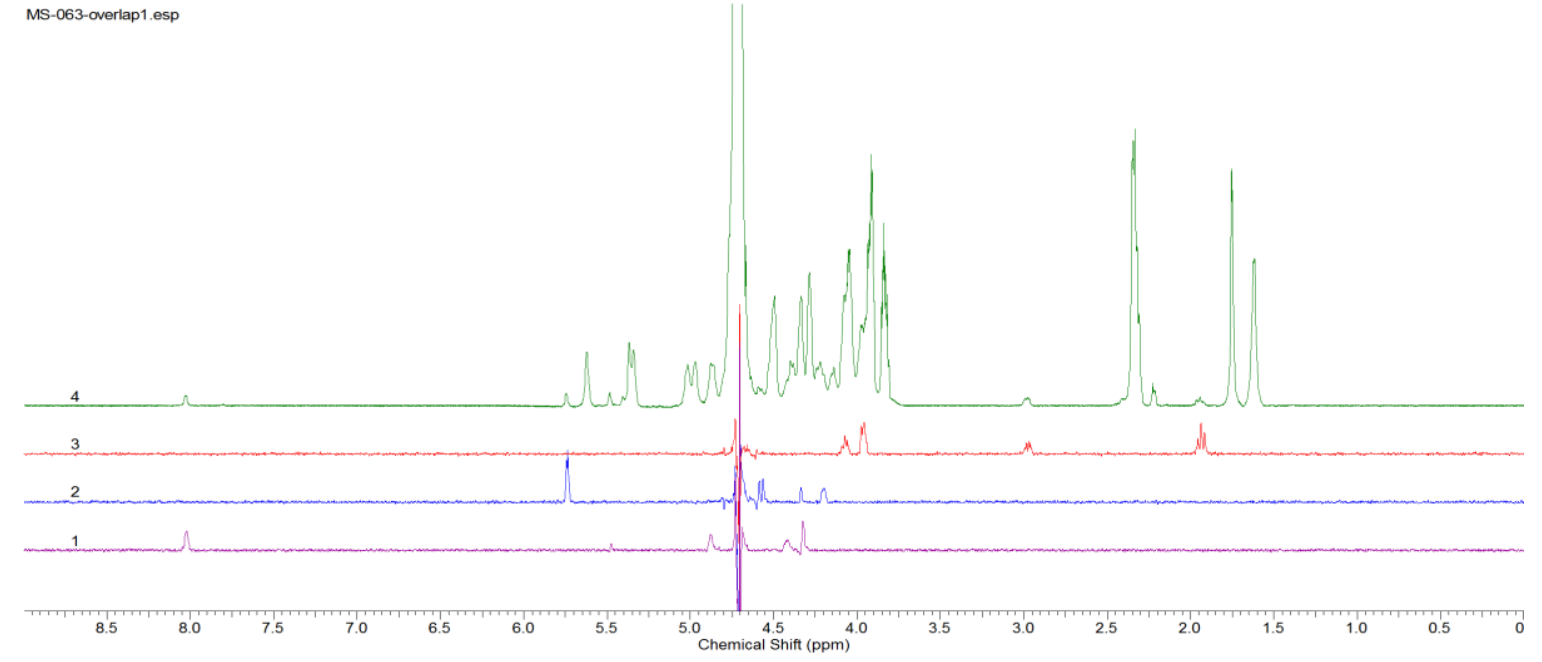


SI Figure 2. Spin system of oxidized galactofuranose residue of PS A1.

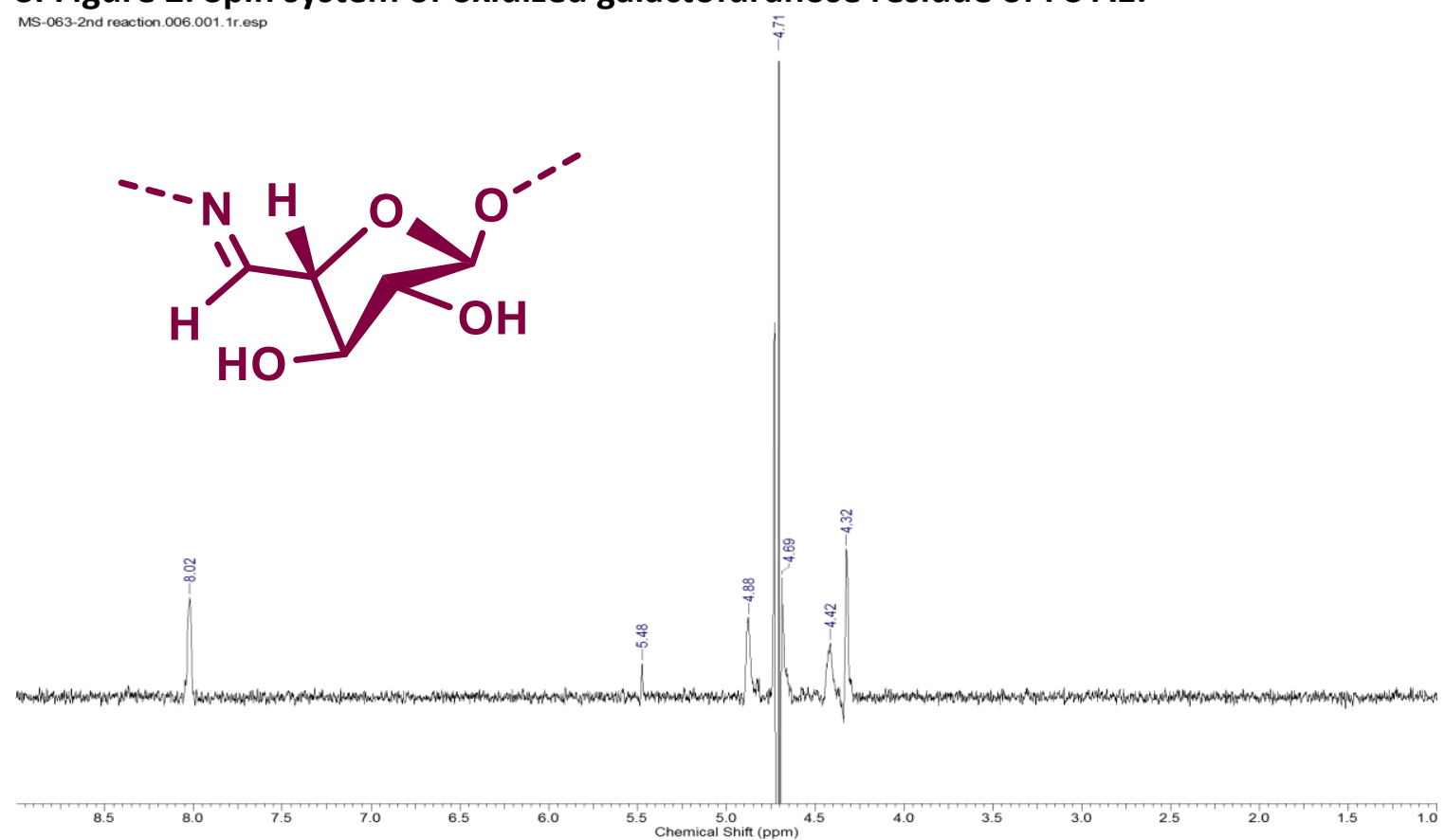

SI Figure 3. Spin system of $\mathbf{N}$-acetylgalactosamine of STn.

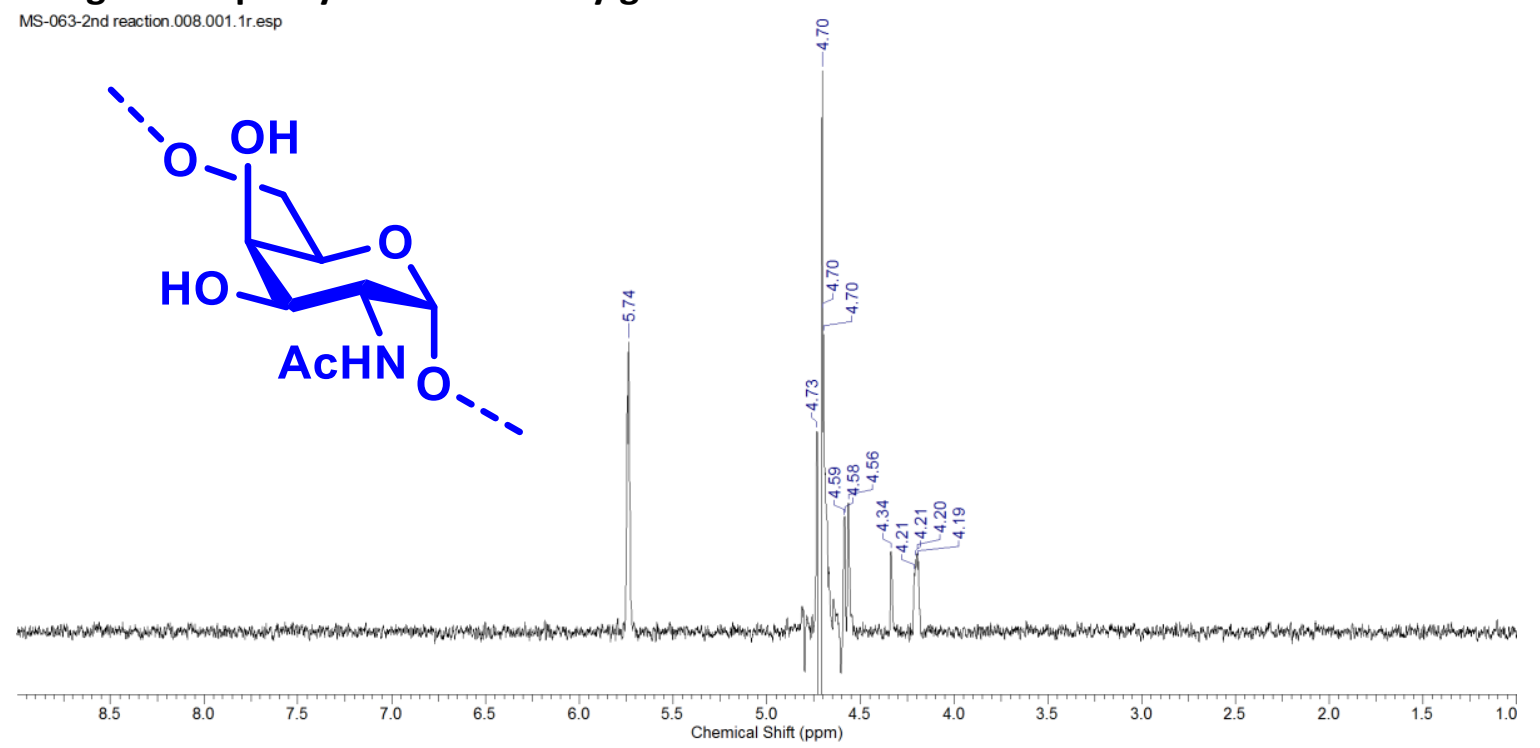


SI Figure 4. Spin system of sialic acid residue of STn. MS-063-2nd reaction.009.001.1r.esp

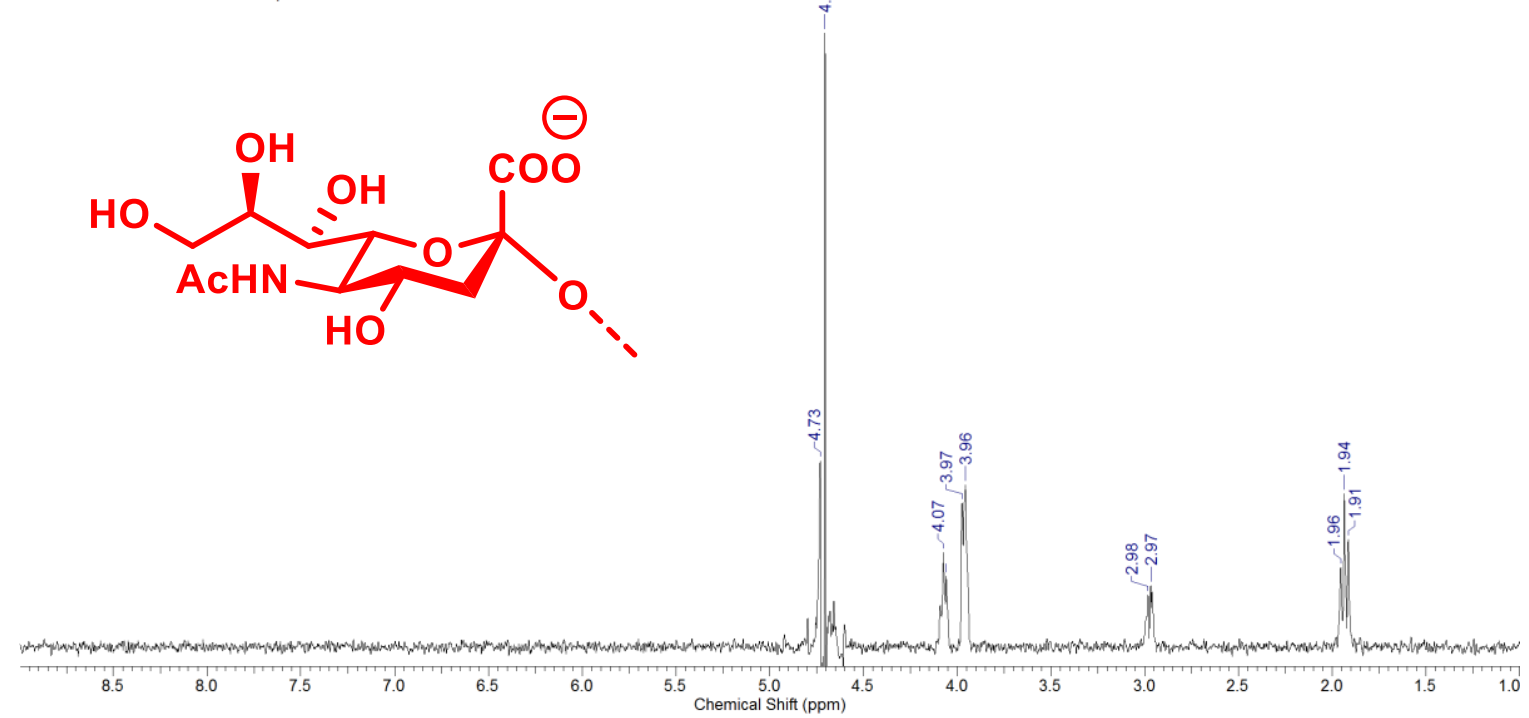

SI Figure 5. Spin system of galactofuranose reside of PS A1.

PSA1-MS-1DTOCSY-01.ESP 엉

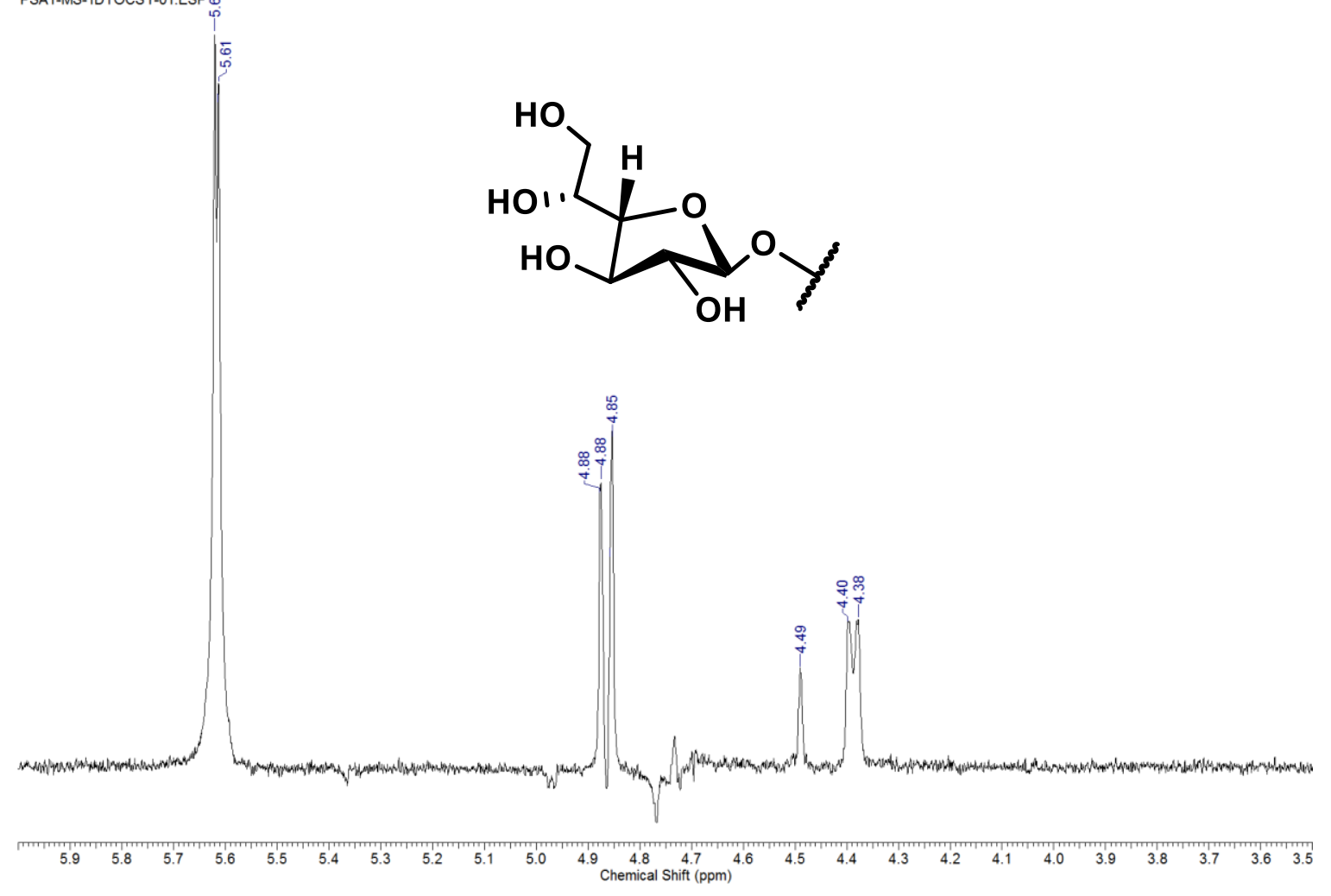


SI Figure 6. Spin system of $\mathbf{N}$-acetylgalactosamine residue of PS A1.

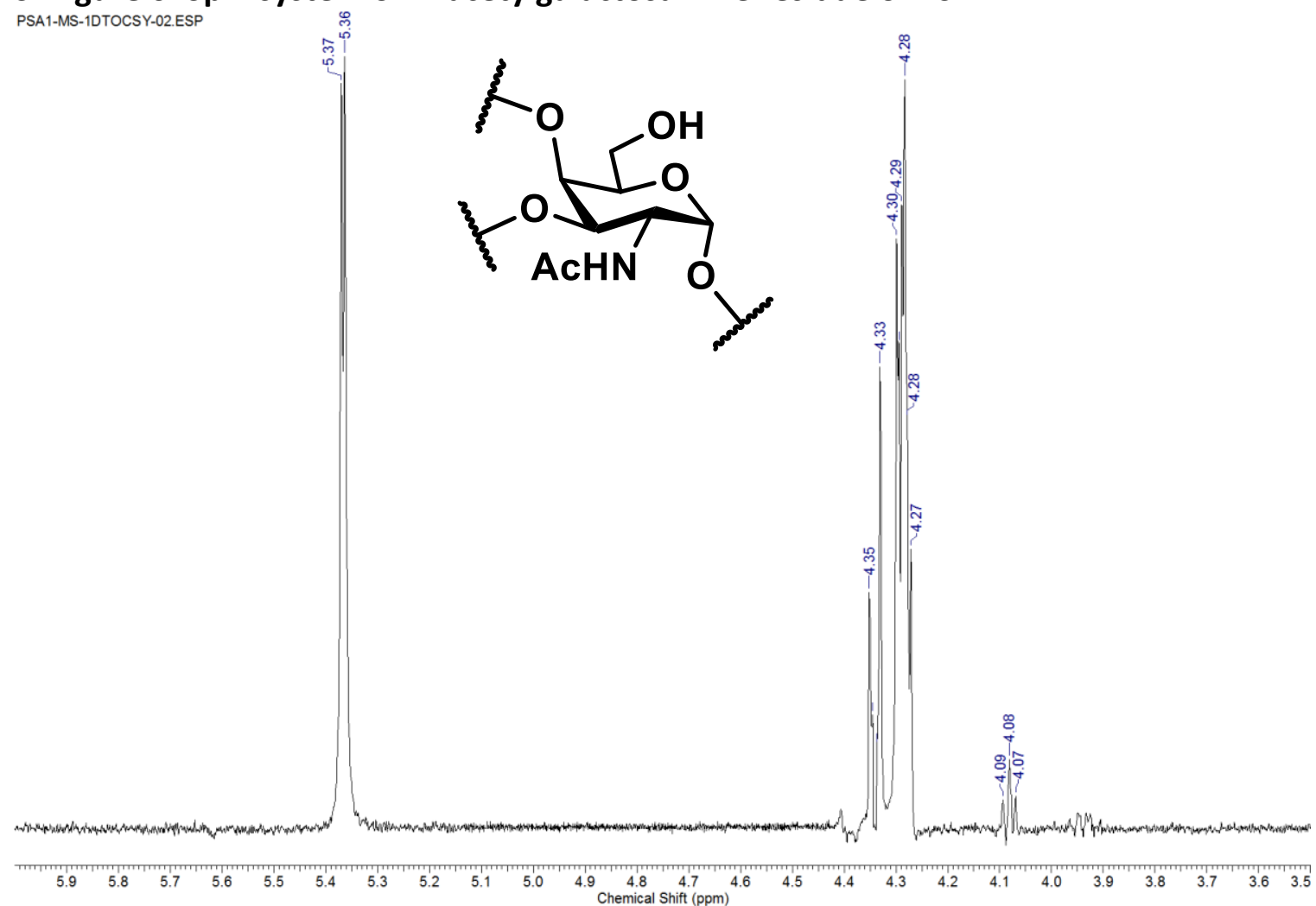

SI Figure 7. Spin system of 2-acetamido-4-amino-6-deoxy-galactose residue of PS A1. PSA1-MS-1DTOCSY-03.ESP

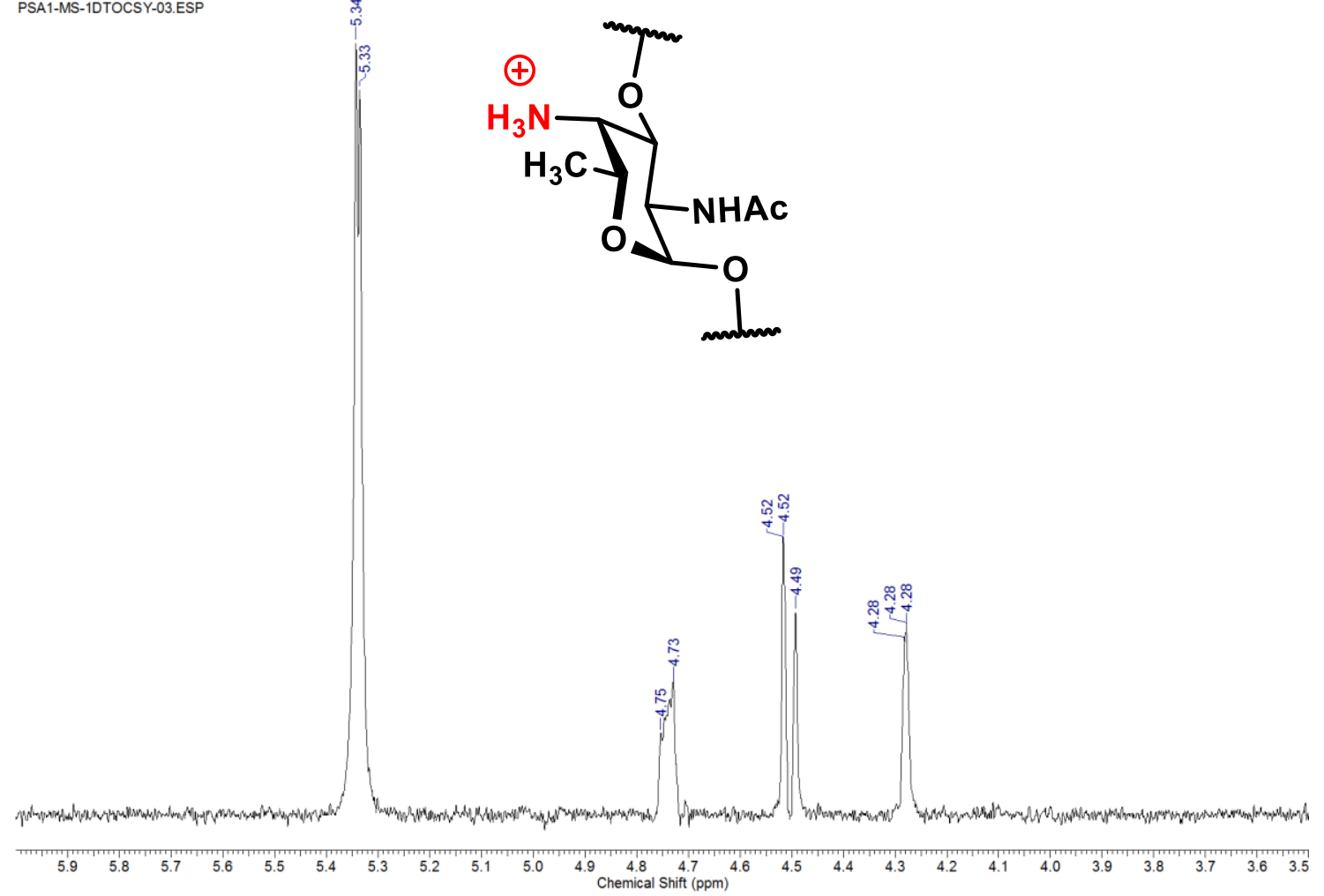




\section{SI Figure 8. Spin system of pyruvate galactose residue of PS A1.} PSA1-MS-1DTOCSY-04.ESP

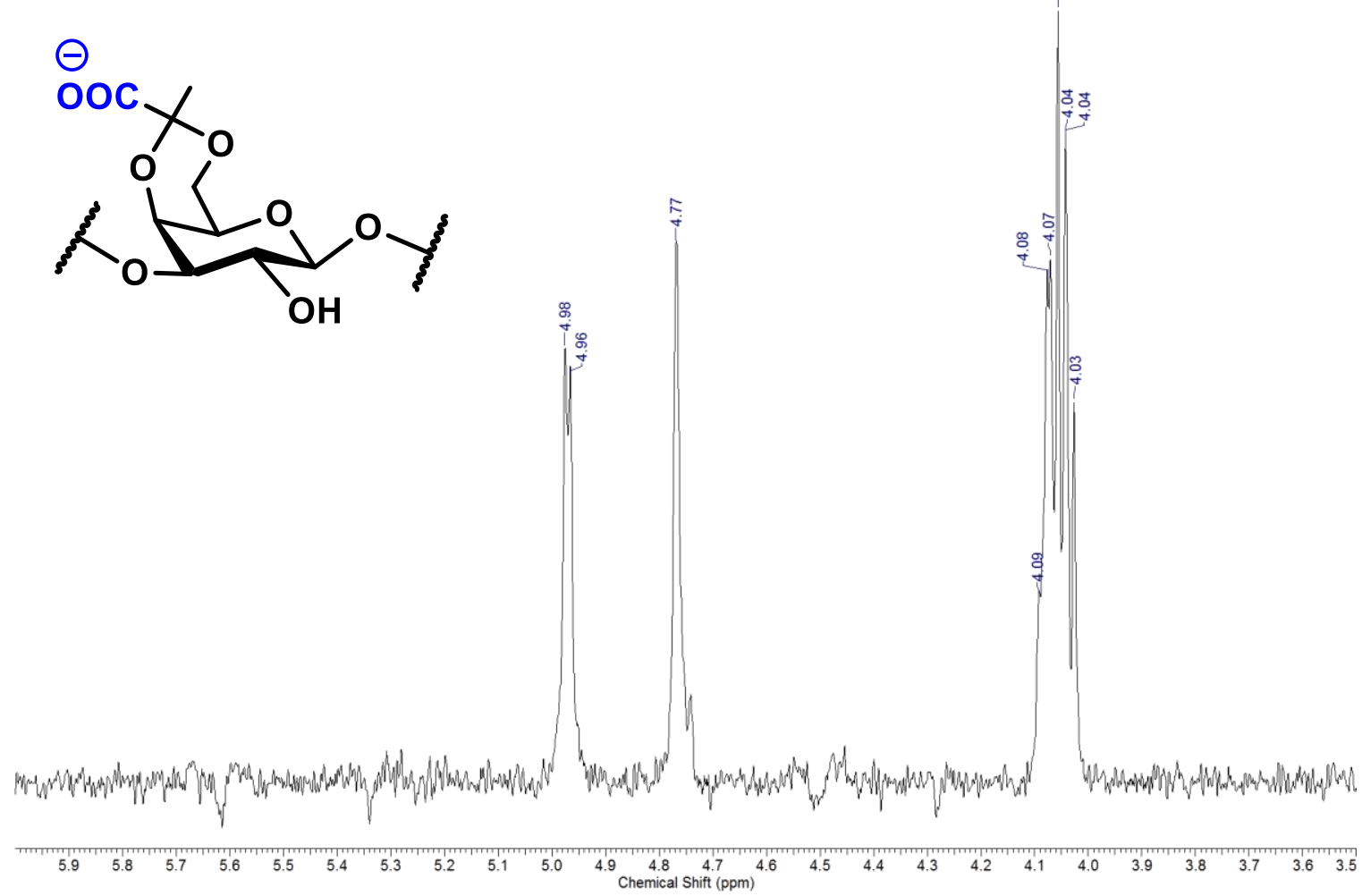

\section{Determination of STn loading by ${ }^{1} \mathrm{H}$ NMR}

The anomeric proton signals of sugar residues on STn-PS A1 (16) do not overlap with any other PS A1 signals. Therefore, the two proton signals at the 3 position on sialic acid residue are very distinguishable, thus these "diagnostic" signals are an ideal target for calculating STn loading. The calculated loading of STn by this method was determined to be $11 \%$.

The average mole ratio of STn/PS A1 is 24:1 (on average 24 STn residues on one PS A1 molecule), which can then be converted to \% loading by following the equation below:

$$
\% \text { Loading }=\frac{N 1 \times M 1}{(N 1 \times M 1)+M 2} \times 100
$$

$N 1$ = average number of STn residues on PS A1

$M 1=$ molecular weight of $\mathrm{STn}$ residue

$M 2$ = average molecular weight of PS A1 
SI Figure 9. Integration of anomeric protons.

MS-063-3r time.001.001.1r.esp

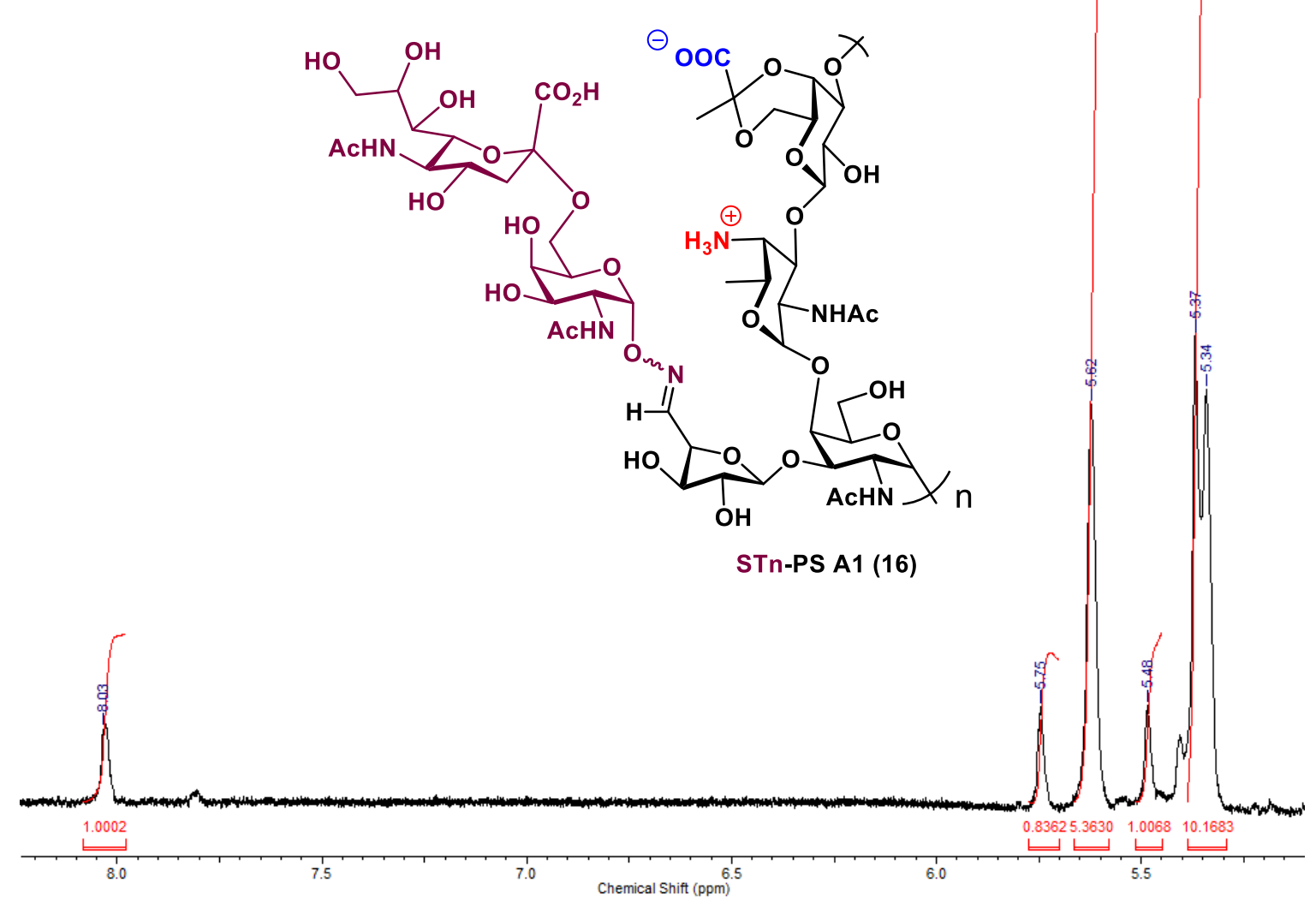


SI Figure 10. Integration of the 3-position of sialic acid and methyl groups.

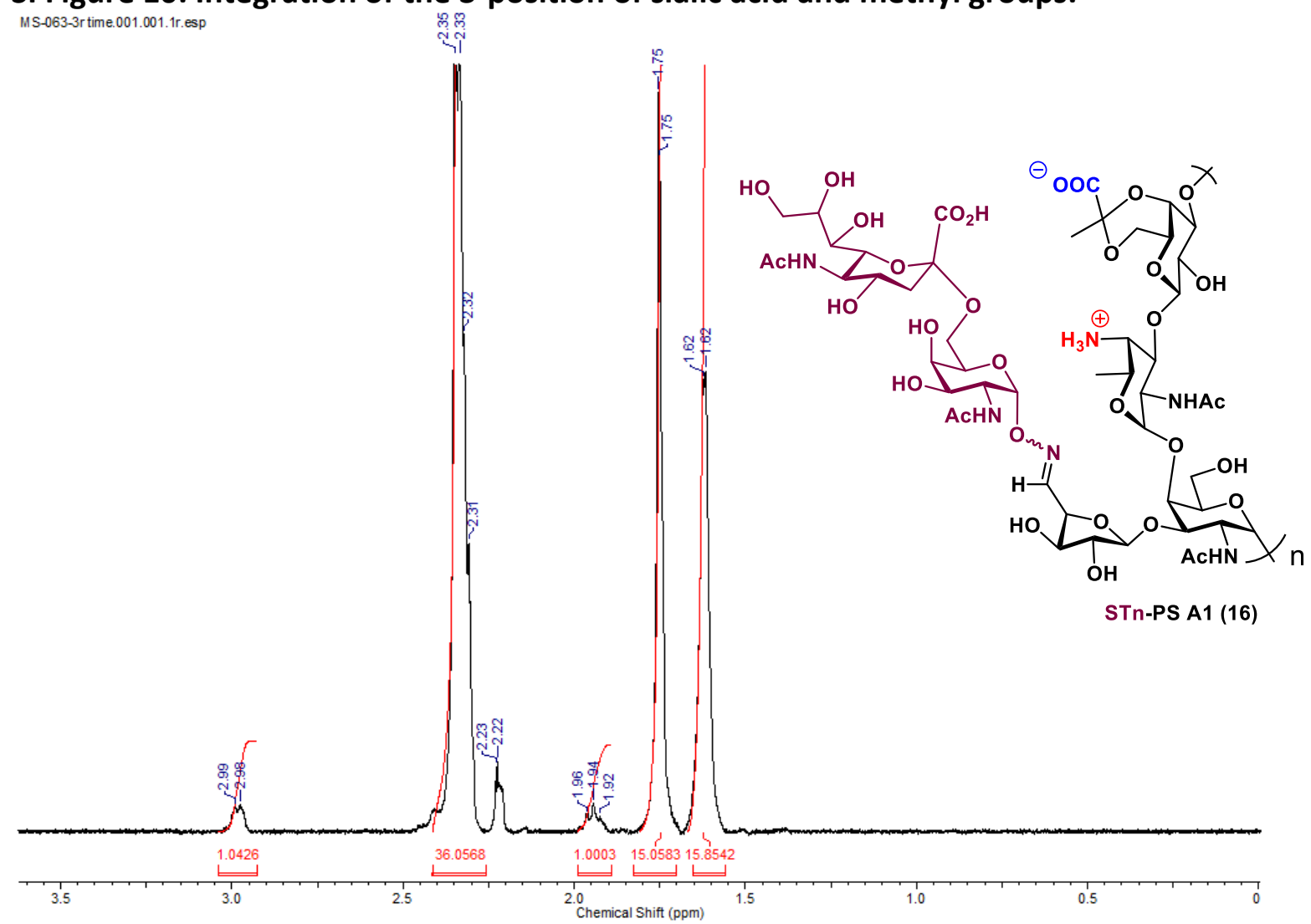

\section{Determination of STn loading by a modified Svennerholm method 6}

An accurately weighed STn-PS A1 (16) sample $(0.3 \mathrm{mg})$ was dissolved in $1 \mathrm{~mL}$ DI water. $40 \mu \mathrm{L}$ of above solution was transferred to a 96 well plate in triplicate. $10 \mu \mathrm{L}$ of $5 \mathrm{mM}$ $\mathrm{NaIO}_{4}$ was added to the PS A1 solution and incubated for $35 \mathrm{~min}$ on an ice bath. $100 \mu \mathrm{L}$ of a resorcinol solution $(0.6 \mathrm{~g}$ of resorcinol in $100 \mathrm{~mL}$ of $17 \% \mathrm{HCl}$ solution and 0.0025 $\mathrm{mM}$ of $\mathrm{CuSO}_{4}$ ) was added and incubated for $60 \mathrm{~min}$ at $90{ }^{\circ} \mathrm{C}$. The absorbance was determined at $580 \mathrm{~nm}$ by a UV-Vis plate reader using a blank resorcinol solution as the control. The standard calibration curve of sialic acid was created with different concentrations of sialic acid solutions analyzed under the same conditions. The calibration curve was then used to calculate the weight of sialic acid released by STn-PS A1. The weight sialic acid was converted to STn loading according to the following equation: 


\section{Biological Study}

\section{Animal Immunizations}

Two groups of five mice (male C57BL/6J) were vaccinated using interperitoneal injections (i.p.) with the STn-PS A1 vaccine containing $20 \mu \mathrm{g}$ of STn-PS A1 conjugate plus $20 \mu \mathrm{g}$ of Sigma adjuvant system (SAS) or $20 \mu \mathrm{g}$ of TiterMAX® Gold (TMG) in $200 \mu \mathrm{L}$ PBS buffer. The SAS group was injected at $0,3,5$, and 7 weeks, and bled 10 days after the fourth injection. The TMG group was injected at 0, 2, 4, 6 weeks and bled 10 days after the fourth injection. One group of five mice was i.p. immunized with $20 \mu \mathrm{g}$ of STn-PS A1 conjugate in $200 \mu \mathrm{L}$ PBS buffer at 0, 2, 4, 6 weeks. Lastly, one group of three mice was used as a negative control and was only treated with $200 \mu \mathrm{L}$ PBS buffer at $0,2,4,6$ weeks.

\section{Serum ELISA assay}

Enzyme-linked immunosorbent assays (ELISA) were performed as described previously. ${ }^{7}$ In order to determine the IgM and IgG antibody titers against the natural STn antigen, ELISA plates were coated with $0.1 \mu \mathrm{g} /$ well of bovine submaxillary mucin (BSM, expressing STn) and were incubated overnight at $4{ }^{\circ} \mathrm{C}$. Nonspecific sites were blocked with $3 \%$ bovine serum albumin (BSA) for 2 hours and serially diluted antiserum was added to each well. After 1 hour of incubation, the plates were washed and alkaline phosphatase labeled goat antimouse IgM or IgG (Jackson ImmunoResearch) was added at 1:200 dilution. Titers are usually shown as the serum serial dilution resulting in an absorbance of OD405 equal to twice the mean background of the assay. 
SI Table 1. The antibody titers of STn-specific antibodies of each group.

\begin{tabular}{|c|c|c|}
\hline \multirow{6}{*}{ Group $1^{a}$} & & Mean \\
\hline & $\lg G$ & 15787 \\
\hline & $\lg M$ & 4353 \\
\hline & $\lg G 1$ & 1886 \\
\hline & $\lg G 2 b$ & 10613 \\
\hline & $\lg G 3$ & 97 \\
\hline \multirow{6}{*}{ Group $2^{b}$} & & Mean \\
\hline & $\lg G$ & 2041 \\
\hline & $\lg M$ & 449 \\
\hline & $\lg G 1$ & 1.2 \\
\hline & $\lg G 2 b$ & 774 \\
\hline & $\lg G 3$ & 0.3 \\
\hline \multirow{6}{*}{ Group $3^{c}$} & & mean \\
\hline & $\lg G$ & 840 \\
\hline & $\lg M$ & 0.3 \\
\hline & $\lg G 1$ & 0.2 \\
\hline & $\lg G 2 b$ & 0.3 \\
\hline & $\lg \mathrm{G} 3$ & 0.5 \\
\hline \multirow{6}{*}{ Group $4^{d}$} & & mean \\
\hline & $\lg G$ & 139 \\
\hline & $\lg M$ & 1.3 \\
\hline & $\lg G 1$ & 0.3 \\
\hline & $\lg G 2 b$ & 0.3 \\
\hline & $\lg G 3$ & 0.4 \\
\hline
\end{tabular}

${ }^{a}$ Group 1: STn-PS A1 plus Sigma Adjuvant System (STn-PS A1+SAS)

${ }^{b}$ Group 2: STn-PS A1 plus TiterMax Gold (STn-PS A1+TMG)

${ }^{c}$ Group 3: STn-PS A1

${ }^{d}$ Group 4: negative control - mice injected with $1 \mathrm{X}$ PBS buffer (pH 7.0) 


\section{Fluorescence-Activated Cell Sorting (FACS)}

Cancer cell surface binding of anti-STn antibodies was tested using FACS analysis with human colon and human ovarian cell lines. Ovarian cancer cell line OVCAR-5 and breast cancer cell lines MCF-7 were provided by Dr. Frederic Valeriote at 21st Century Therapeutics. Human mammary cell lines MCF-7 were provided by Dr. Kadance Williams at the University of Toledo College of Medicine and Life Sciences. Single-cell suspensions of $5 \times 10^{5}$ cells/tube were washed in phosphate-buffered saline with $3 \%$ fetal calf serum and then incubated with $20 \mu \mathrm{L}$ of $1 / 50$ diluted antisera for $30 \mathrm{~min}$ on ice. A total of $20 \mu \mathrm{L}$ of $1 / 15$ goat antimouse IgG or IgM labeled with FITC (Jackson ImmunoResearch) was added and percent positive cells and mean fluorescent intensity (MFI) of stained cells were analyzed using a BD FACSCalibur instrument. Data were processed with BD CellQuest Pro software (Becton Dickinson, San Jose, CA) and FlowJo software (FlowJo, LLC).

\section{Complement-dependent cytoxicity (CDC)}

CDC was determined using the LDH Cytotoxicity Detection Kit (Roche Applied Science) according to the manufacture protocol. Targeted tumor cells $\left(1.0 \times 10^{4}\right.$ cells per well $)$ were seeded in 96-well plates and were incubated at $37^{\circ} \mathrm{C}$ overnight. After washing cells, $100 \mu \mathrm{L}$ of antiserum (1:50 dilution in medium) was added to each well and the plates incubated at $37^{\circ} \mathrm{C}$ for 2 hours. The cells were washed and then incubated with $100 \mu \mathrm{L}$ of rabbit complement serum (1:10 dilution in medium) at $37^{\circ} \mathrm{C}$ for 1 hour. After incubation, $20 \mu \mathrm{L}$ of supernatant was carefully transferred from each well into another 96-well plate. Then, $80 \mu \mathrm{L}$ of PBS buffer and $100 \mu \mathrm{L}$ of the LDH detection solution was added to each well. The mixture was incubated at room temperature for 1 hour. For the low control (spontaneous LDH release) no antisera and complement was added and therefore these were only treated with media. For the high control (maximum LDH release) the antisera and complement were replaced with $100 \mu \mathrm{L}$ of $2 \%$ Triton X-100. The substance control treated cells, with only rabbit complement serum, were used to test the innate LDH activity. The optical absorption $(A)$ of each well was read at $490 \mathrm{~nm}$ wavelength using a plate reader. The percentage of cytotoxicity was calculated according to the following equation:

$$
\text { Cytotoxicity }(\%)=\frac{\text { experimental } A-\text { low control } A}{\text { high control } A-\text { low control } A} \times 100
$$

where "experimental $A$ " is the optical absorption at $490 \mathrm{~nm}$ of targeting cells treated with antisera and complement; "low control $A$ " is the optical absorption of cells without antisera and complement; "high control $A$ " is the absorption of cells completely lysed with $2 \%$ Triton X-100 solution. 
SI Table 2. Test results of CDC on MCF-7.

\begin{tabular}{|c|c|c|c|}
\hline \multicolumn{4}{|c|}{ MCF-7 } \\
\hline Test \# & STn-PS A1+SAS & Control sera & Complement \\
\hline 1 & $51 \%$ & $25 \%$ & $17 \%$ \\
\hline 2 & $55 \%$ & $27 \%$ & $16 \%$ \\
\hline 3 & $57 \%$ & $26 \%$ & $18 \%$ \\
\hline 4 & $48 \%$ & $22 \%$ & $14 \%$ \\
\hline 5 & $58 \%$ & $24 \%$ & $20 \%$ \\
\hline 6 & $61 \%$ & $26 \%$ & $18 \%$ \\
\hline Mean & $55 \%$ & $25 \%$ & $17 \%$ \\
\hline
\end{tabular}

SI Table 3. Test results of CDC on OVCAR-5

\begin{tabular}{|c|c|c|c|}
\hline \multicolumn{4}{|c|}{ OVCAR-5 } \\
\hline Test \# & STn-PS A1+SAS & Control sera & Complement \\
\hline 1 & $39 \%$ & $22 \%$ & $16 \%$ \\
\hline 2 & $33 \%$ & $20 \%$ & $16 \%$ \\
\hline 3 & $36 \%$ & $18 \%$ & $14 \%$ \\
\hline 4 & $41 \%$ & $22 \%$ & $15 \%$ \\
\hline 5 & $36 \%$ & $19 \%$ & $17 \%$ \\
\hline 6 & $31 \%$ & $21 \%$ & $13 \%$ \\
\hline Mean & $36 \%$ & $20 \%$ & $15 \%$ \\
\hline
\end{tabular}

SI Table 4. Test results of CDC on MCF-10A

\begin{tabular}{|c|c|c|c|}
\hline \multicolumn{4}{|c|}{ MCF-10A } \\
\hline Test \# & STn-PS A1+SAS & Control sera & Complement \\
\hline 1 & $17 \%$ & $19 \%$ & $19 \%$ \\
\hline 2 & $20 \%$ & $19 \%$ & $20 \%$ \\
\hline 3 & $13 \%$ & $14 \%$ & $16 \%$ \\
\hline 4 & $20 \%$ & $21 \%$ & $19 \%$ \\
\hline 5 & $17 \%$ & $22 \%$ & $17 \%$ \\
\hline 6 & $18 \%$ & $17 \%$ & $17 \%$ \\
\hline Mean & $18 \%$ & $19 \%$ & $18 \%$ \\
\hline
\end{tabular}




\section{IFN- $\gamma$ ELISpot assay}

Five C57BL/6 mice were immunized with STn-PS A1 + Sigma Adjuvant System (SAS) according to our described procedure above. Mice were euthanized and spleens were harvested 10 days after the final injection. Spleens were suspended in complete RPMI 1640 culture media and set on ice. Single cell splenocyte suspensions were prepared by "grinding" the spleens between two frosted tip microscope slides. Cells suspensions were passed through a $40 \mu \mathrm{m}$ filter and centrifuged at $1000 \mathrm{RPM}$ and $4{ }^{\circ} \mathrm{C}$. Cell pellets were resuspended in $1 \mathrm{X} \mathrm{RBC}$ lysis buffer $(5 \mathrm{~mL} / \mathrm{spleen})$ at $4^{\circ} \mathrm{C}$ for 3 minutes. $\mathrm{RBC}$ lysis buffer was quenched by adding $30 \mathrm{~mL}$ of DPBS and the resulting suspension was centrifuged. The resultant cell pellet was resuspended in $10 \mathrm{~mL}$ complete RPMI 1640 culture media. An aliquot of the cell suspension was diluted 1:3 in DPBS followed by a 1:1 dilution in Trypan Blue. Total cells were ascertained after cell counting and the cells were plated in the corresponding wells with decreasing cell density. All cells were stimulated with $20 \mu \mathrm{g}$ of stimuli (STn-PS A1 or BSM) and incubate at $37^{\circ} \mathrm{C}$ and $5 \% \mathrm{CO}_{2}$ for $24 \mathrm{~h}$. No stimuli were added to the control wells. For the positive control, no cells were used; only adding $5 \mathrm{ng}$ of IFN- $\gamma$ to the well. For the negative control, only culture medium was added. The ELISpot procedure was performed according to the Kit Protocol (R\&D Systems, Inc.; EL485). Spot counts were obtained using MVS Pacific QuantiHub Color 4.1 ELISpot plate reader and its corresponding software. Spots were counted using the automated spot counting algorithm available in the QuantiHub 4.1 software. 
SI Table 5. Test results of IFN- $\gamma$ ELISpot assay

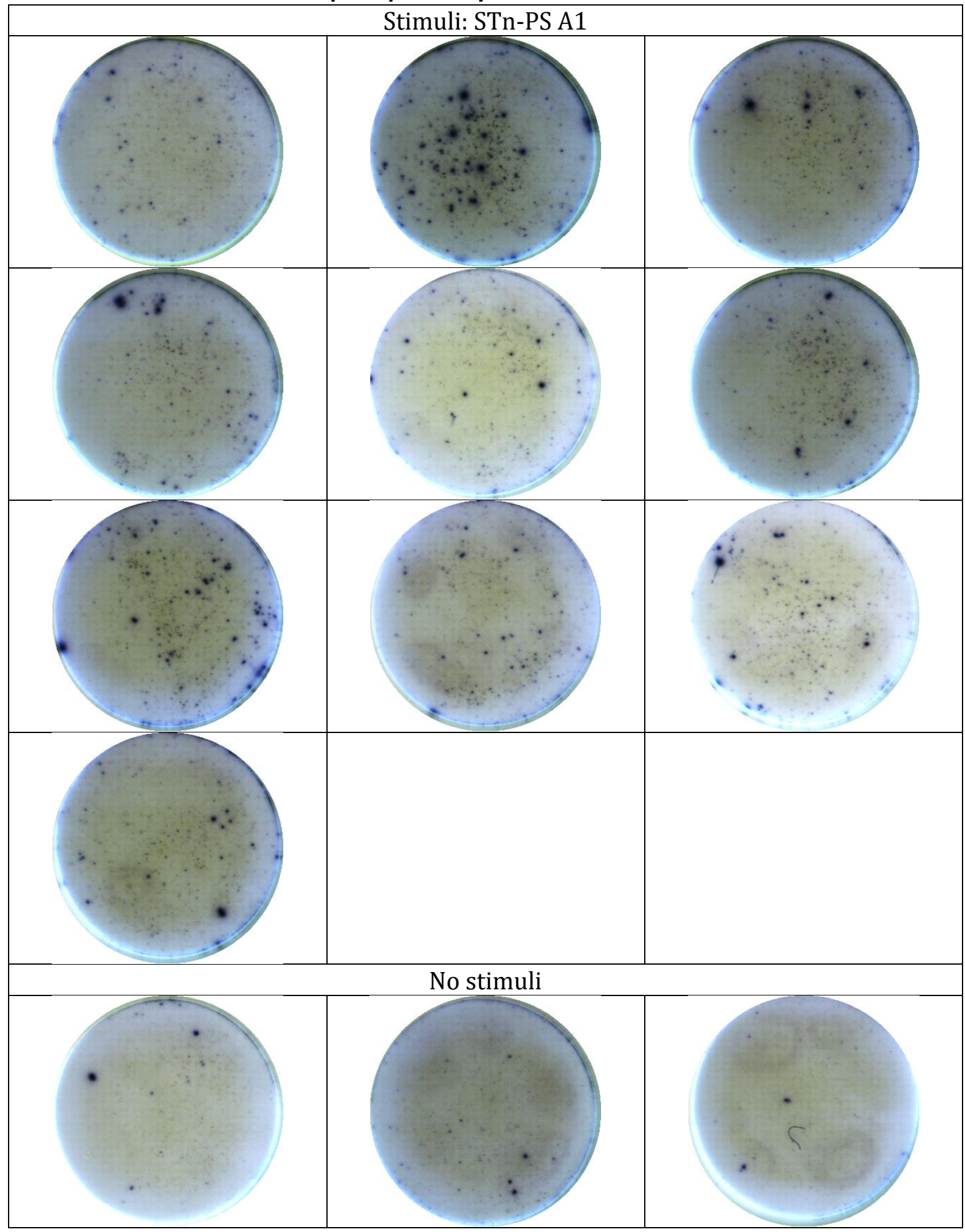




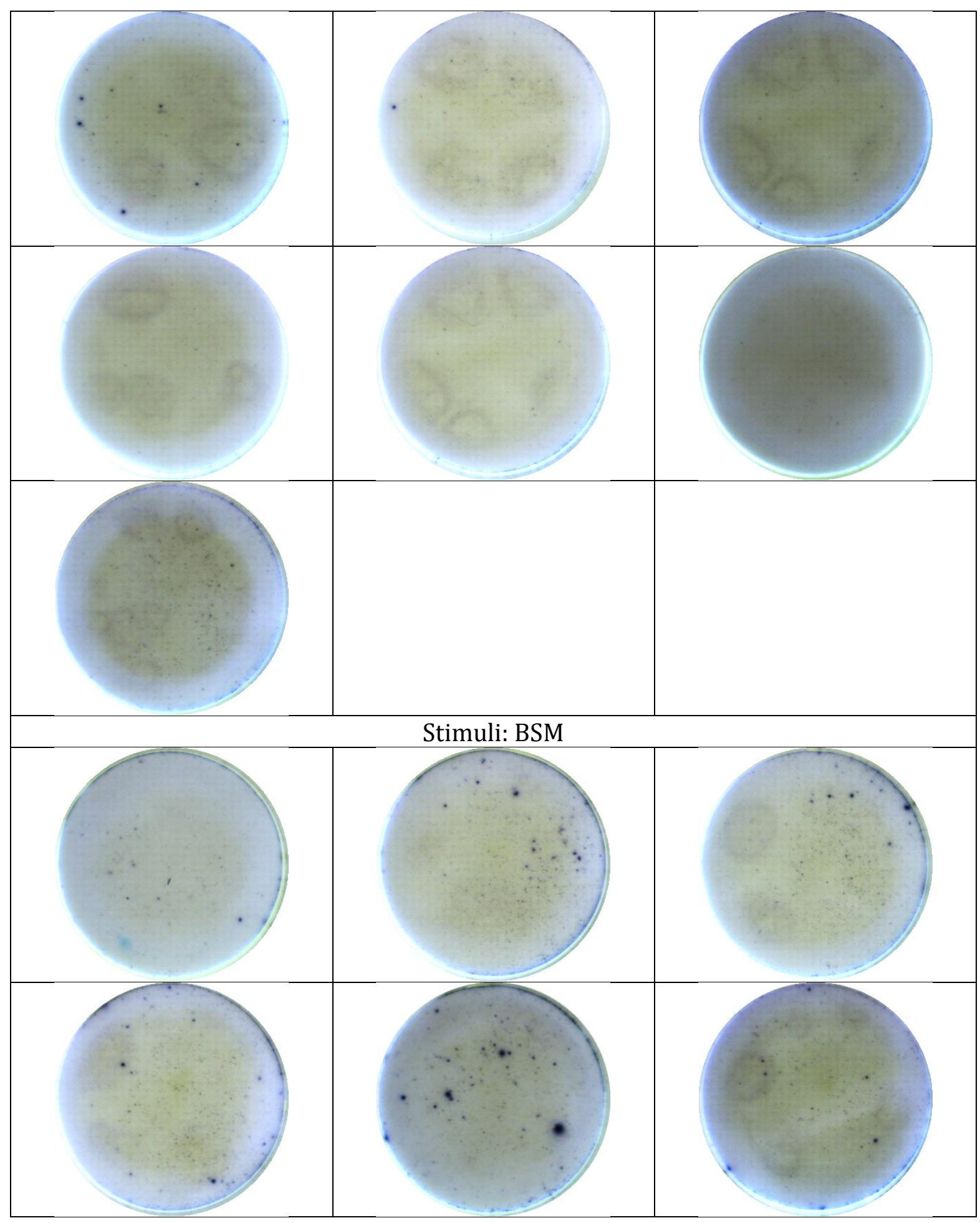




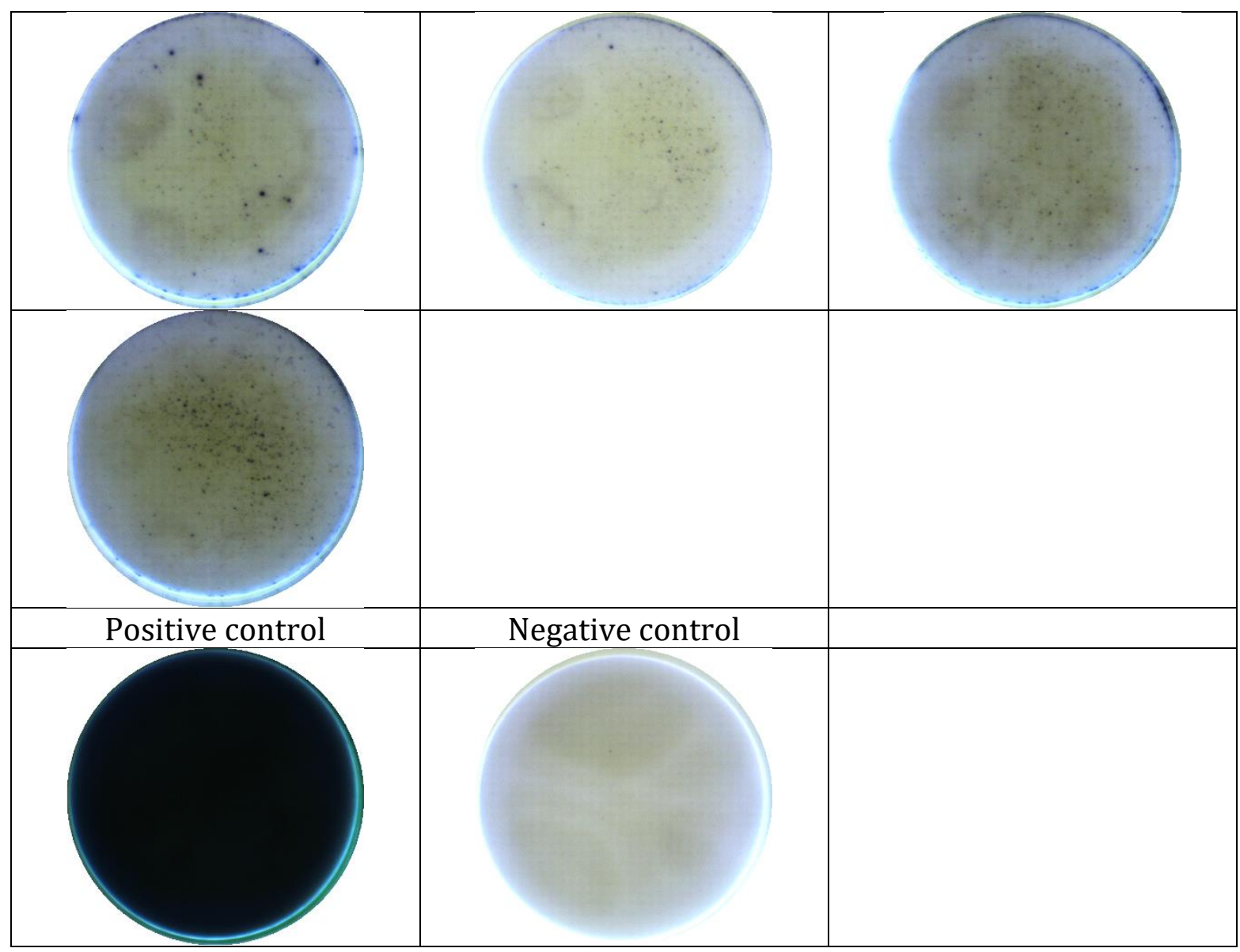




\section{Determination of PS A1-specific antibody}

Four reagents were prepared to mobilize PS A1 on the 96-well plates: (I) $0.5 \mathrm{~mL}$ of 0.01 $\mathrm{M} \mathrm{NaOH}$ with $0.001 \%$ phenolphthalein indicator; (II) $0.5 \mathrm{mg}$ cyanuric chloride; (III) 0.1 $\mathrm{mL}$ of $0.1 \%$ poly-L-lysine (mol. wt. 30,000-70,000); (IV) $1000 \mu \mathrm{g} / \mathrm{mL}$ PS A1 (15) solution in ultra-pure water. $0.09 \mathrm{~mL}$ of $\mathbf{1 5}$ (IV) was added to reagent (I) and vortexed, resulting mixture was added to reagent (II) and vortexed until the $\mathrm{pH}$ indicator became colorless. Reagent (III) was added to above mixture, kept shaking at $4{ }^{\circ} \mathrm{C}$ for $3 \mathrm{~h}$ to afford poly-Llysine-PS A1 conjugate. $30 \mathrm{~mL}$ of $0.1 \mathrm{M}$ sodium bicarbonate coating buffer ( $\mathrm{pH} 9.6$ ) was added to obtain a diluted poly-L-lysine-PS A1 solution (final concentration $=3 \mu \mathrm{g} / \mathrm{mL}$ ). 96-well polystyrene plates (Immulon 4HBX, Thermo Electron) were coated with $100 \mu \mathrm{L}$ of the poly-L-lysine-PS A1 each well at $4{ }^{\circ} \mathrm{C}$ overnight. The plates were then washed with 1X PBS buffer $(200 \mu \mathrm{L} \times 3, \mathrm{pH} 7.2)$. This was followed by blocking with $3 \%$ BSA in PBS buffer and then incubated at r.t. for $1 \mathrm{~h}$ and finally washed with $1 \mathrm{X}$ PBS buffer $(200 \mu \mathrm{L} \times 3$, $\mathrm{pH}$ 7.2). Serially diluted antiserum was added to each well. After 1 hour of incubation, the plates were washed and alkaline phosphatase labeled goat antimouse IgM or IgG (Jackson ImmunoResearch) was added at a 1:200 dilutions. Titers are usually shown as the serum serial dilution resulting in an absorbance of OD405 equal to twice the mean background of the assay.

SI Table 6. The antibody titers of anti-PS A1 of Group 1.

\begin{tabular}{|c|c|c|}
\hline \multirow{2}{*}{$\begin{array}{c}\text { Group 1: } \\
\text { STn-PS A1+SAS }\end{array}$} & Anti-STn IgG & 15787 \\
\cline { 2 - 3 } & Anti-STn IgM & 4353 \\
\cline { 2 - 3 } & Anti-PS A1 IgG & 36225 \\
\cline { 2 - 3 } & Anti-PS A1 IgM & 36060 \\
\hline
\end{tabular}

\section{Determination of Tn-specific antibody}

The Tn-BSA conjugate was prepared through a reported reductive amination method; 8 the loading on BSA is $12.4 \%$ and the average molar ratio of Tn/BSA is 34:1.

Tn-BSA conjugate was diluted in $30 \mathrm{~mL}$ of a $0.1 \mathrm{M}$ sodium bicarbonate coating buffer $\mathrm{pH}$ 7.6 (resulting concentration: $3 \mu \mathrm{g} / \mathrm{mL}$ ). Each well of the 96 -well polystyrene microtiter plates was coated with $100 \mu \mathrm{L}$ of the Tn-BSA conjugate at $4{ }^{\circ} \mathrm{C}$ overnight. Nonspecific sites were blocked with $3 \%$ bovine serum albumin (BSA) at an incubation period of 2 hours and serially diluted antiserum was added to each well. After $1 \mathrm{~h}$ of incubation, the 
plates were washed and alkaline phosphatase labeled goat antimouse IgM or IgG (Jackson ImmunoResearch) was added at a 1:200 dilutions. Titers are usually shown as the serum serial dilution resulting in an absorbance of $0 D 405 \mathrm{~nm}$ equal to twice the mean background of the assay.

SI Table 7. The average antibody titers of Tn-specific antibodies of each group.

\begin{tabular}{|c|c|c|c|c|}
\hline Group \# & $1^{a}$ & $2^{b}$ & $3^{c}$ & $4^{d}$ \\
\hline IgM & 181 & 68 & 13 & 0.5 \\
\hline IgG & 133 & 91 & 61 & 19 \\
\hline
\end{tabular}

${ }^{a}$ Group 1: STn-PS A1 plus Sigma Adjuvant System (STn-PS A1+SAS)

${ }^{b}$ Group 2: STn-PS A1 plus TiterMax Gold (STn-PS A1+TMG)

${ }^{c}$ Group 3: STn-PS A1

${ }^{d}$ Group 4: negative control, injected with 1X PBS buffer ( $\mathrm{pH}$ 7.0) 
SI Figure 11. MALDI-TOF of Tn-BSA.

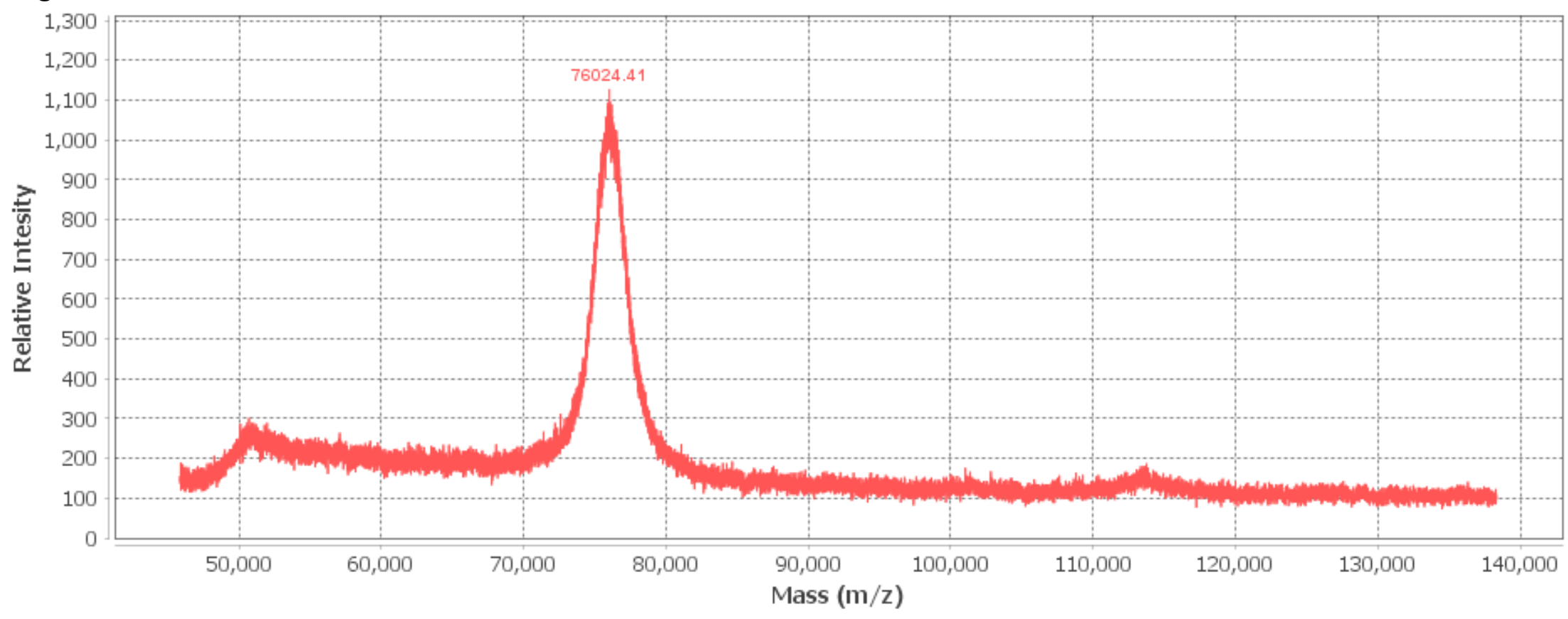

- Spectrum 1: TN-BSA 1.mzXML [17408] 
NMR Spectrum of related compounds

${ }^{1} \mathrm{H}$ NMR spectrum of $\mathrm{S1}$
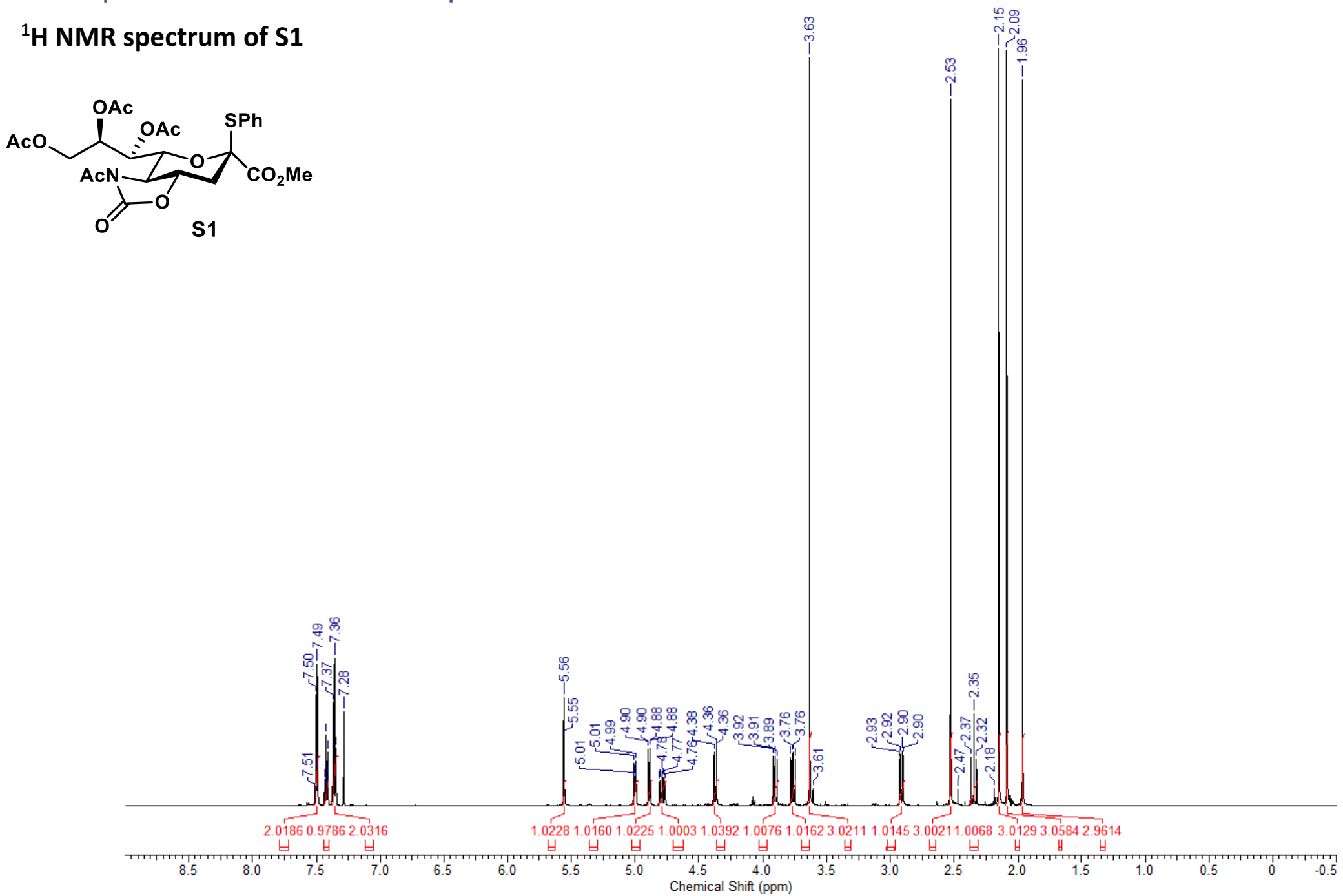
${ }^{13} \mathrm{C}$ NMR spectrum of S1
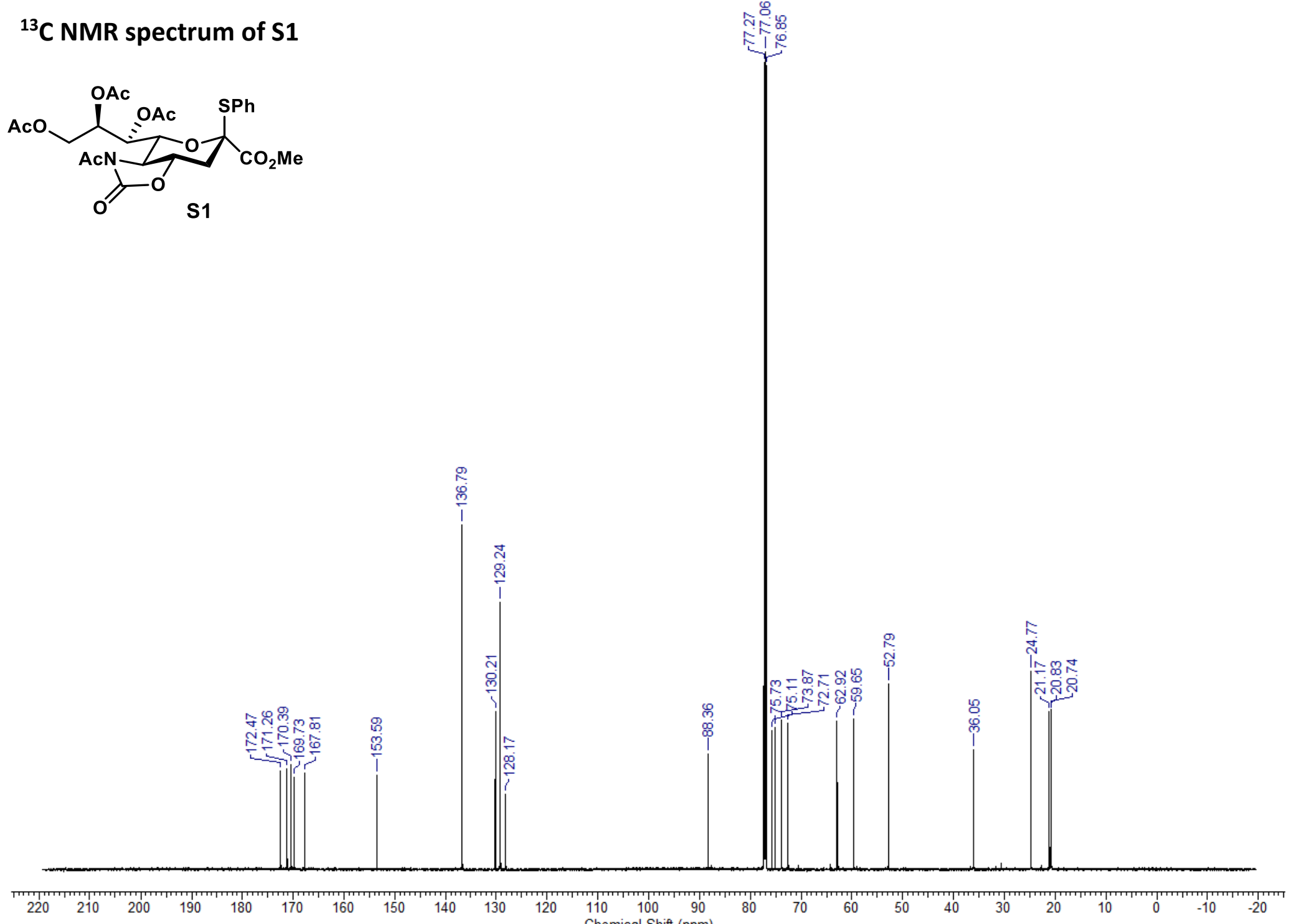

$220 \quad 210 \quad 200190$

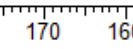

150

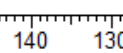

$120 \quad 11$ $\begin{array}{ll}110 & 100 \quad 90\end{array}$ 
${ }^{1} \mathrm{H}$ NMR spectrum of 3
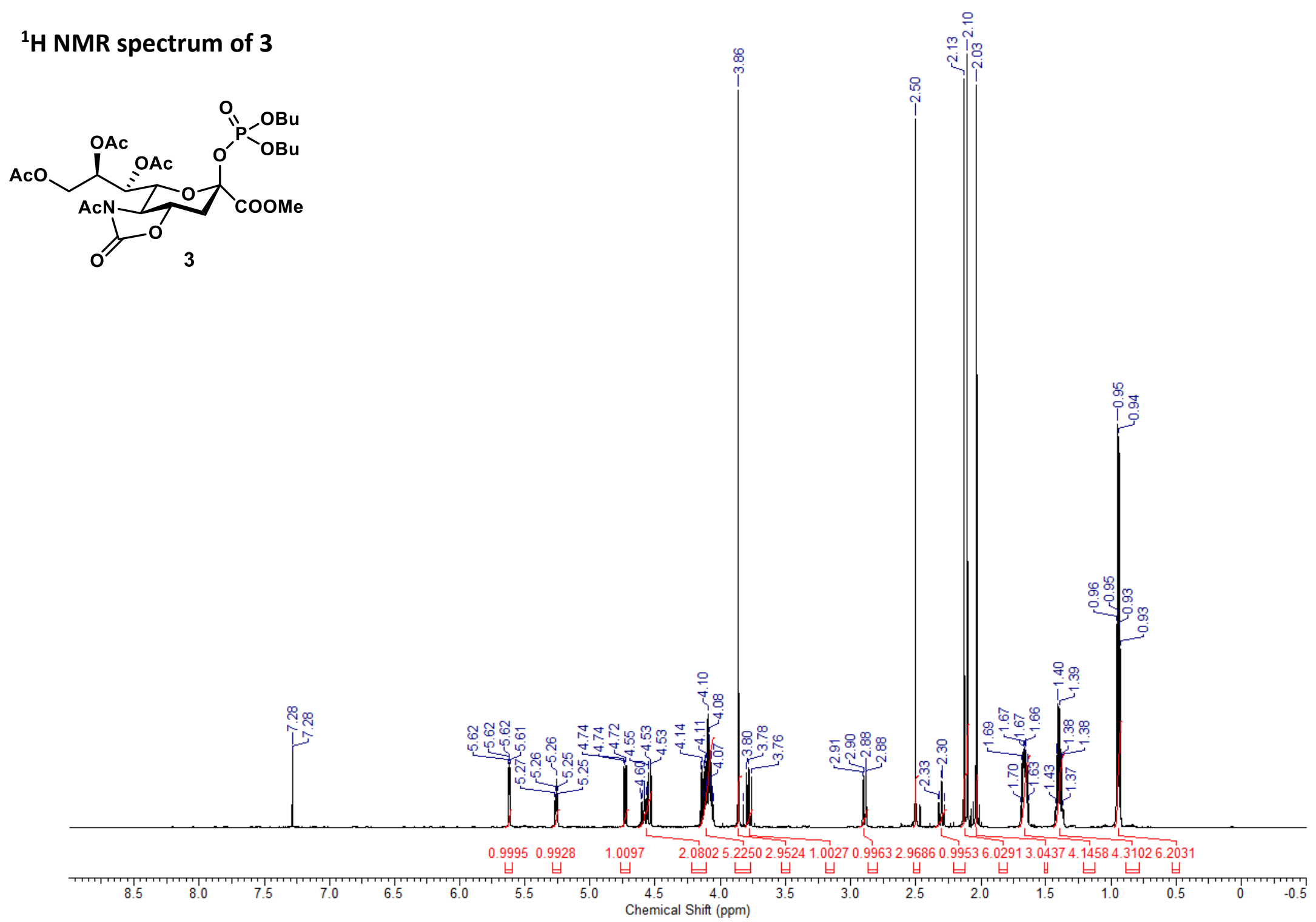
${ }^{13} \mathrm{C}$ NMR spectrum of 3
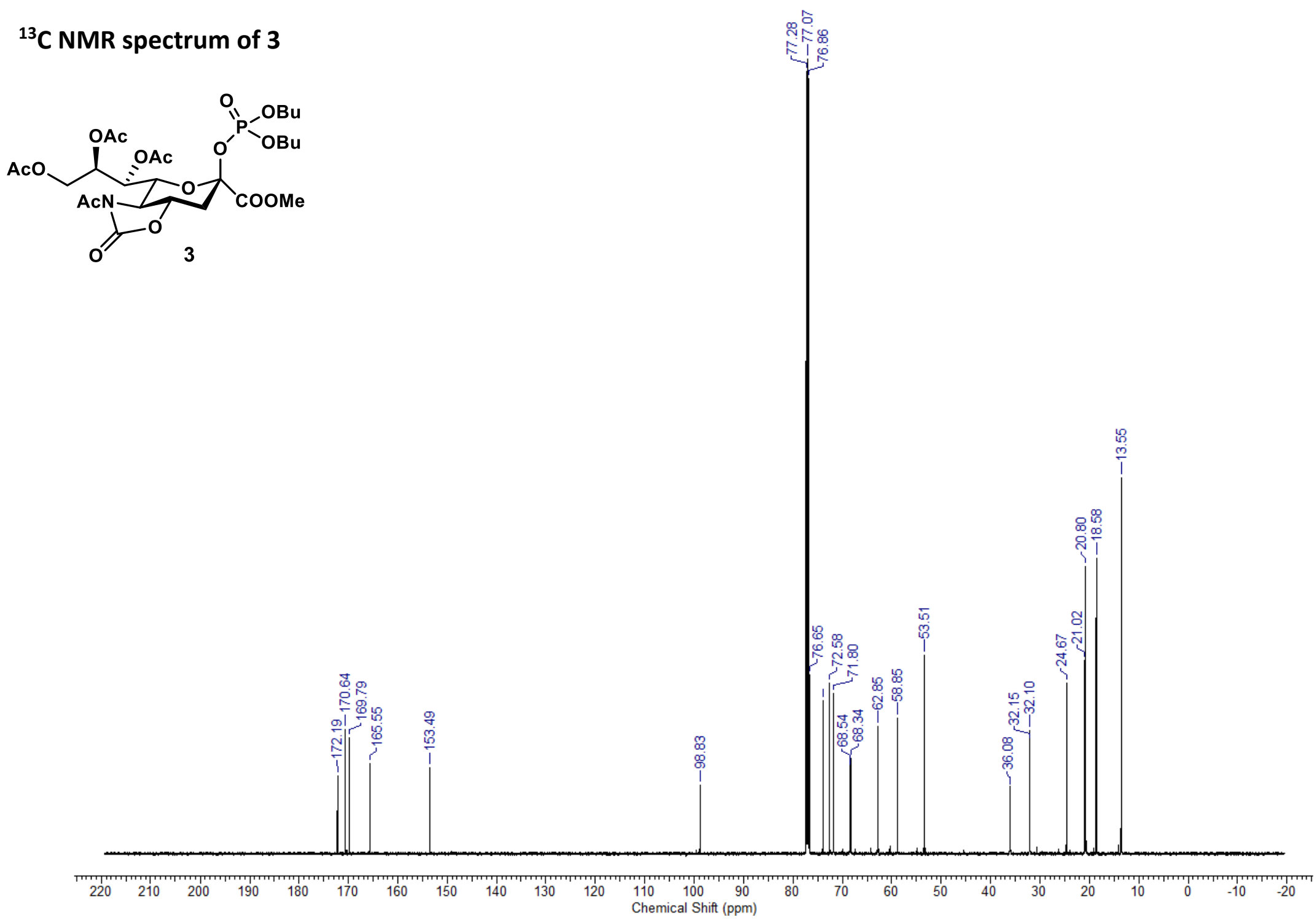


\section{DEPT135 spectrum of 3}
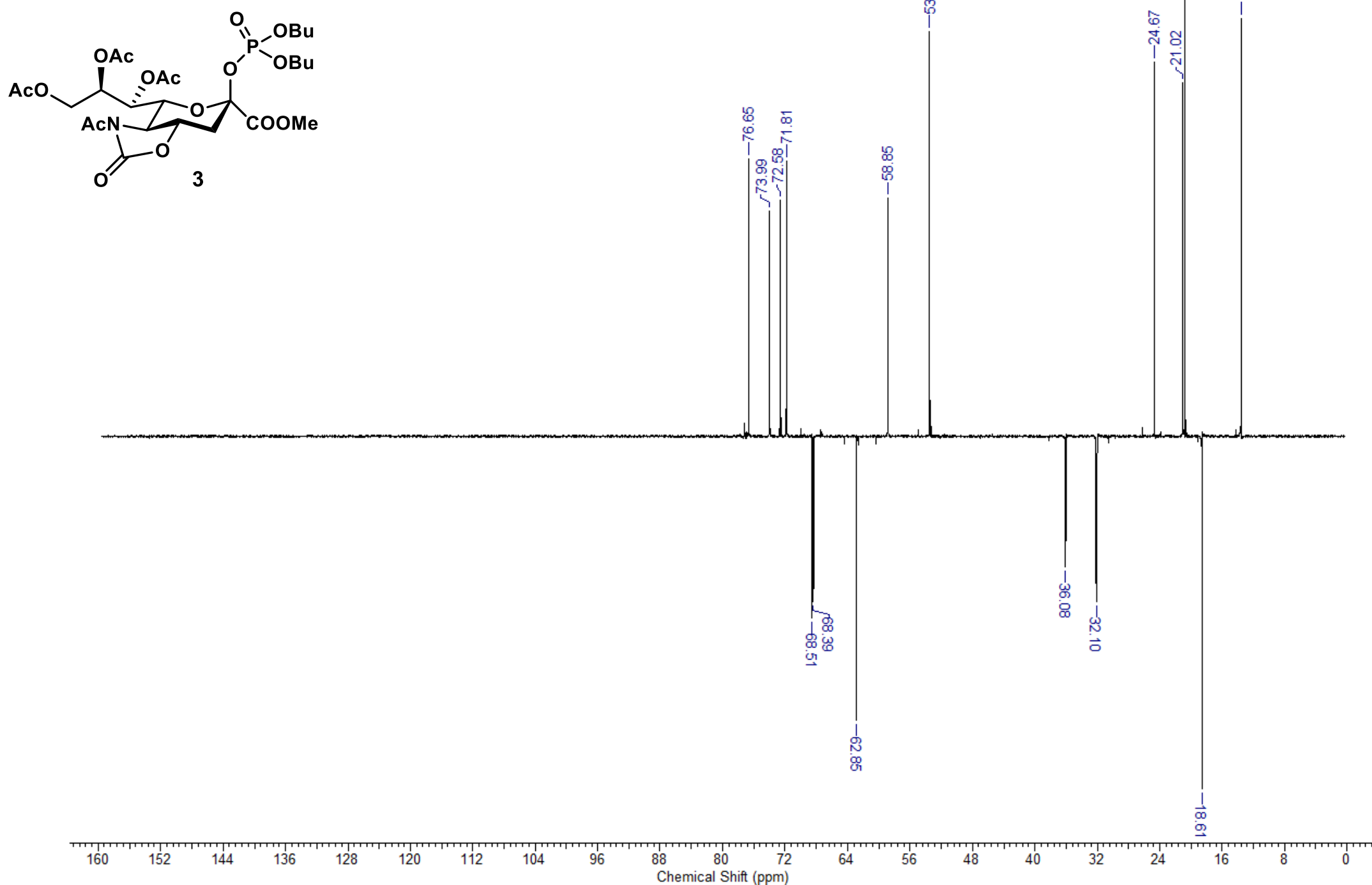
COSY spectrum of 3

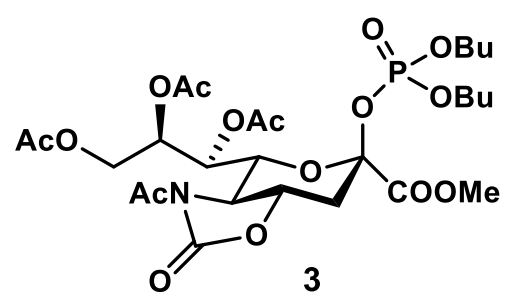

MS-003 -purified.004.001.2rr.esp

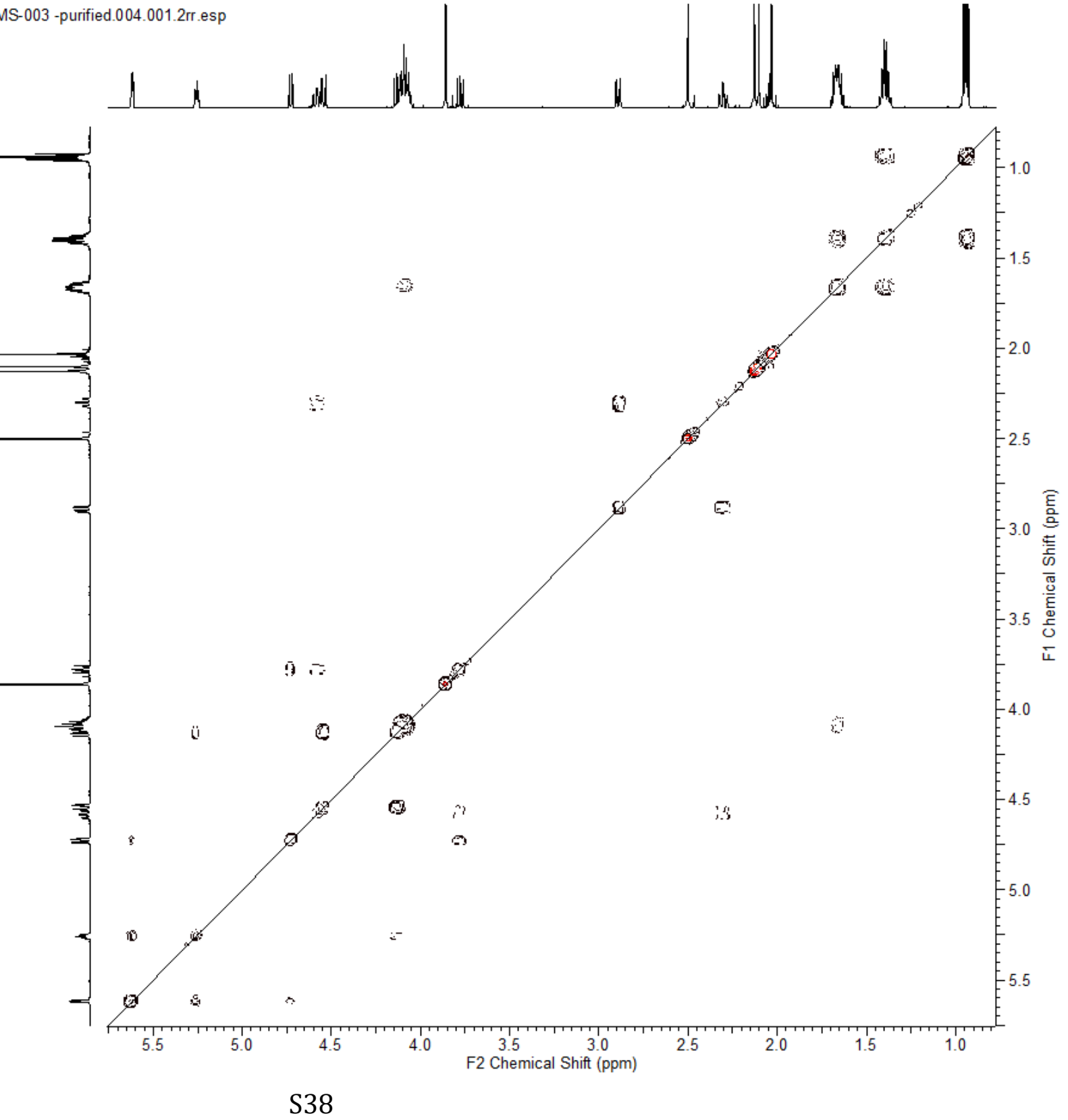


${ }^{1} \mathrm{H}$ NMR spectrum of 4

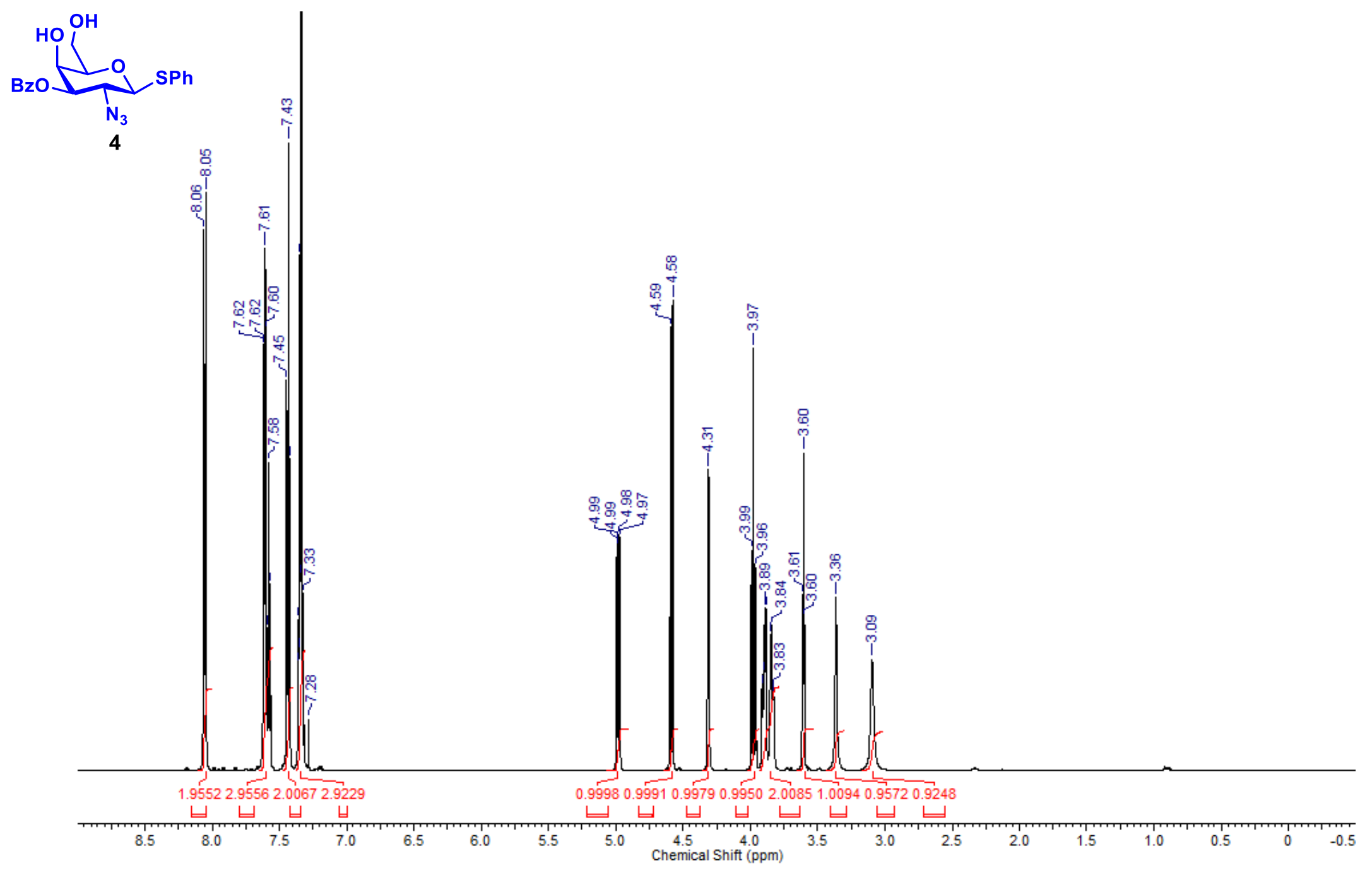


${ }^{13} \mathrm{C}$ NMR spectrum of 4
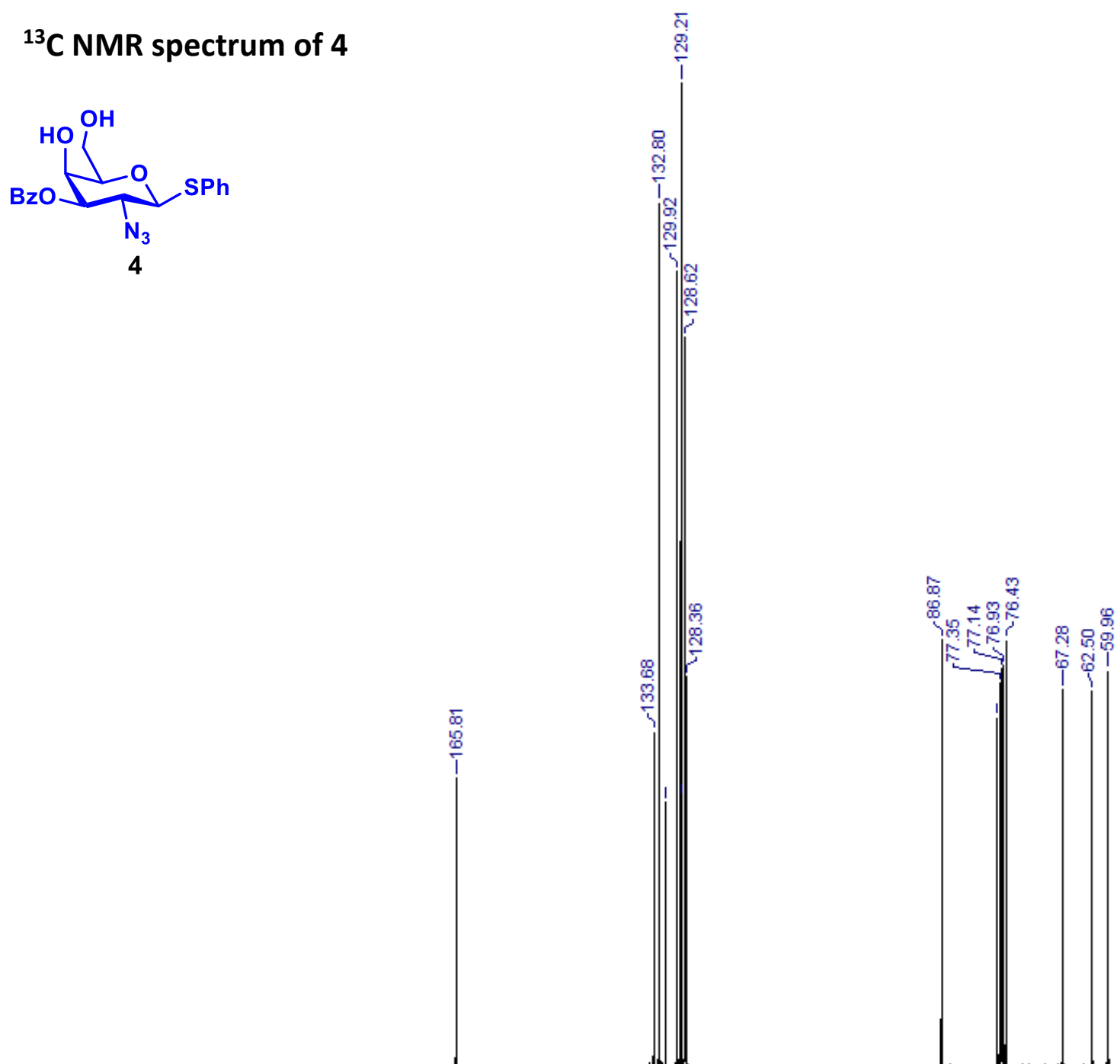

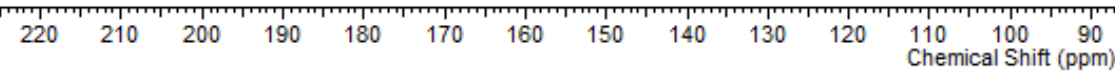

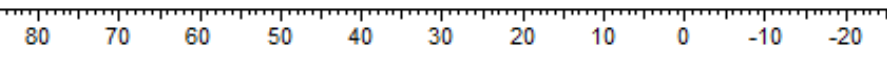




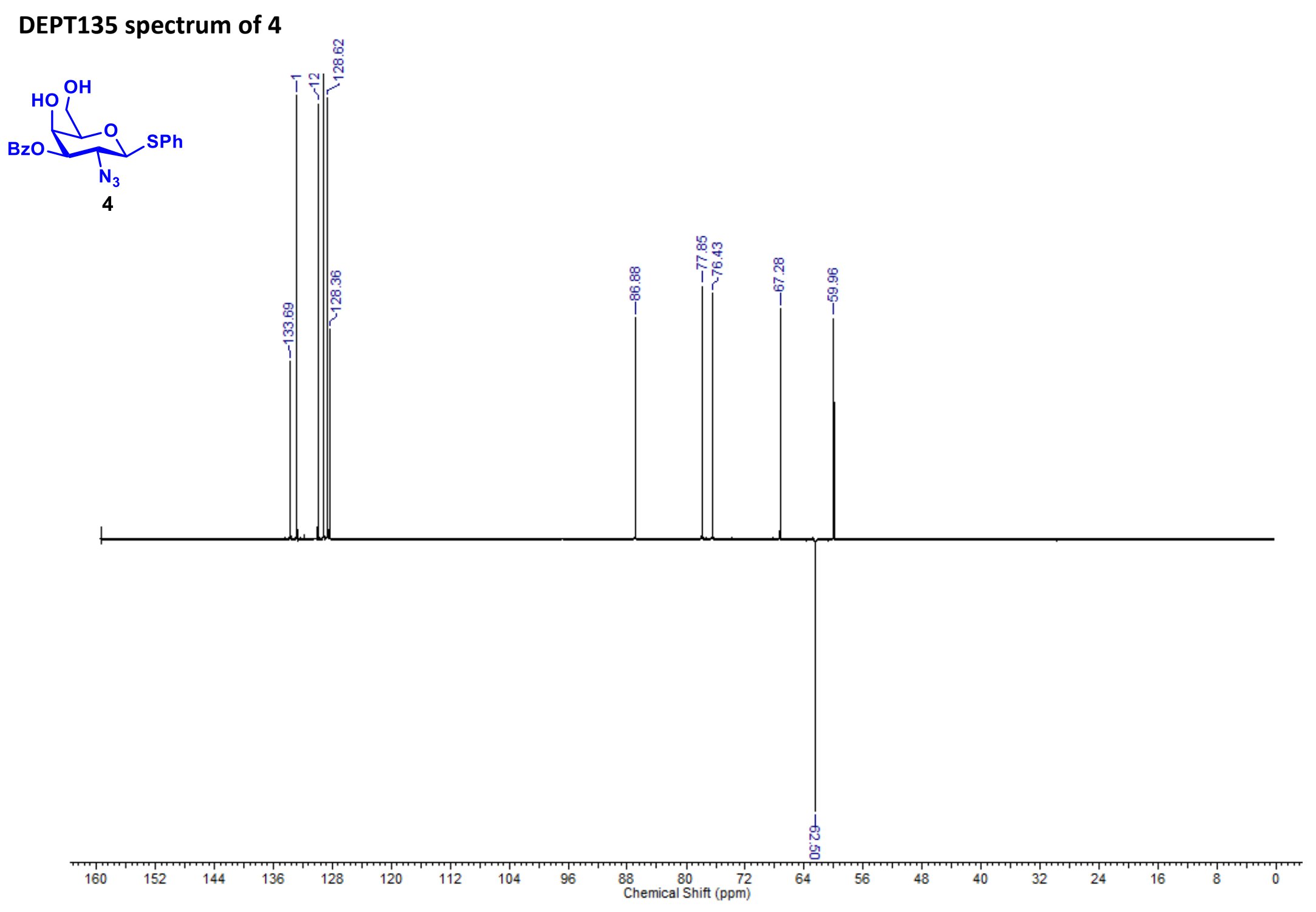




\section{COSY spectrum of 4}

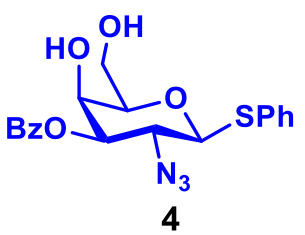

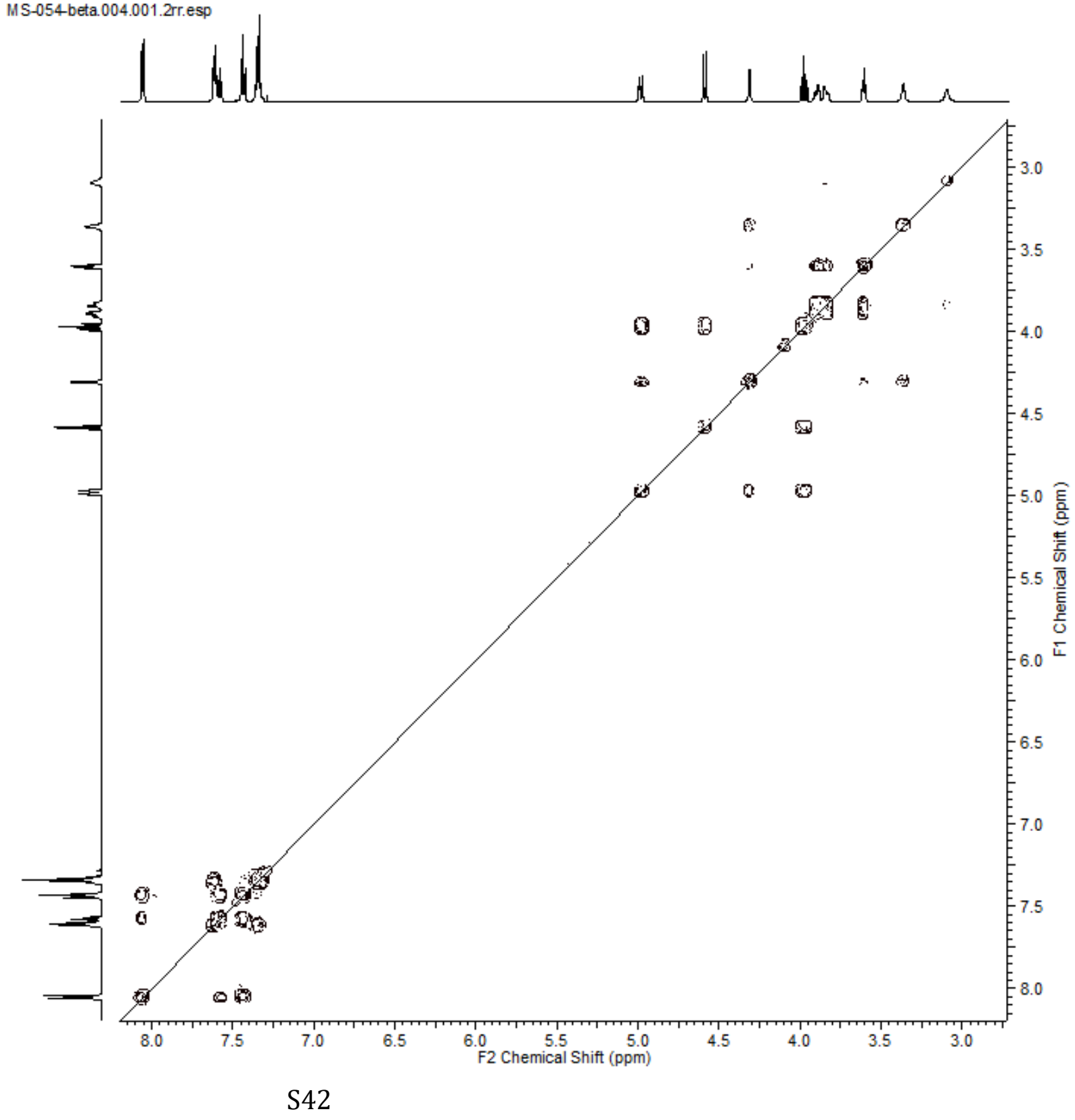


${ }^{1} \mathrm{H}$ NMR spectrum of 8
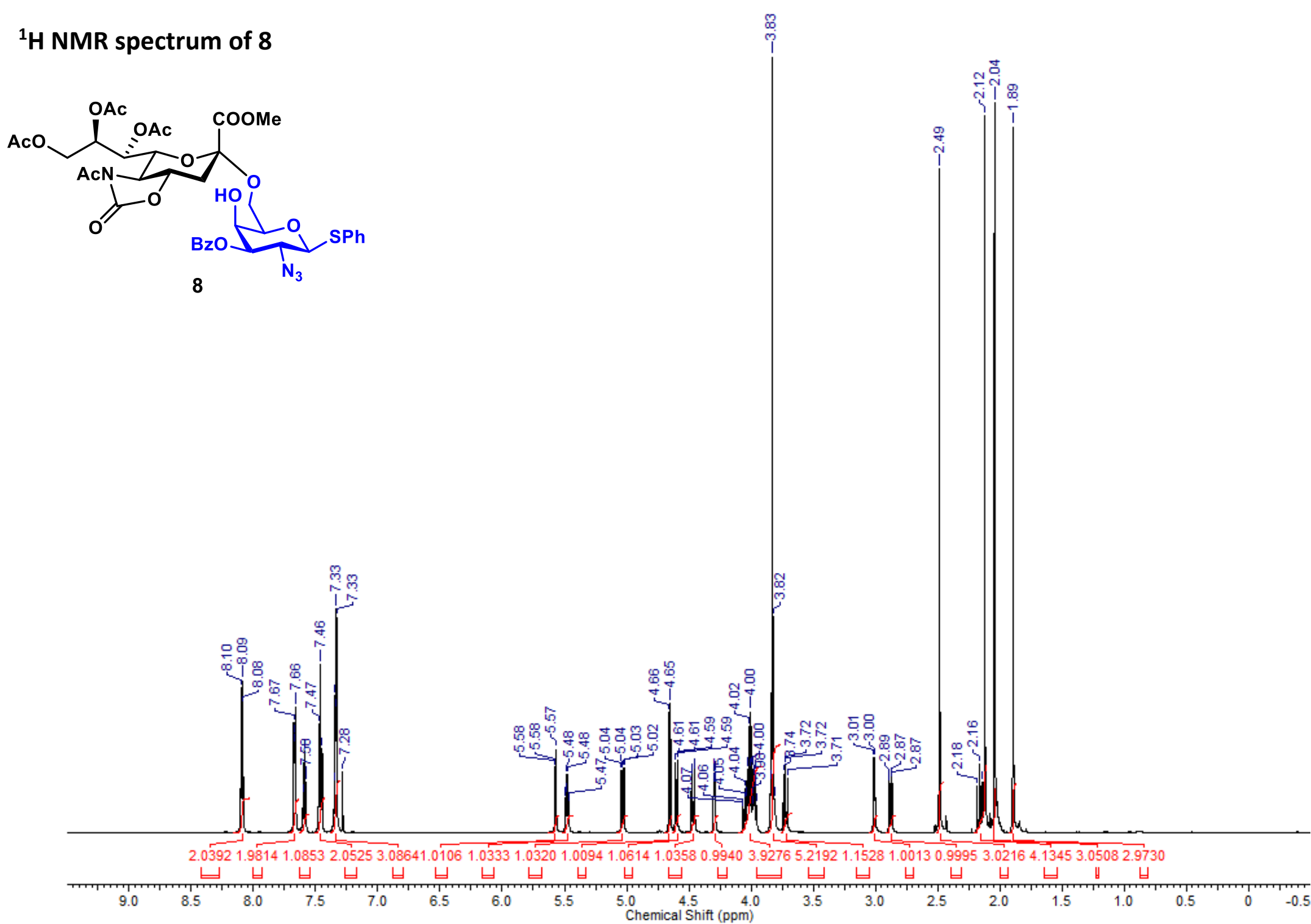
${ }^{13}$ C NMR spectrum of 8
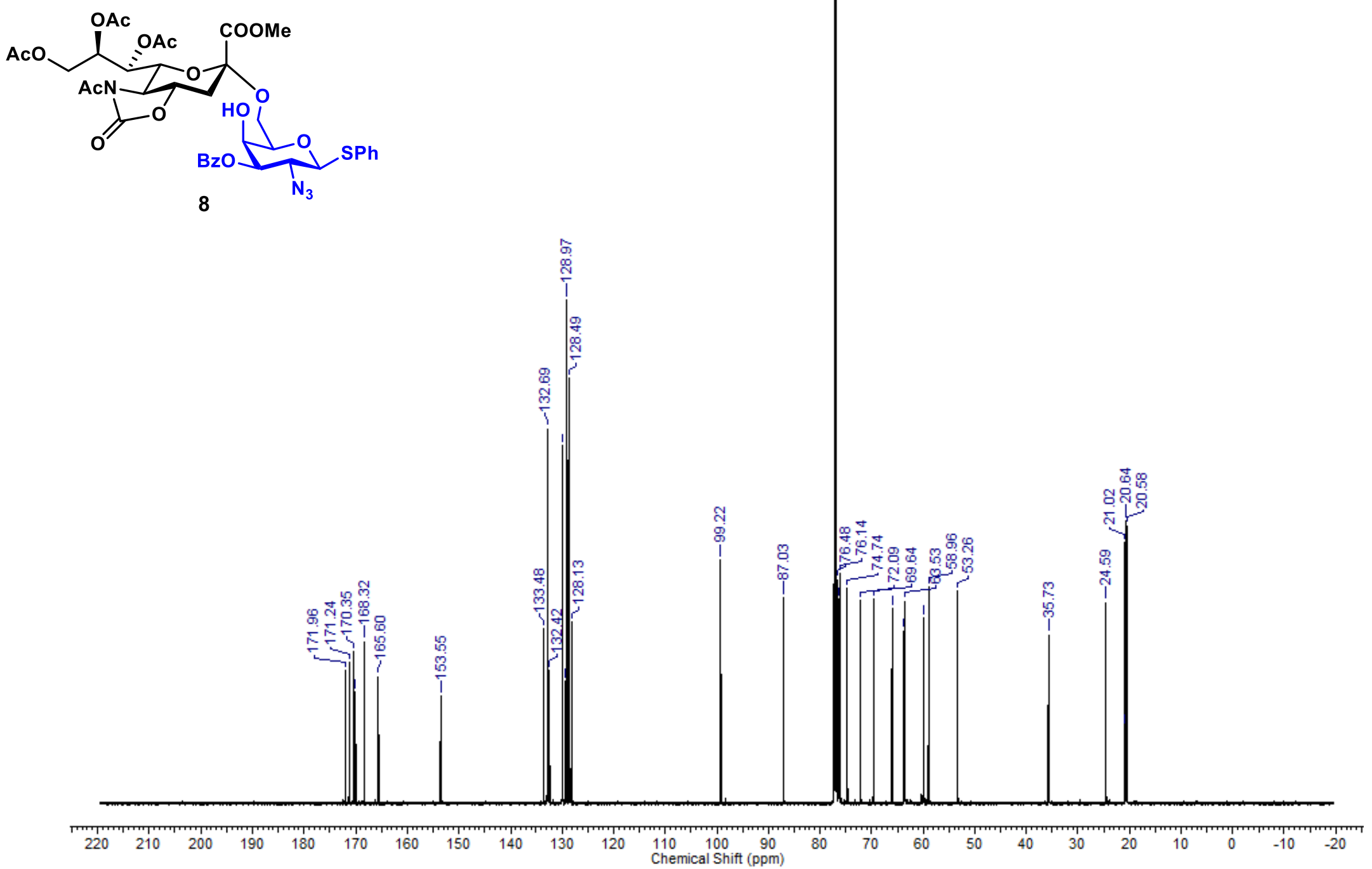


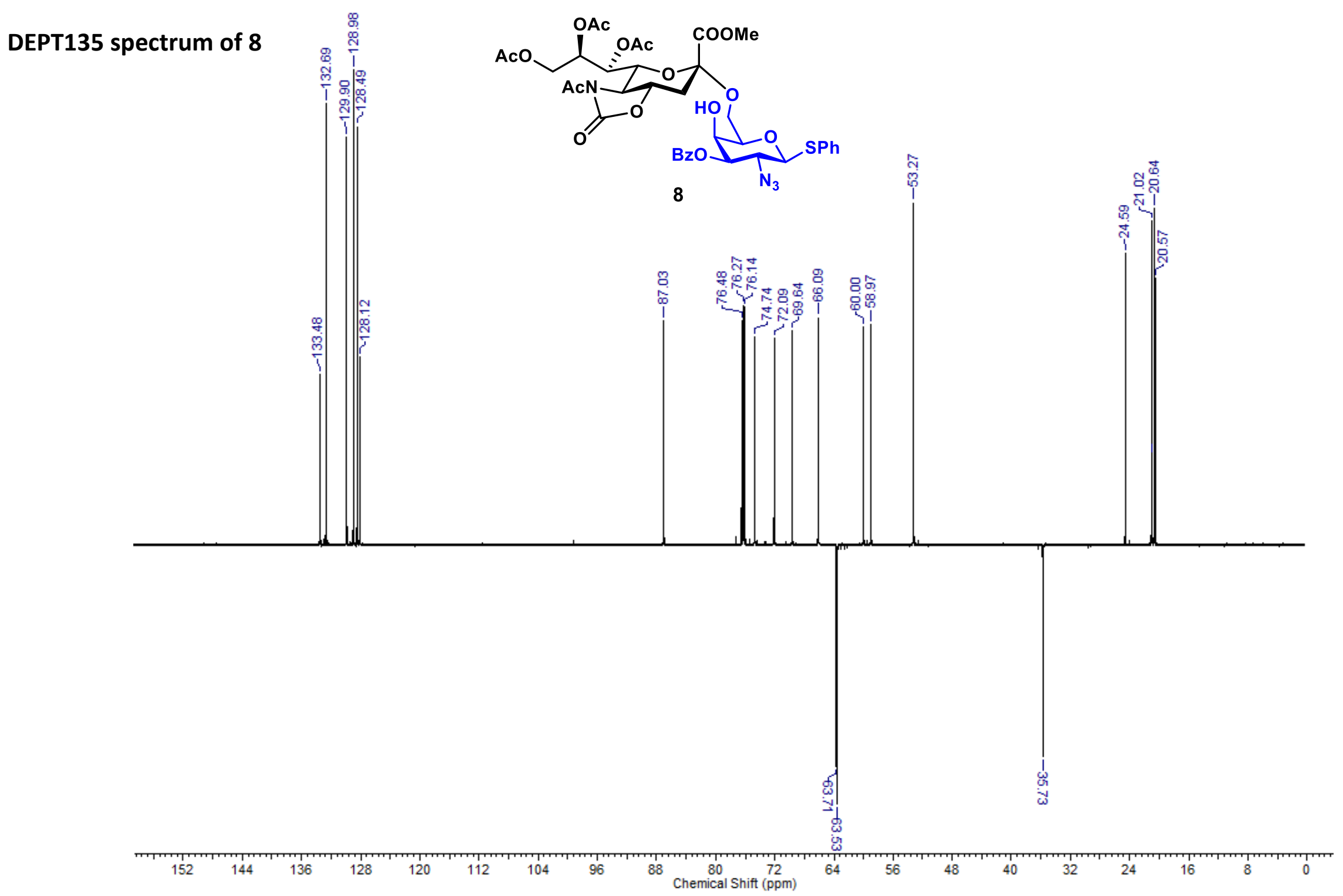




\section{COSY spectrum of 8}

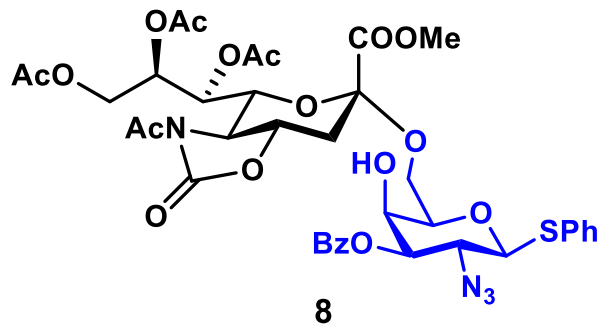

MS-055-beta.004.001.2rr.esp

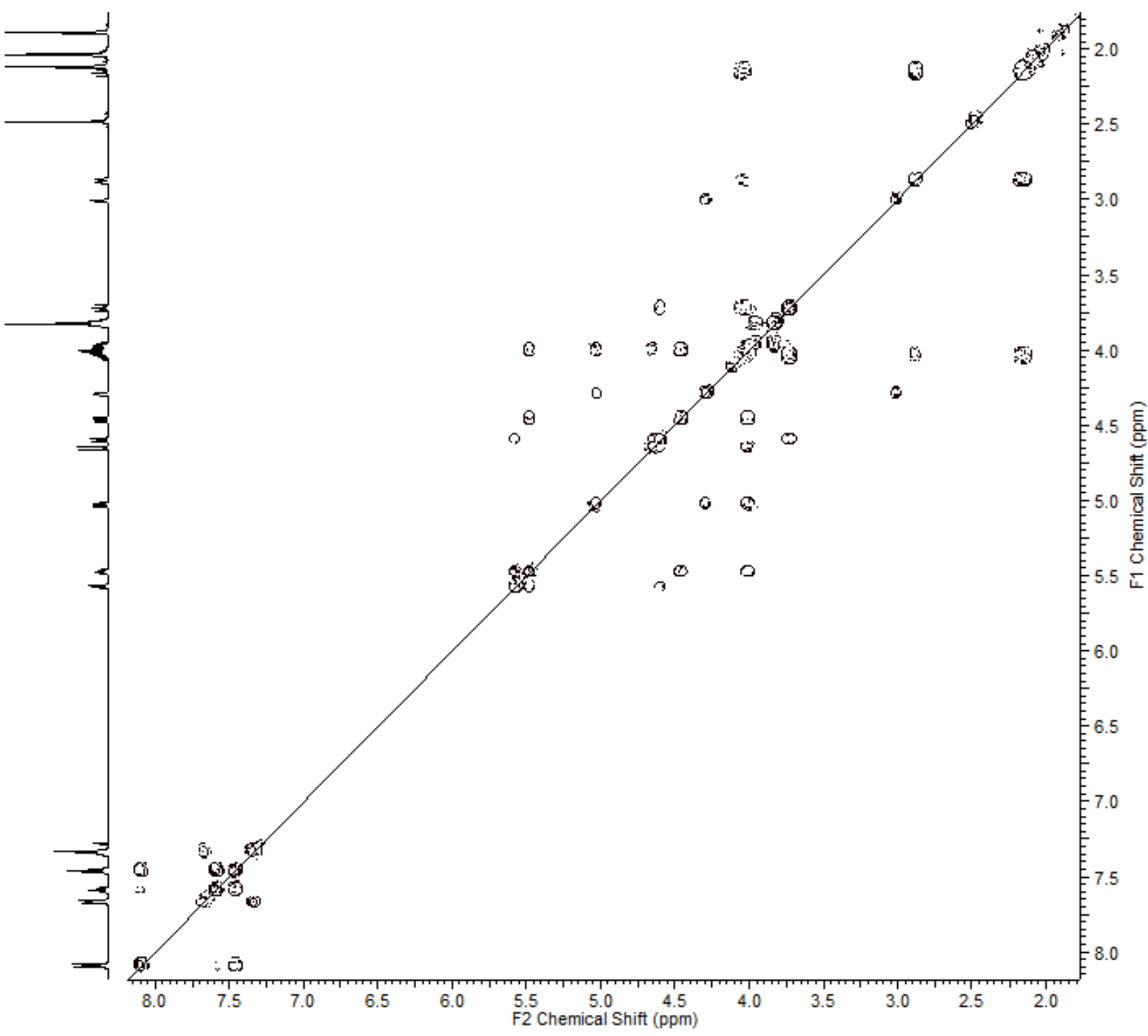


HSQC spectrum of 8

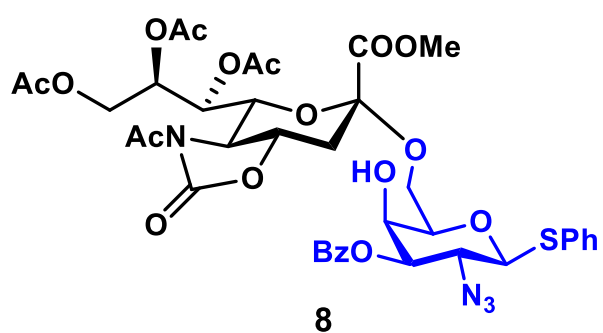

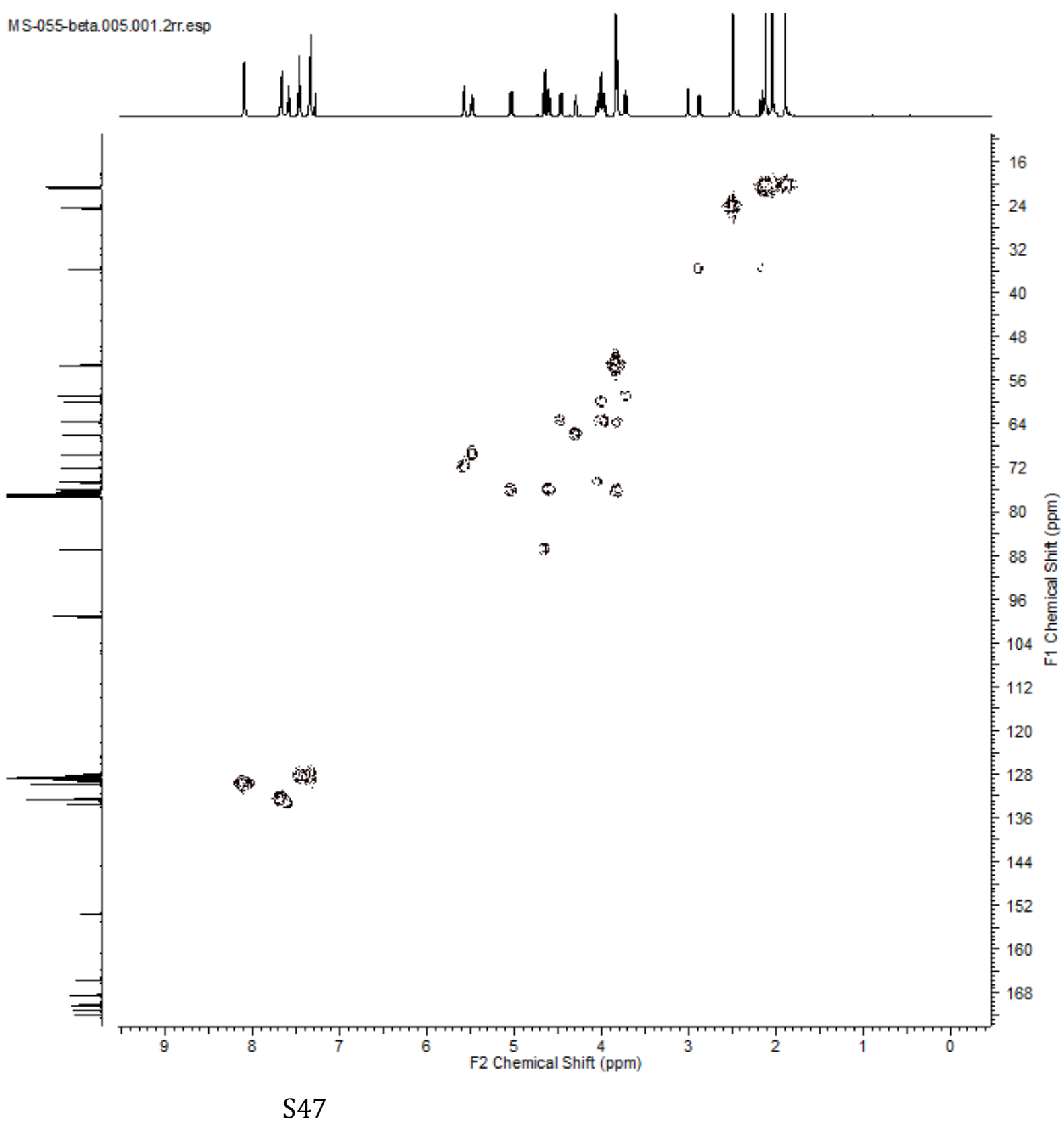




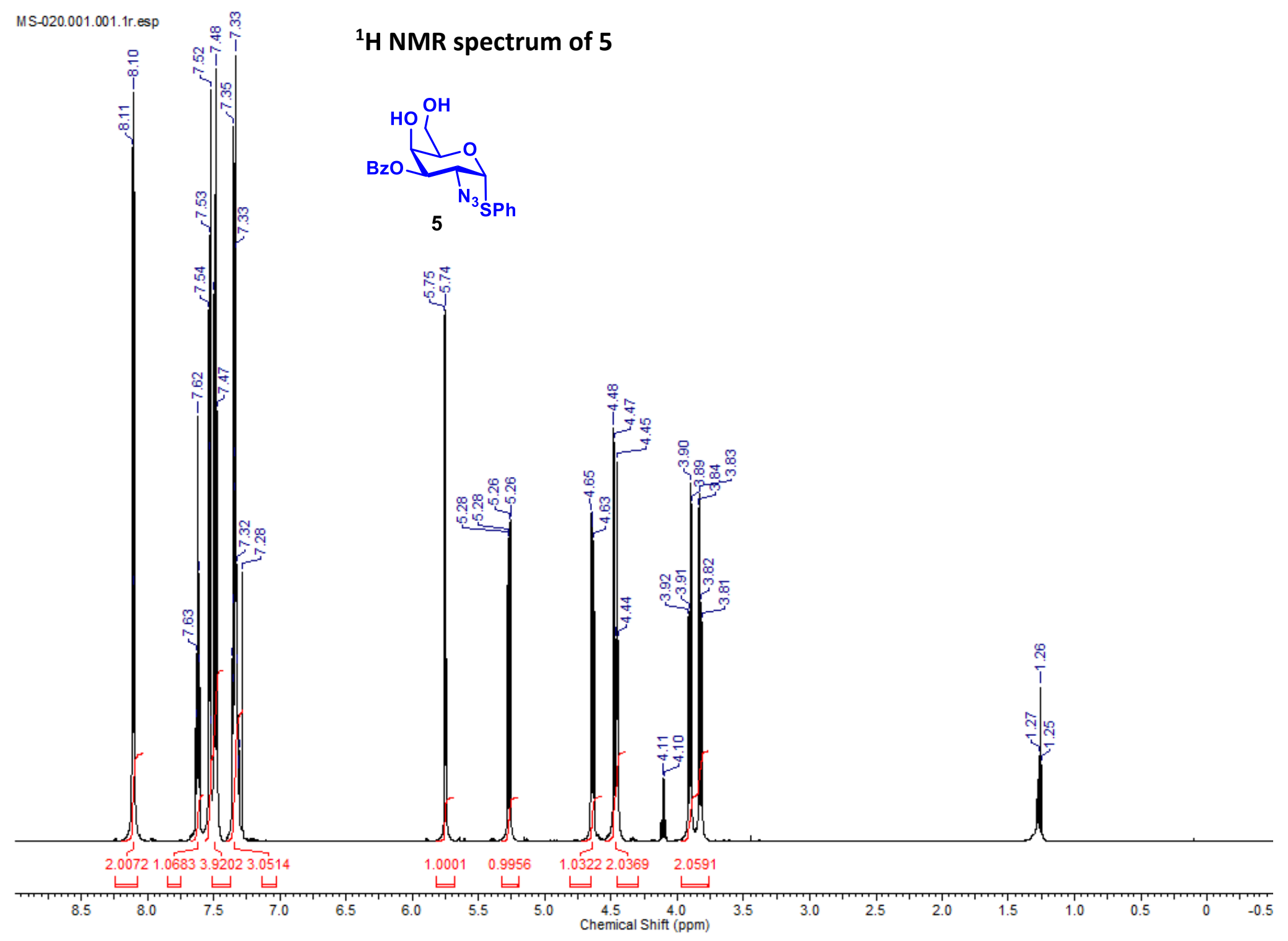


${ }^{13} \mathrm{C}$ NMR spectrum of 5
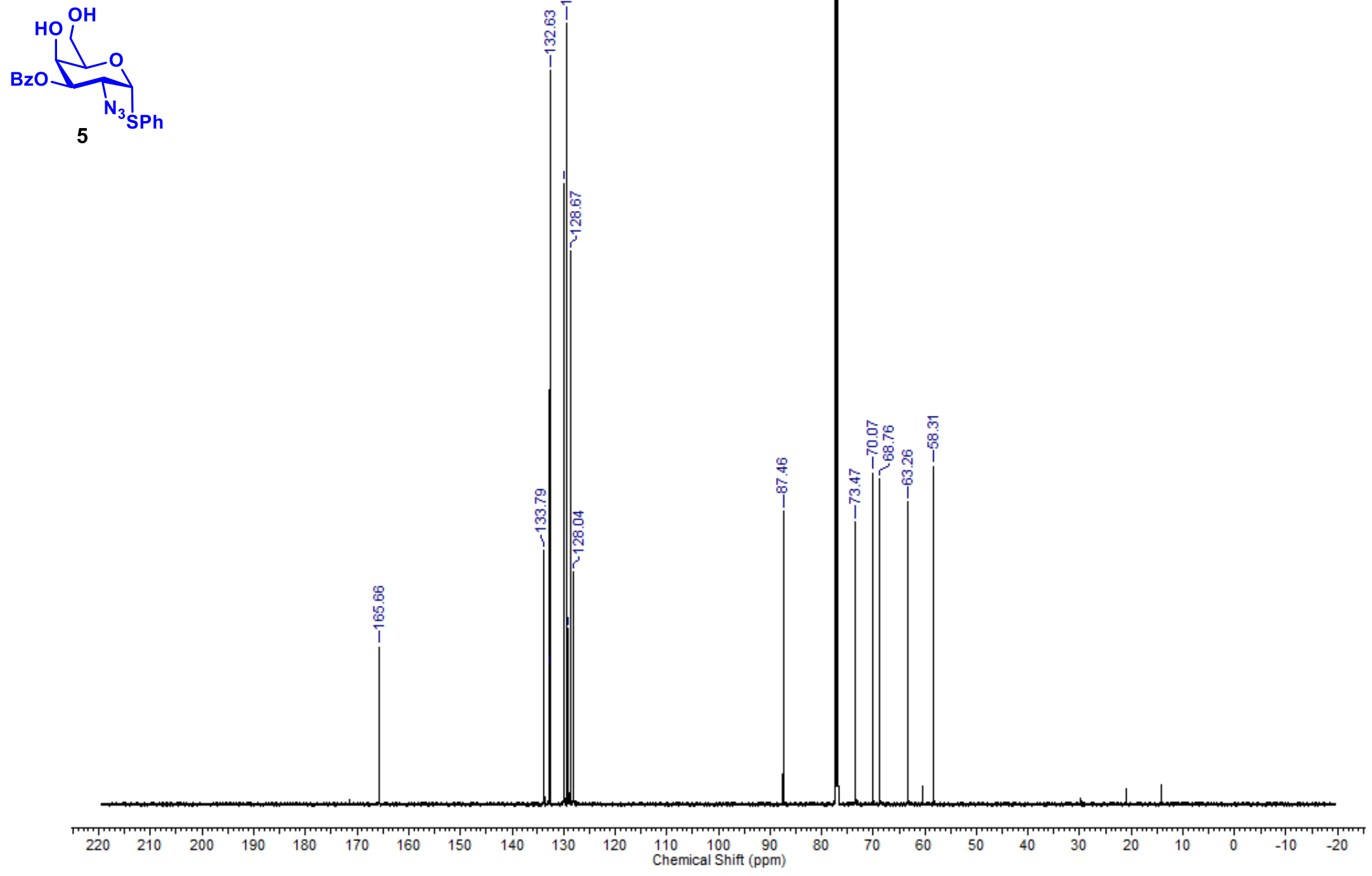

S49 


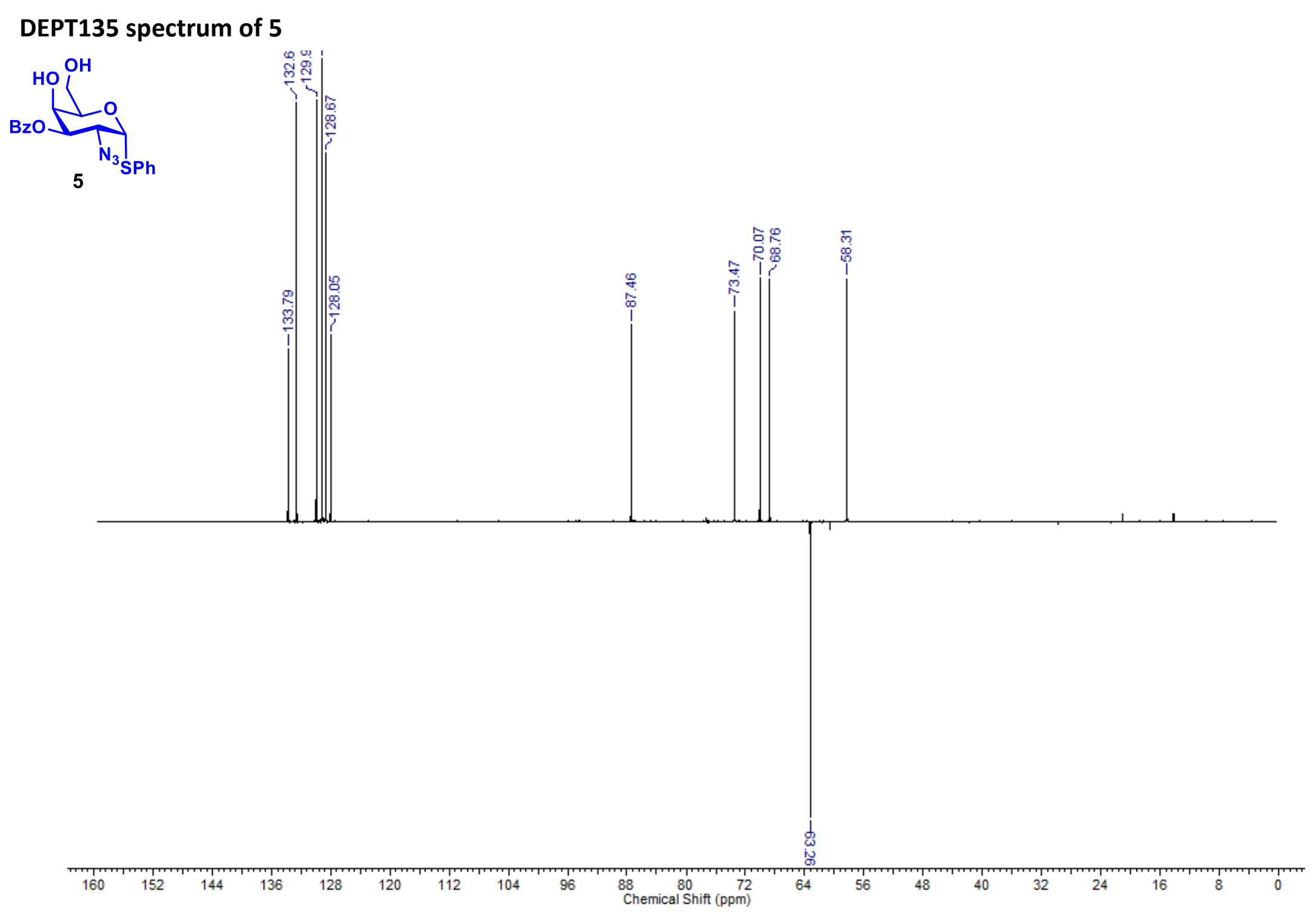


COSY spectrum of 5

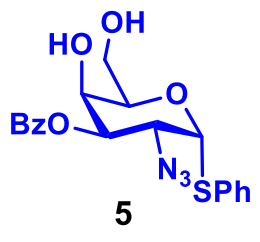

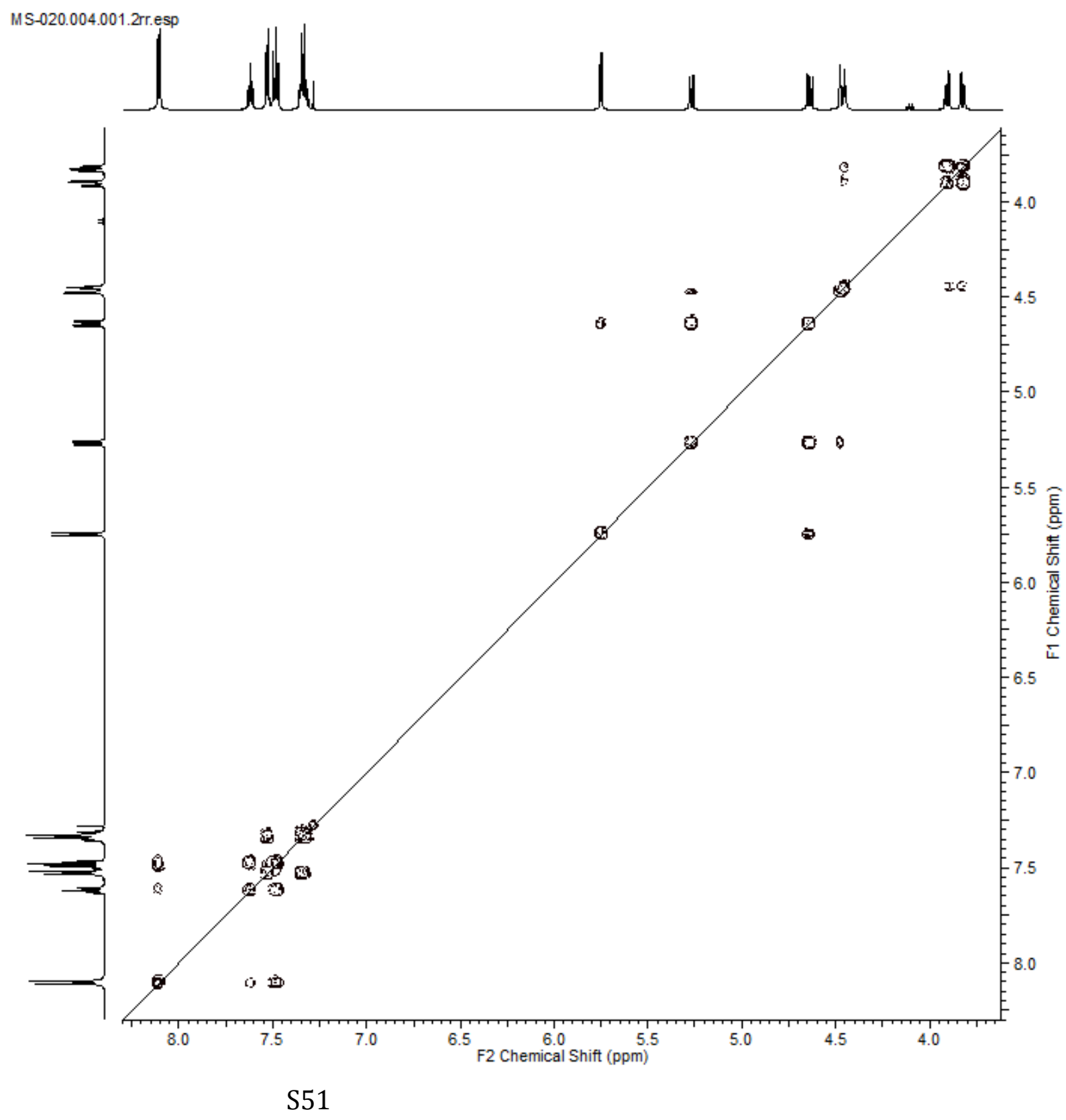


HMBC spectrum of 5

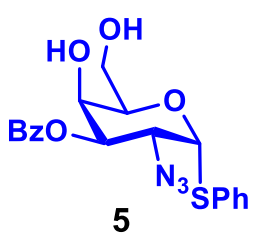

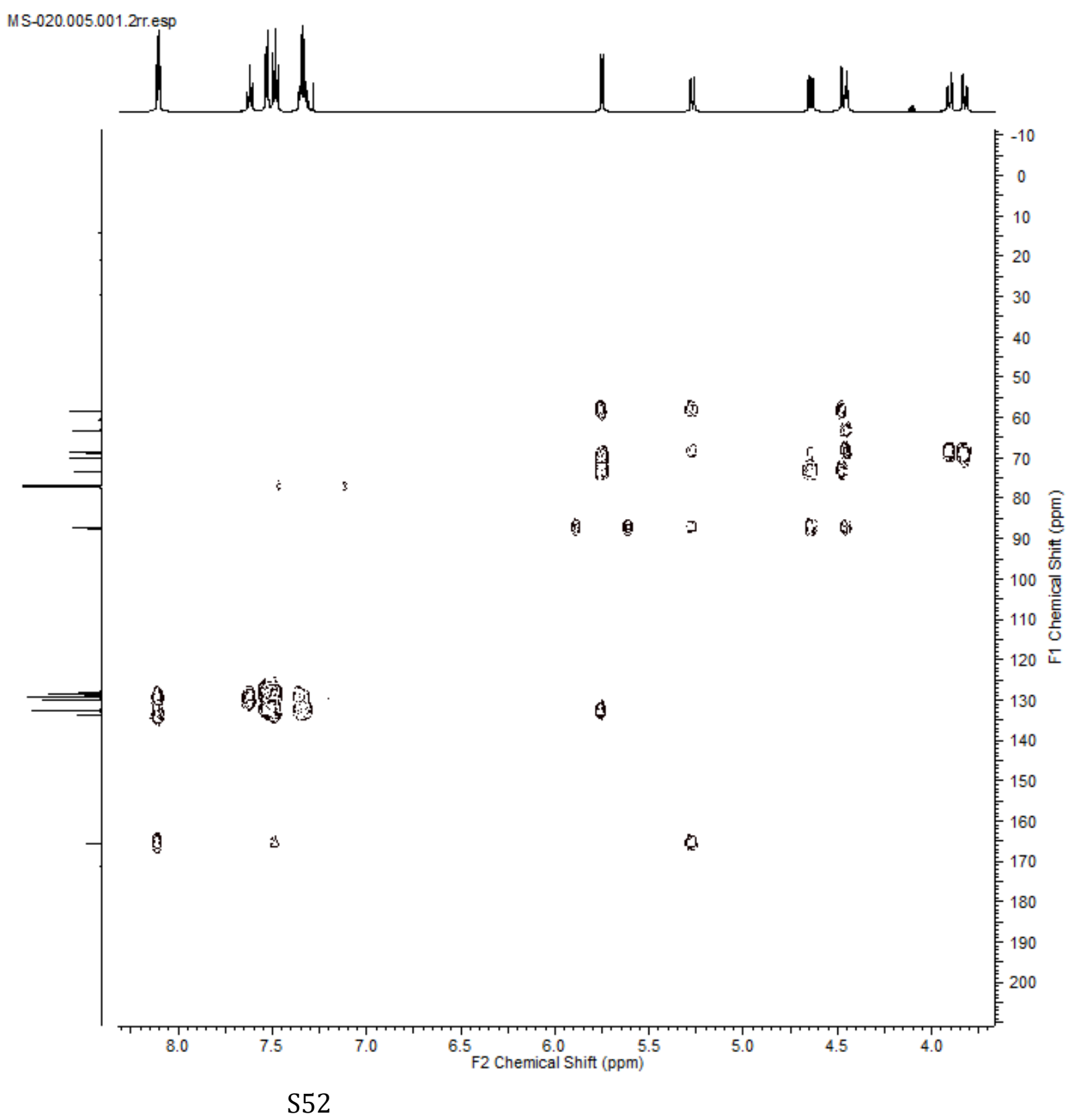


${ }^{1} \mathrm{H}$ NMR spectrum of 9
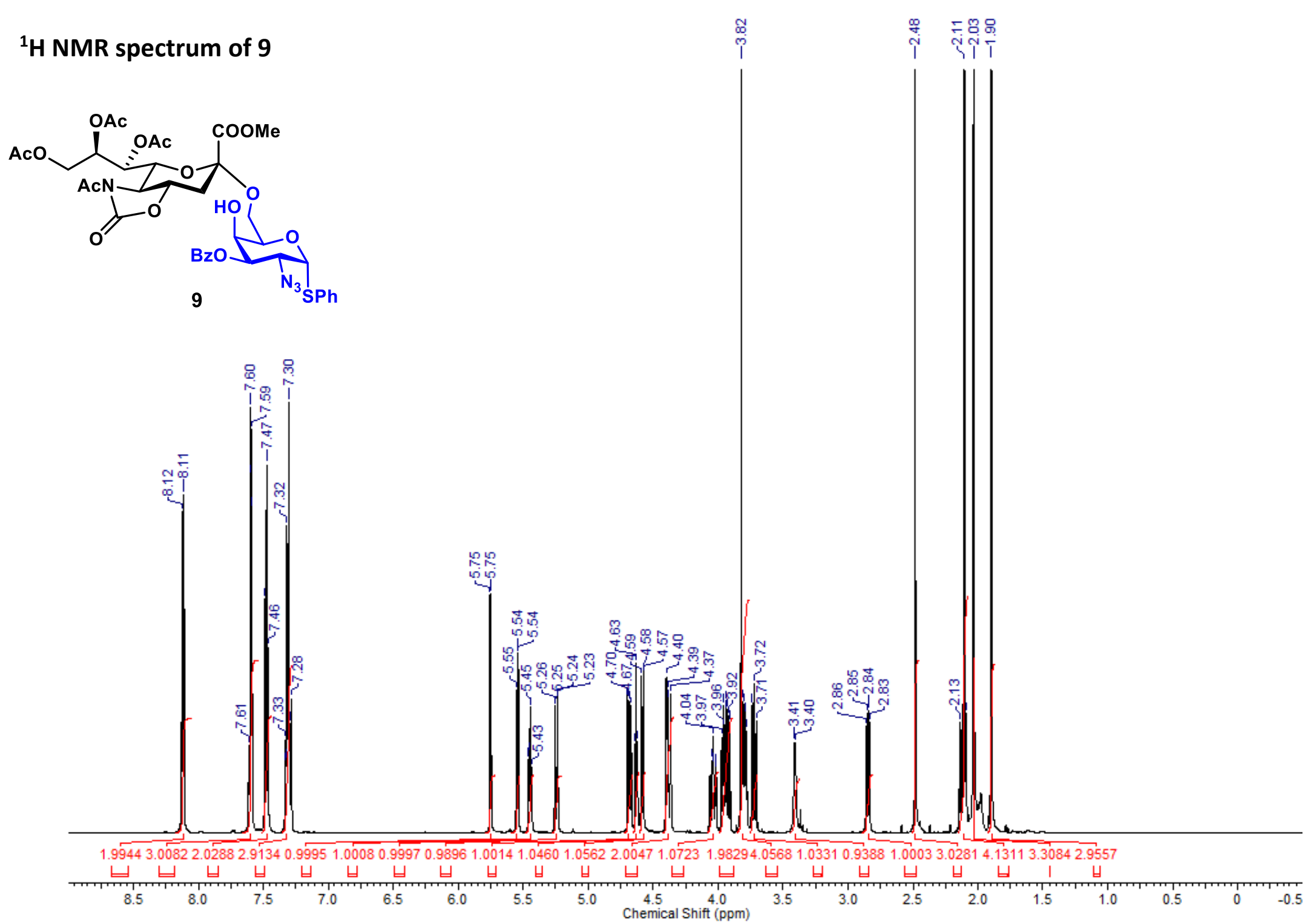


\section{${ }^{13} \mathrm{C}$ NMR spectrum of 9}
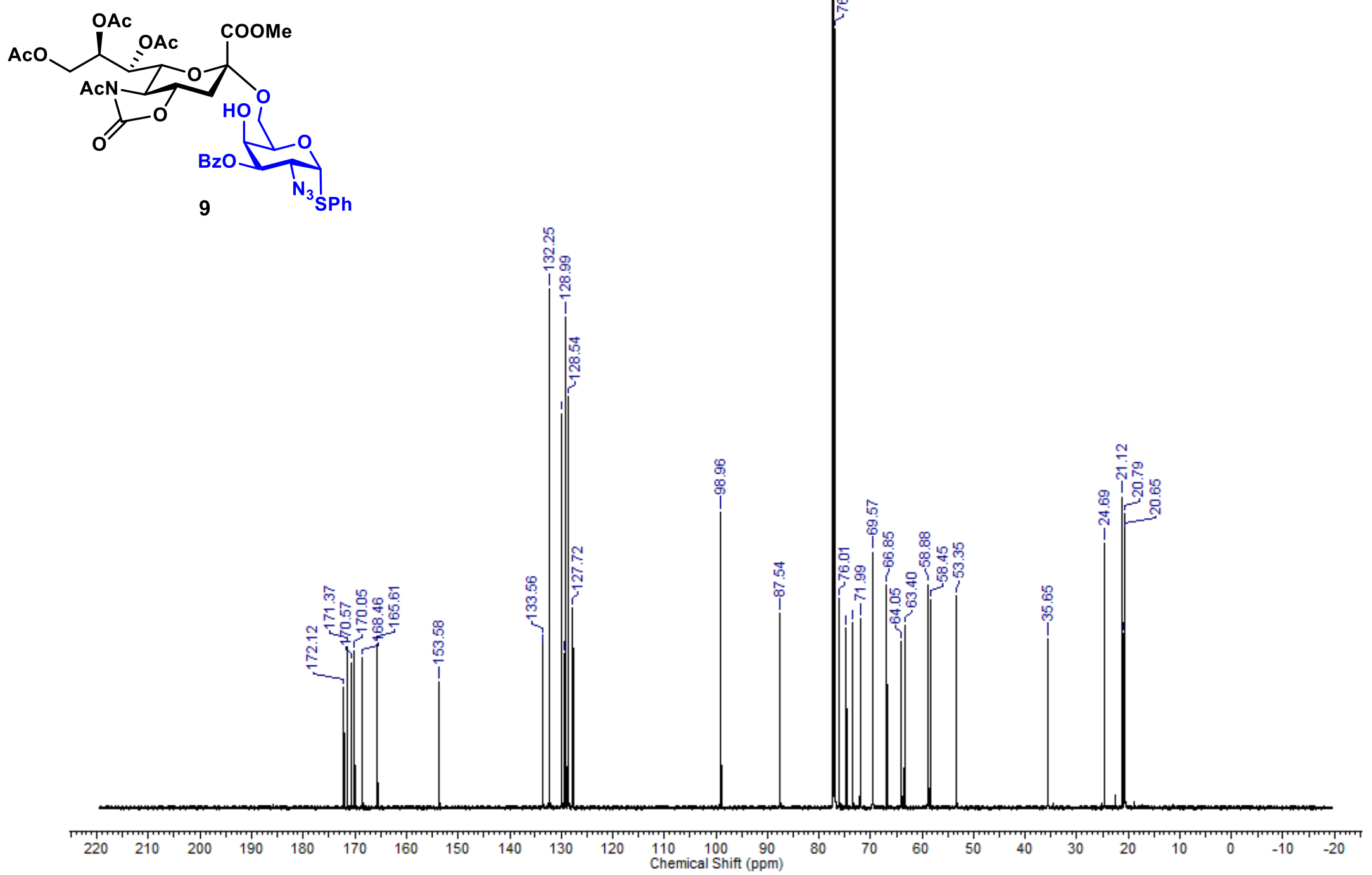


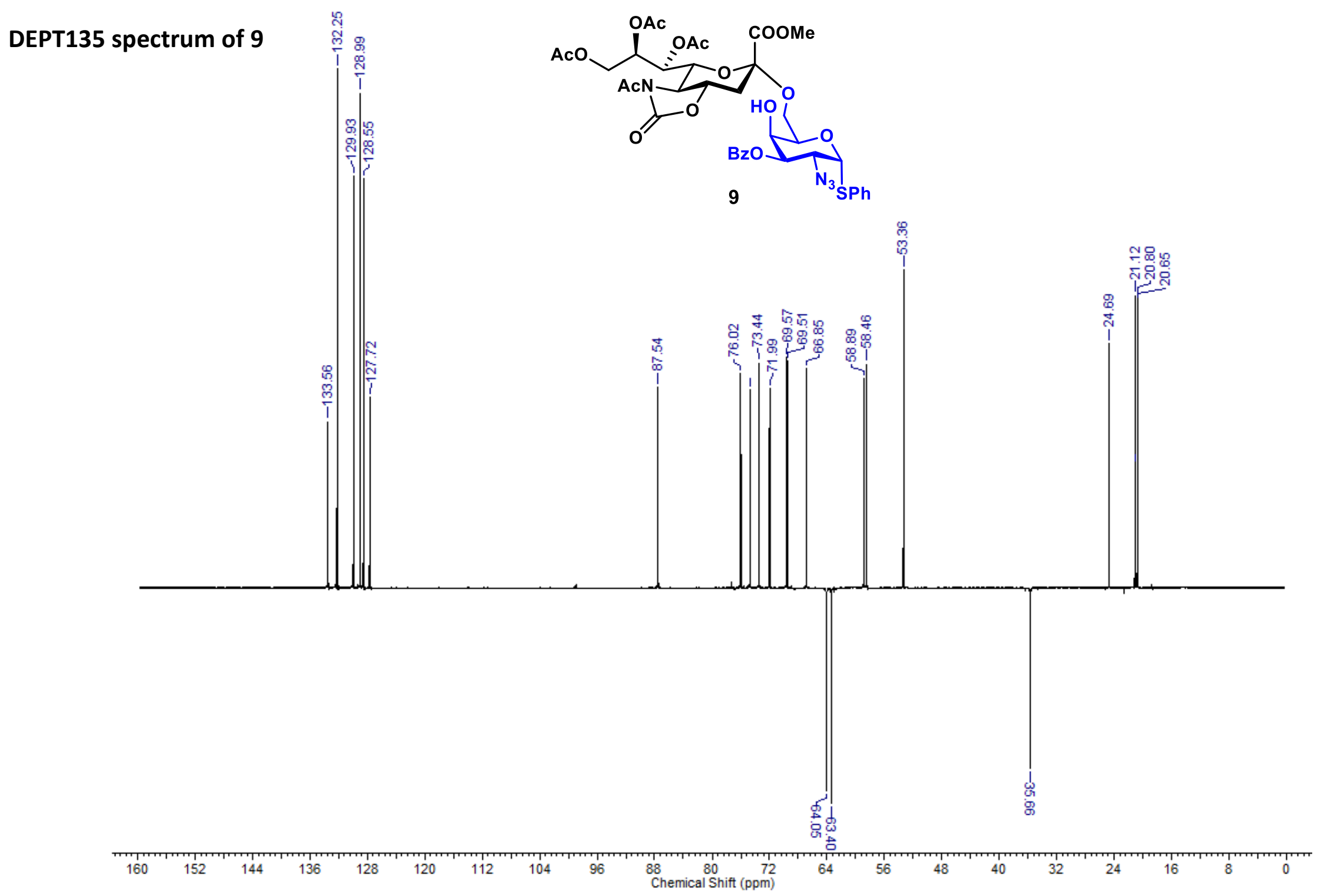




\section{COSY spectrum of 9}

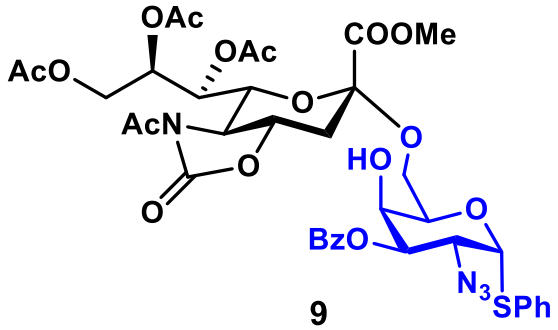

MS-022-purified.005.001.2r.esp
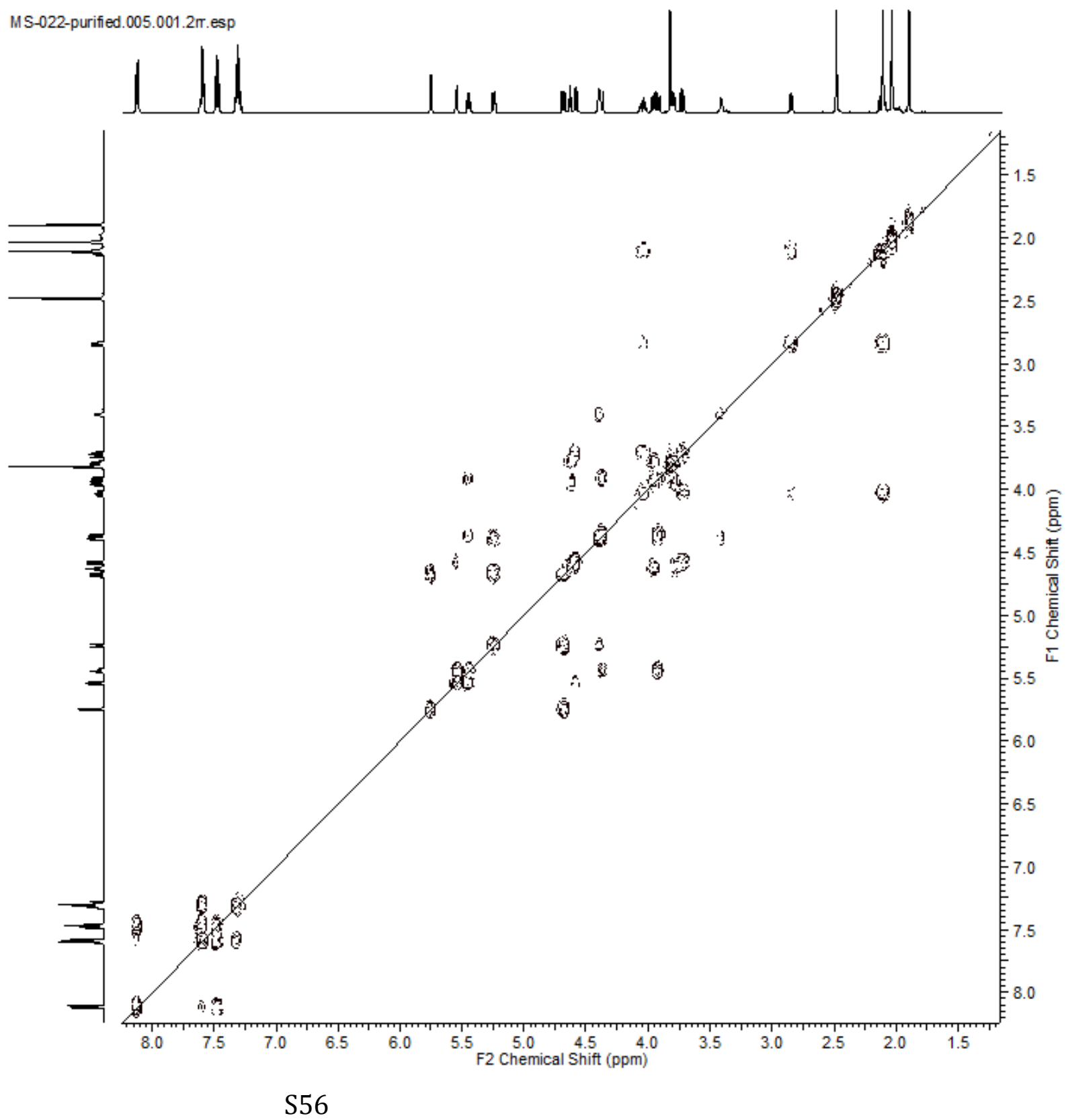
HMBC spectrum of 9

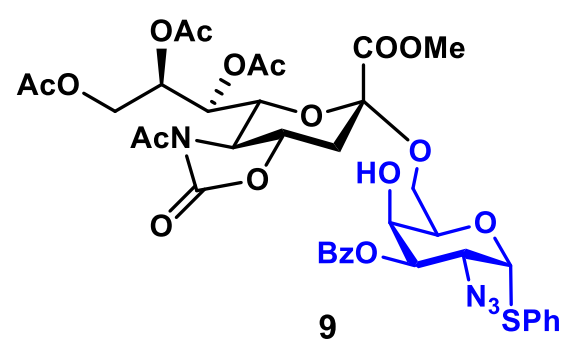

MS-022-purified. 006.001.2r.esp
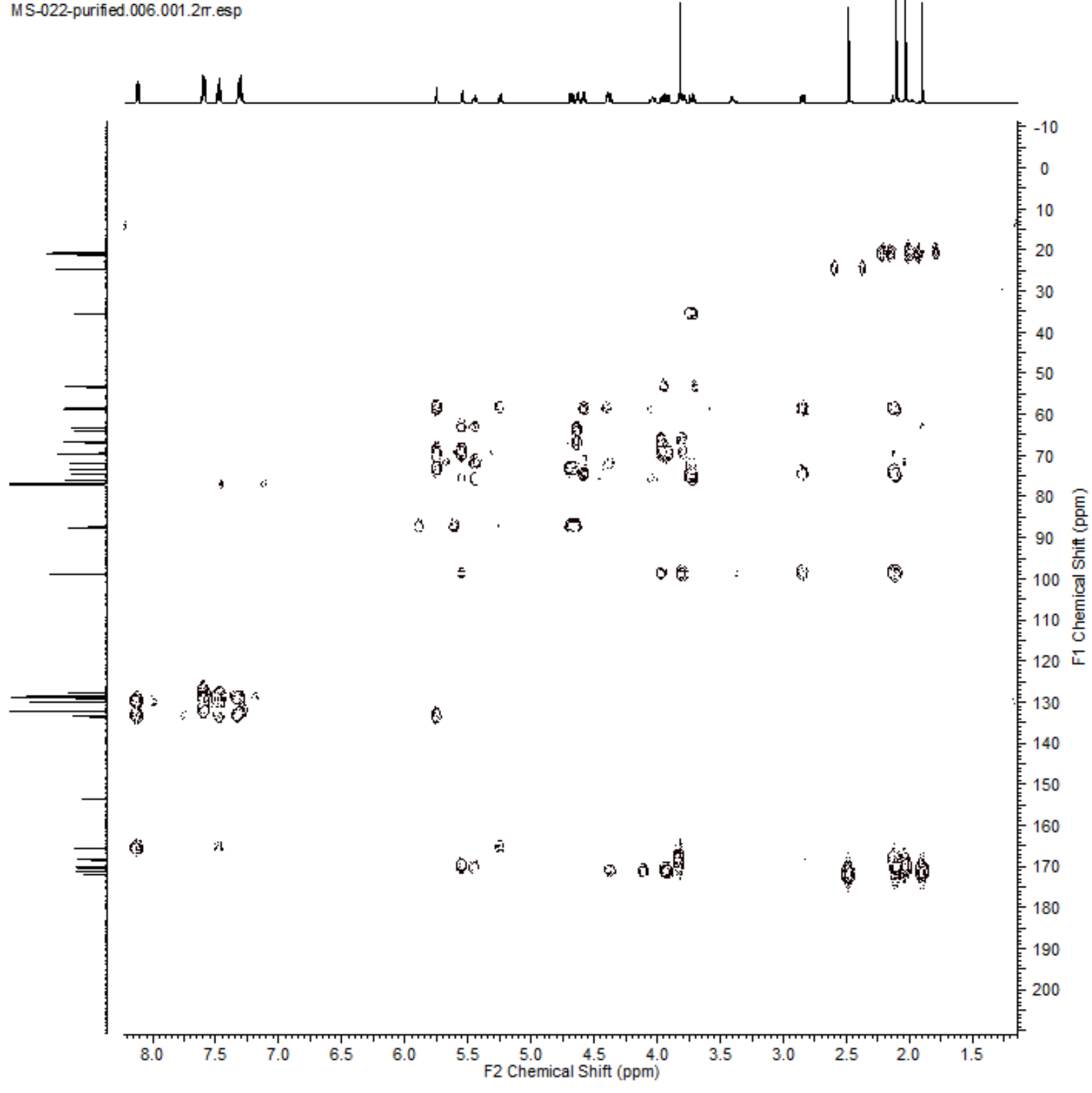

S57 


\section{HSQC spectrum of 9}
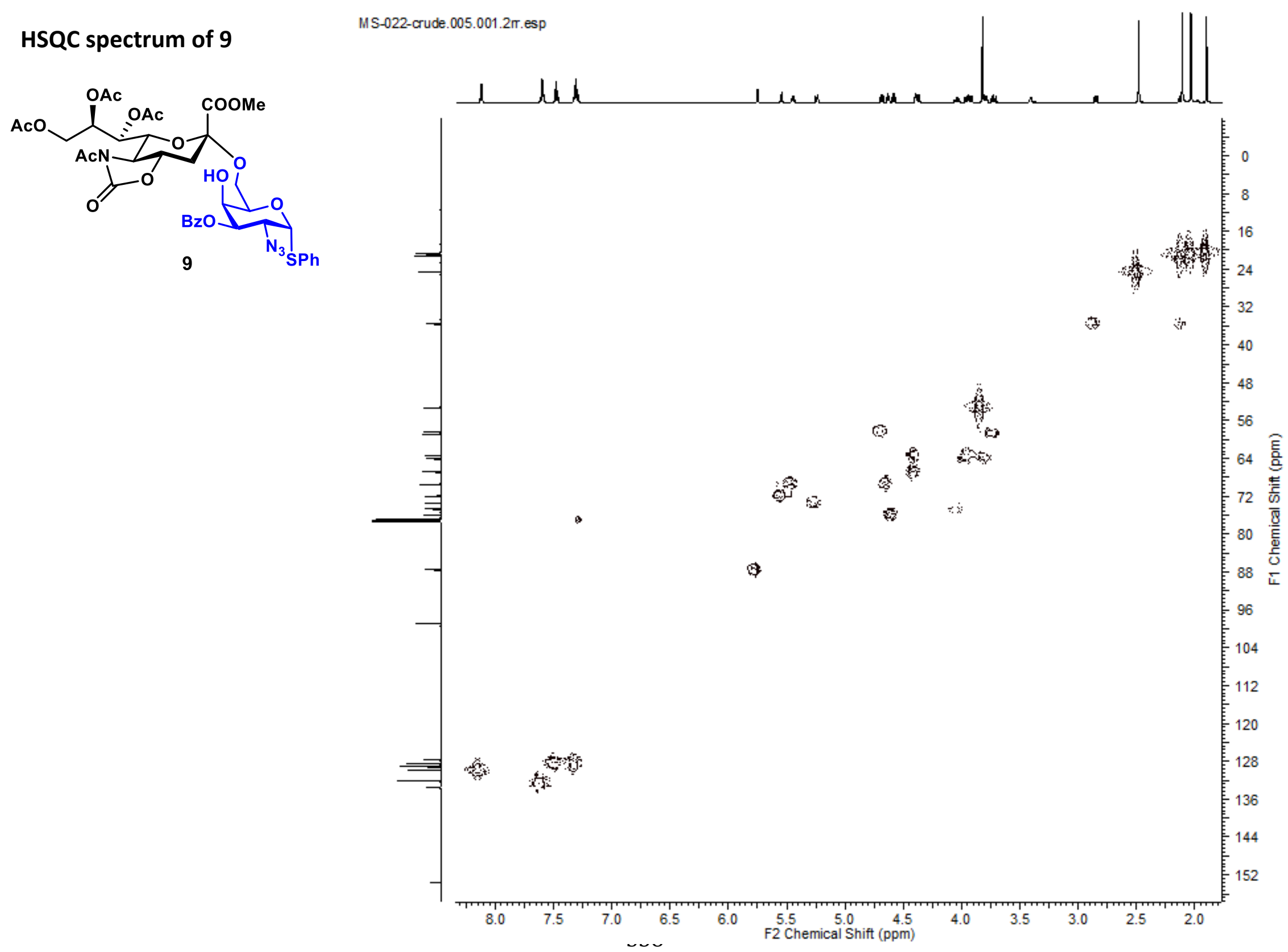
${ }^{1} \mathrm{H}$ NMR spectrum of 6

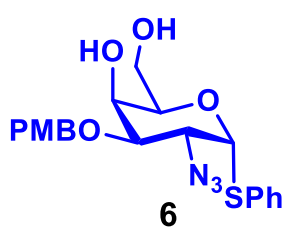

6

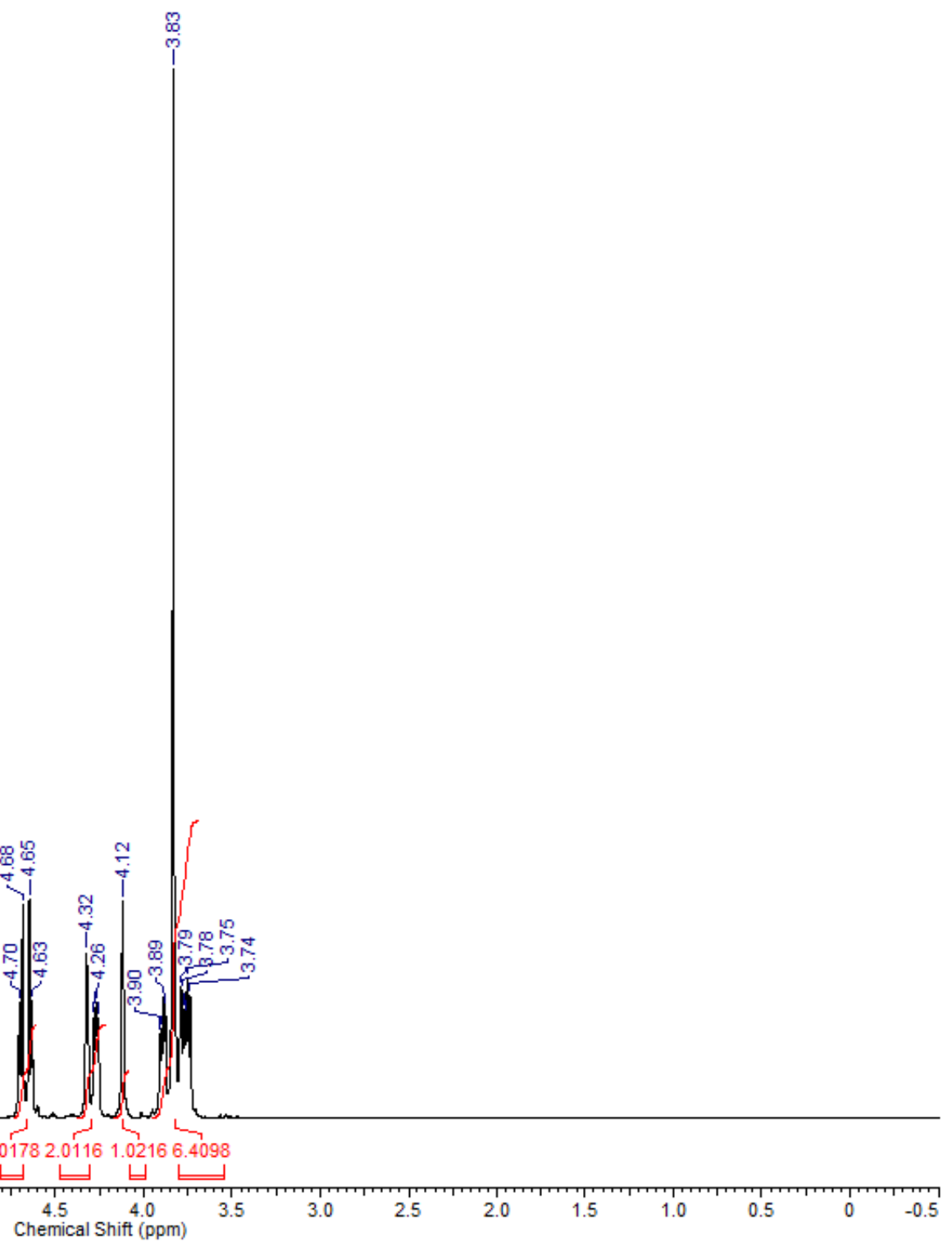


${ }^{13} \mathrm{C}$ NMR spectrum of 6
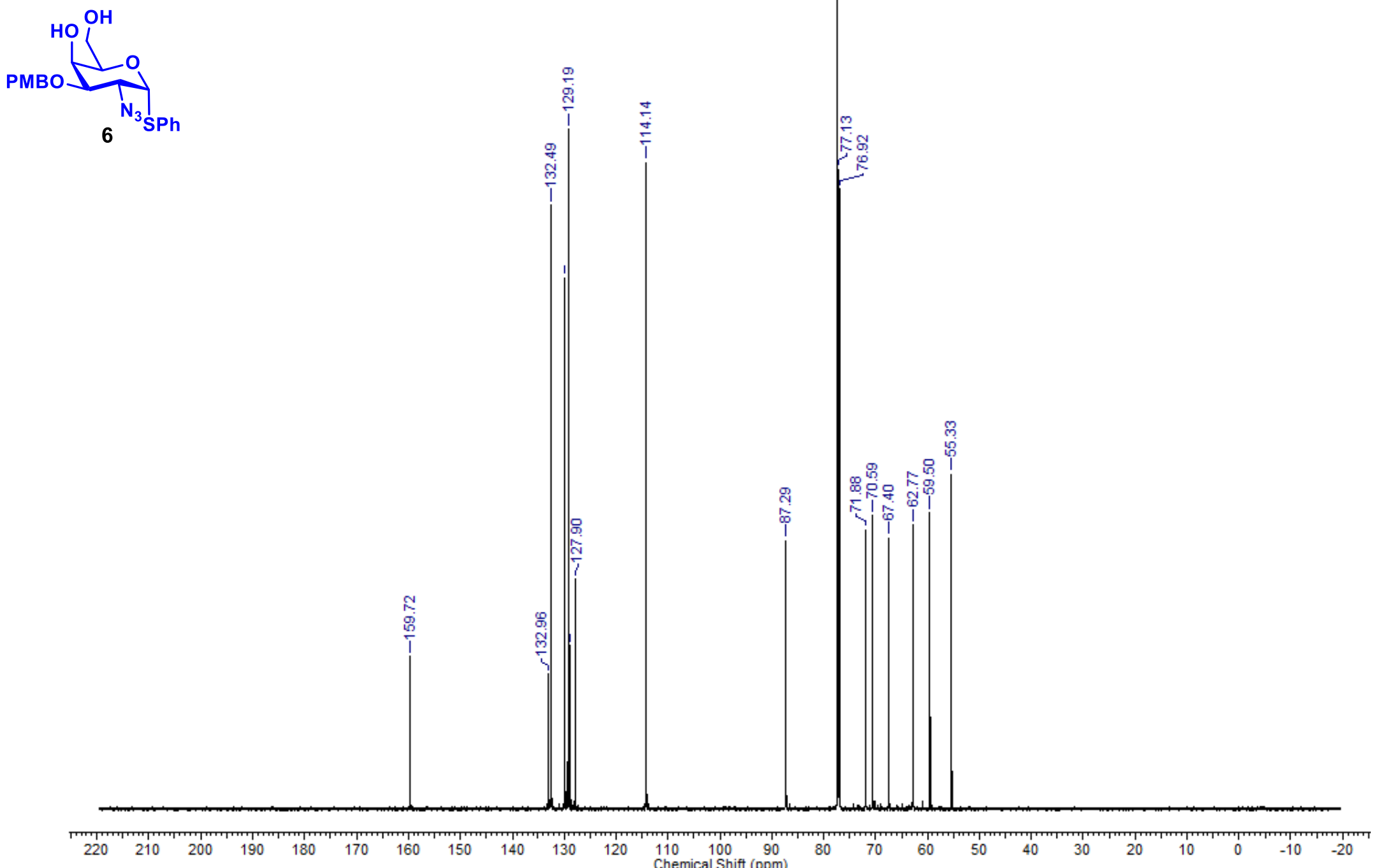
DEPT135 spectrum of 6
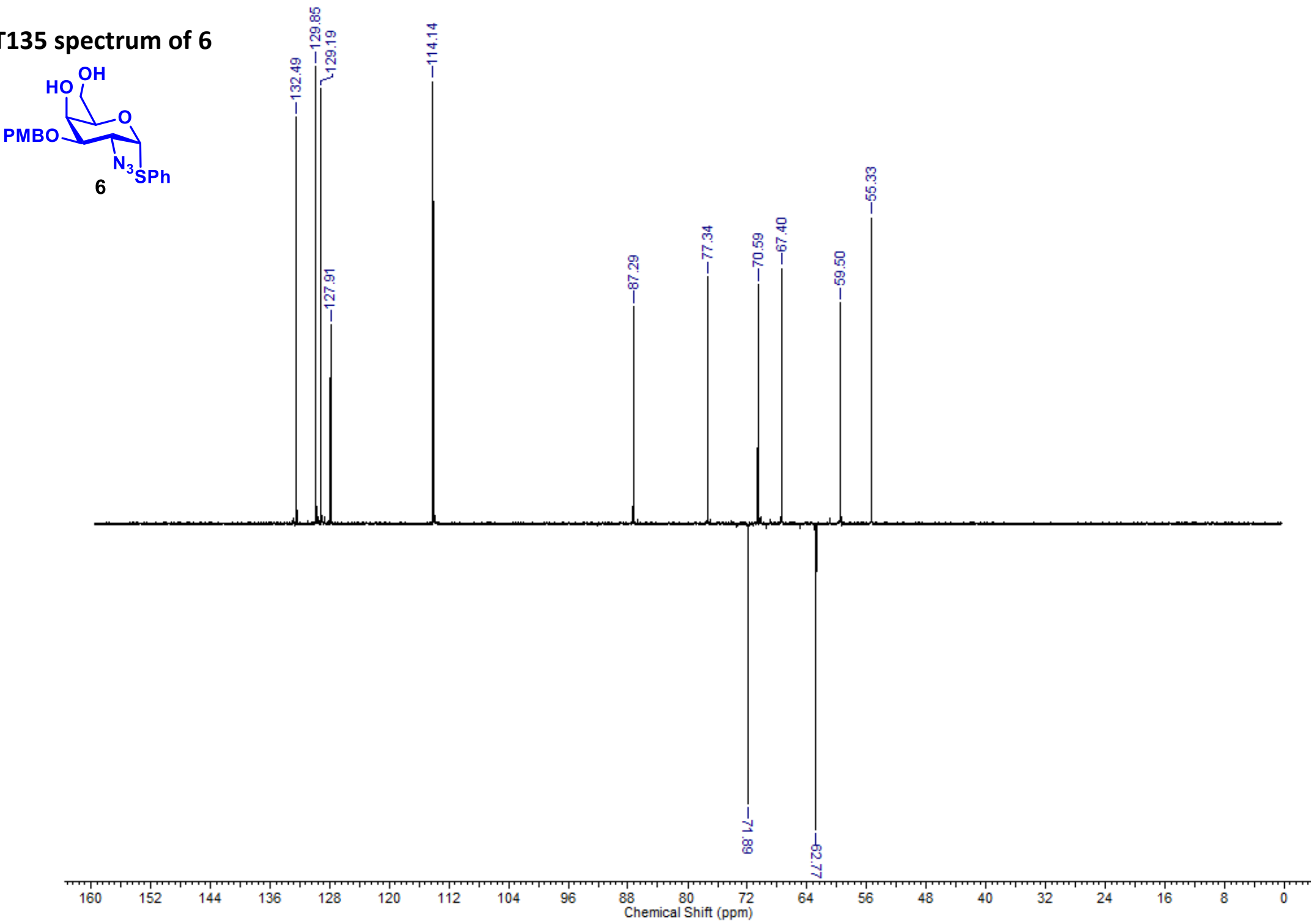

S61 


\section{COSY spectrum of 6}

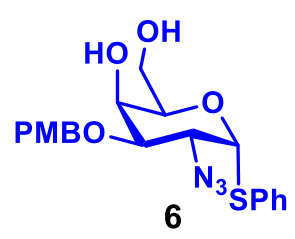

MS-008-crude. $004.001 .2 \pi$.esp

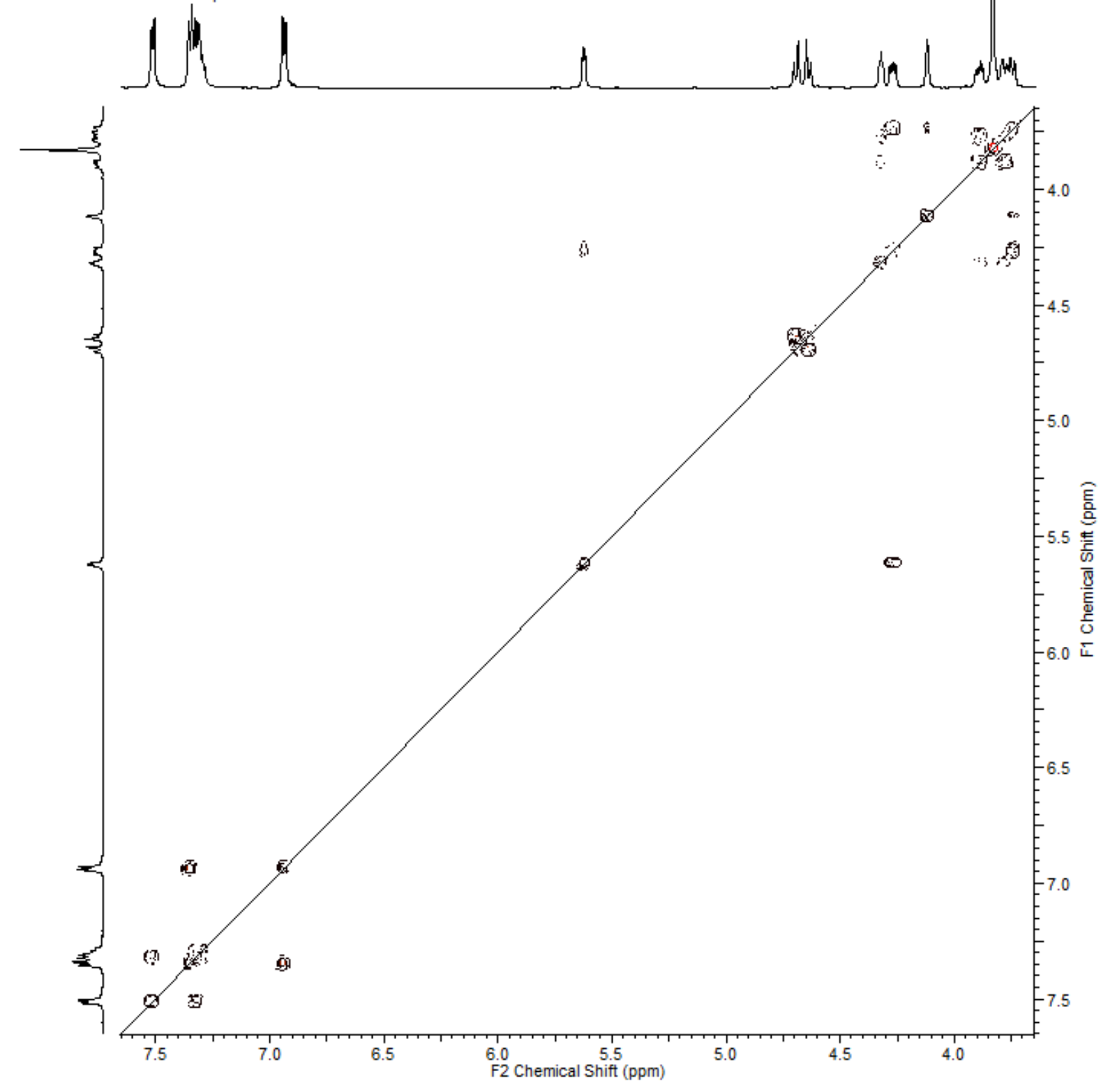


${ }^{1} \mathrm{H}$ NMR spectrum of 10
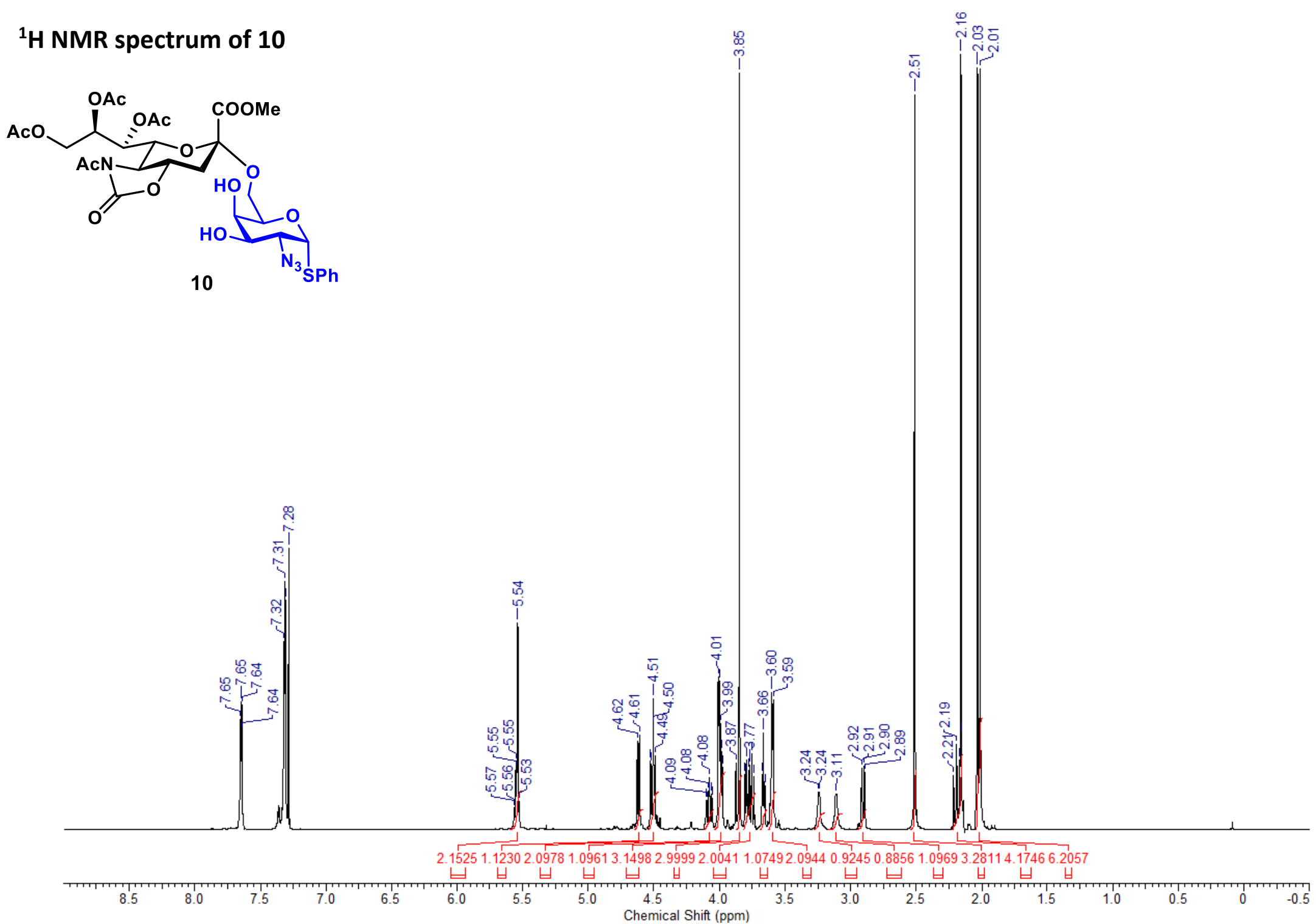


\section{${ }^{13} \mathrm{C}$ NMR spectrum of 10}
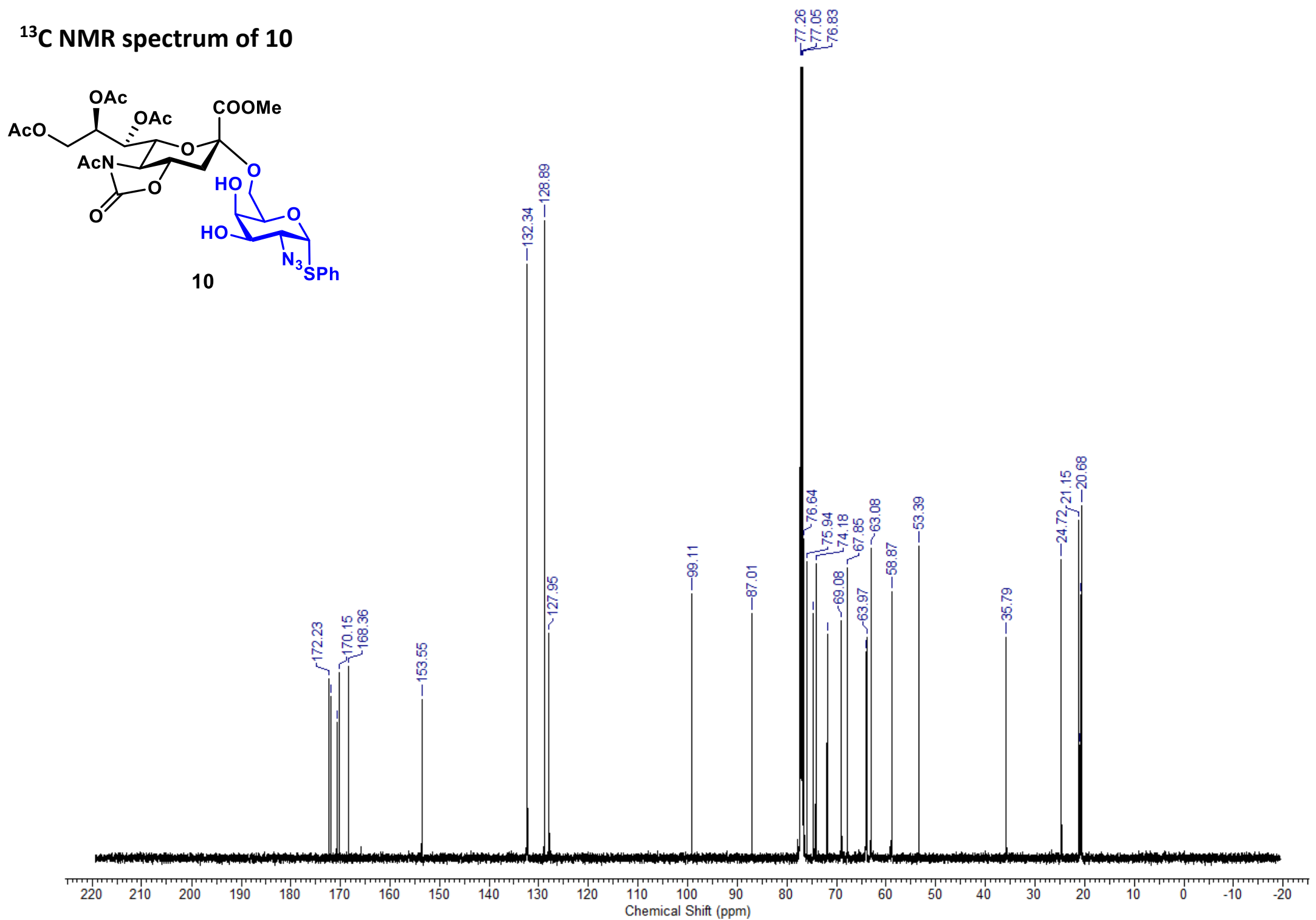


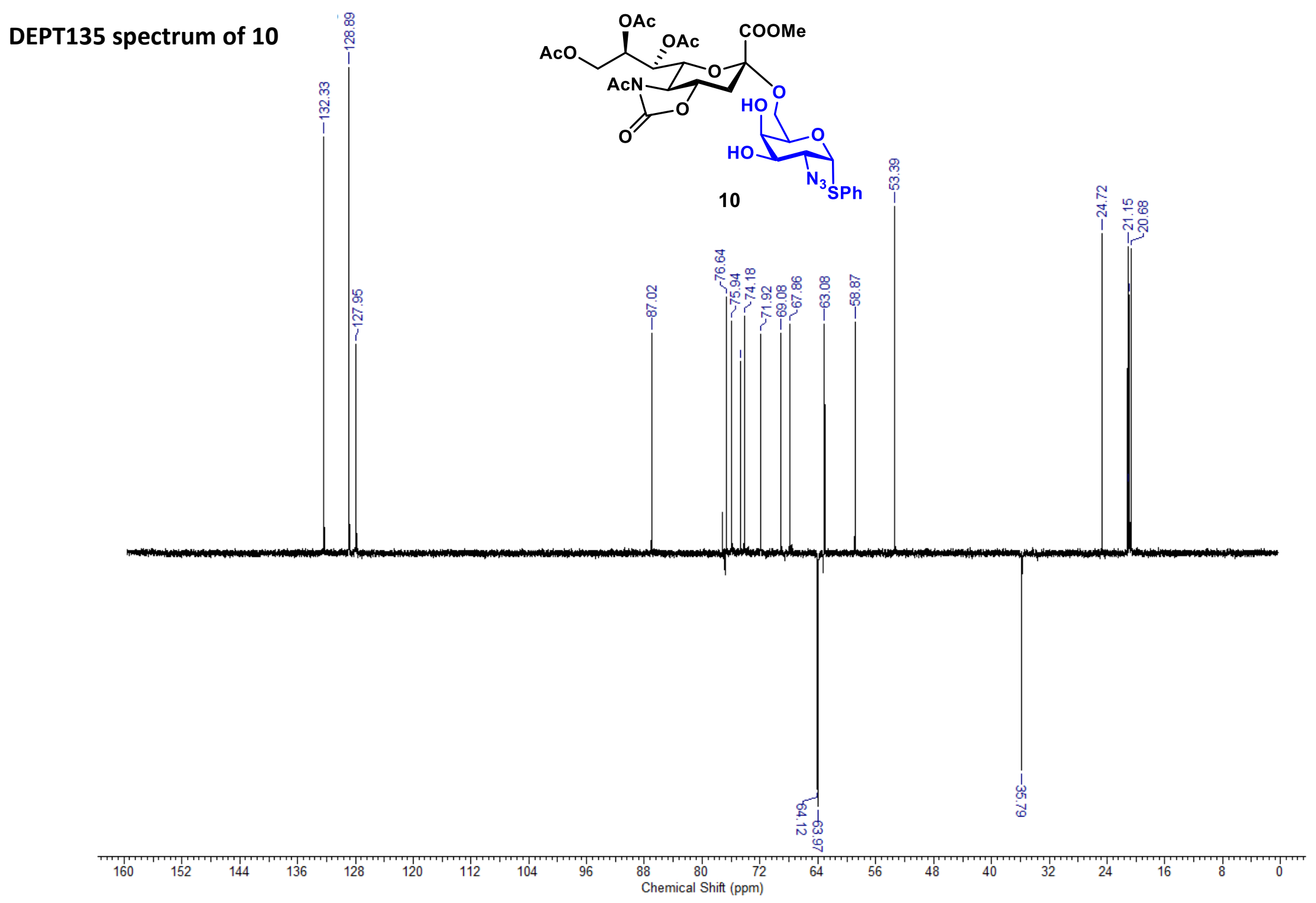




\section{COSY spectrum of 10}

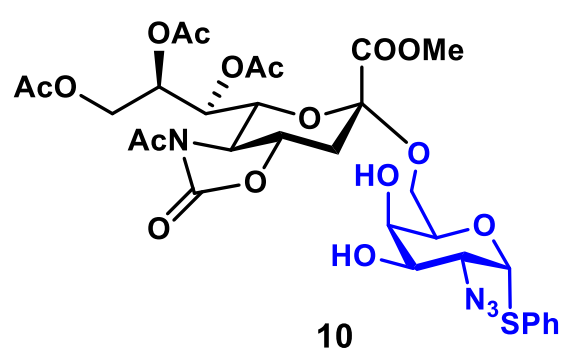

10
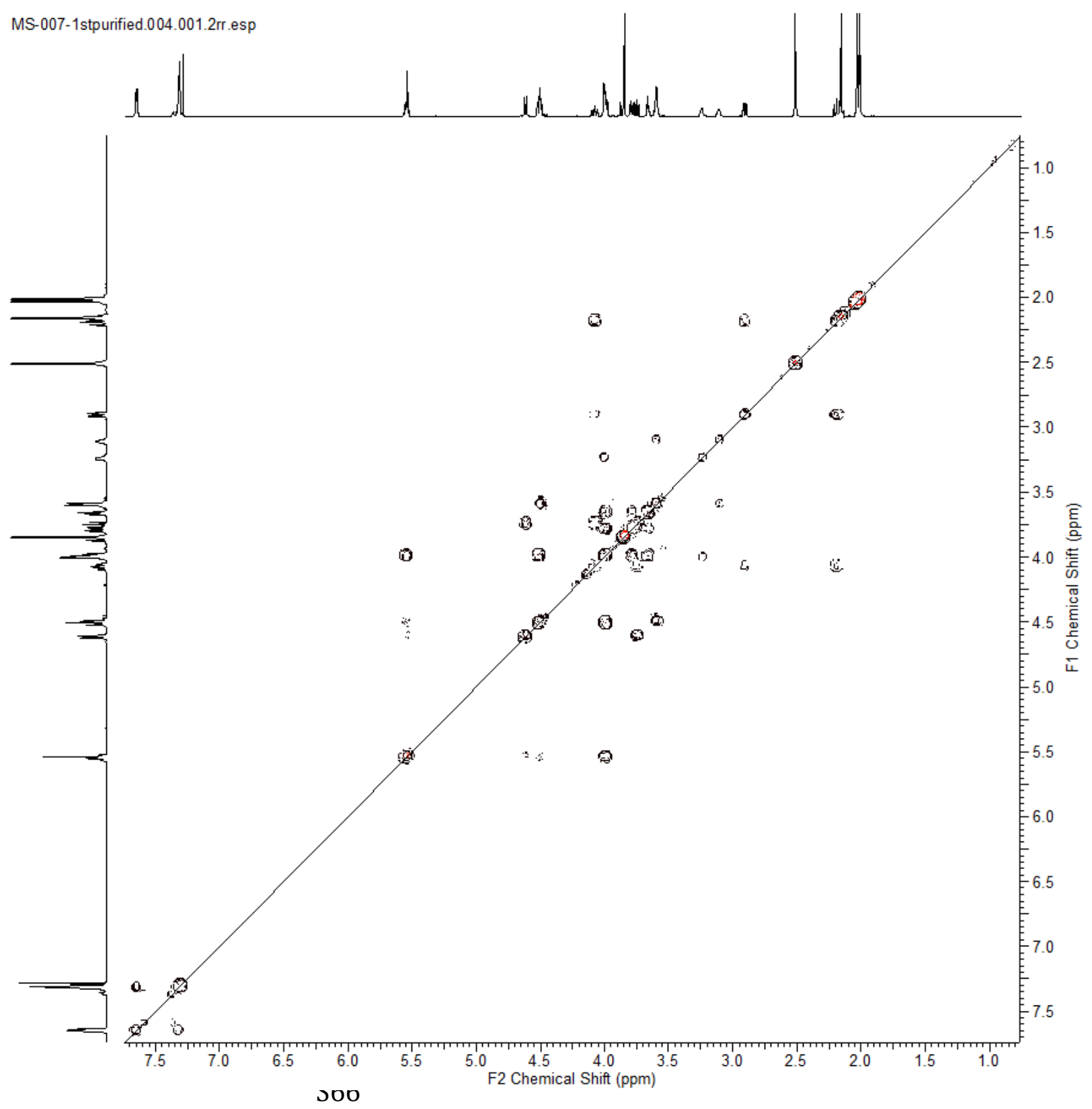


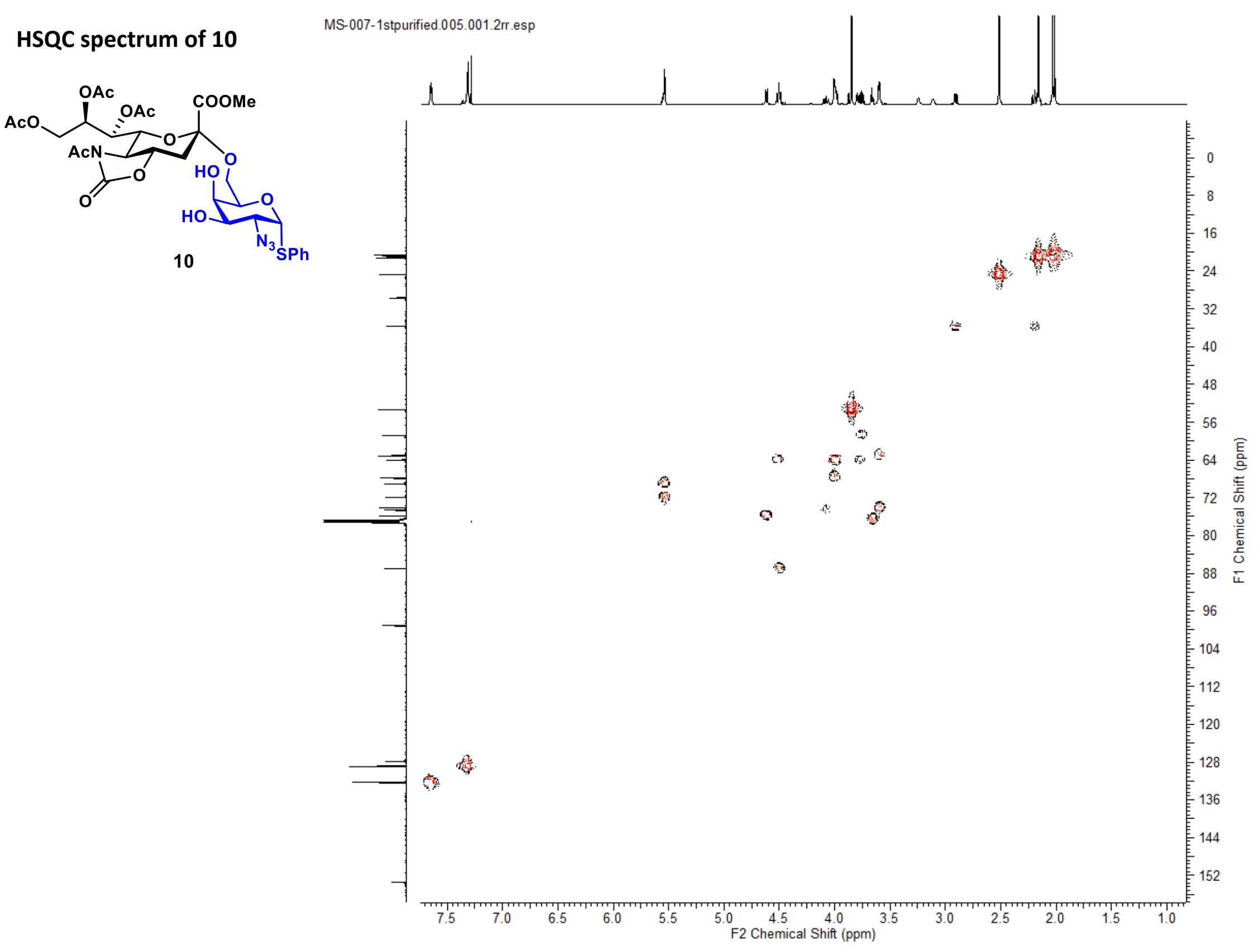




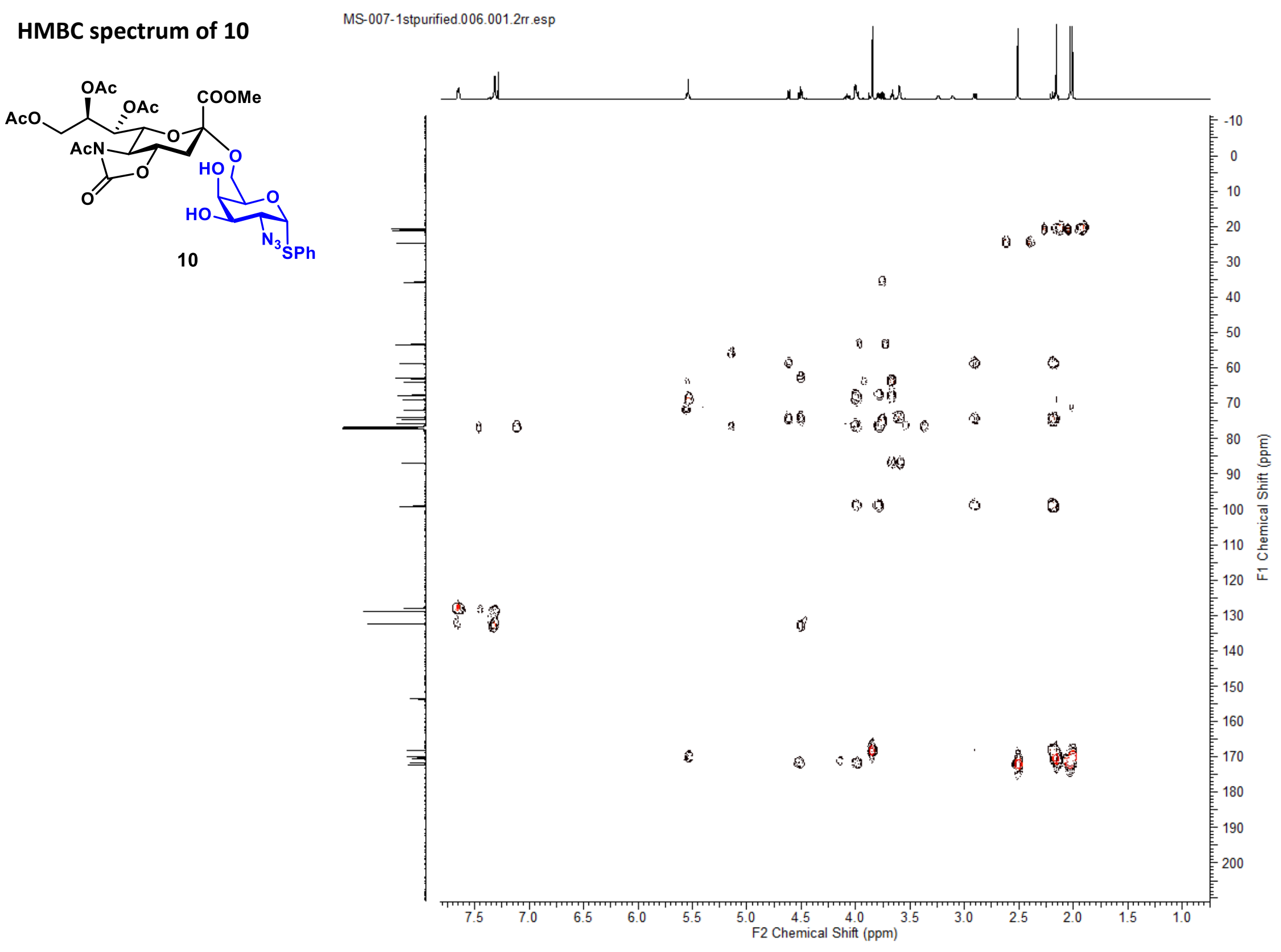


${ }^{1} \mathrm{H}$ NMR spectrum of 7
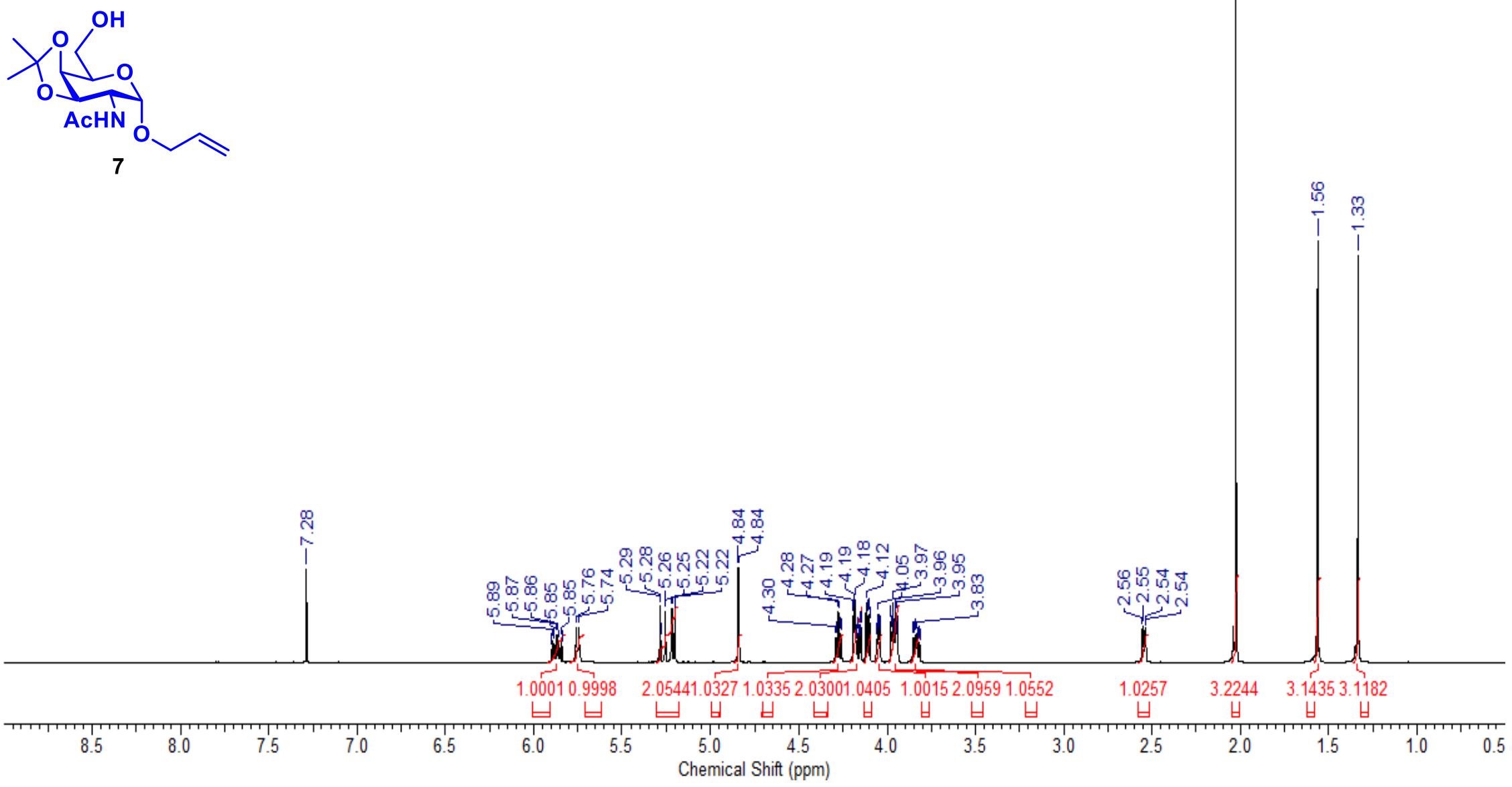
${ }^{13} \mathrm{C}$ NMR spectrum of 7
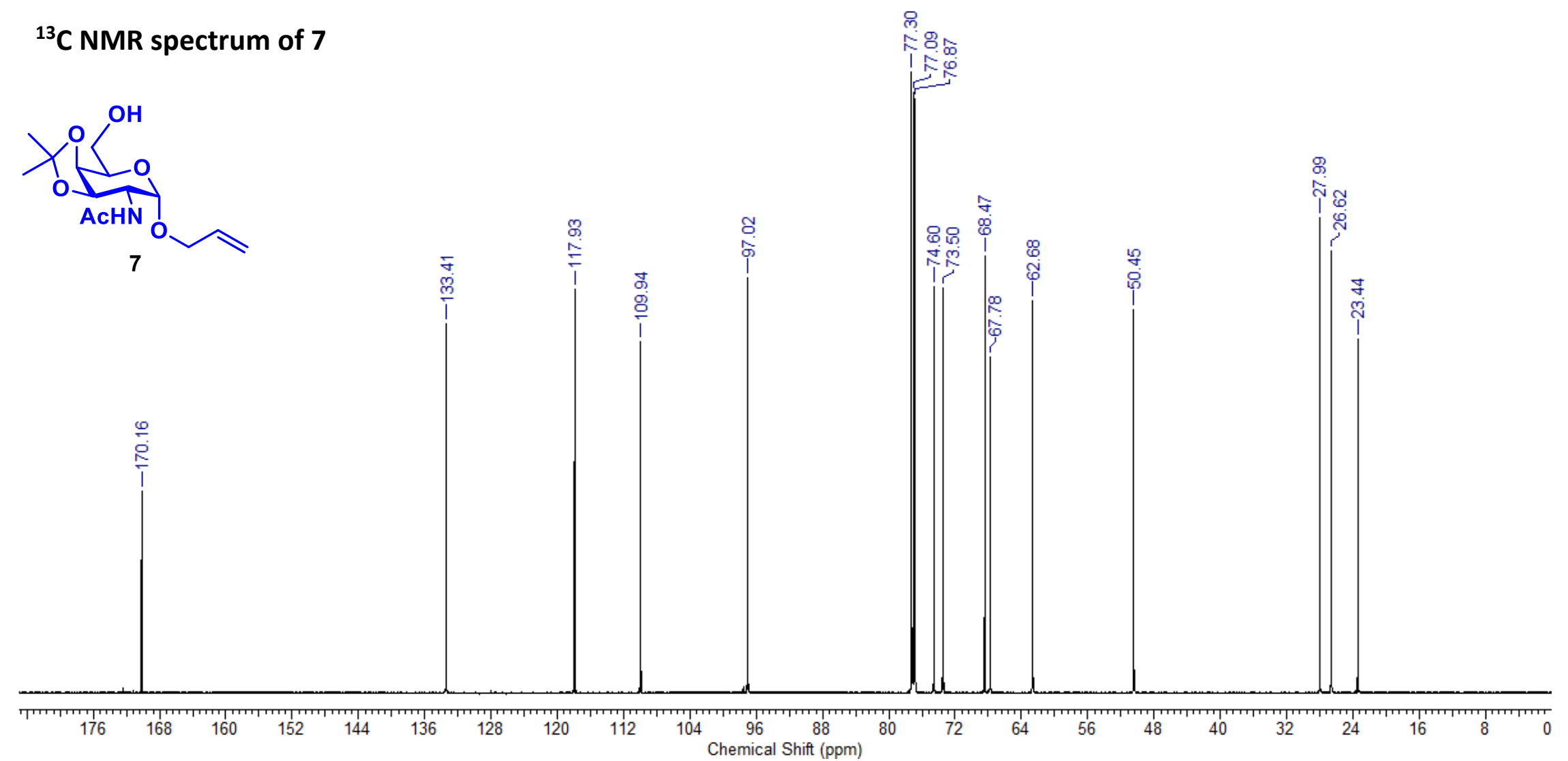


\section{DEPT135 spectrum of 7}

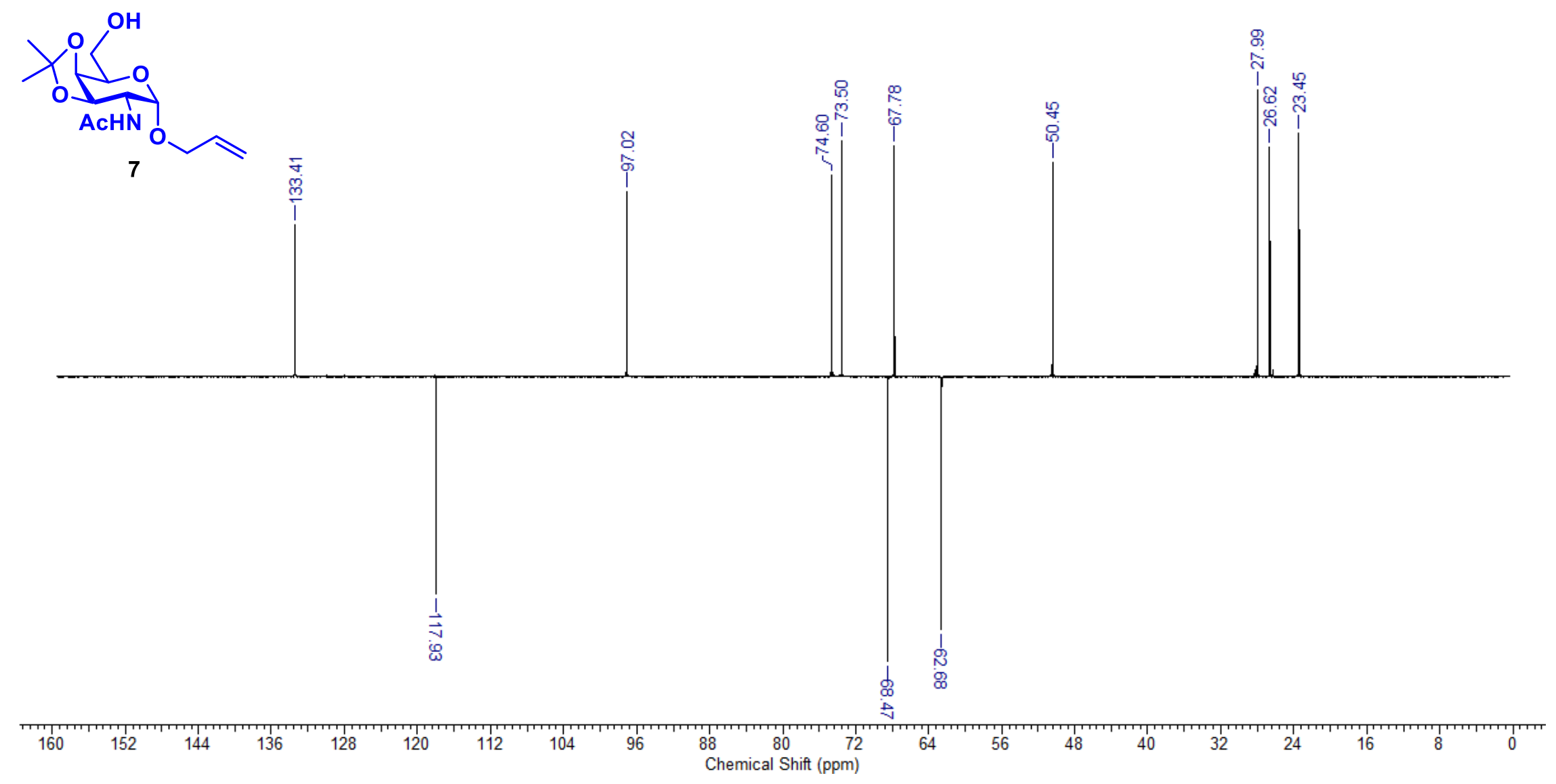




\section{COSY spectrum of 7}

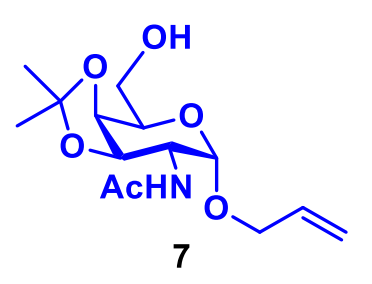

MST-008-purified.005.001.2rr.esp

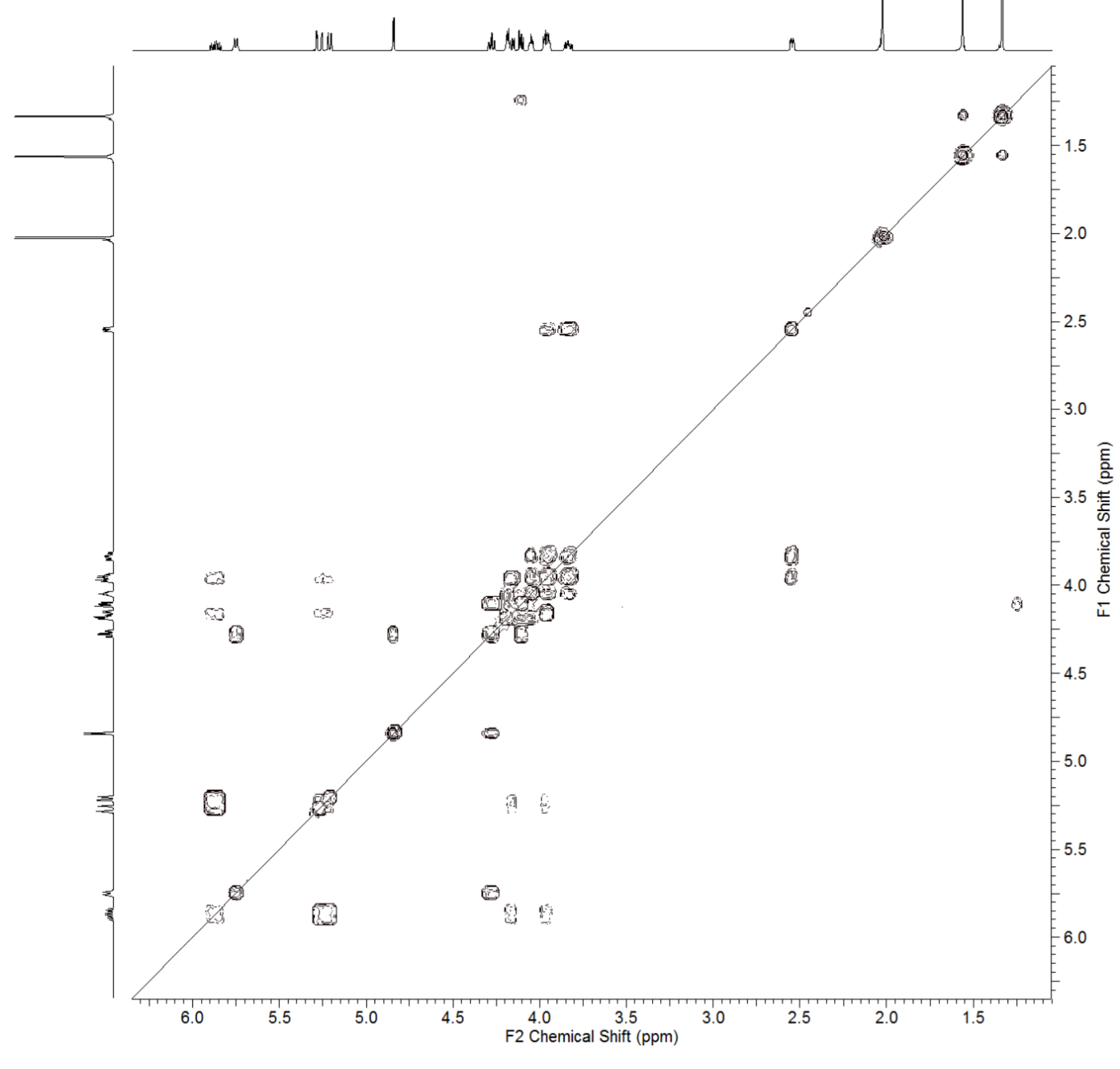


HMBC spectrum of 7

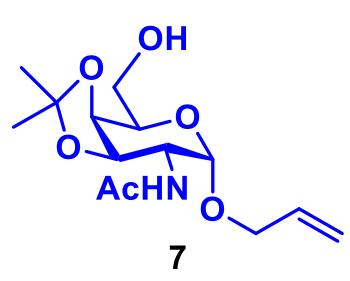

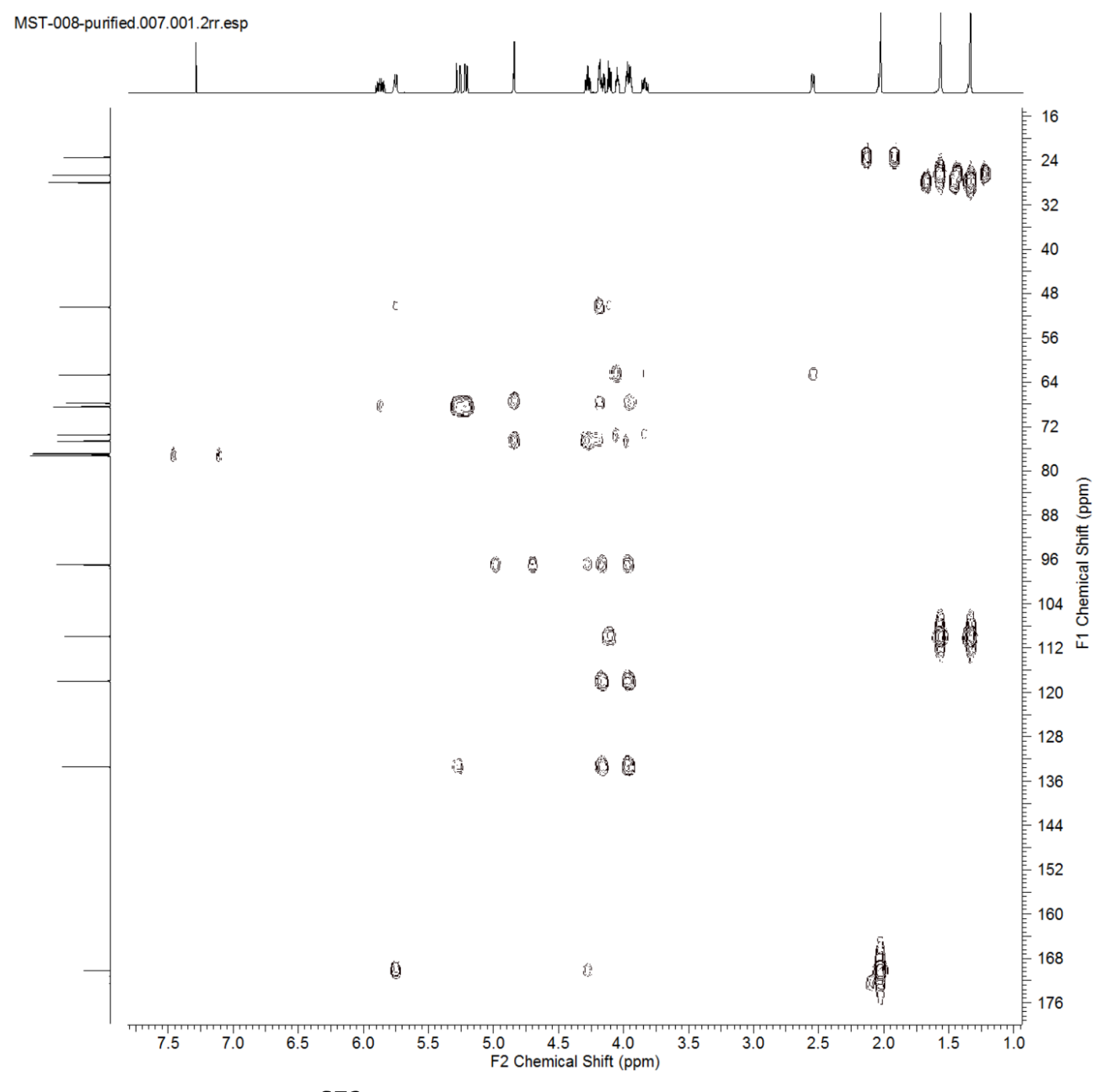




\section{HSQC spectrum of 7}

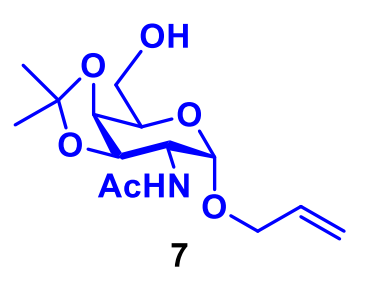

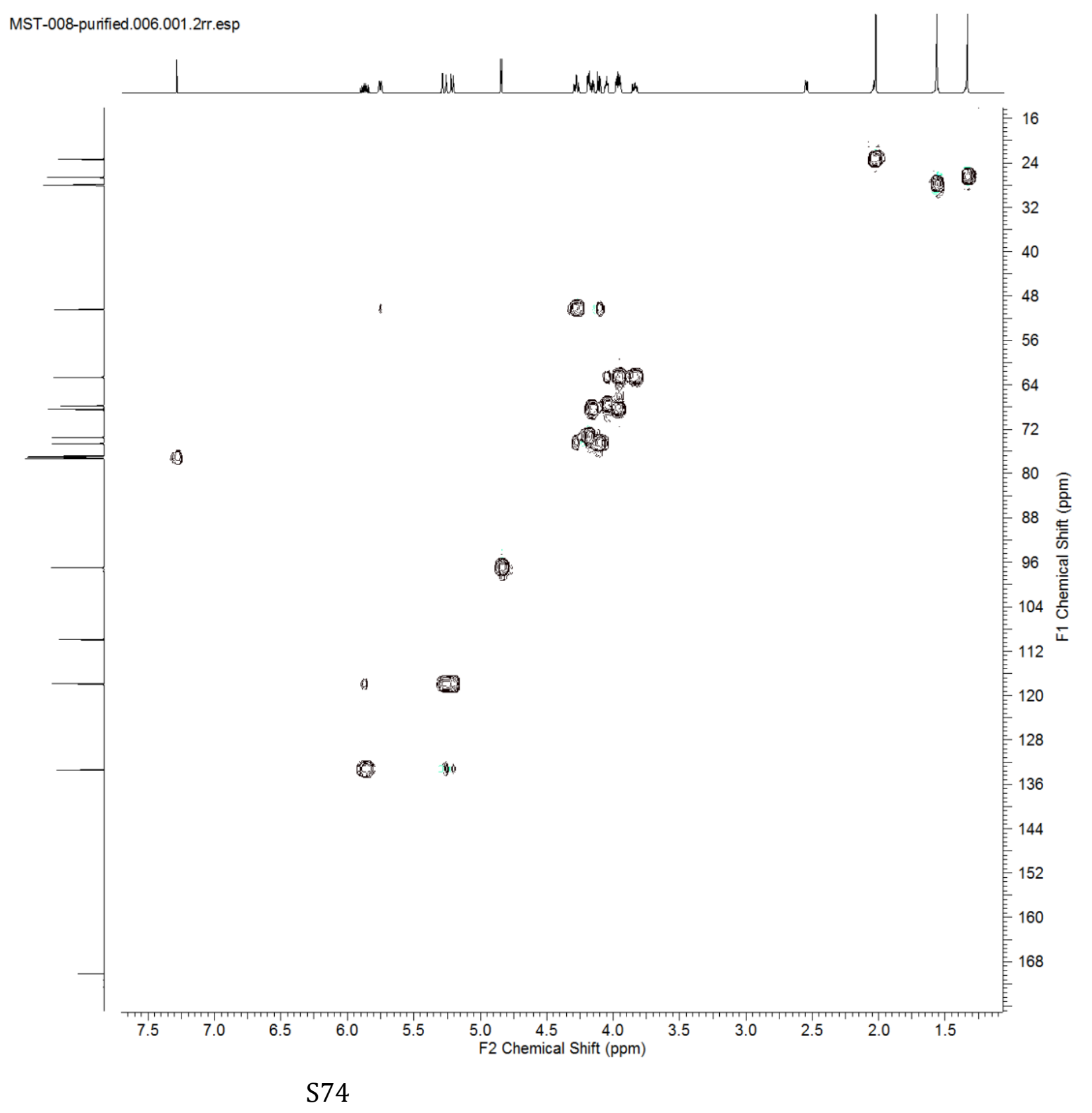


${ }^{1} \mathrm{H}$ NMR spectrum of 11

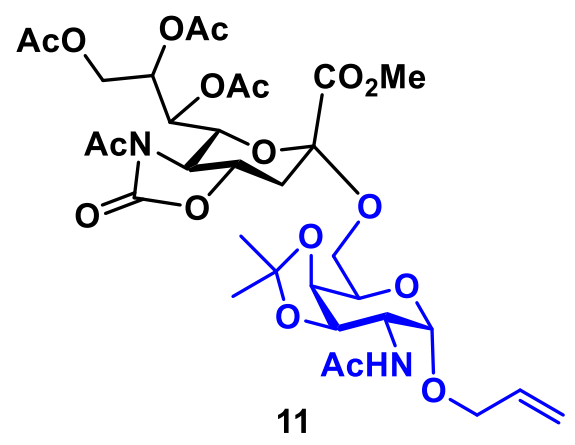

11

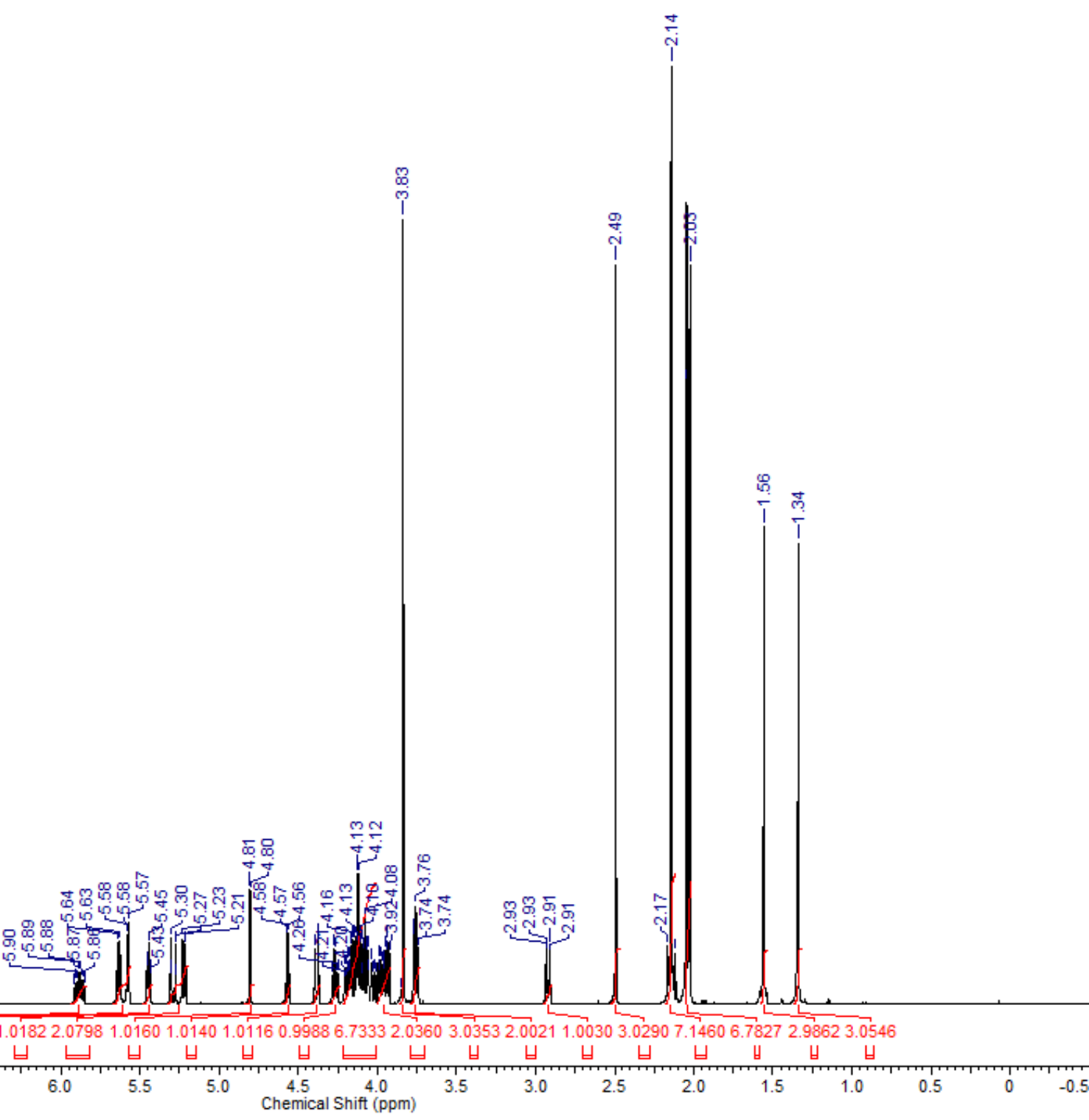


${ }^{13} \mathrm{C}$ NMR spectrum of 11

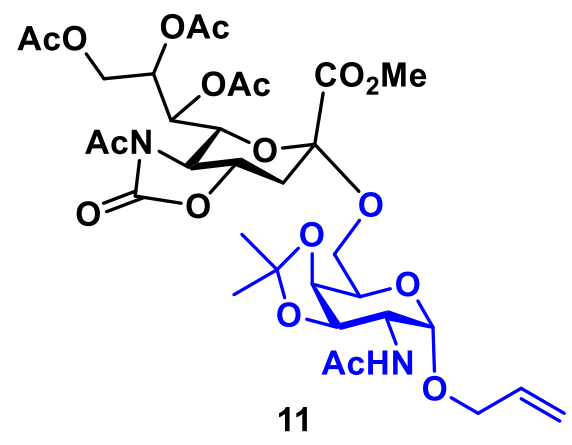

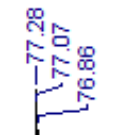

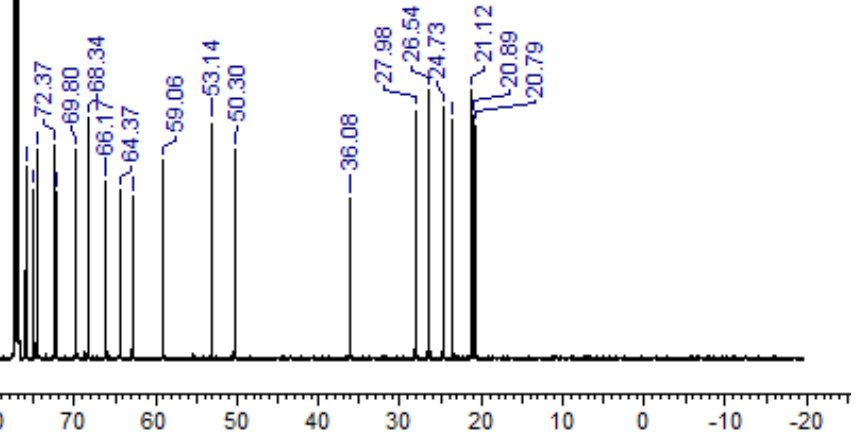

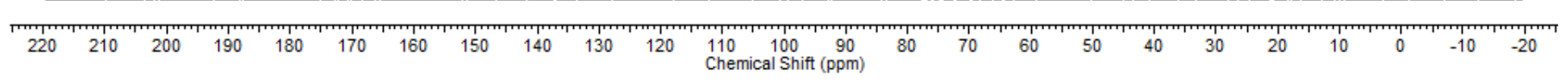

S76 


\section{DEPT135 spectrum of 11}

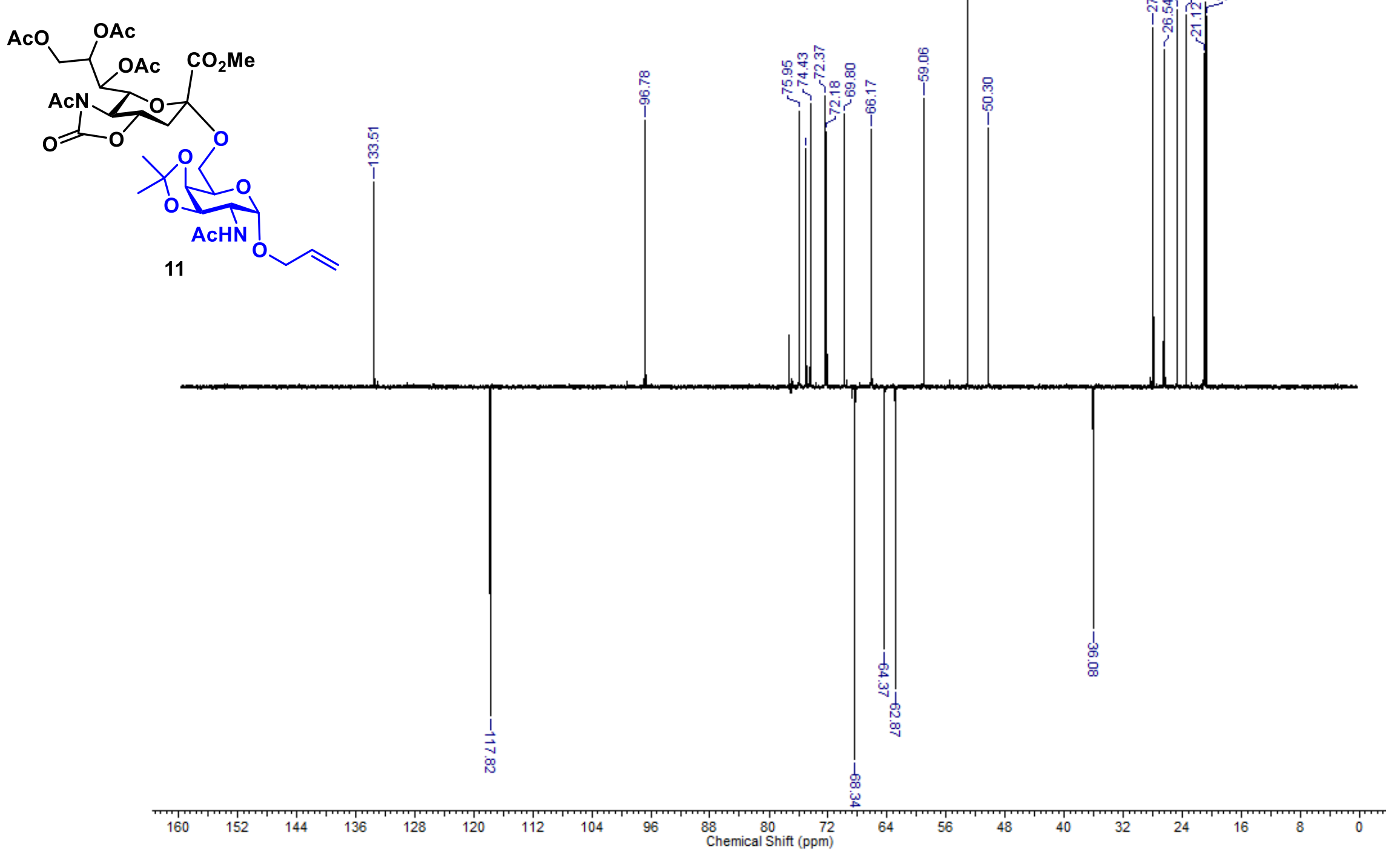




\section{COSY spectrum of 11}

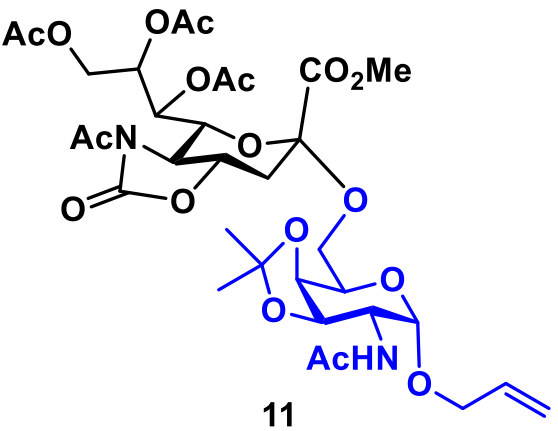

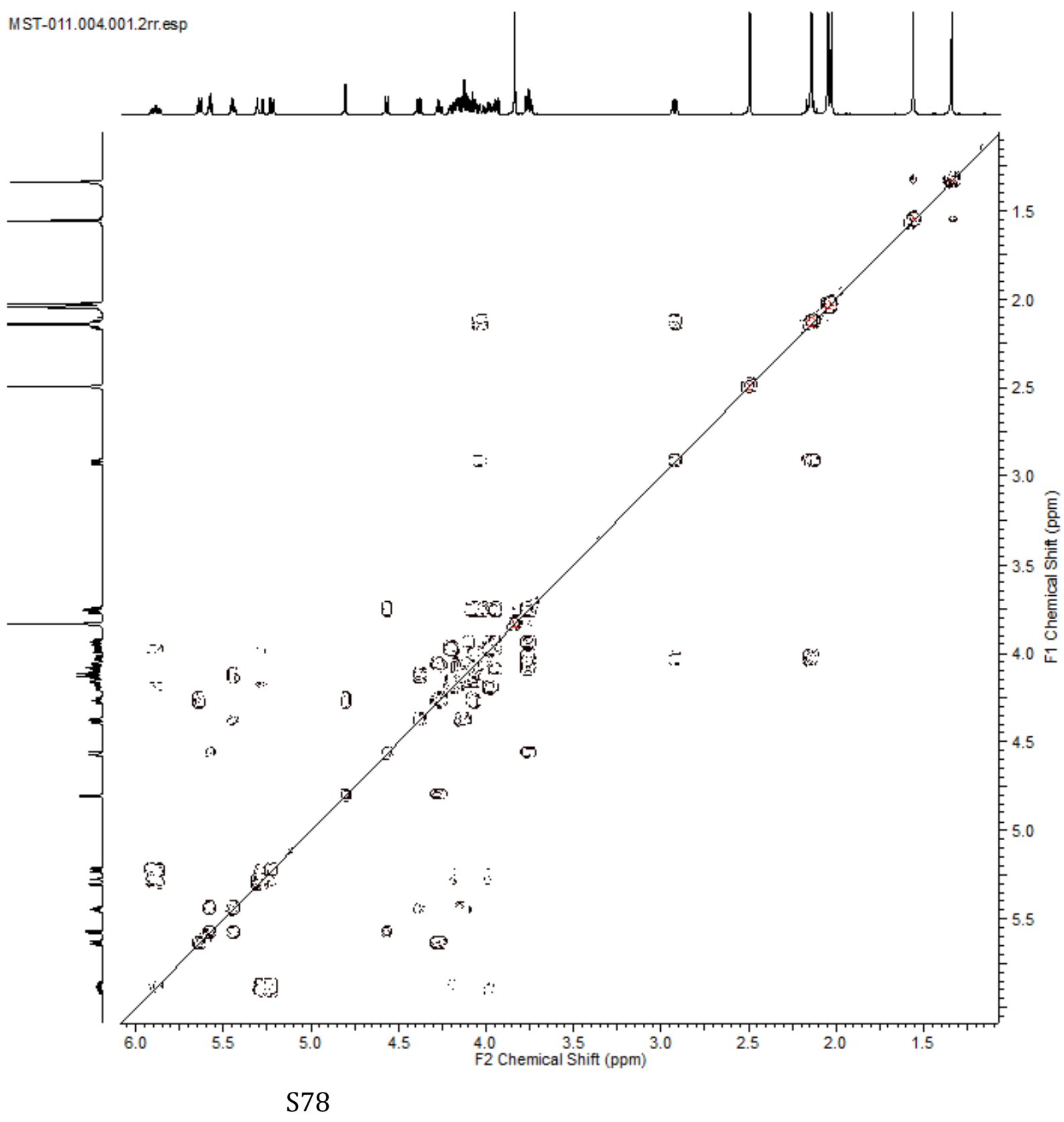


HMBC spectrum of 11

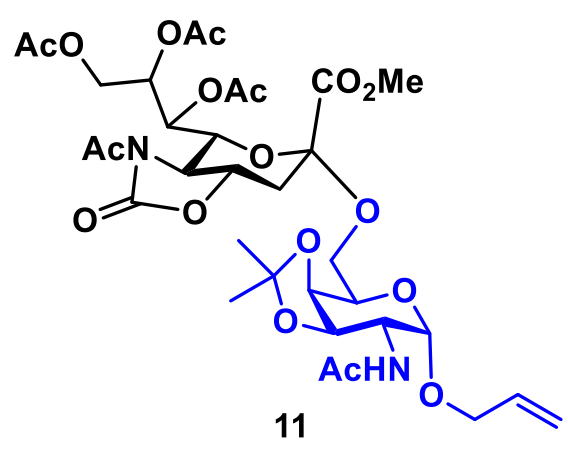

MST-011.008.001.2rr.esp

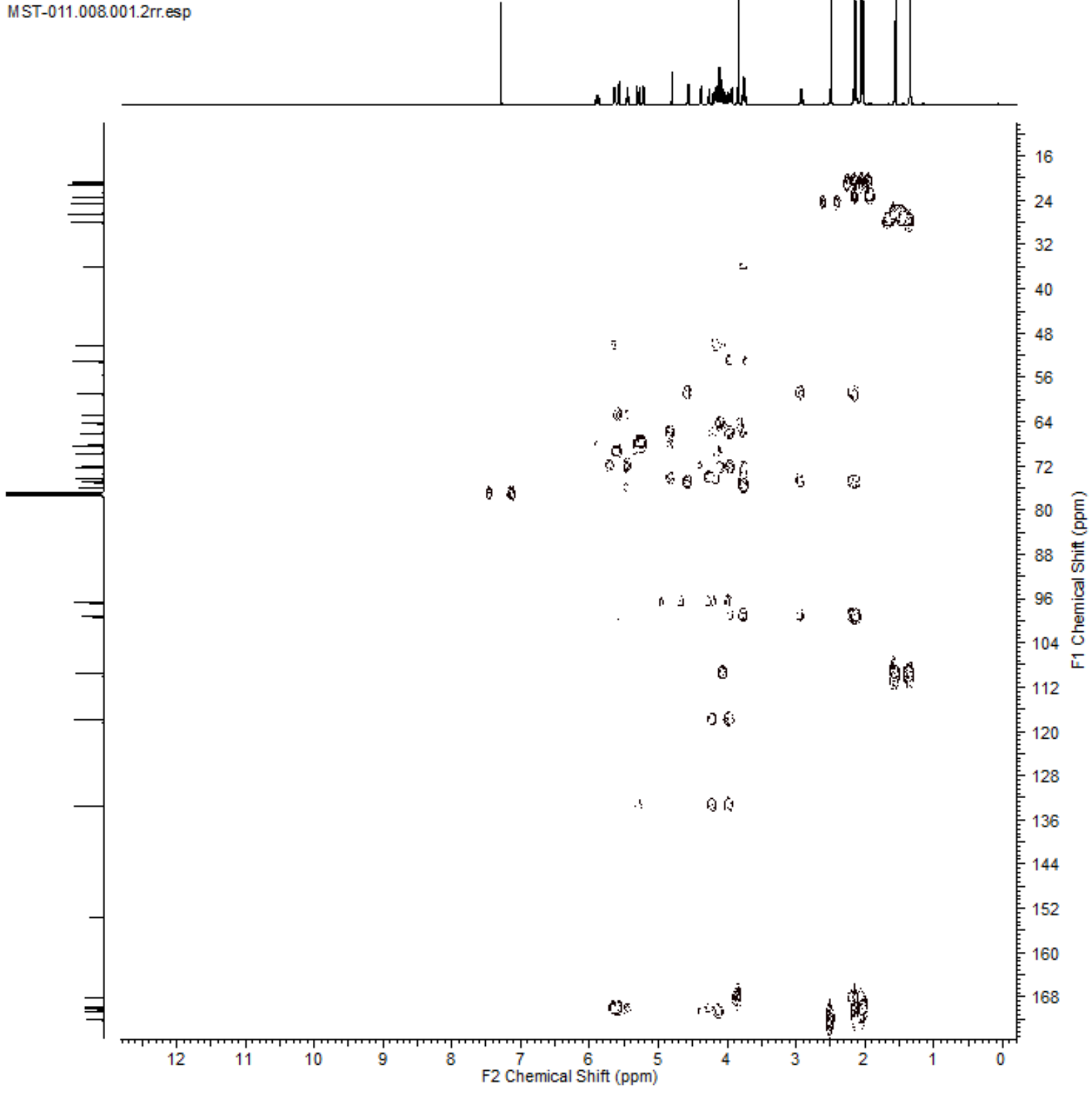




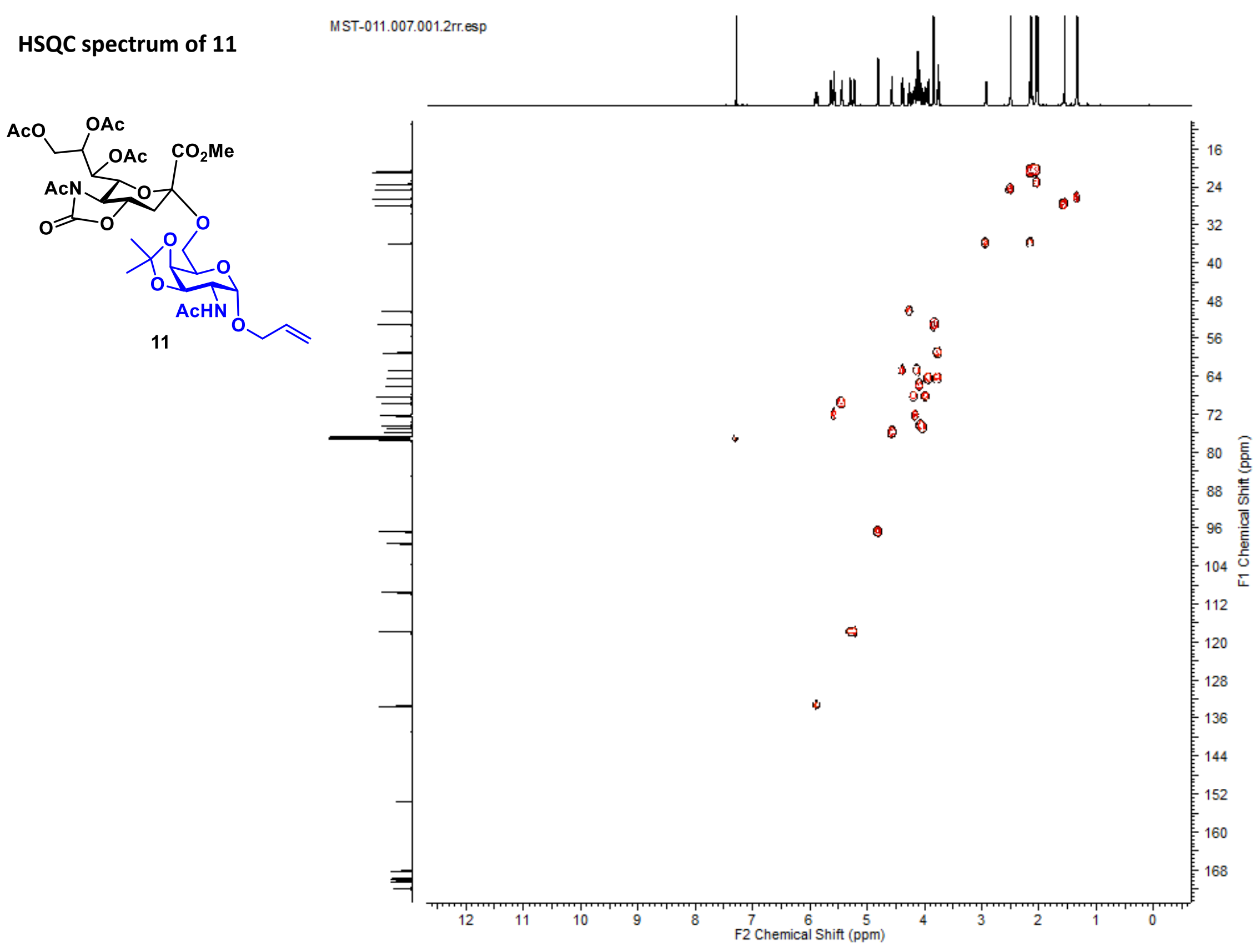


${ }^{1} \mathrm{H}$ NMR spectrum of 12

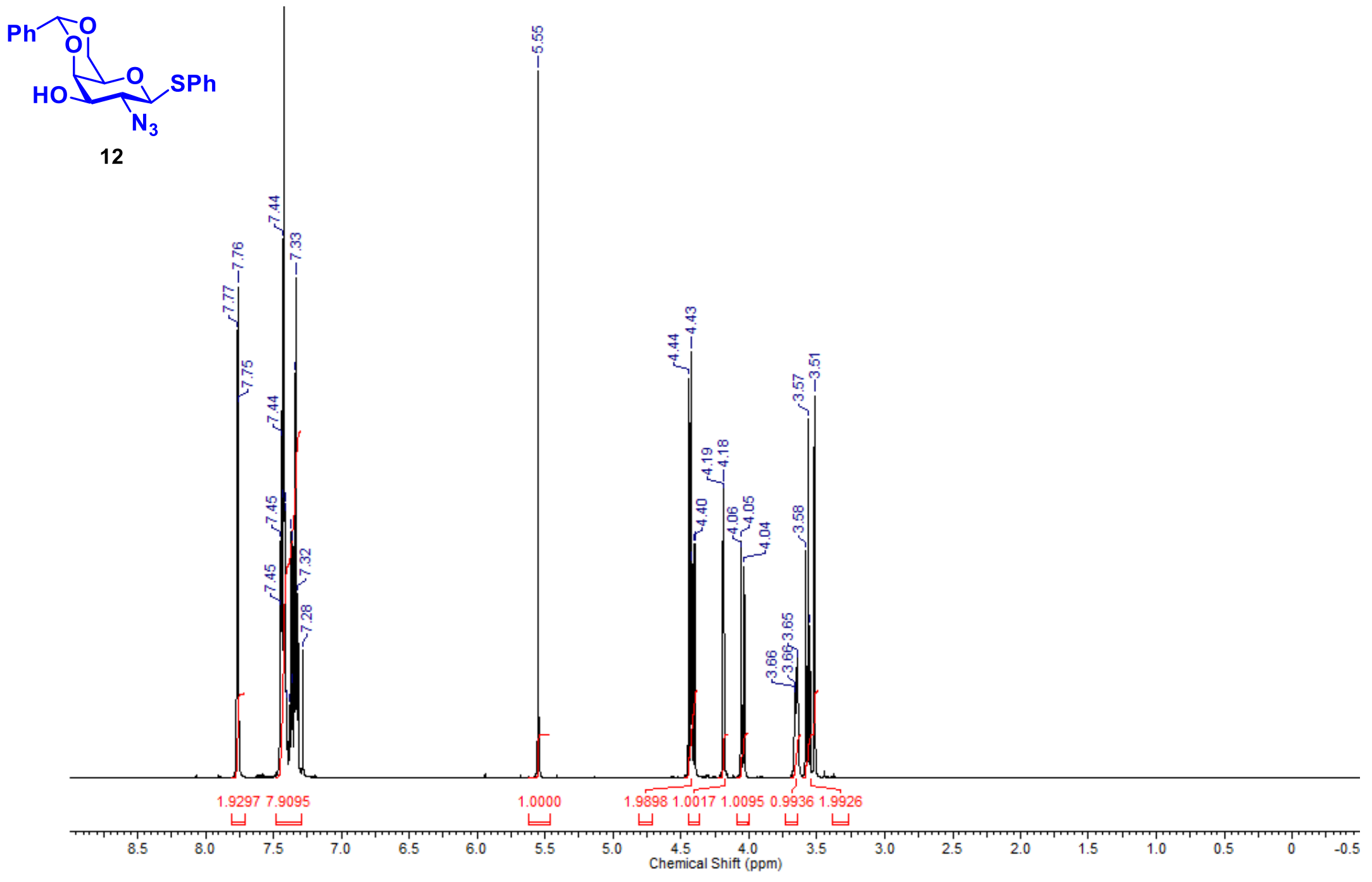


${ }^{13} \mathrm{C}$ NMR spectrum of 12

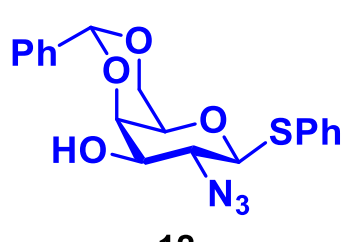

12

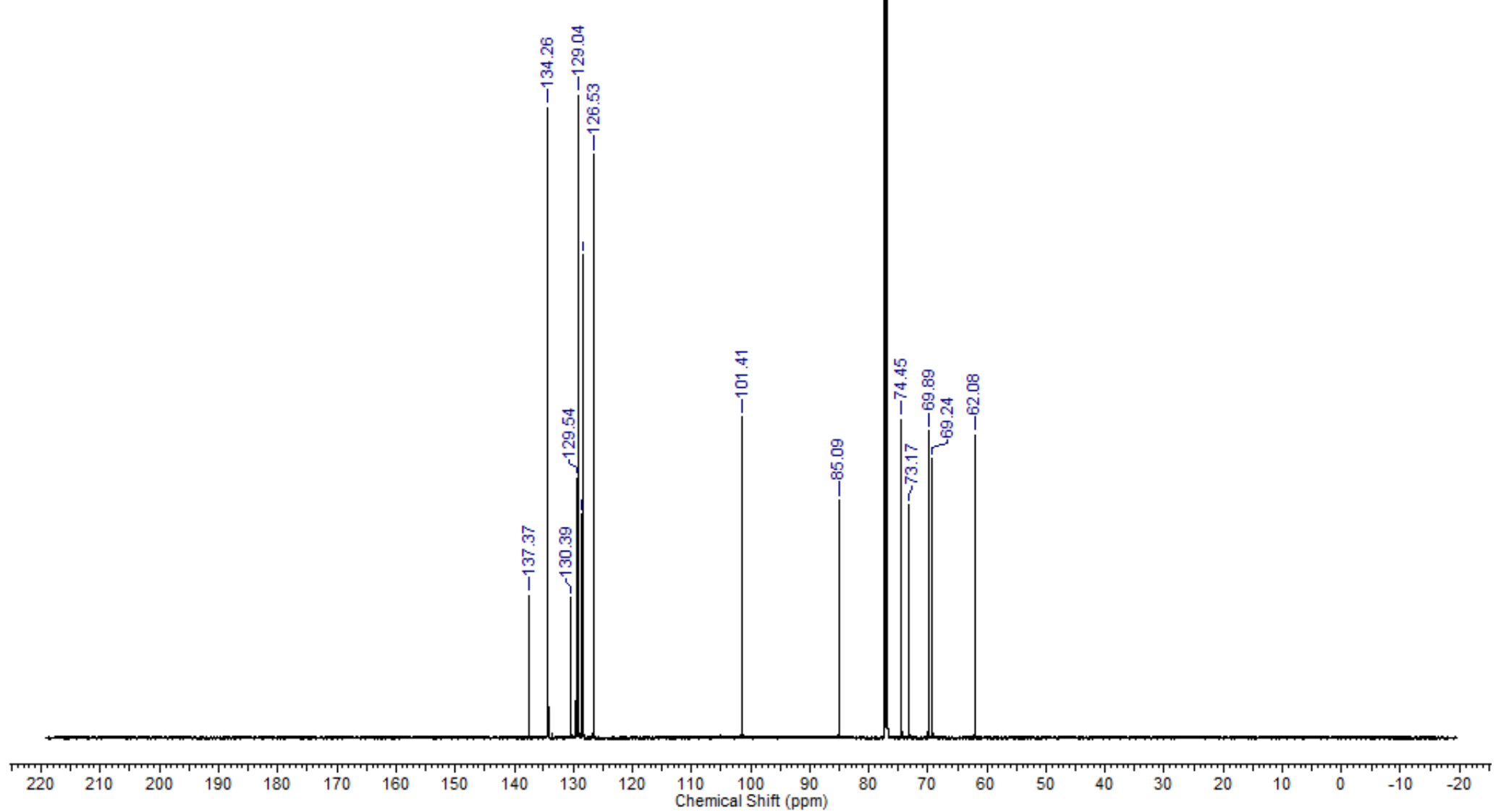




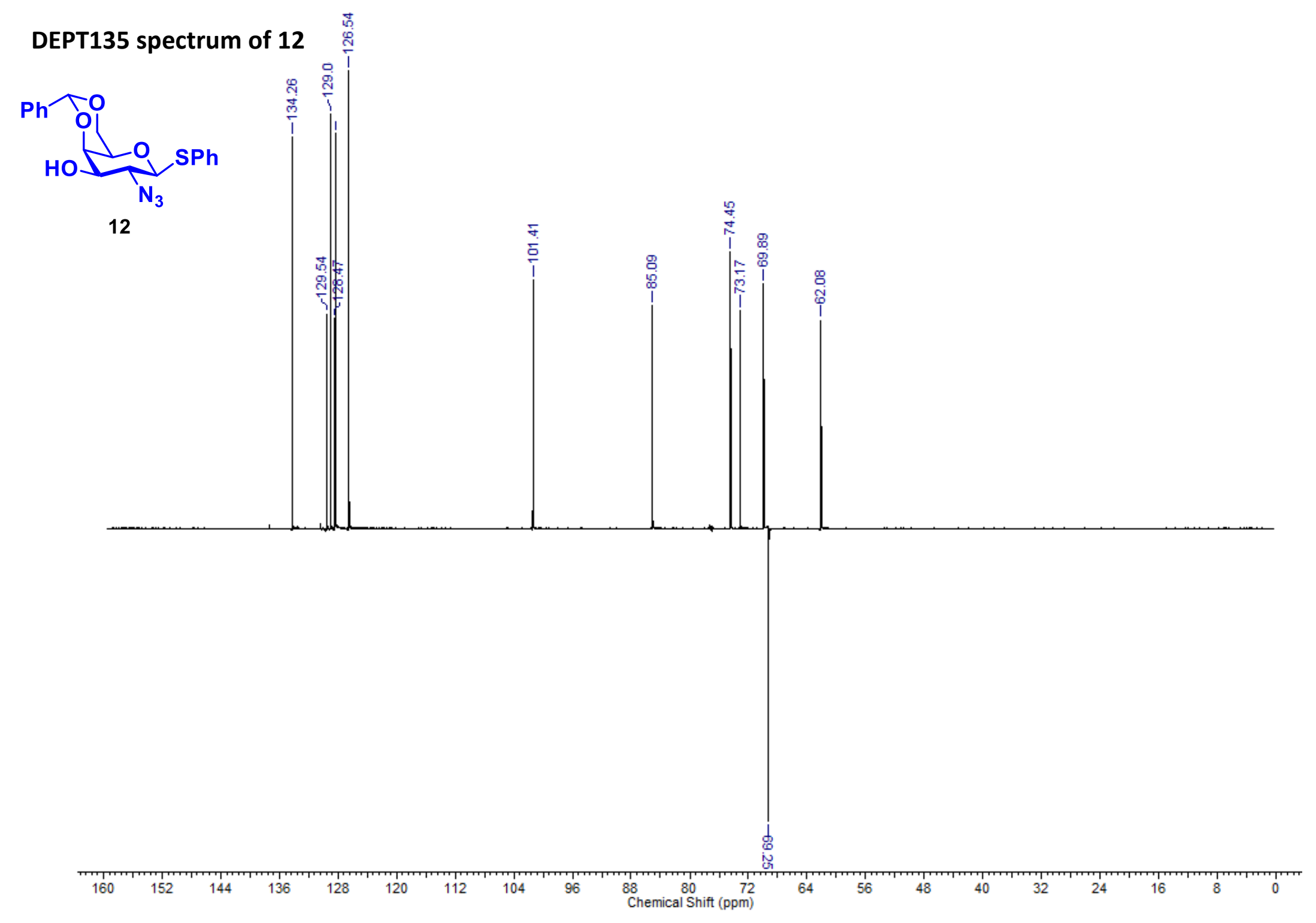




\section{COSY spectrum of 12}

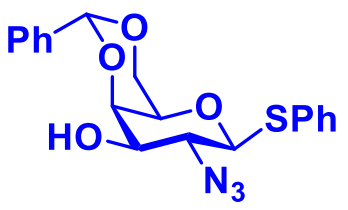

12

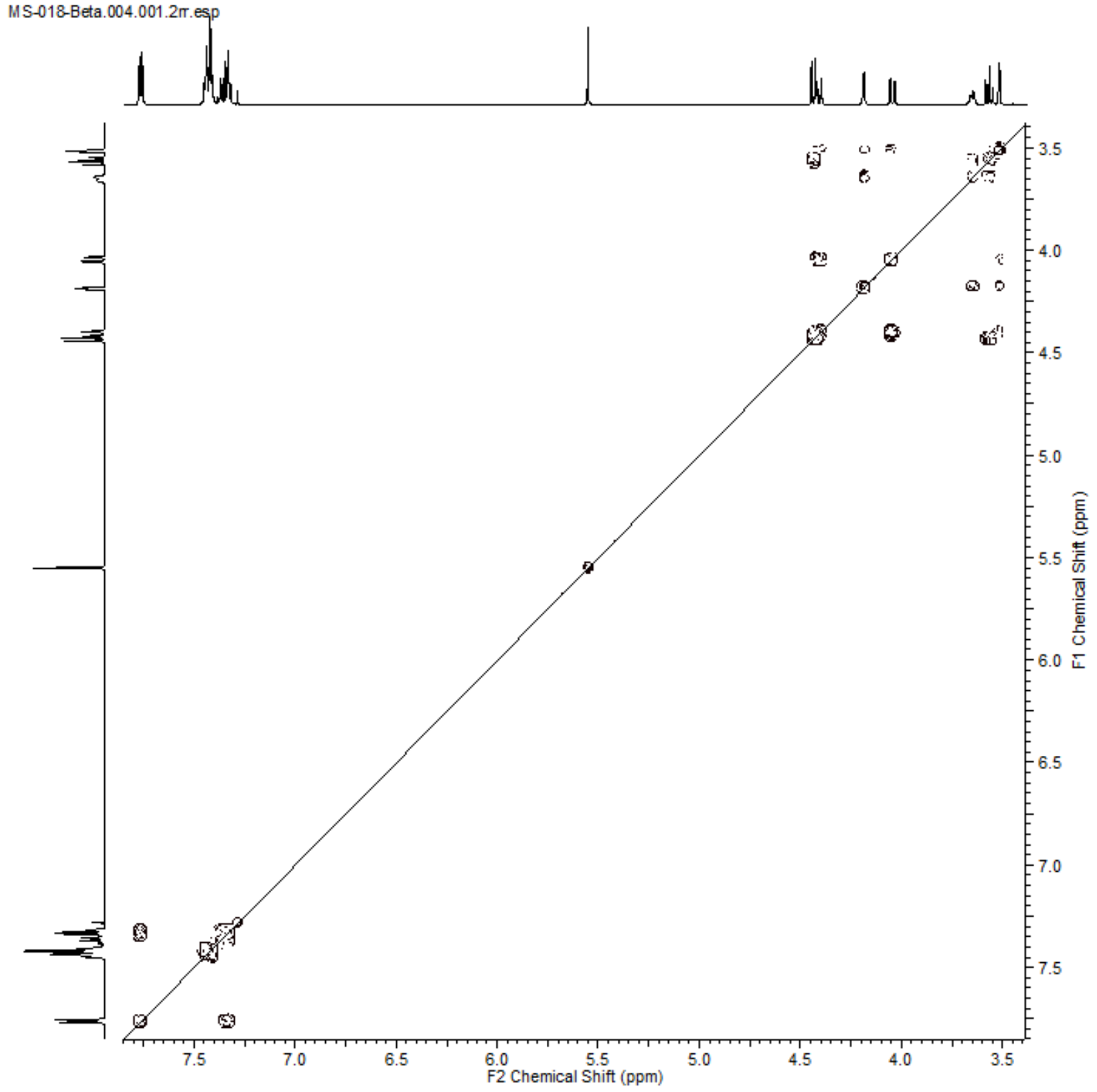

S84 
HMBC spectrum of 12

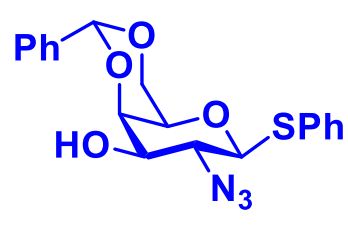

12

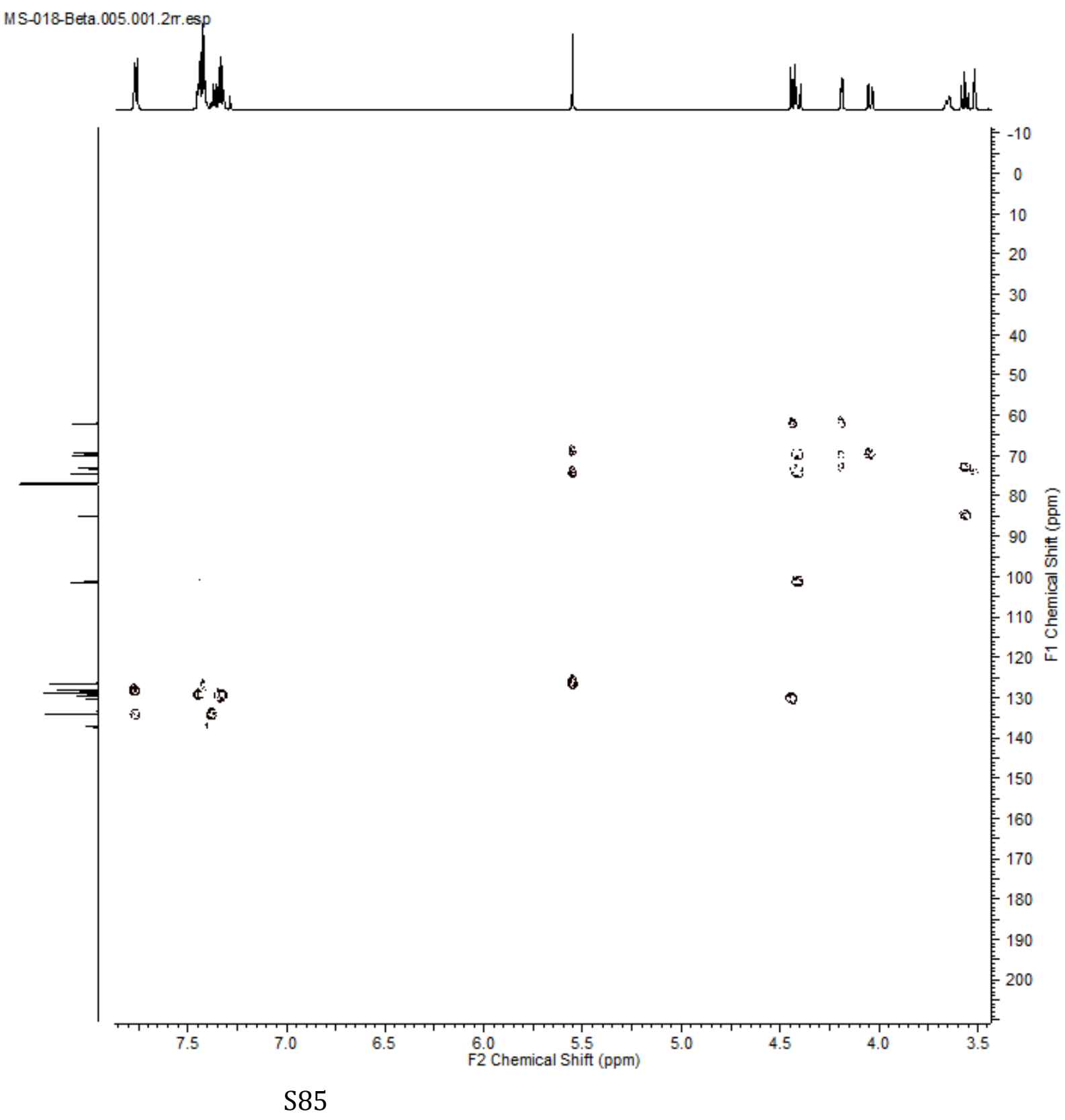




\section{${ }^{1} \mathrm{H}$ NMR spectrum of $\mathbf{2}$}
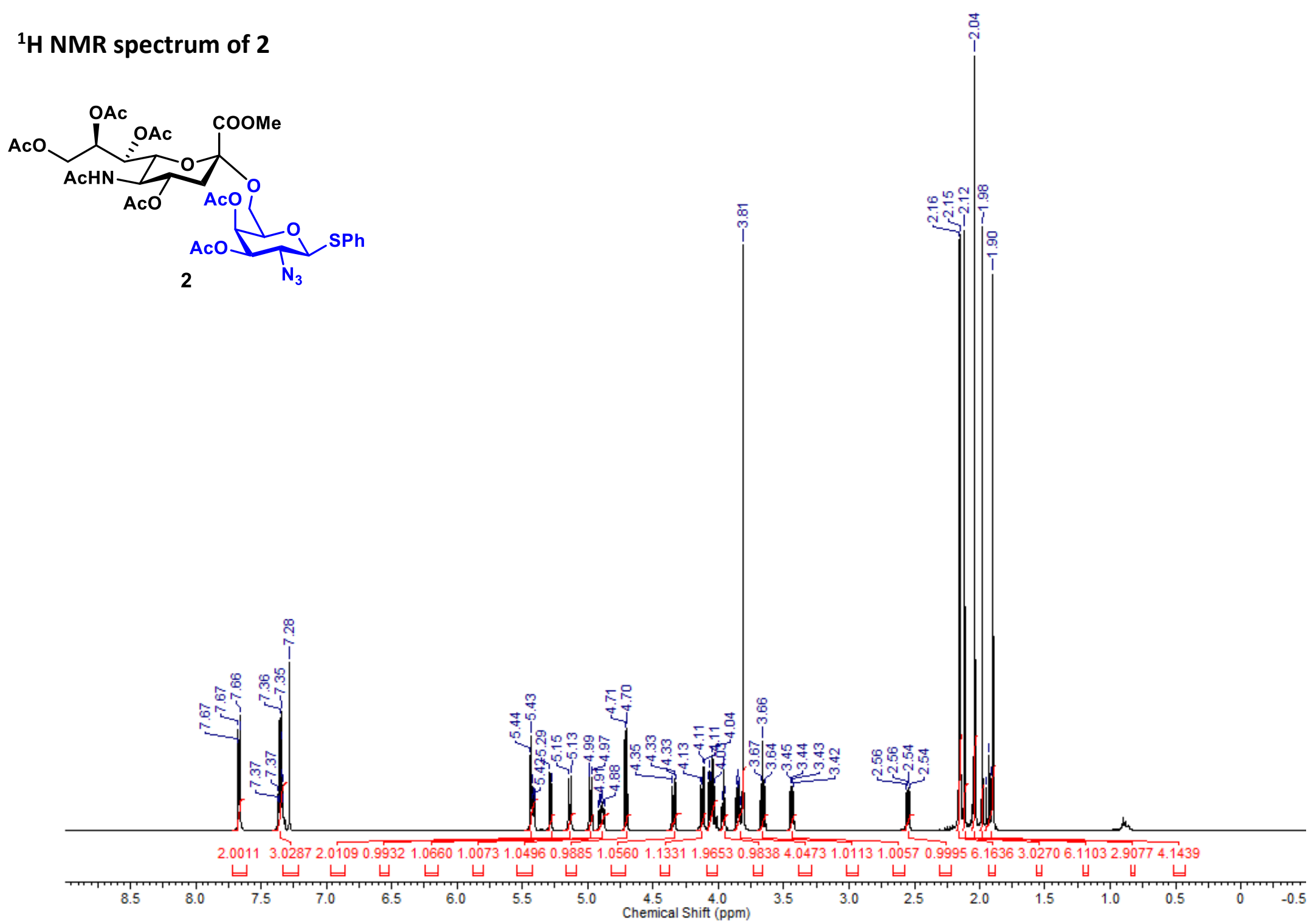
${ }^{13}$ C NMR spectrum of 2
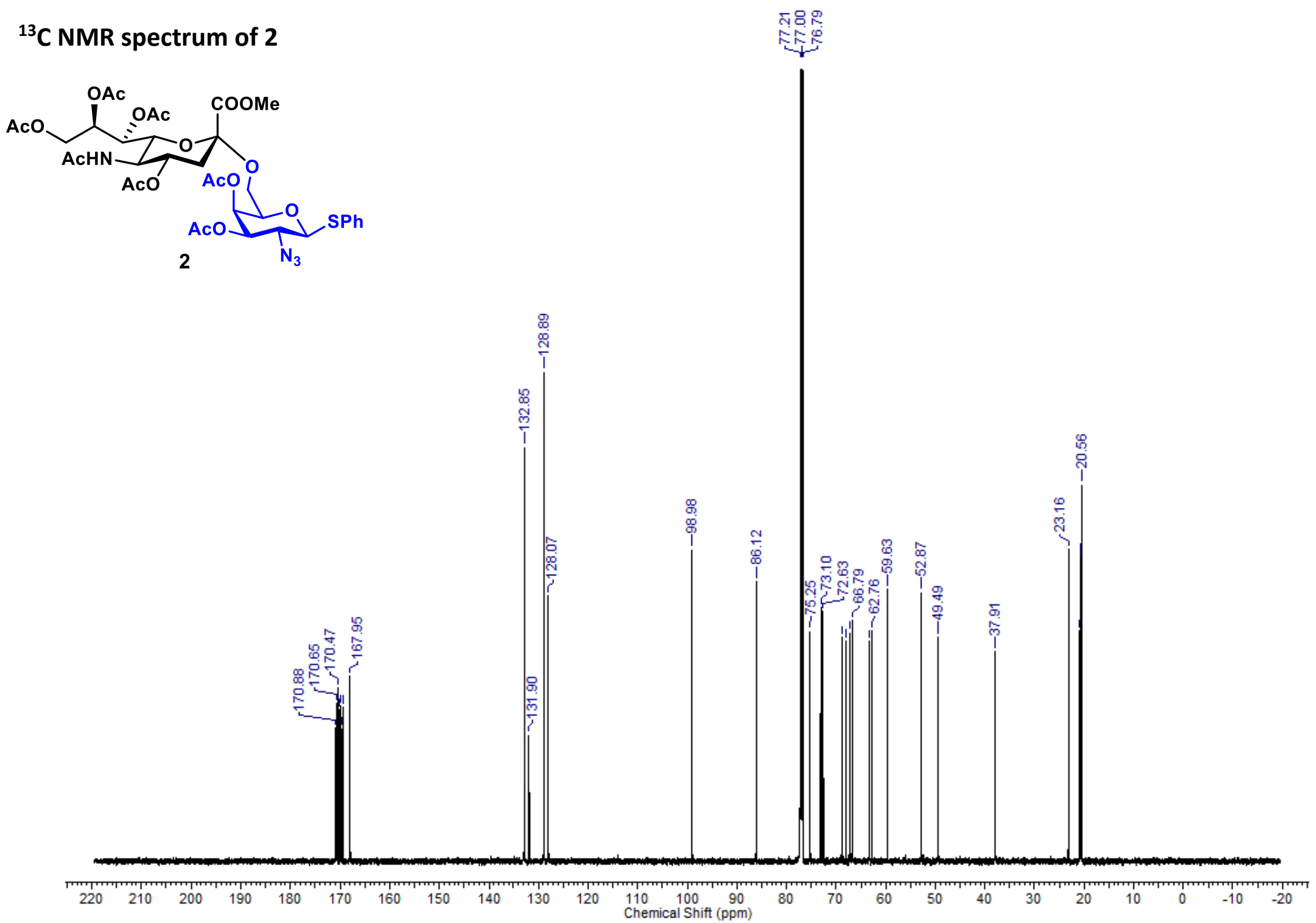


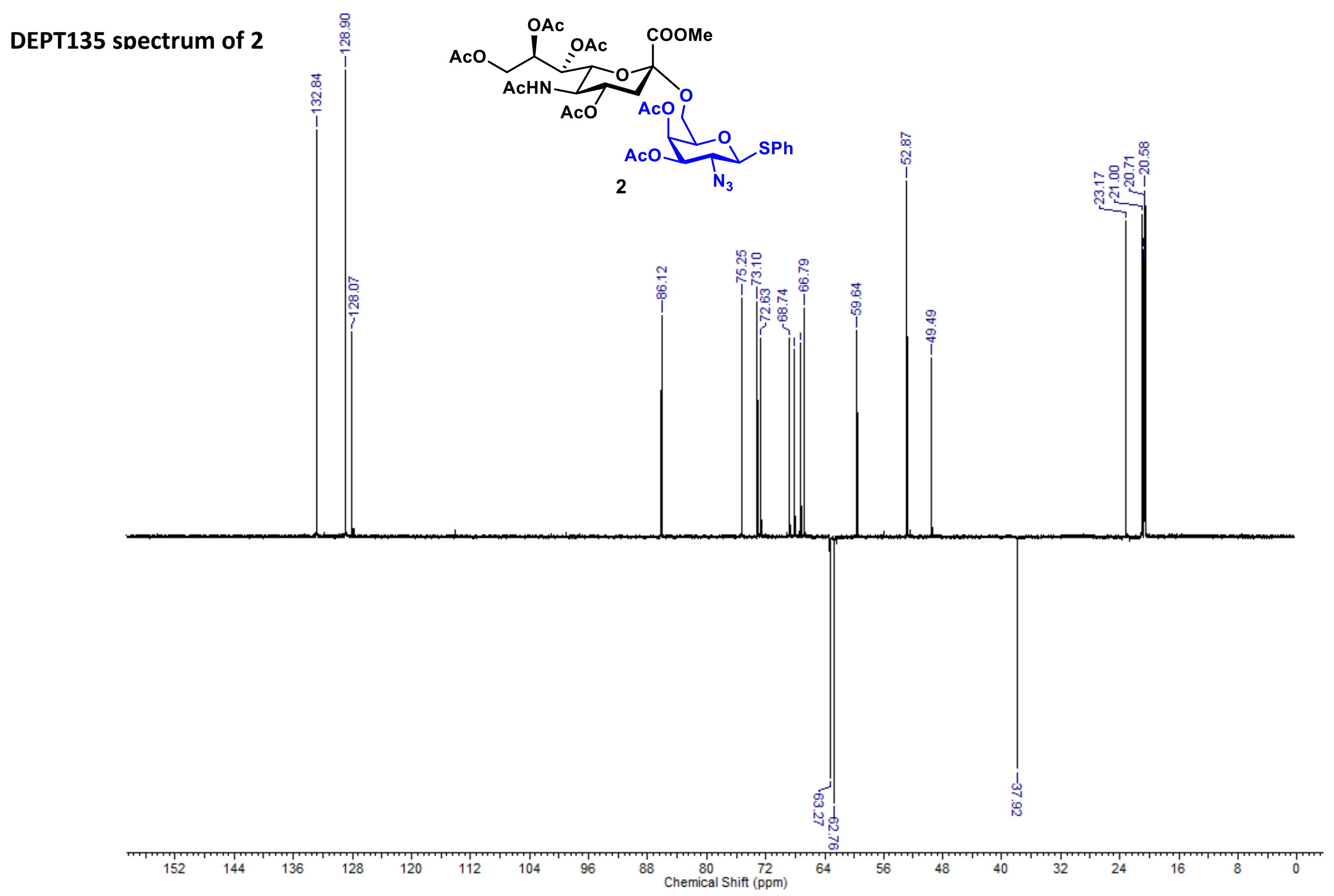




\section{COSY spectrum of 2}

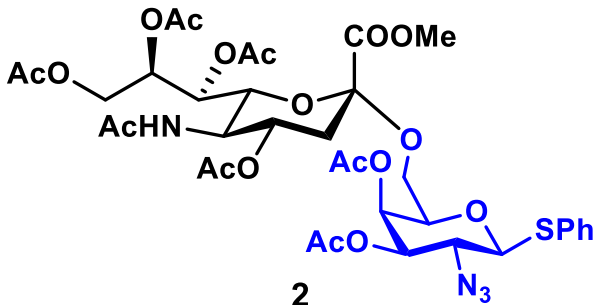

MS-056-beta.004.001.2rr.esp
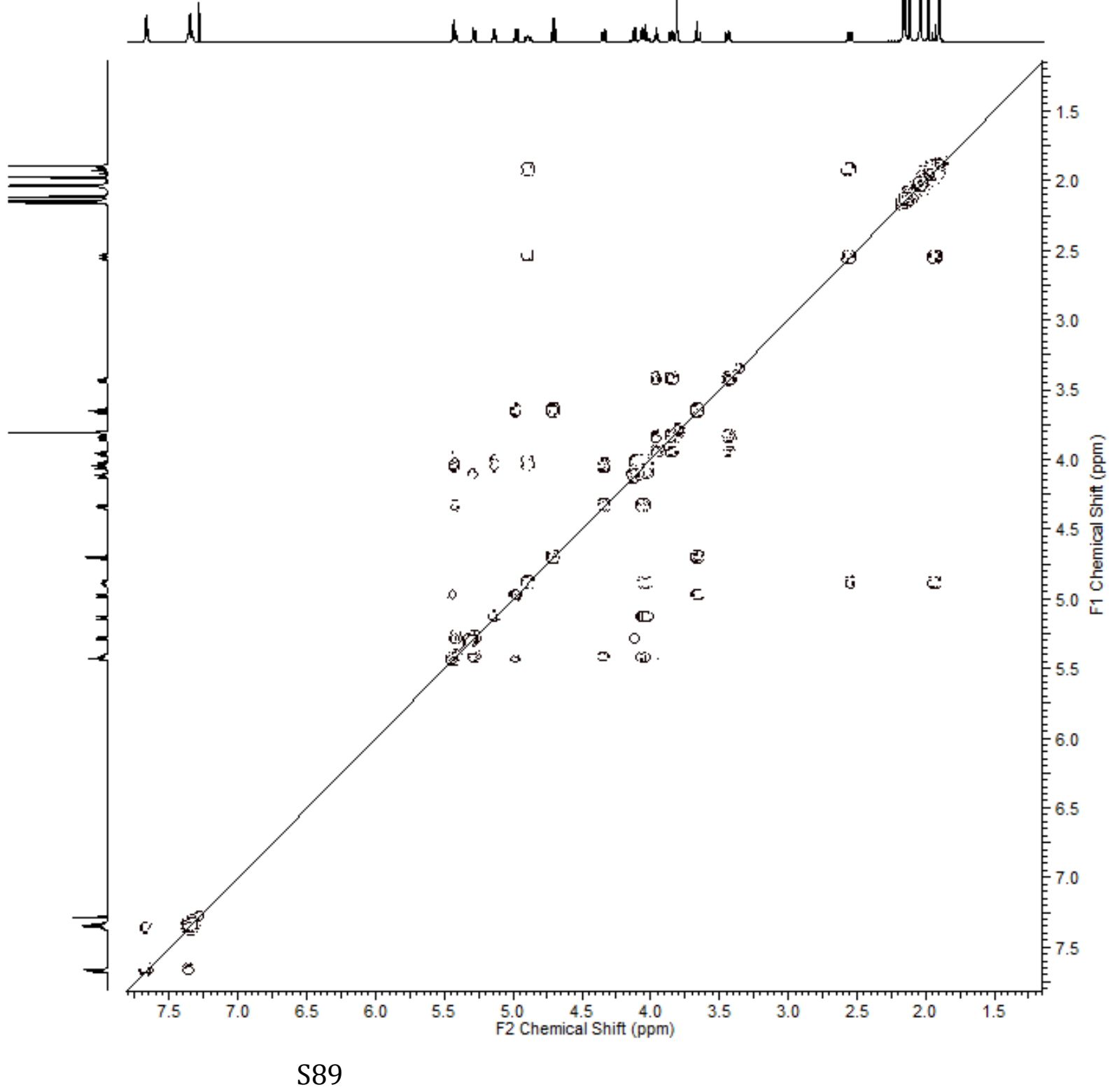


\section{HMC spectrum of 2}

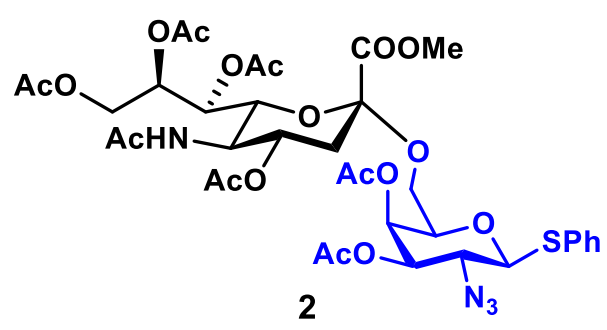

MS-056-purified.004.001.2r.esp

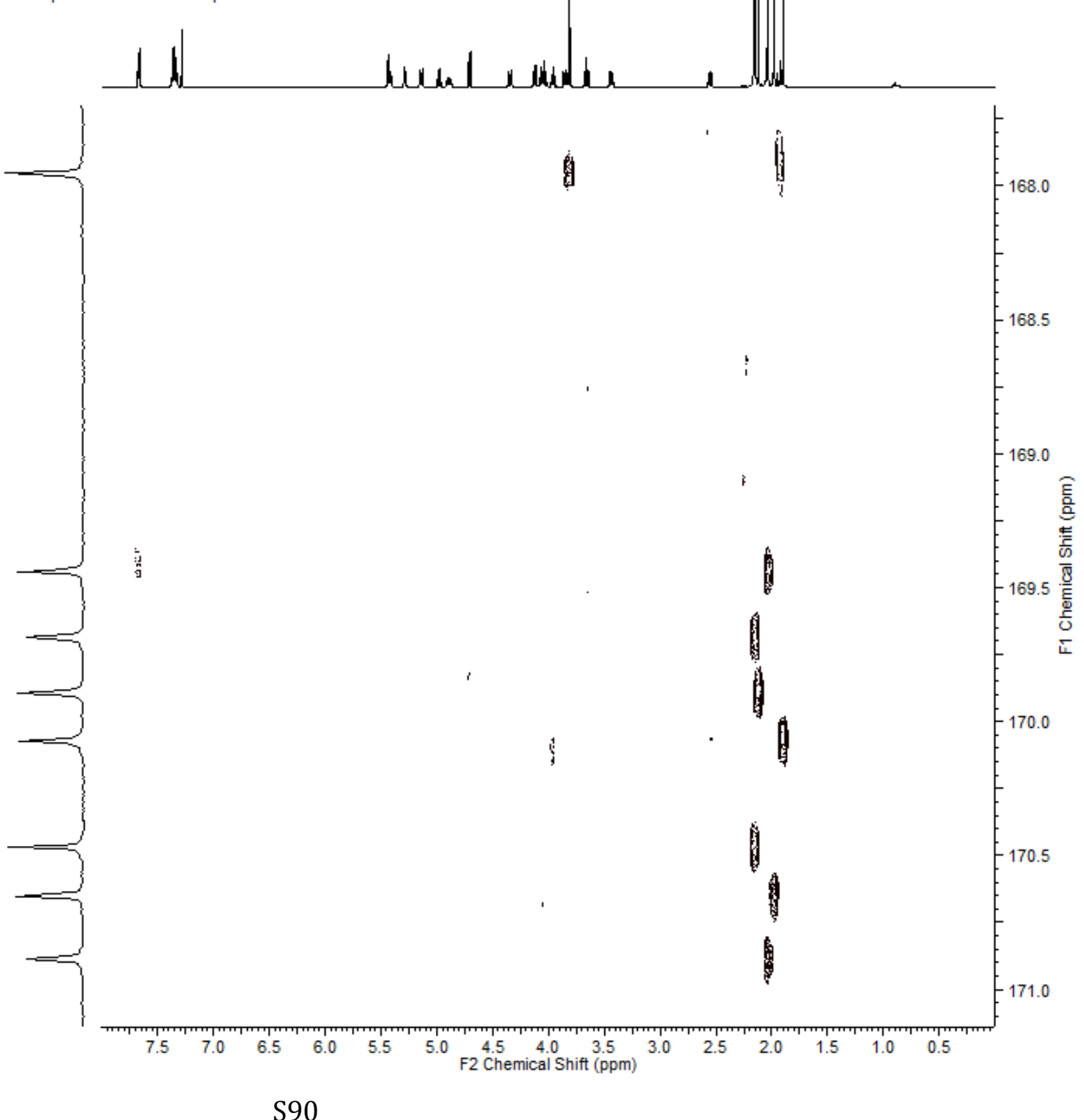


HSQC spectrum of 2

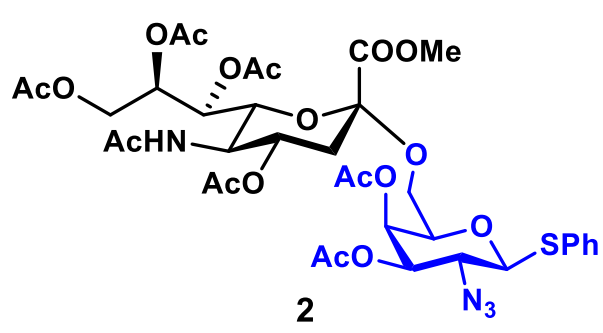

MS-056-beta.005.001.2rr.esp

1.

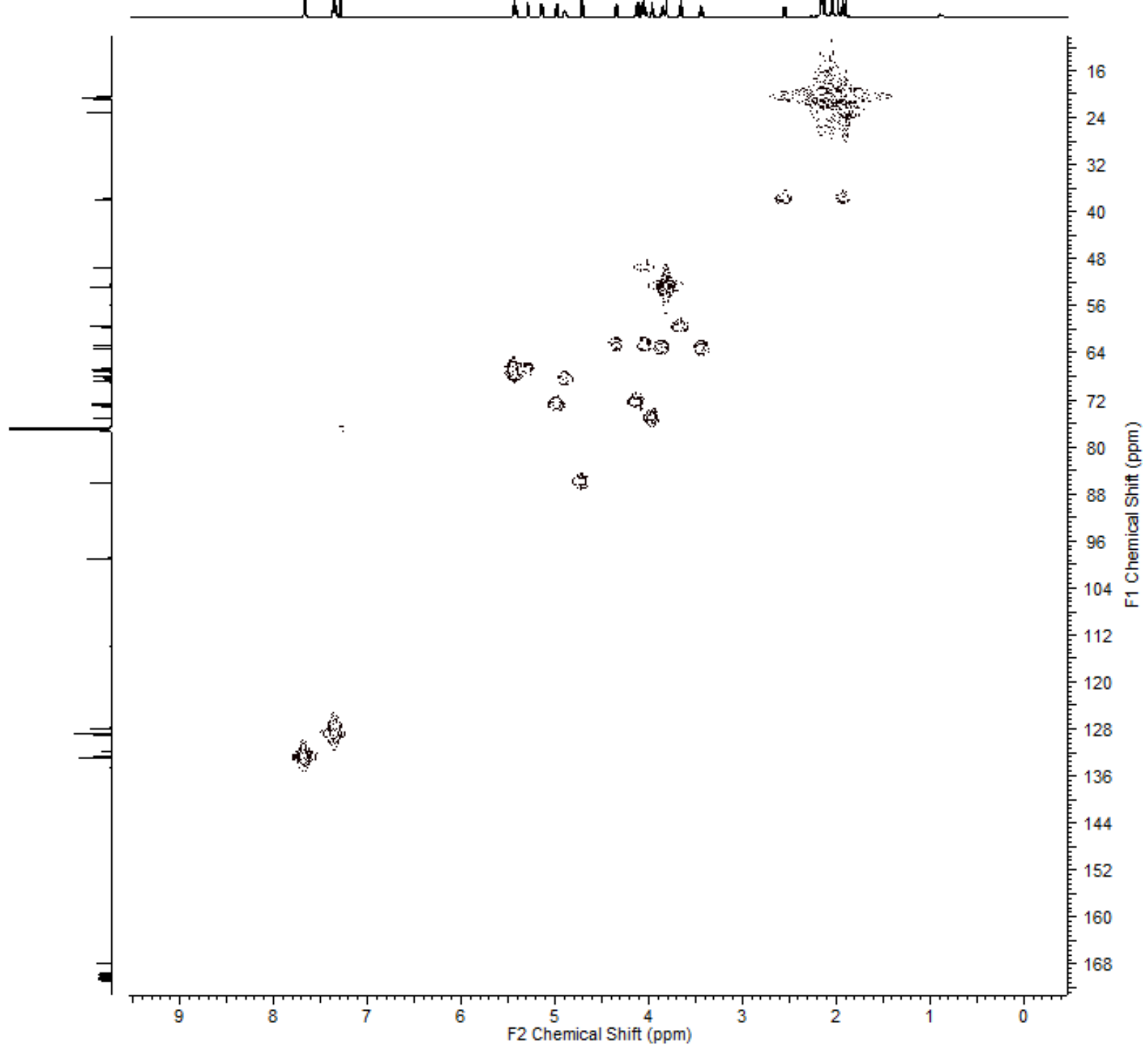




\section{${ }^{1} \mathrm{H}$ NMR spectrum of 13}
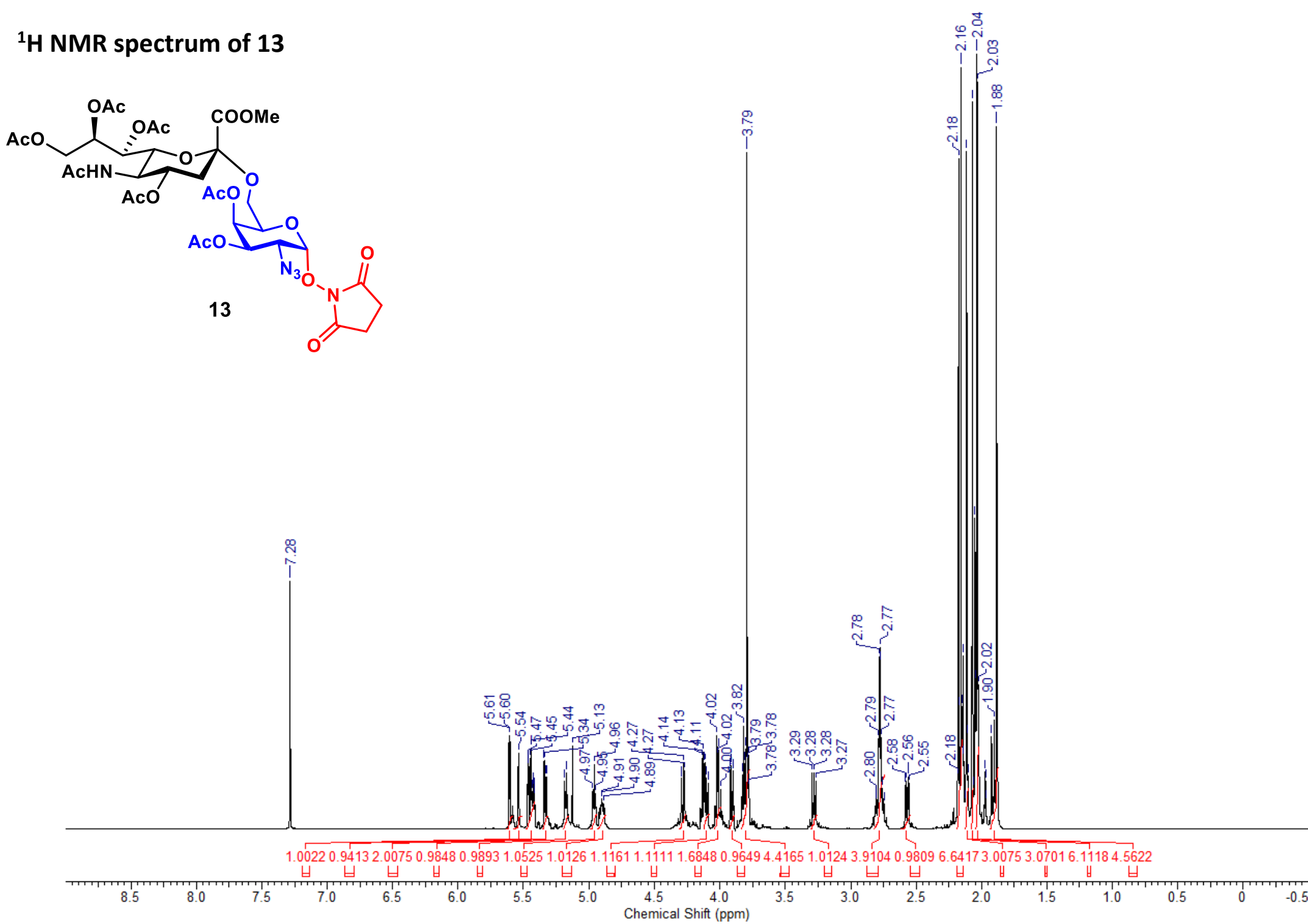


\section{${ }^{13} \mathrm{C}$ NMR spectrum of 13}
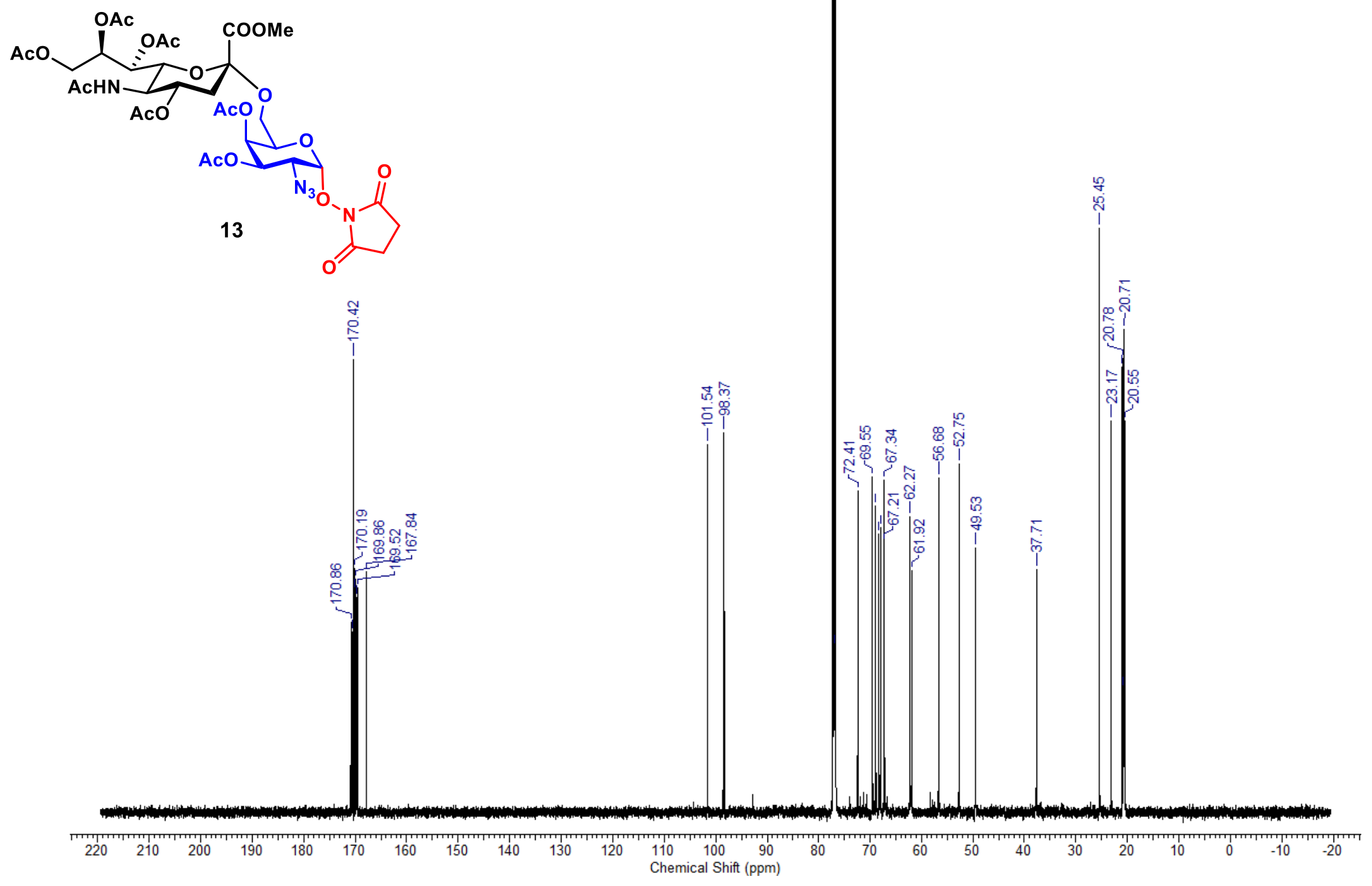


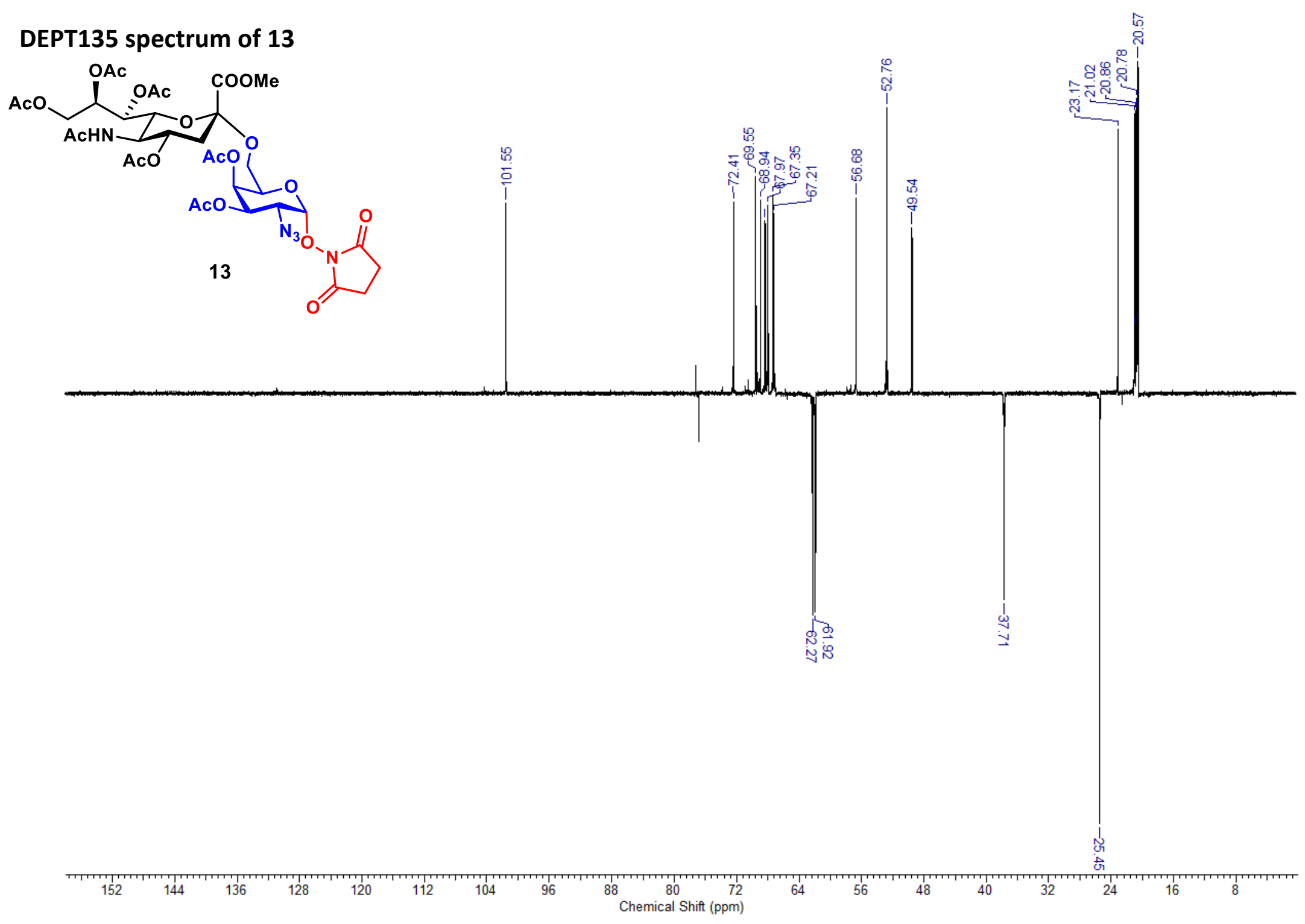




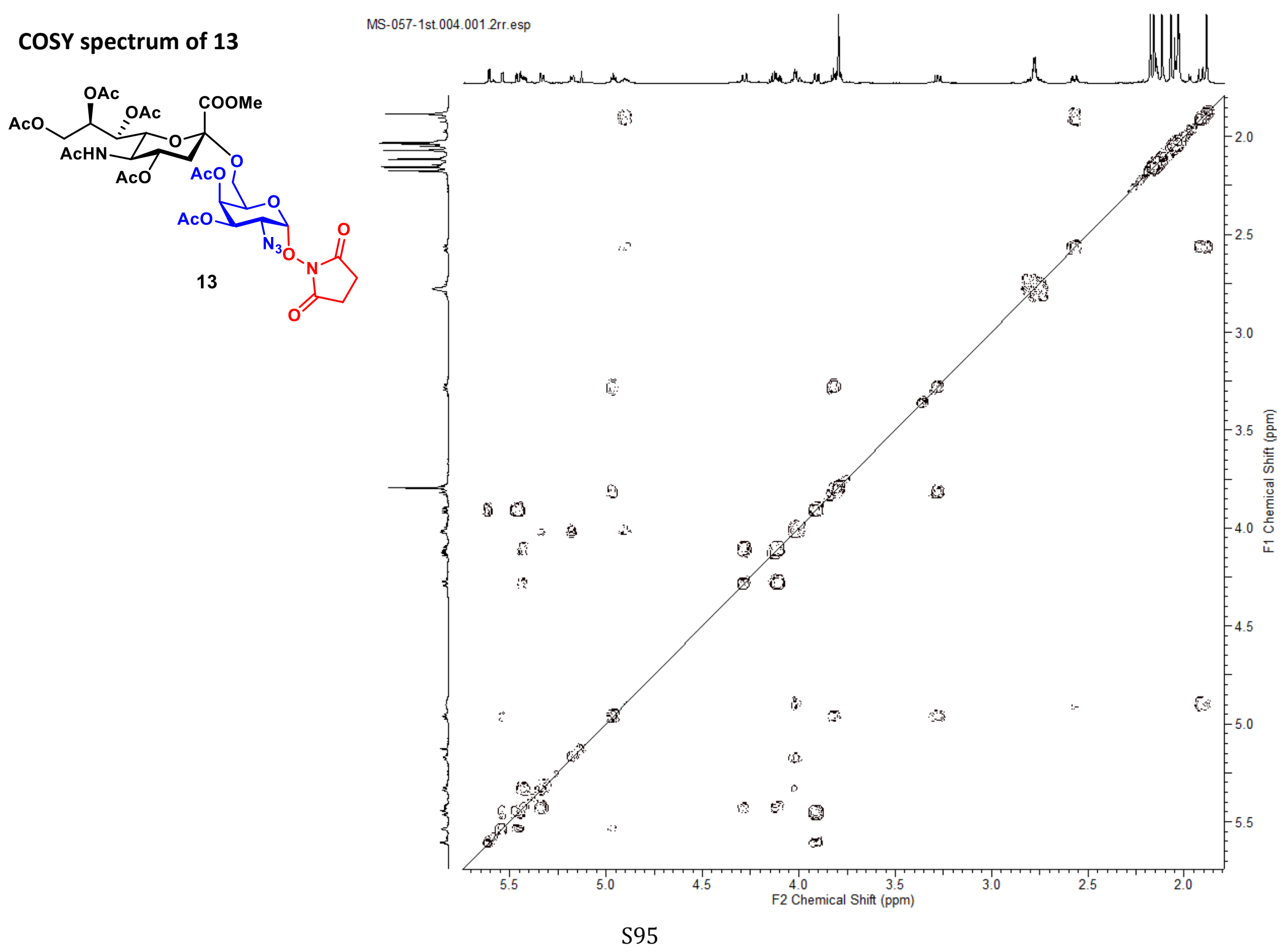




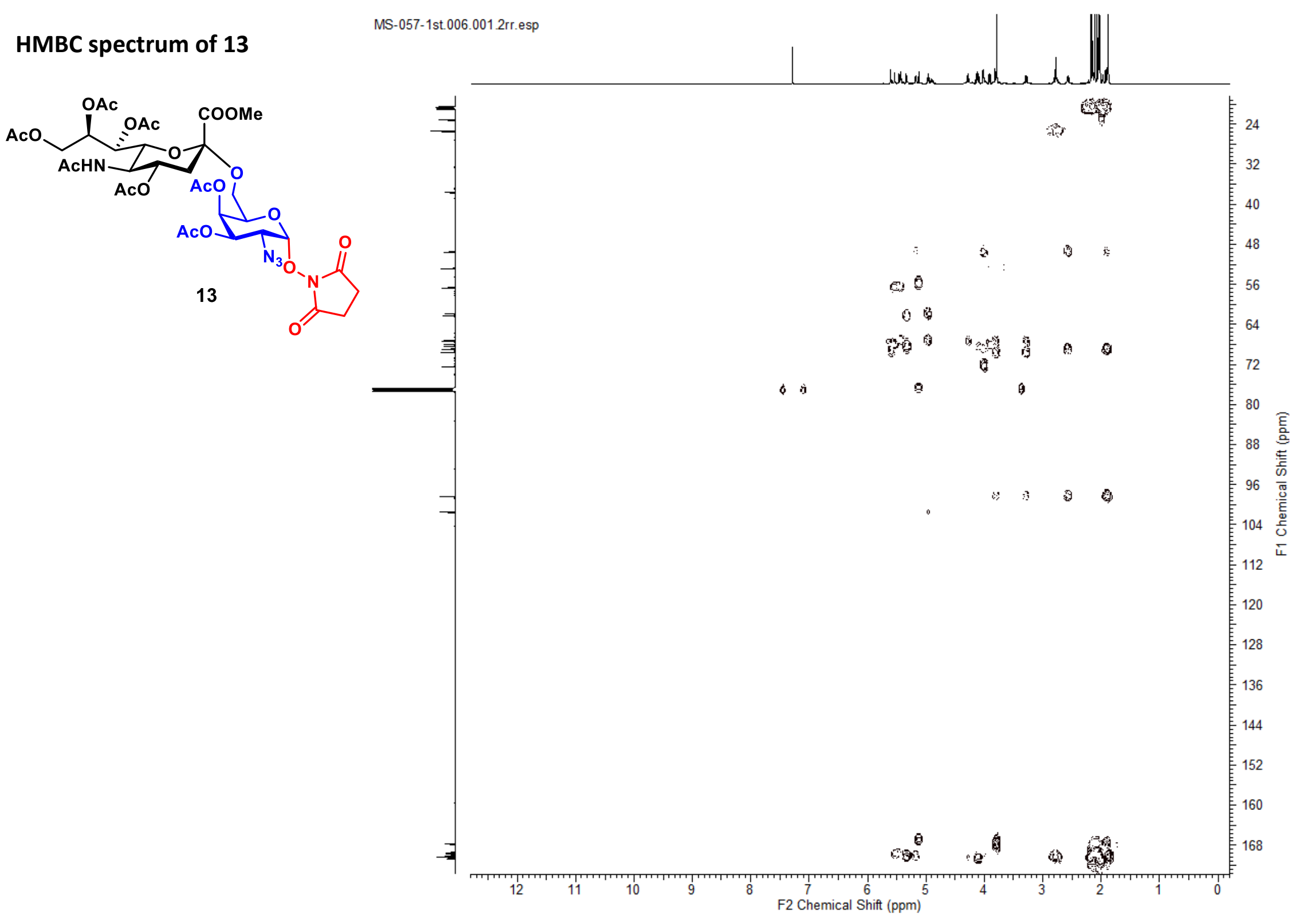




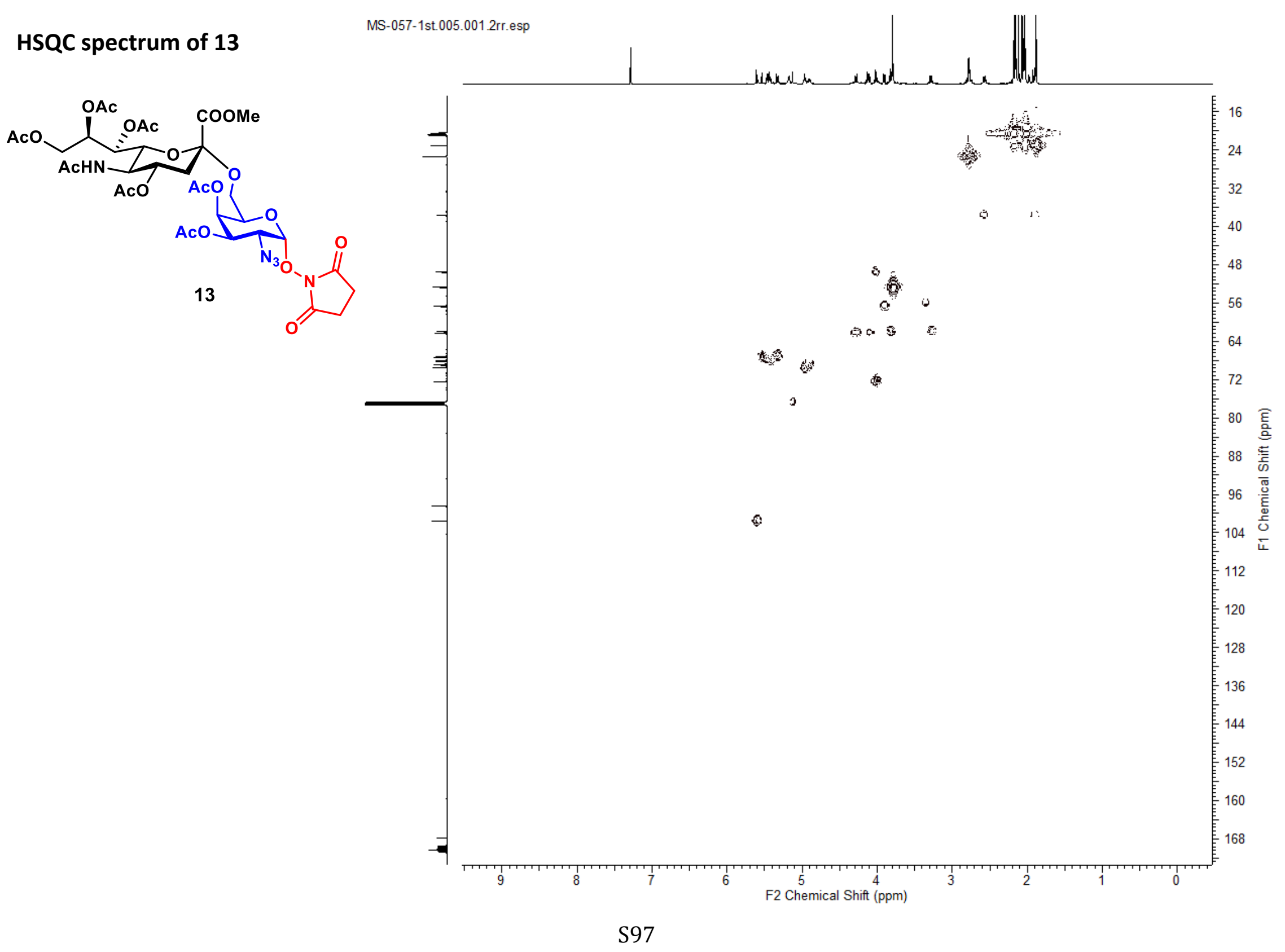


${ }^{1} \mathrm{H}$ NMR spectrum of 14
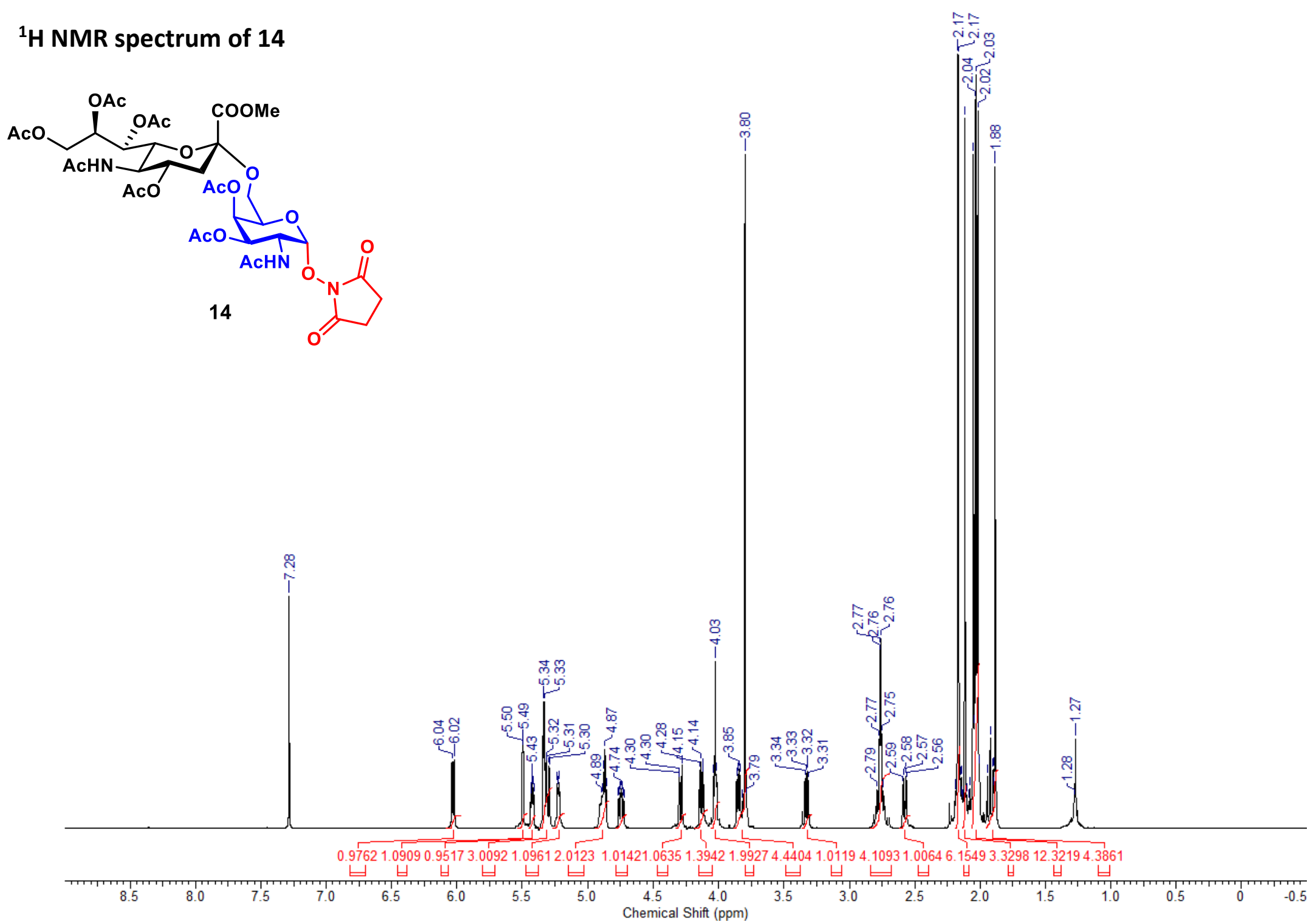
${ }^{13} \mathrm{C}$ NMR spectrum of 14
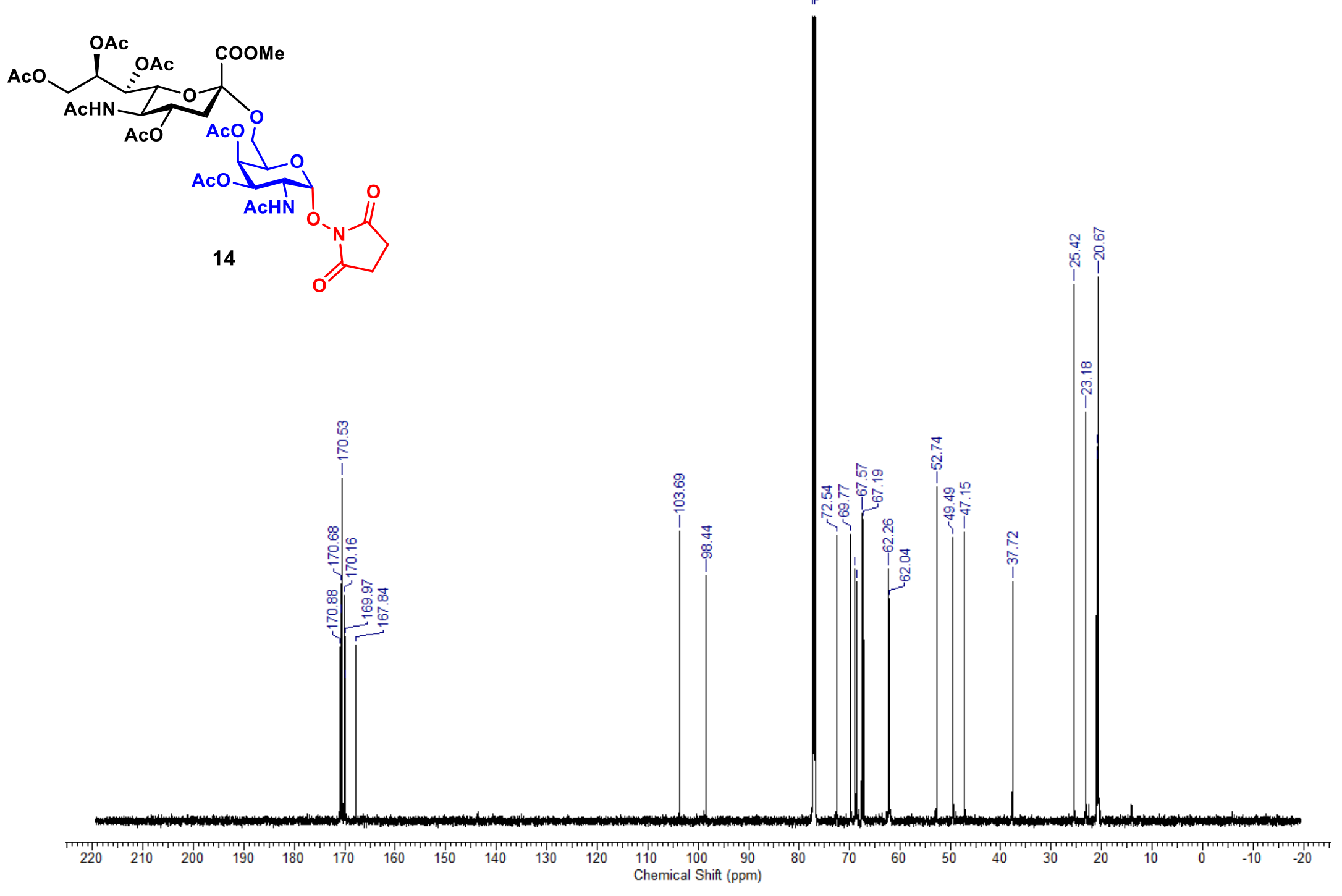


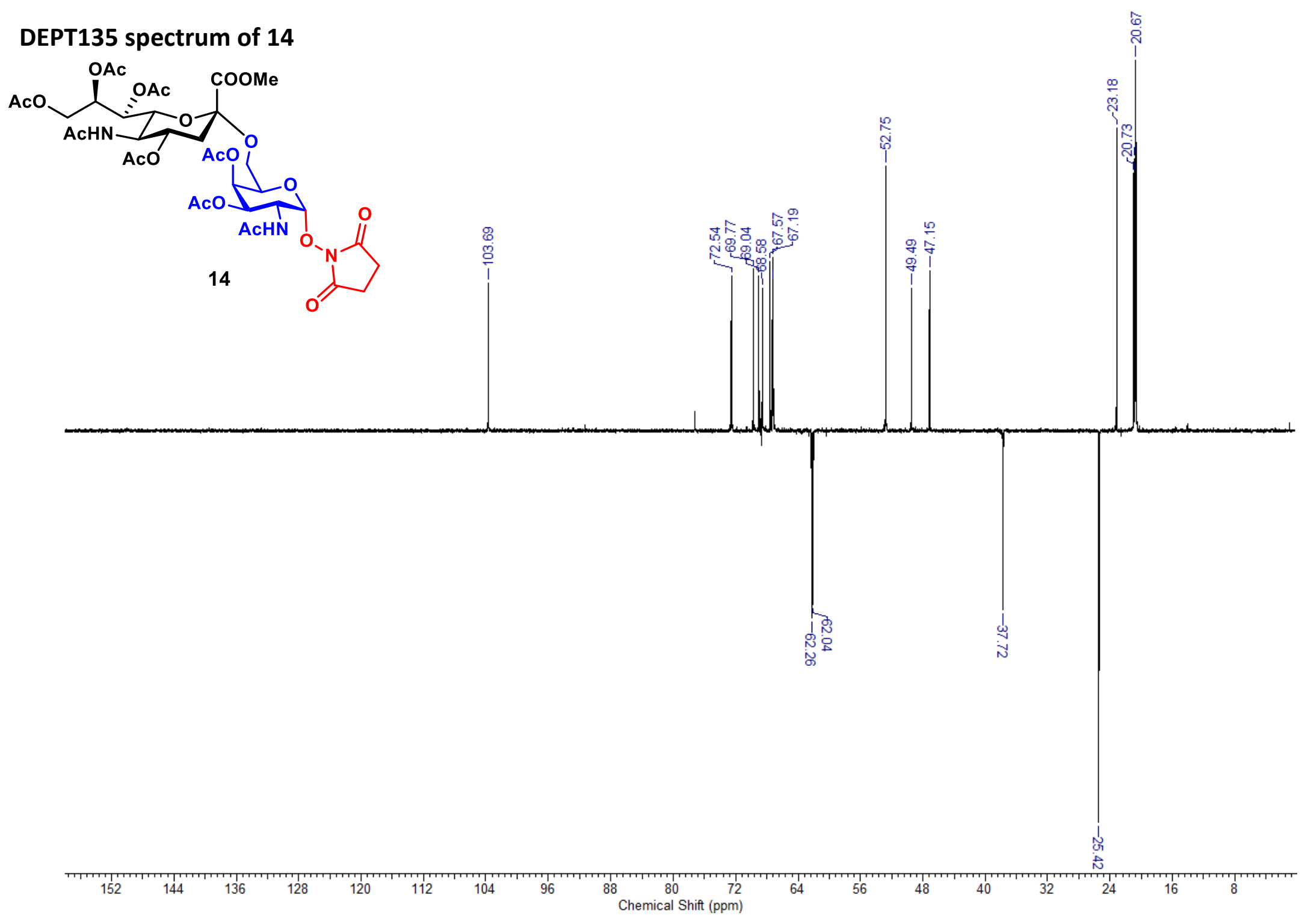




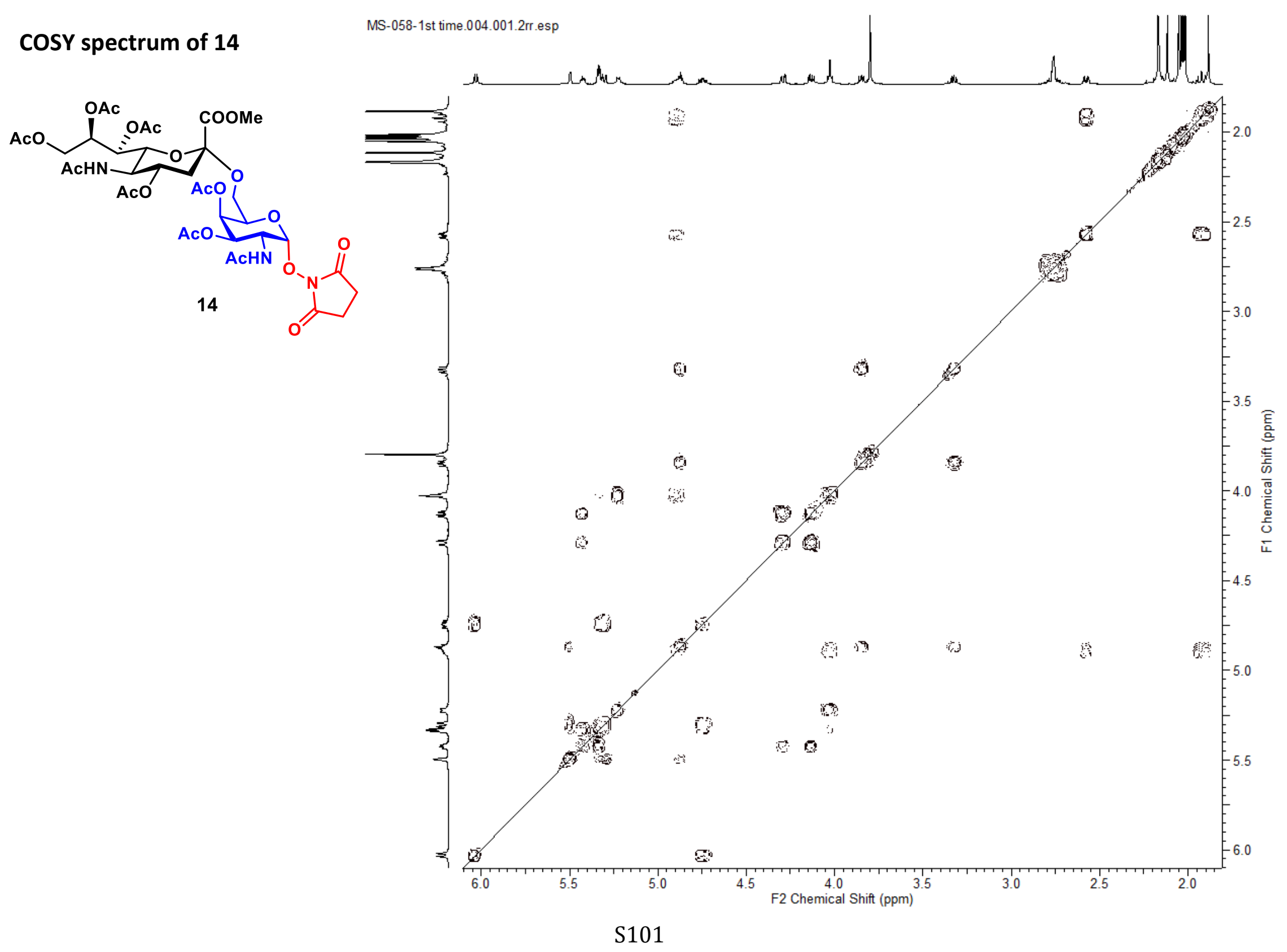




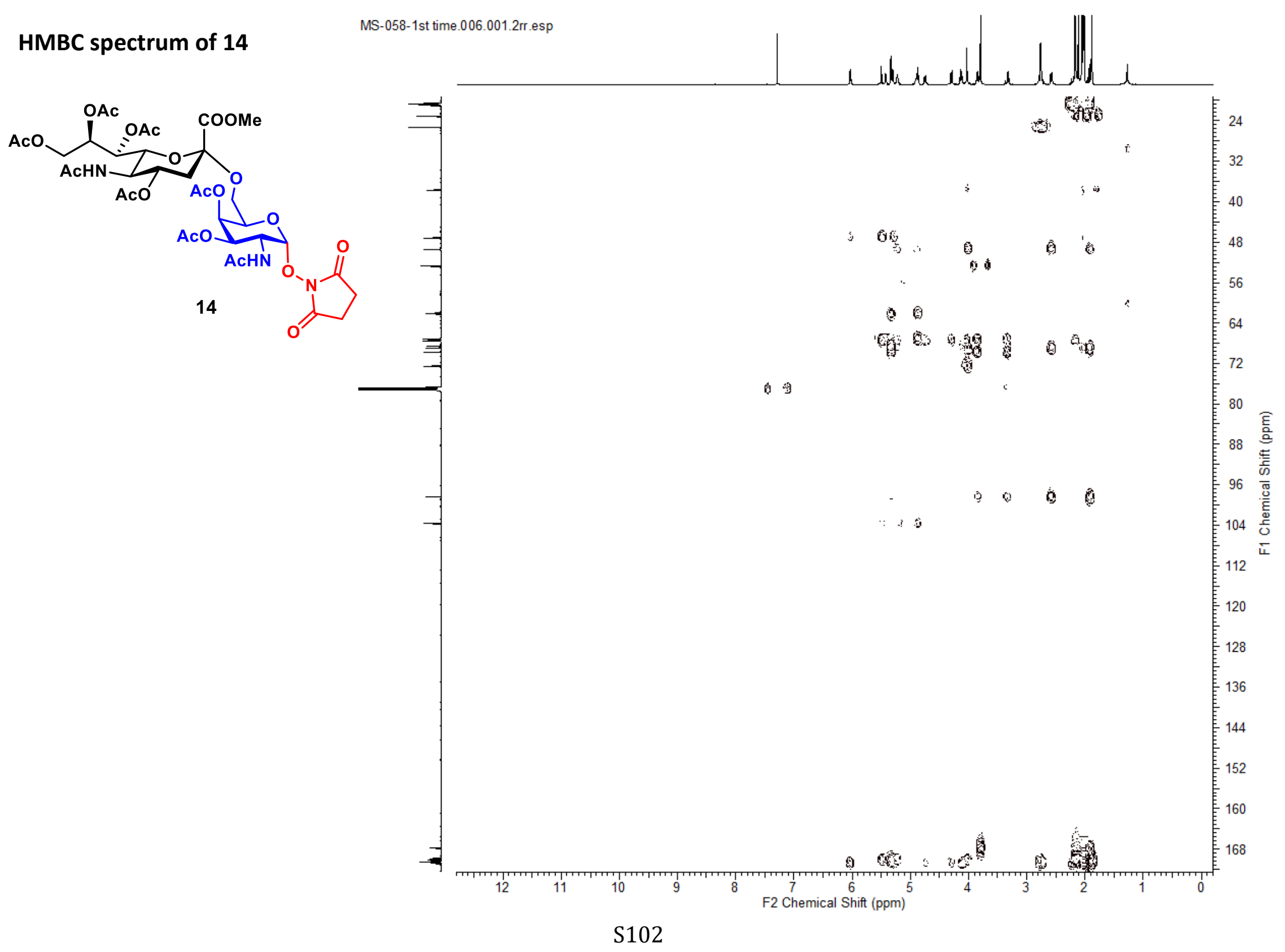




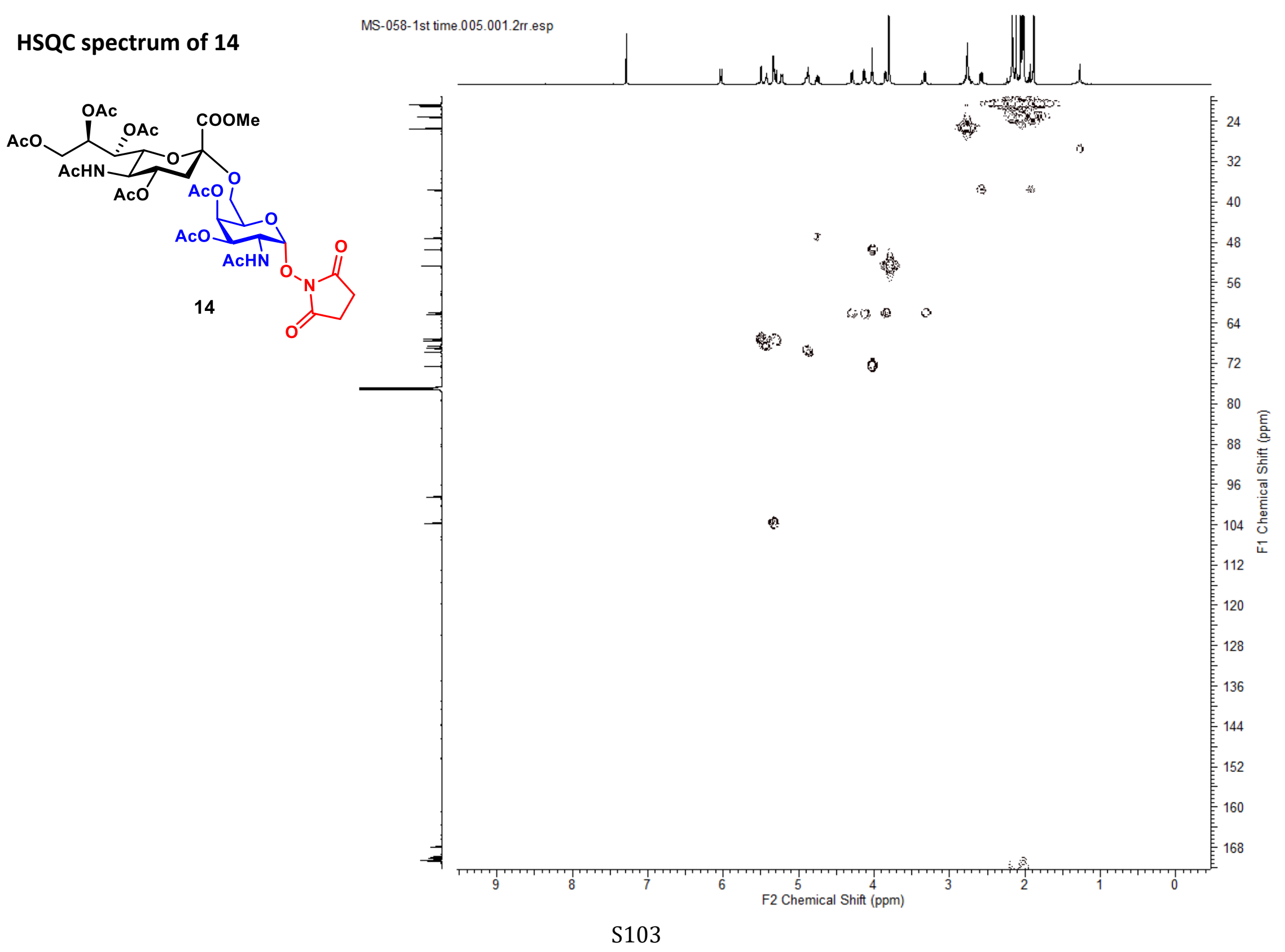


${ }^{1} \mathrm{H}$ NMR spectrum of $\mathbf{1}$

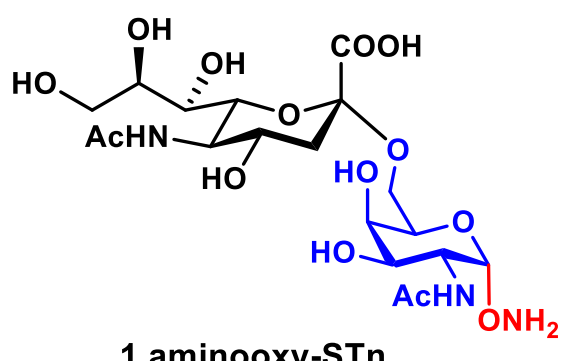

1 aminooxy-STn

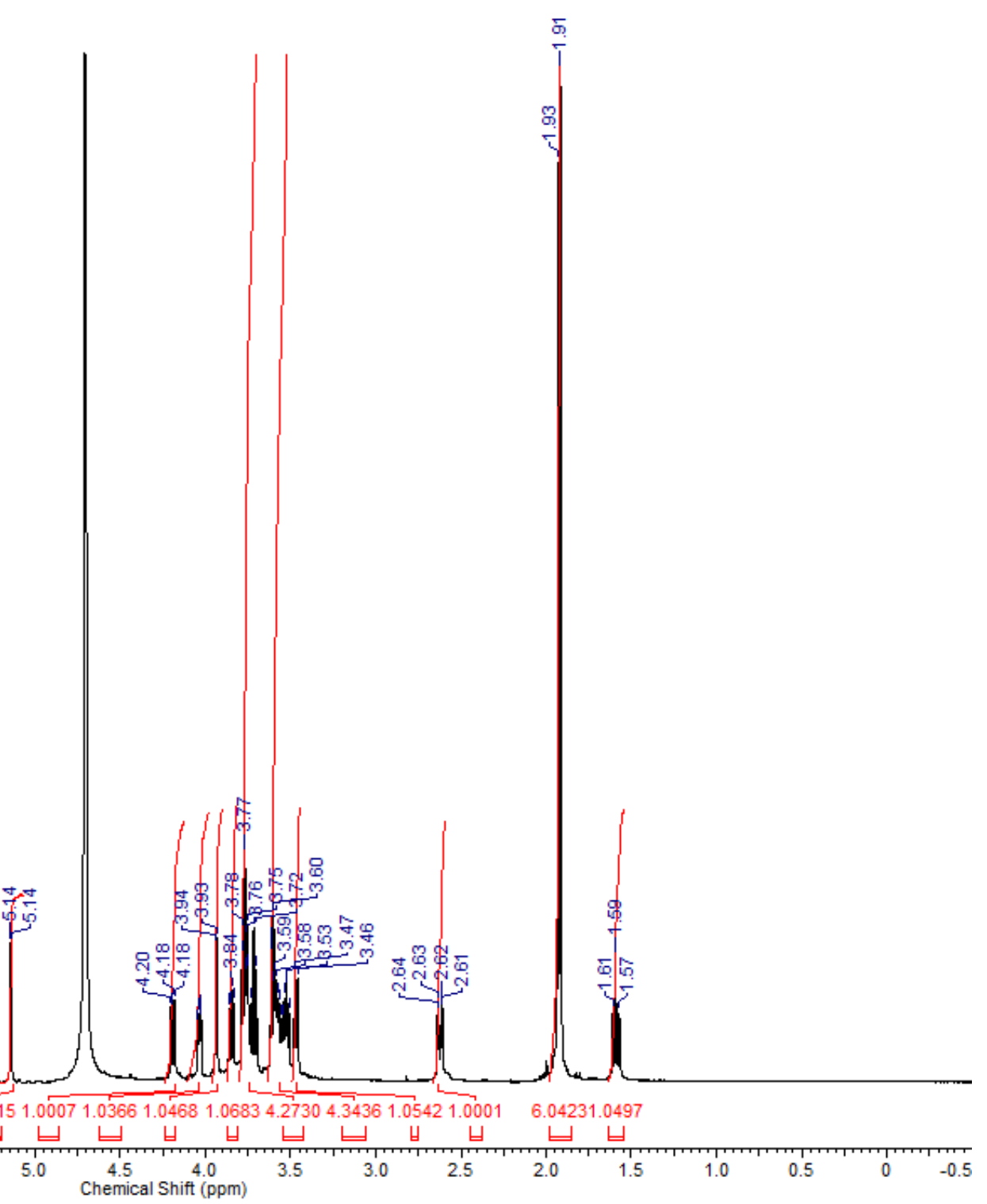


${ }^{13} \mathrm{C}$ NMR spectrum of 1

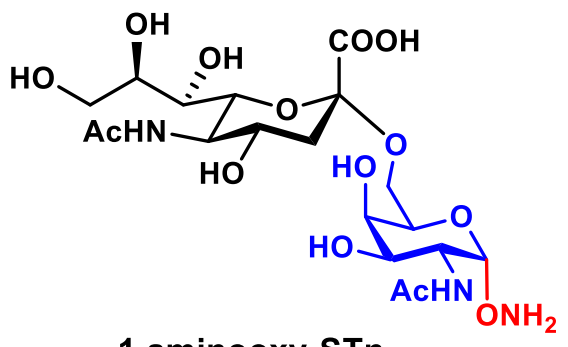

1 aminooxy-STn $\mathrm{ONH}_{2}$

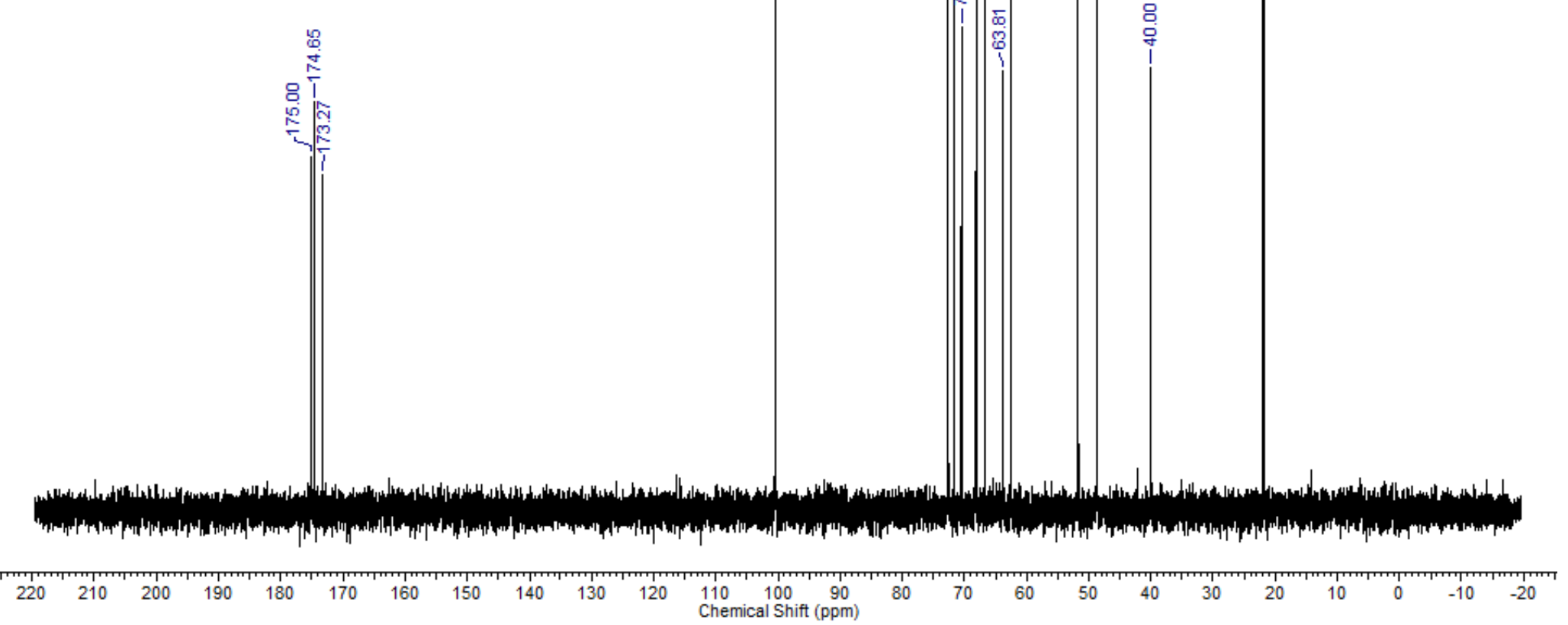




\section{DEPT135 spectrum of 1}

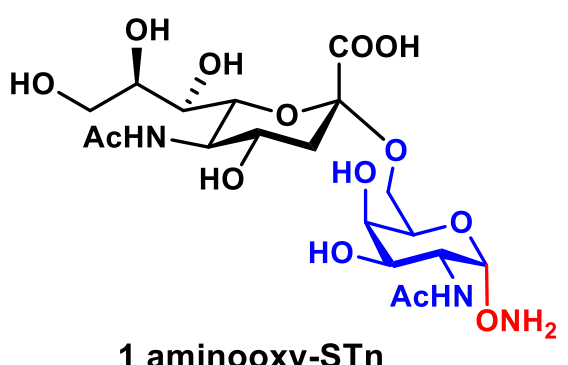

1 aminooxy-STn

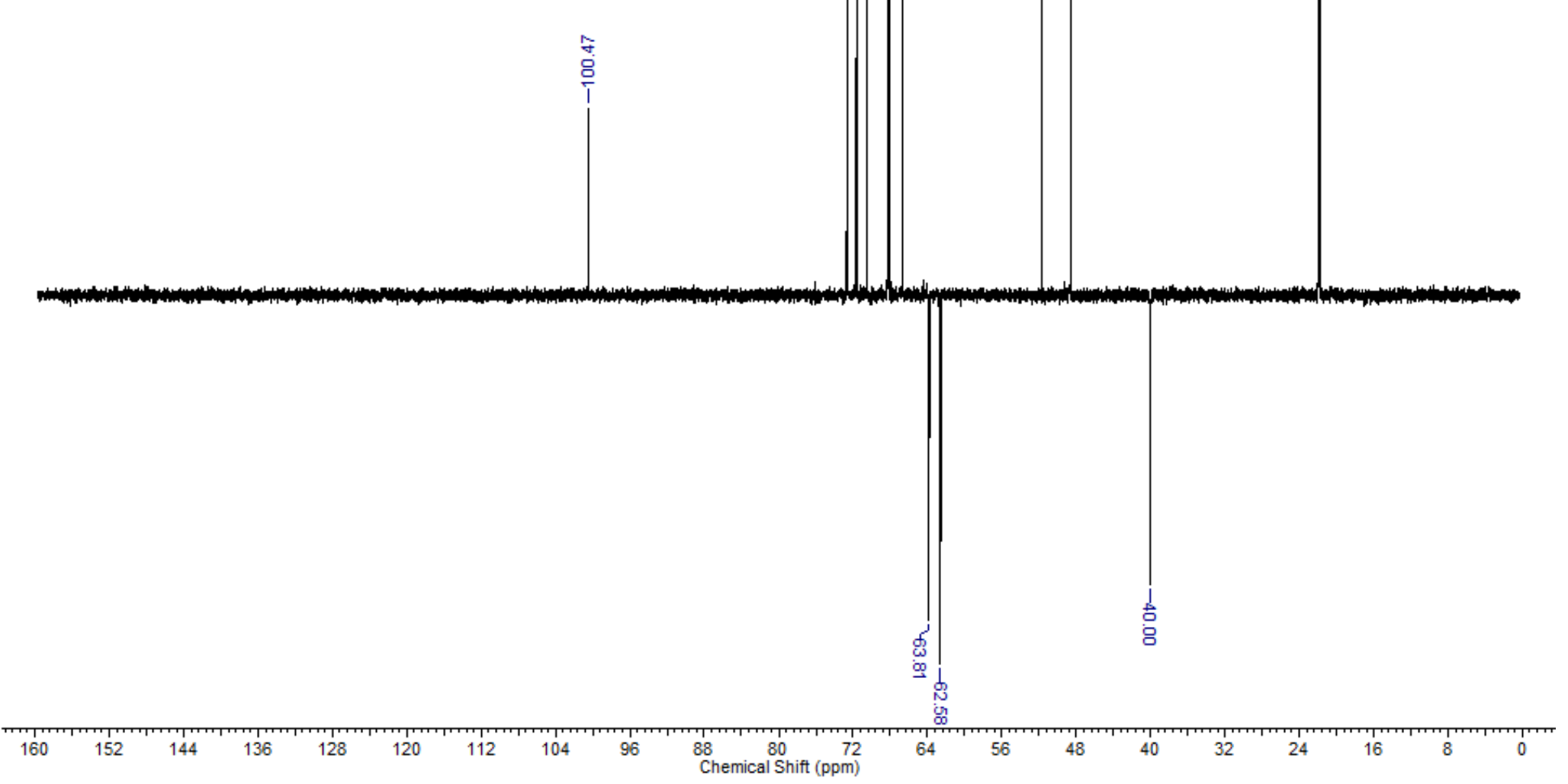




\section{COSY spectrum of 1}

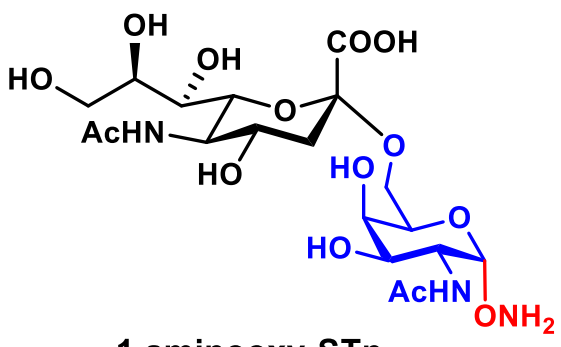

1 aminooxy-STn

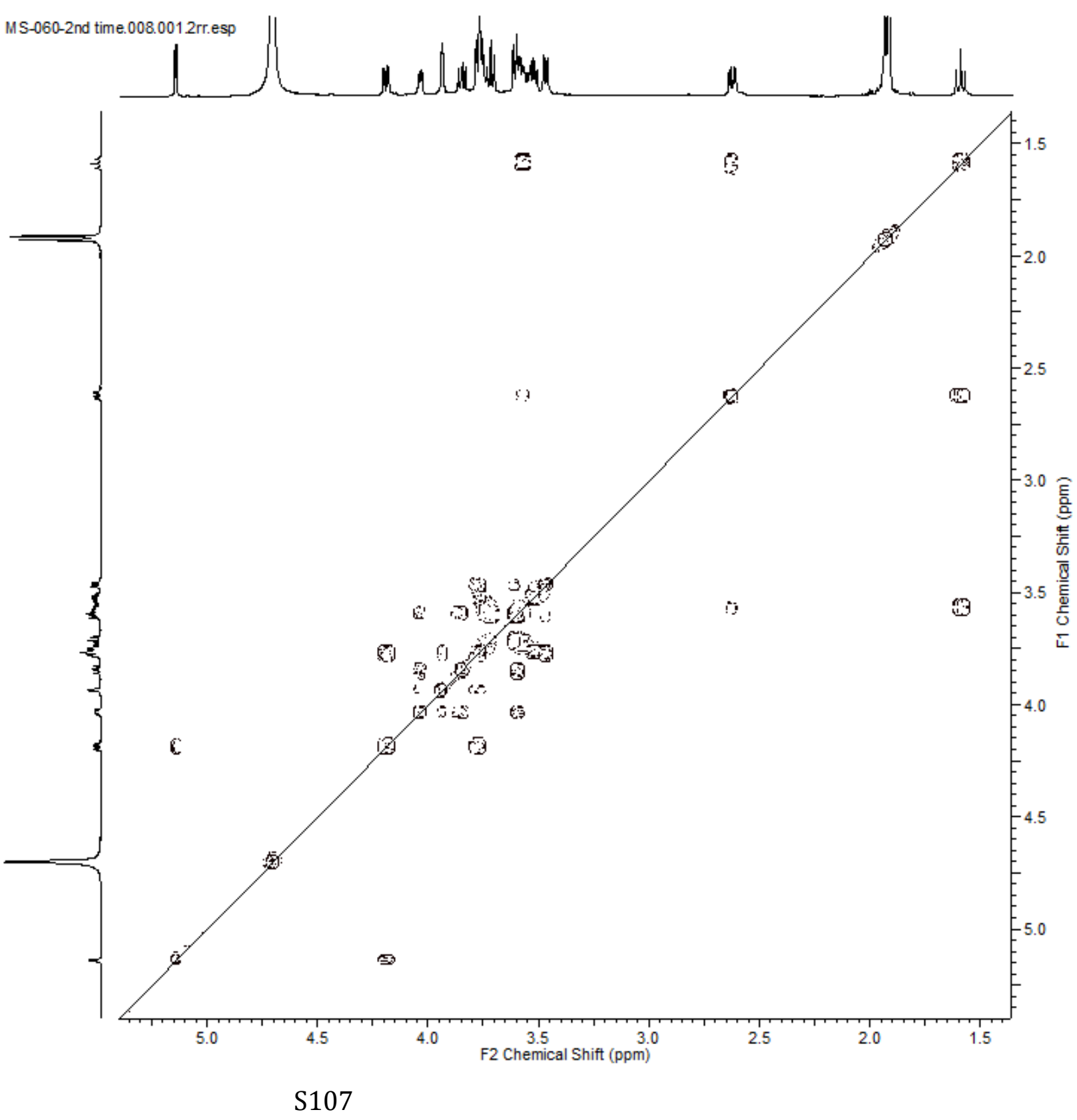



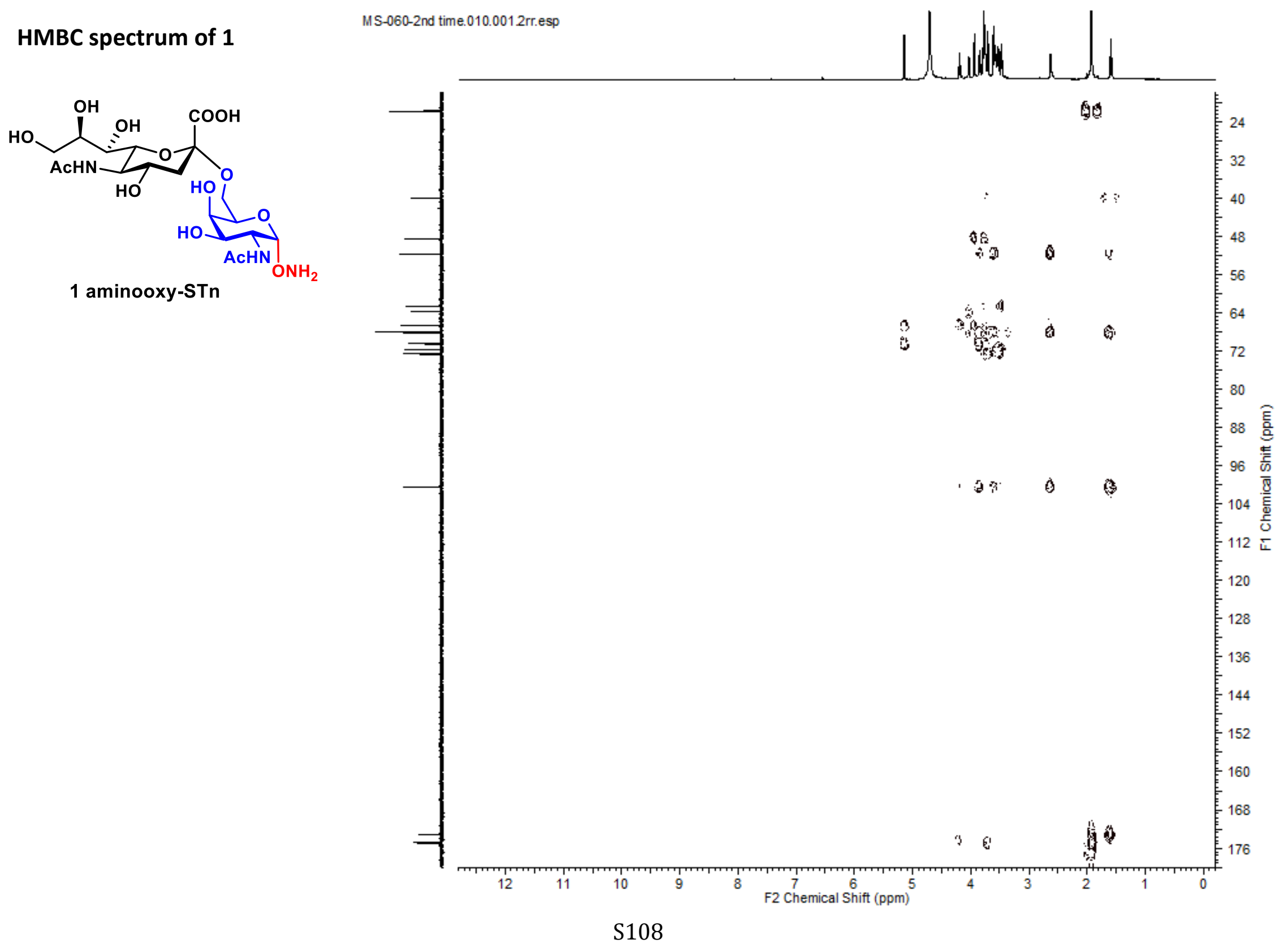


\section{HSQC spectrum of 1}

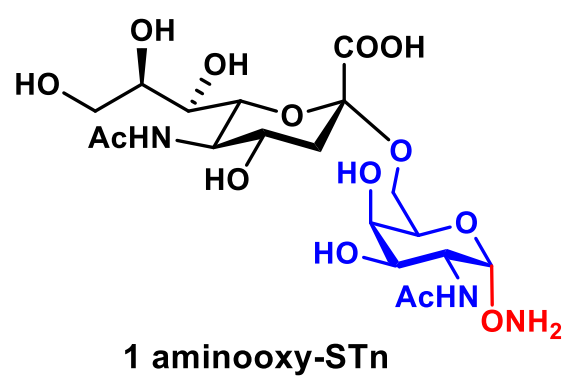

1 aminooxy-STn
MS-060-2nd time.009.001.2rr.esp
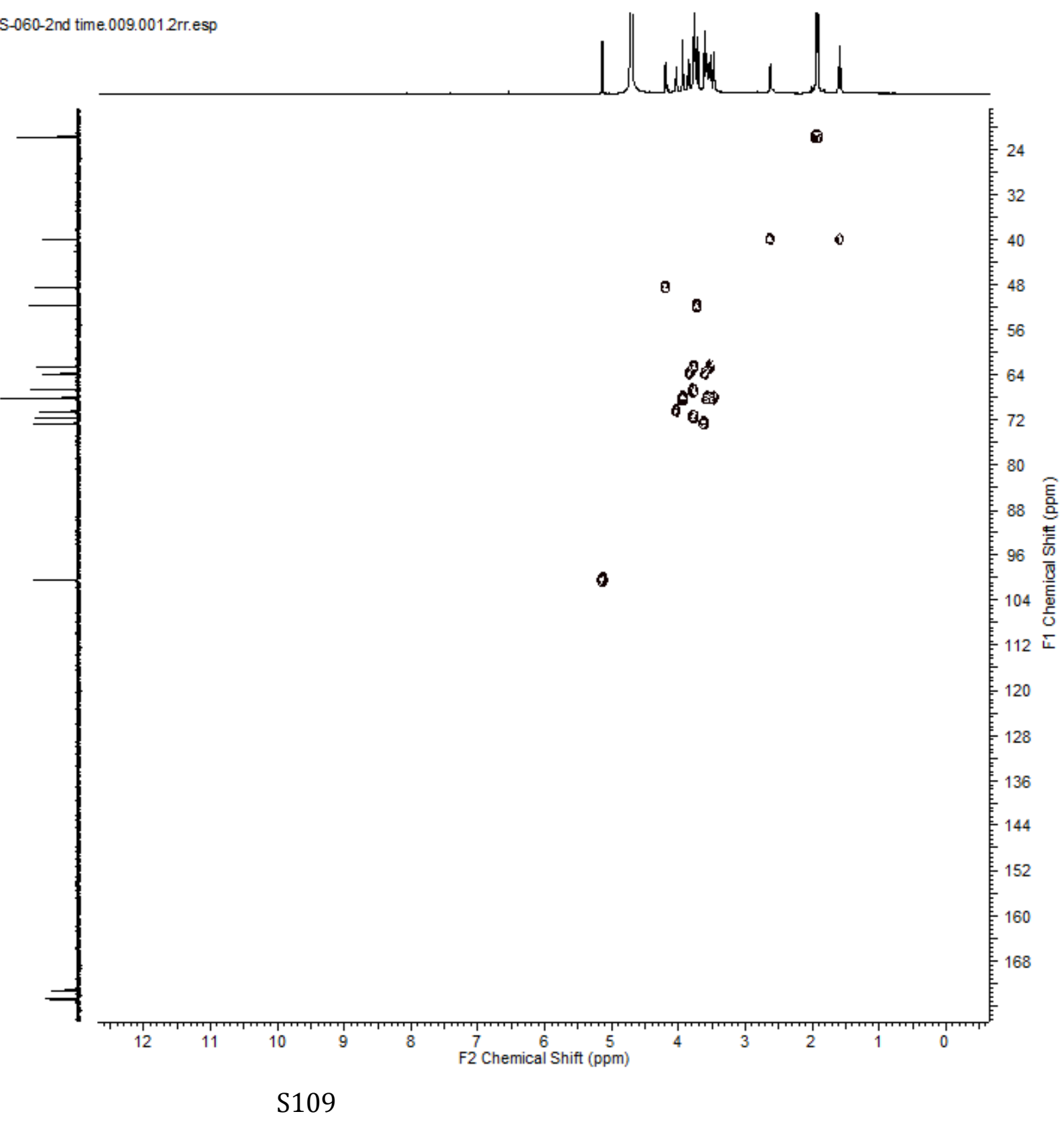
${ }^{1} \mathrm{H}$ NMR spectrum of PS A1 (15)
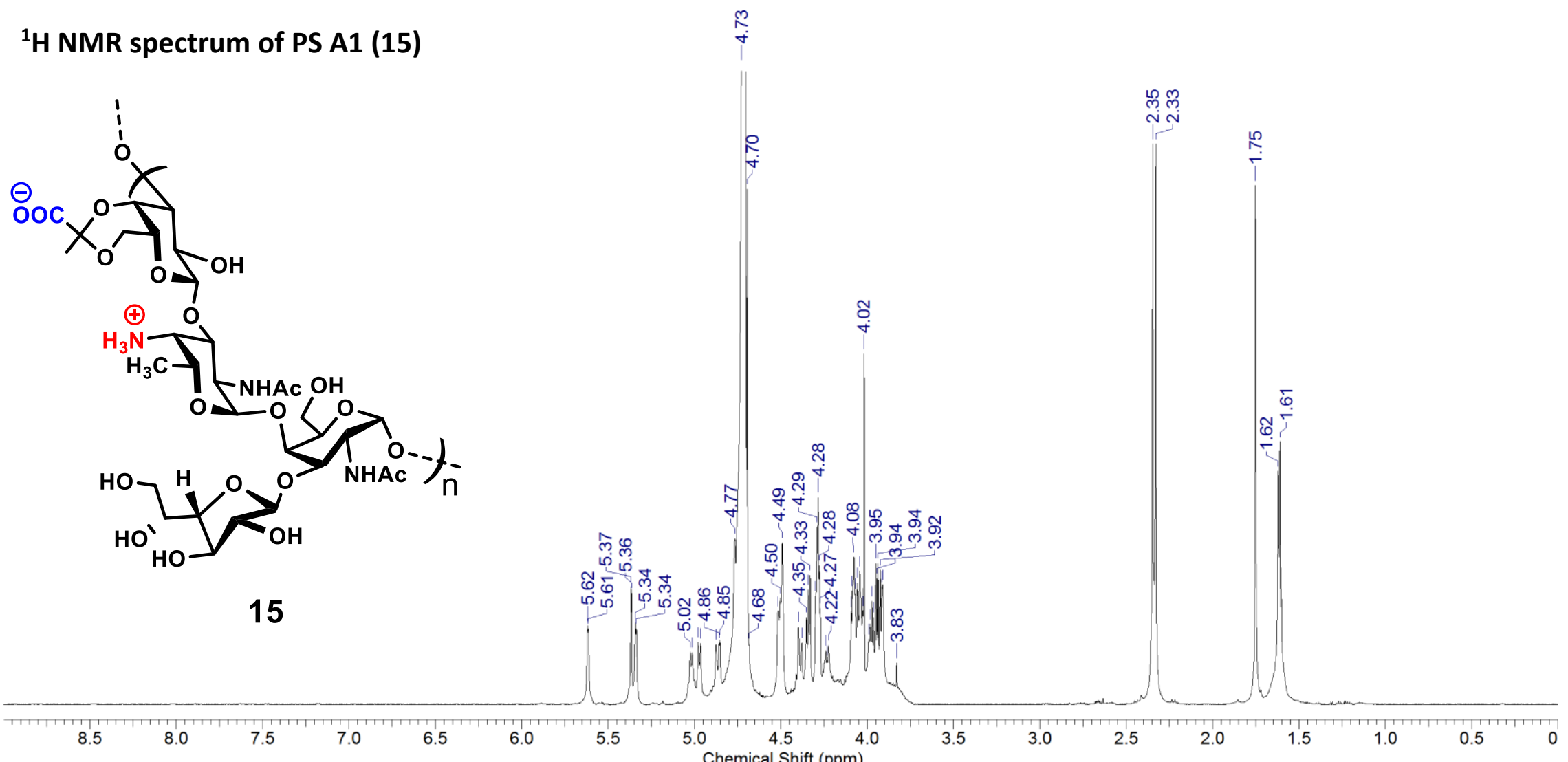


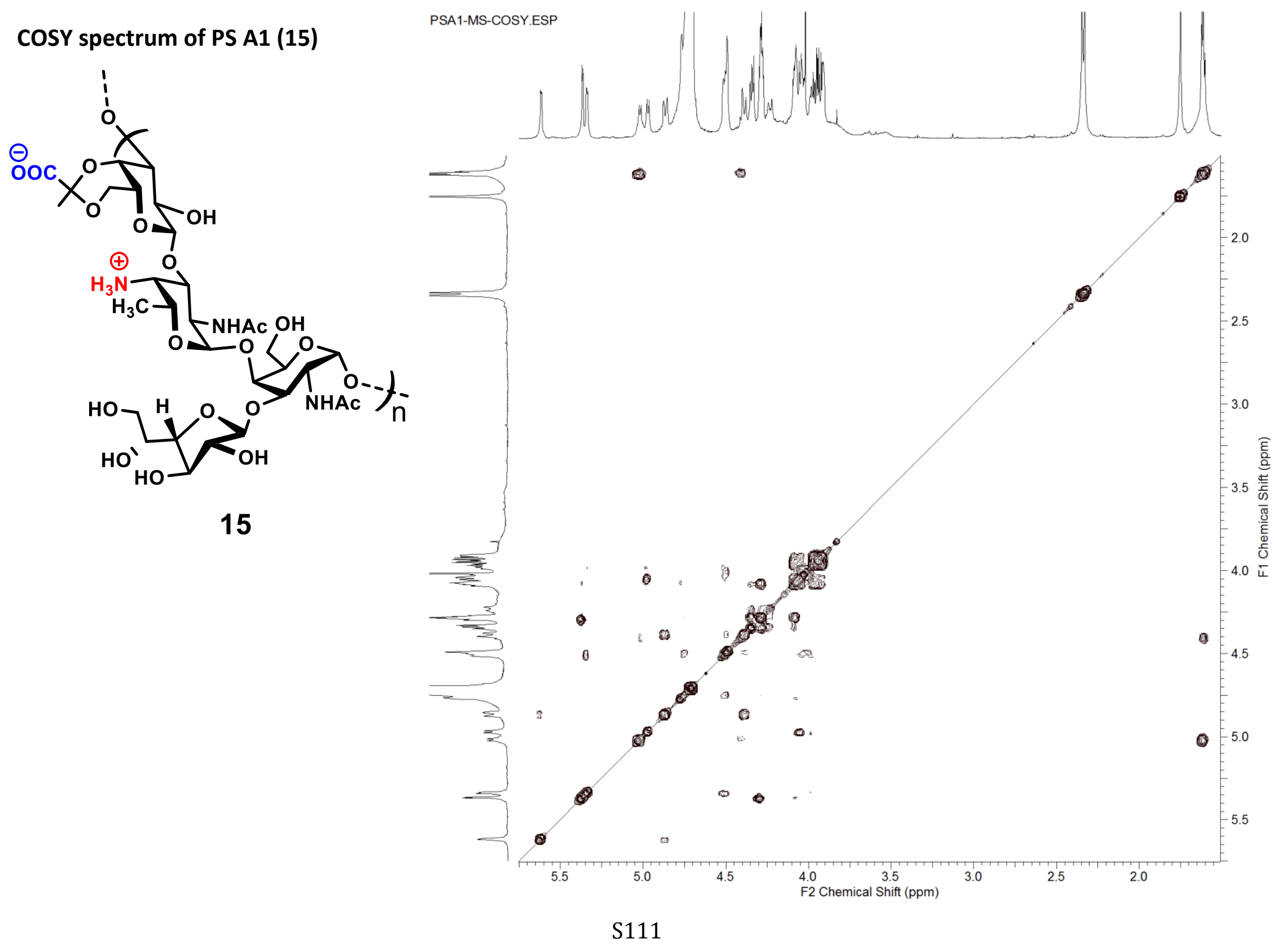


${ }^{1} \mathrm{H}$ NMR spectrum of STn-PS A1 (16)

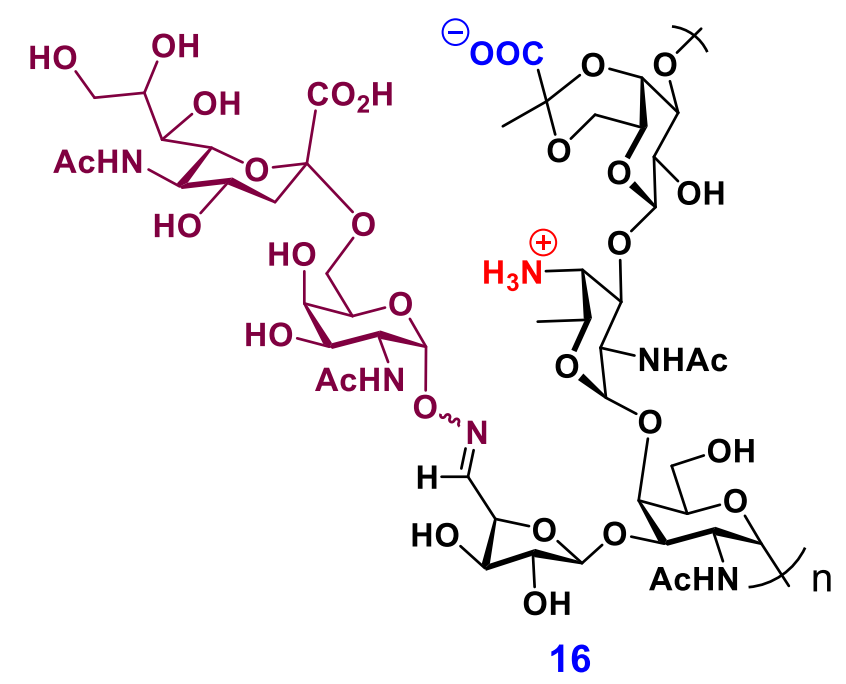

是后足

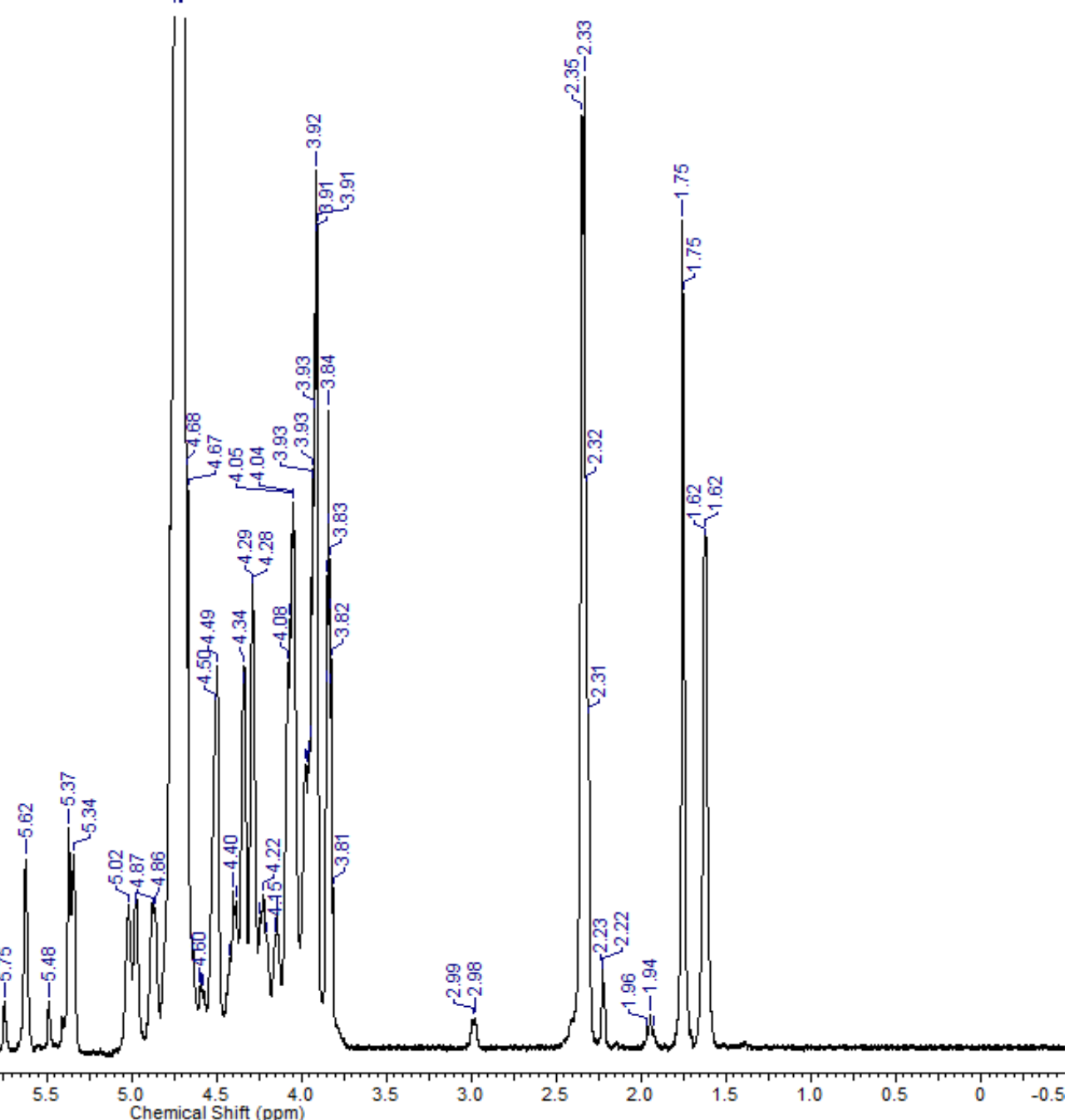




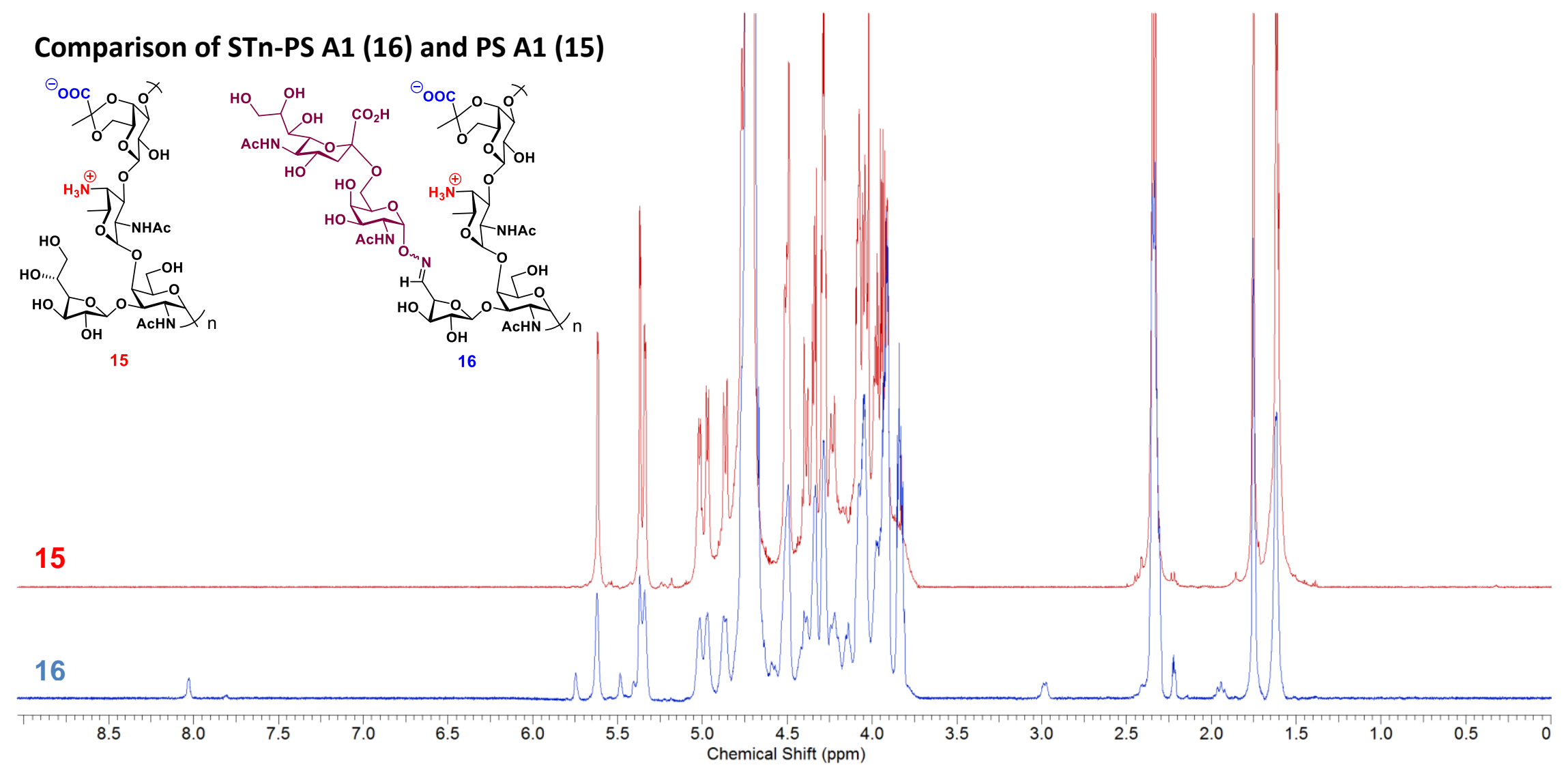




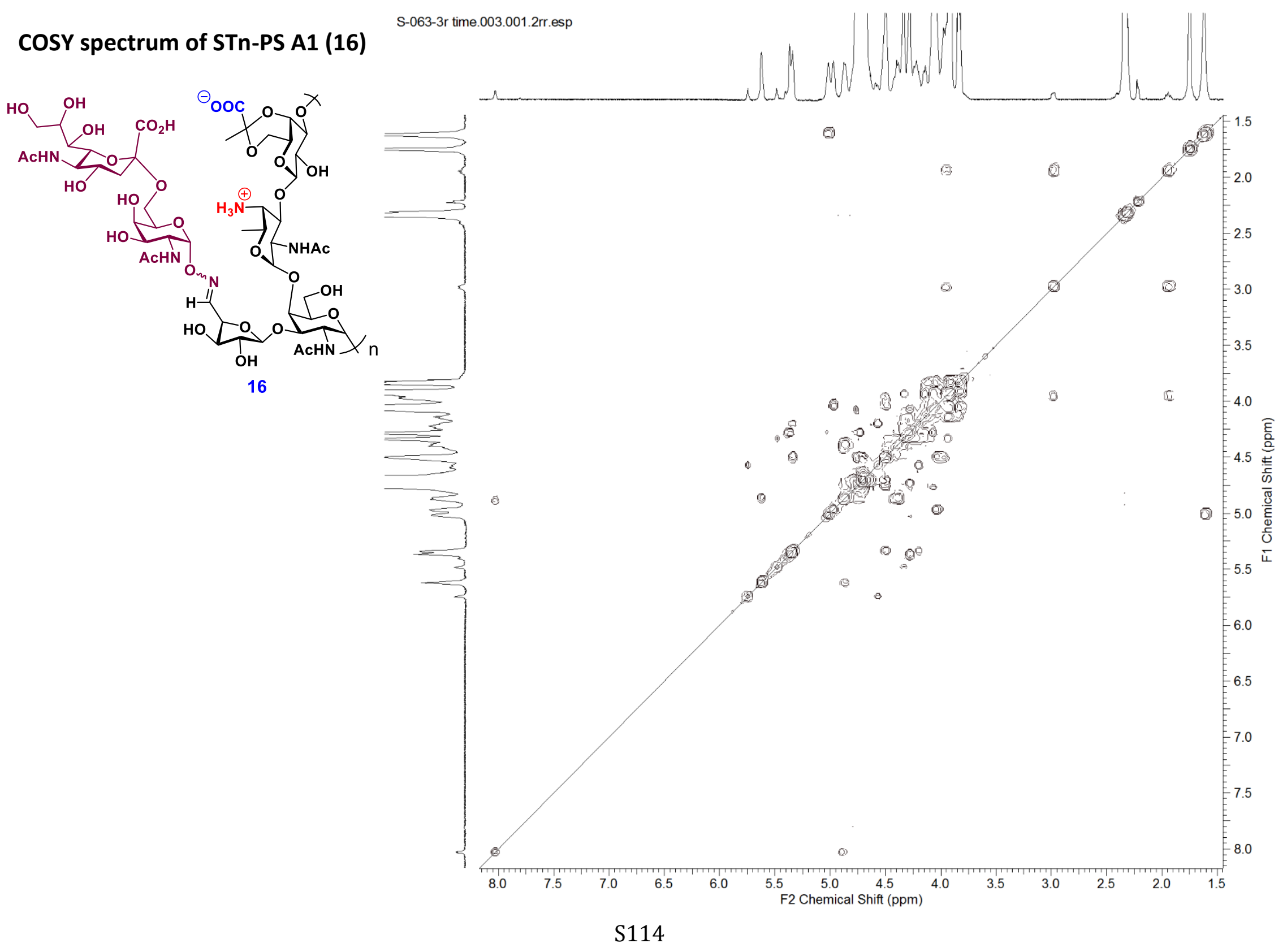




\section{References}

(1) Baumann, H.; Tzianabos, A. O.; Brisson, J. R.; Kasper, D. L.; Jennings, H. J. Biochemistry 1992, 31, 4081-4089.

(2) Tzianabos, A. O.; Pantosti, A.; Baumann, H.; Brisson, J. R.; Jennings, H. J.; Kasper, D. L. J. Biol. Chem. 1992, 267, 18230-18235.

(3) Crich, D.; Li, W. J. Org. Chem. 2007, 72, 2387-2391.

(4) Bourgault, J. P.; Trabbic, K. R.; Shi, M.; Andreana, P. R. Org. Biomol. Chem. 2014, 12, 1699-1702.

(5) Hsu, C. H.; Chu, K. C.; Lin, Y. S.; Han, J. L.; Peng, Y. S.; Ren, C. T.; Wu, C. Y.; Wong, C. H. Chem. Eur. J. 2010, 16, 1754-1760.

(6) Svennerholm, L. Biochim. Biophys. Acta 1957, 24, 604-611.

(7) Trabbic, K. R.; Bourgault, J. P.; Shi, M.; Clark, M.; Andreana, P. R. Org. Biomol. Chem. 2016, 14, 3350-3355.

(8) Yang, F.; Zheng, X. J.; Huo, C. X.; Wang, Y.; Zhang, Y.; Ye, X. S. ACS Chem. Biol. 2011, 6, 252-259. 